\title{
Characterizing Marine \\ Gas-Hydrate Reservoirs and Determining Mechanical Properties of Marine Gas-Hydrate \\ Strata with 4-Component \\ Ocean-Bottom-Cable Seismic Data
}

\section{FINAL REPORT}

Period of Performance

September 29, 2000, through September 19, 2001

by

B. A. Hardage, M. M. Backus, M. V. DeAngelo, S. Fomel,

R. J. Graebner, P. Murray, and L. J. Wood assisted by $\mathrm{K}$. Rogers

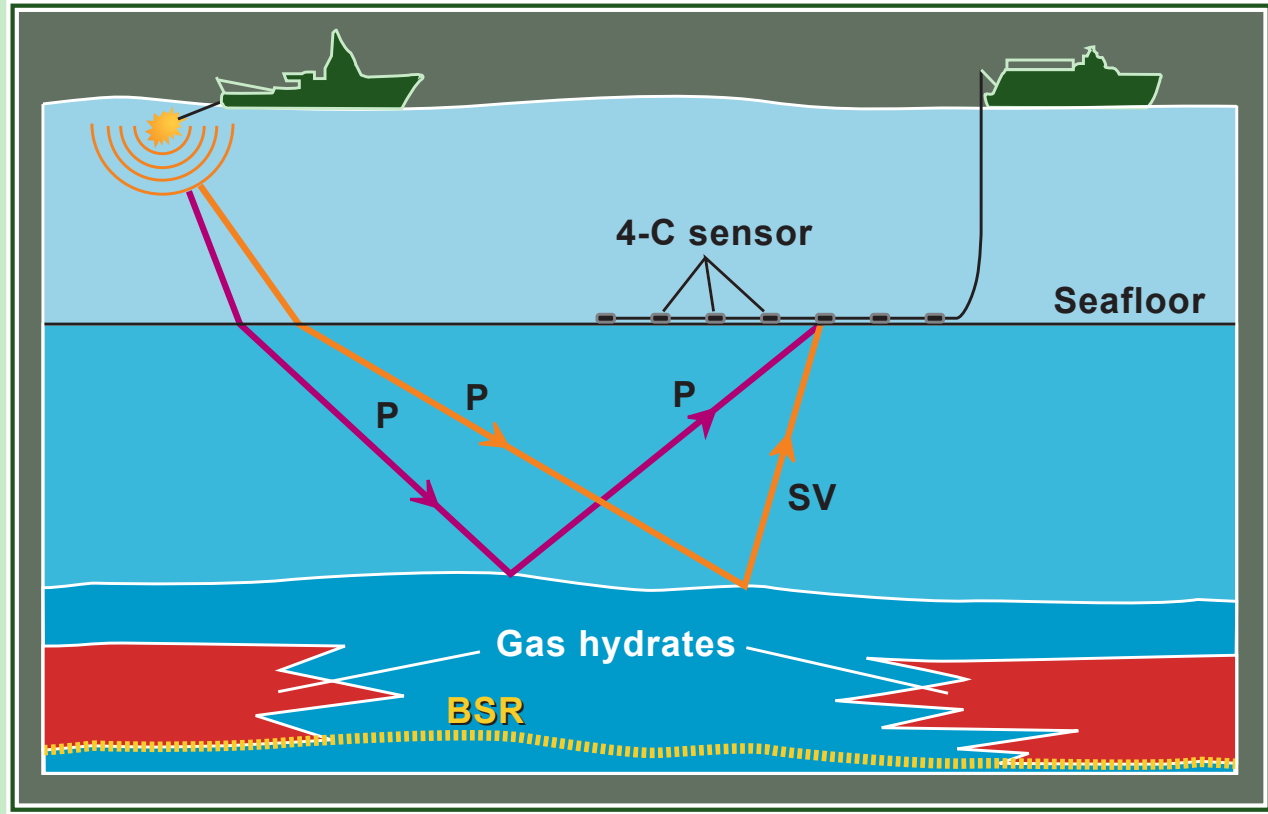

November 2002

Prepared for U.S. Department of Energy

Under Contract No. DE-FC26-00NT41024

\section{Bureau of Economic Geology}

Scott W. Tinker, Director

John A. and Katherine G. Jackson School of Geosciences

The University of Texas at Austin

University Station, Box X

Austin, Texas 78713-8924

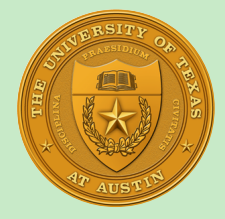

DOE 


\section{Characterizing Marine Gas-Hydrate Reservoirs and Determining Mechanical Properties of Marine Gas-Hydrate Strata with 4-Component Ocean-Bottom-Cable Seismic Data}

FINAL REPORT

Period of Performance

September 29, 2000, through September 19, 2001

by

B. A. Hardage, M. M. Backus, M. V. DeAngelo, S. Fomel,

R. J. Graebner, P. Murray, and L. J. Wood assisted by K. Rogers

November 2002

Prepared for U.S. Department of Energy

Under Contract No. DE-FC26-00NT41024

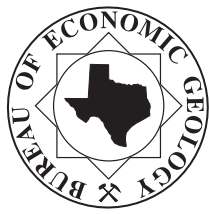

\section{Bureau of Economic Geology}

Scott W. Tinker, Director

John A. and Katherine G. Jackson School of Geosciences

The University of Texas at Austin

University Station, Box X

Austin, Texas 78713-8924

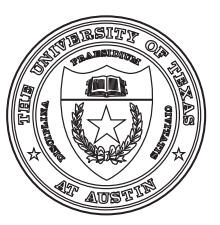

DOE 


\section{DISCLAIMER}

This system is made available by an agency of the United States Government. Neither the United States Government nor any agency thereof, nor any of their employees, makes any warranty, express or implied, or assumes any legal liability or responsibility for the accuracy, completeness, or usefulness of any information, apparatus, product or process disclosed, or represents that its use would not infringe privately owned rights. Reference herein to any specific commercial product, process, or service by trade name, trademark, manufacturer, or otherwise, does not necessarily constitute or imply its endorsement, recommendation, or favoring by the United States Government or any agency thereof. The views and opinions of originators expressed herein do not necessarily state or reflect those of the United States Government or any agency thereof. 


\begin{abstract}
The research findings described in this report confirm that four-component oceanbottom-cable (4-C OBC) seismic data provide valuable information about stratigraphy, lithofacies, and mechanical properties of sediments that cannot be extracted from conventional cable-towed P-wave marine seismic data. The key advantages of 4-C OBC data documented in this study that need to be considered for gas-hydrate applications are

1. the ability to image inside gas-hydrate $\mathrm{P}$-wave wipeout zones with $\mathrm{C}$ waves;

2. the increase in stratigraphic information that results from combining P-wave stratal surfaces, seismic sequences, and seismic facies with $\mathrm{C}$-wave stratal surfaces, sequences, and facies;

3. the increased spatial resolution of shallow seafloor strata that results when the time coordinates of C-wave data are warped (transformed) to P-wave imagetime coordinating;

4. the mapping of lithofacies distributions using the lithofacies-sensitive velocity ratio, $\mathrm{V}_{\mathrm{p}} / \mathrm{V}_{\mathrm{s}}$; and

5. the estimation of the spatially averaged mechanical strength of ocean-floor strata using interval values of $\mathrm{V}_{\mathrm{p}}$ and $\mathrm{V}_{\mathrm{s}}$ to calculate elastic moduli.

These technical advantages of 4-C OBC data will be discussed and illustrated in the main text of the report. Geologic and geophysical details developed during the investigation have been placed in appendices. The impact of the research findings can be understood by concentrating on the main text and ignoring the appendices. However, the appendices are important in that they document critical information and principles.
\end{abstract}




\section{TABLE OF CONTENTS}

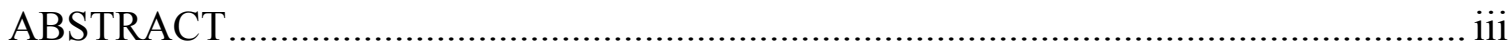

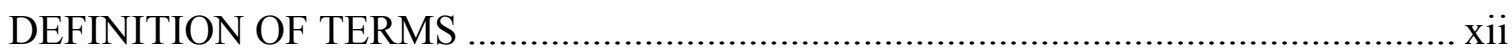

EXPERIMENTAL RESULTS AND DISCUSSION

GAS-HYDRATE MODEL: NORTHERN GULF OF MEXICO....................................1

ESTABLISHING DEPTH-EQUIVALENT P AND C STRATAL SURFACES ...............3

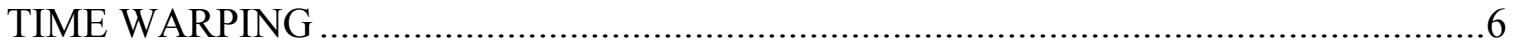

SEISMIC STRATIGRAPHY IMPLICATIONS OF P AND C STRATAL

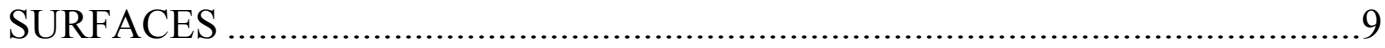

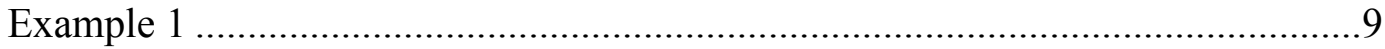

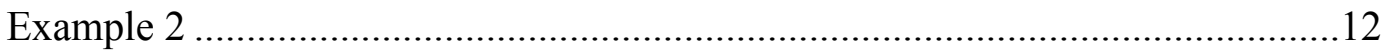

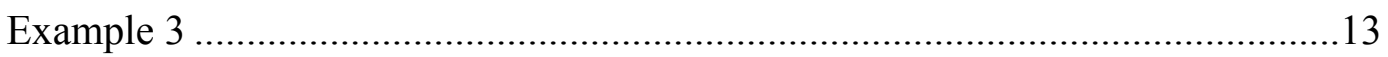

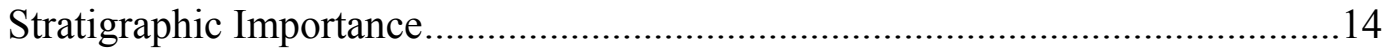

SEISMIC-BASED PROCEDURES FOR DETERMINING V $\mathrm{V}_{\mathrm{P}}$ AND $\mathrm{V}_{\mathrm{S}}$ IN

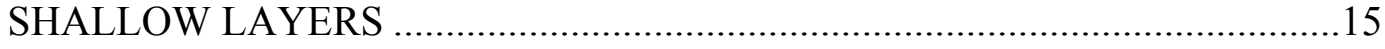

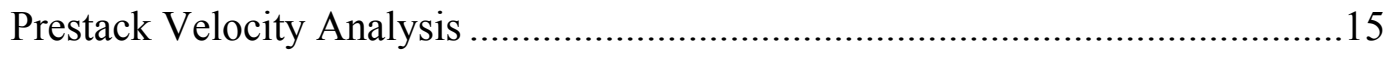

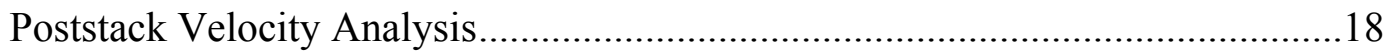

COMPARISON OF PRESTACK AND POSTSTACK DETERMINATIONS OF

LAYER PARAMETERS ..............................................................................19

$\mathrm{V}_{\mathrm{P}}$ AND $\mathrm{V}_{\mathrm{S}}$ IN SEAFLOOR SEDIMENTS: PREVIOUS STUDIES ...........................21

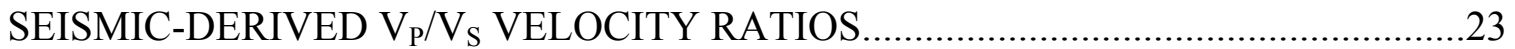

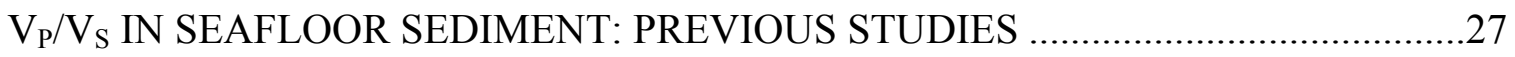

$\mathrm{V}_{\mathrm{P}} / \mathrm{V}_{\mathrm{S}}$ AS A QUALITY CONTROL ON P AND C INTERPRETATION .....................29

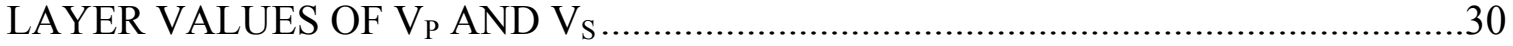

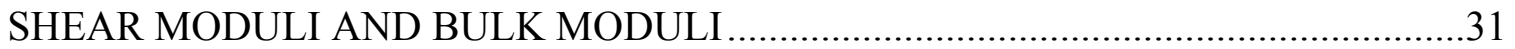

ELASTIC CONSTANTS OF SHALLOW SEAFLOOR SEDIMENT:

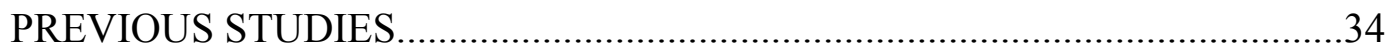

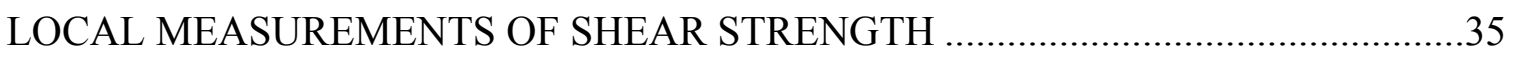

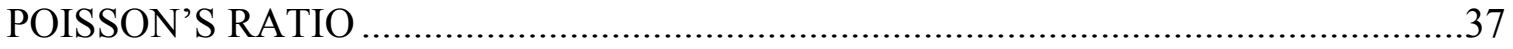

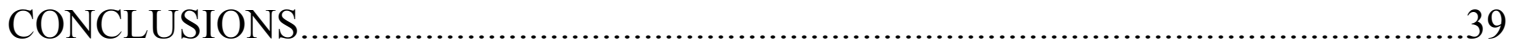

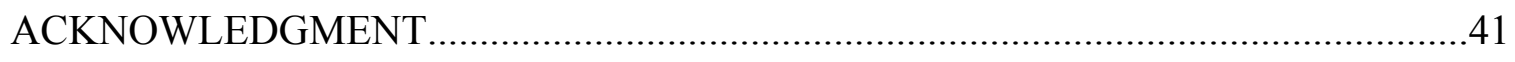

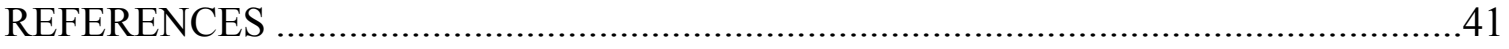




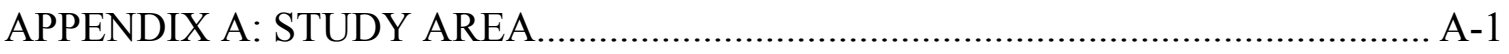

APPENDIX B: GEOLOGIC CHARACTER OF STUDY AREA ……………………....

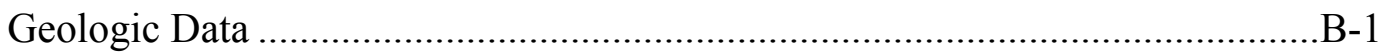

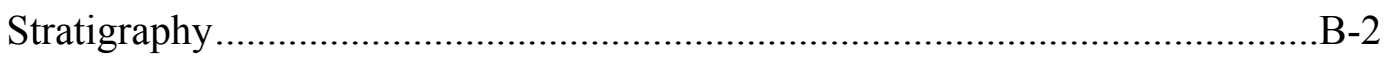

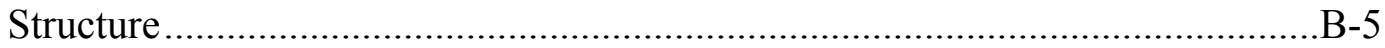

APPENDIX C: MULTICOMPONENT SEISMIC DATA ACQUISITION .....................-1

Seismic Acquisition Templates..........................................................................

APPENDIX D: NUMERICAL MODELING OF SEAFLOOR SEISMIC SENSOR

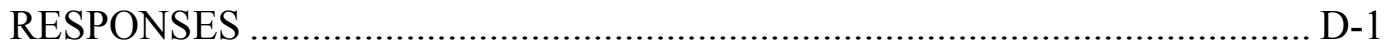

APPENDIX E: SEISMIC DATA PROCESSING ISSUES ..............................................

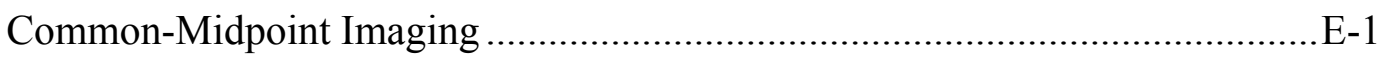

Common-Conversion-Point Imaging .............................................................

Contrast between CMP and CCP Velocity Analyses ...........................................

Contrast between CMP and CCP Stacking ....................................................... E-3

Using Static Corrections to Map Sedimentary Facies Associated with Gas Hydrates ...................................................................................

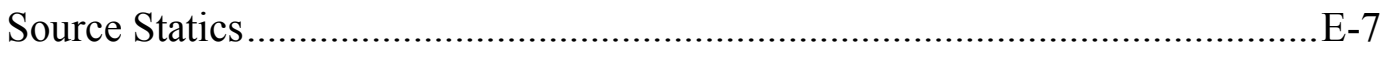

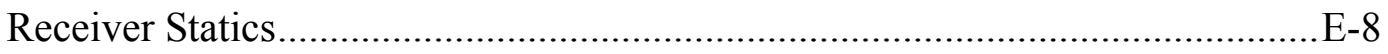

APPENDIX F: GEOPHYSICAL DATA QUALITY ………………………………......

Tables

1. Time thicknesses and $\mathrm{V}_{\mathrm{p}} / \mathrm{V}_{\mathrm{s}}$ ratios resulting from poststack interpretation of depth-equivalent surfaces across $\mathrm{P}$ and $\mathrm{C}$ data volumes................................................20

2. Layer thicknesses and velocities obtained via prestack data analyses...........................20

Figures

1. Widely accepted geological model of gas-hydrate systems across the northern Gulf of Mexico

2. P-wave seismic profile across gas chimney located at crossline coordinate 10,100 (Example 1) 
3. P-wave seismic profile across gas chimney located at inline coordinate 1780 (Example 2)

4. C-wave seismic profile across gas chimney

5. C-wave seismic profile across gas chimney

6. Procedure for defining depth-equivalent $\mathrm{P}$ and $\mathrm{C}$ image surfaces

7. P-wave section showing interpreted horizons that will be used as frequent references

8. C-wave image along the same profile as the $\mathrm{P}$ data in Figure 7

9. C-wave data of Figure 8 after being warped to P image time

10. Frequency spectra of $\mathrm{P}, \mathrm{C}$, and warped-C wavefields in the intervals defined by stratal layers $\mathrm{WB}, \mathrm{H} 4, \mathrm{H} 3, \mathrm{H} 2$, and $\mathrm{H} 1$

11. C-wave search target for establishing depth equivalence to P data (Example 1)

12. C-wave search target (Example 1) with incised-valley feature emphasized

13. Depth-equivalent P-wave image target (Example 1)

14. Depth-equivalent P-wave image target (Example 1), with the incised-valley feature emphasized

15. Inline profile 2800 across image target (Example 1)

16. Crossline profile 10,650 across image target (Example 1)

17. P-wave image search target (Example 2)

18. Depth-equivalent C-wave target (Example 2)

19. P-wave image with its depth-equivalent $\mathrm{C}$-wave image highlighted (Example 2)

20. Inline profile 2100 across seismic image space (Example 2)

21. P-wave search target image (Example 3) 
22. Depth-equivalent C-wave target (Example 3).

23. P-wave and $\mathrm{C}$-wave stacking velocities $\mathrm{V}_{\mathrm{pp}}$ and $\mathrm{V}_{\mathrm{ps}}$ across seismic image space

24. $\mathrm{V}_{\mathrm{p}}$ behavior in shallow marine silt, clay, mudstone and shale sediments

25. $\mathrm{V}_{\mathrm{s}}$ behavior in shallow fine-grained seafloor sediment

26. Normal moveout of shallow $\mathrm{C}$-wave reflection event $\mathrm{H} 4$ when $\mathrm{S}$-wave velocity $\mathrm{V}_{\mathrm{SV}}$ in the layer above $\mathrm{H} 4$ is varied from 254 to $482 \mathrm{~m} / \mathrm{s}$

27. Ray-trace analysis comparing distances to receiver station and to mode-conversion points at horizon $\mathrm{H} 4$

28. $\mathrm{V}_{\mathrm{p}}$ behavior in shallow marine silt, clay, mudstone, and shale sediments

29. $V_{s}$ behavior in shallow fine-grained seafloor sediment

30. Zero-incidence raypath model used to calculate $\mathrm{V}_{\mathrm{p}} / \mathrm{V}_{\mathrm{s}}$ across targeted intervals of $\mathrm{P}$ and $\mathrm{C}$ images

31. $\mathrm{V}_{\mathrm{p}} / \mathrm{V}_{\mathrm{s}}$ values calculated for the layer bounded by the water bottom and stratal surface $\mathrm{H} 4$

32. $\mathrm{V}_{\mathrm{p}} / \mathrm{V}_{\mathrm{s}}$ values calculated for the layer bounded by stratal surfaces $\mathrm{H} 3$ and $\mathrm{H} 4$

33. $\mathrm{V}_{\mathrm{p}} / \mathrm{V}_{\mathrm{s}}$ values calculated for the layer bounded by stratal surfaces $\mathrm{H} 2$ and $\mathrm{H} 3$

34. $\mathrm{V}_{\mathrm{p}} / \mathrm{V}_{\mathrm{s}}$ values calculated for the layer bounded by stratal surfaces $\mathrm{H} 1$ and $\mathrm{H} 2$

35. Distributions of $\mathrm{V}_{\mathrm{p}} / \mathrm{V}_{\mathrm{s}}$ in each study layer

36. Global $\mathrm{V}_{\mathrm{p}} / \mathrm{V}_{\mathrm{s}}$ behavior in shallow fine-grained seafloor sediment

37. Large-area map of $\mathrm{V}_{\mathrm{p}} / \mathrm{V}_{\mathrm{s}}$ for the shallowest study layer, WB to $\mathrm{H} 4$

38. Time thicknesses and $\mathrm{V}_{\mathrm{p}} / \mathrm{V}_{\mathrm{s}}$ values associated with the layers defined along inline 1870, the seismic profile shown in Figures 7 and 8

39. Time thicknesses and $V_{p} / V_{s}$ values associated with the layers defined along inline 1870, the seismic profile shown in Figures 7 and 8 
40. $\mathrm{V}_{\mathrm{p}}$ for layer bounded by the water bottom and stratal surface $\mathrm{H} 4$

41. $\mathrm{V}_{\mathrm{p}}$ for layer bounded by stratal surfaces $\mathrm{H} 3$ and $\mathrm{H} 4$

42. $\mathrm{V}_{\mathrm{p}}$ for layer bounded by stratal surfaces $\mathrm{H} 2$ and $\mathrm{H} 3$

43. $\mathrm{V}_{\mathrm{p}}$ for layer bounded by stratal surfaces $\mathrm{H} 1$ and $\mathrm{H} 2$

44. $\mathrm{V}_{\mathrm{s}}$ for layer bounded by the water bottom and stratal surface $\mathrm{H} 4$

45. $\mathrm{V}_{\mathrm{s}}$ for layer bounded by stratal surfaces $\mathrm{H} 3$ and $\mathrm{H} 4$

46. $\mathrm{V}_{\mathrm{s}}$ for layer bounded by stratal surfaces $\mathrm{H} 2$ and $\mathrm{H} 3$

47. $\mathrm{V}_{\mathrm{s}}$ for layer bounded by stratal surfaces $\mathrm{H} 1$ and $\mathrm{H} 2$

48. Shear moduli for layer bounded by the water bottom and stratal surface $\mathrm{H} 4$

49. Shear moduli for layer bounded by stratal surfaces $\mathrm{H} 3$ and $\mathrm{H} 4$

50. Shear moduli for layer bounded by stratal surfaces $\mathrm{H} 2$ and $\mathrm{H} 3$

51. Shear moduli for layer bounded by stratal surfaces $\mathrm{H} 1$ and $\mathrm{H} 2$

52. Bulk moduli for layer bounded by the water bottom and stratal surface $\mathrm{H} 4$

53. Bulk moduli for layer bounded by stratal surfaces $\mathrm{H} 3$ and $\mathrm{H} 4$

54. Bulk moduli for layer bounded by stratal surfaces $\mathrm{H} 2$ and $\mathrm{H} 3$

55. Bulk moduli for layer bounded by stratal surfaces $\mathrm{H} 1$ and $\mathrm{H} 2$

56. Relationship between shear strength and grain size of seafloor sediment

57. Shear strength and moisture content of first $40 \mathrm{ft}$ of seafloor sediment in Well A near study area

58. Shear strength and moisture content of first $250 \mathrm{ft}$ of seafloor sediment in Well A near study area

59. Shear strength of first $50 \mathrm{ft}$ of seafloor sediment in Well B near study area. 
60. Poisson's ratio in shallow, fine-grained, marine silts, clays, mudstones, and shale sediment

61. Poisson's ratio in shallow marine sands

62. Poisson's ratio for layer between seafloor and stratal surface H4

63. Poisson's ratio for layer between $\mathrm{H} 3$ and $\mathrm{H} 4$

64. Poisson's ratio for layer between $\mathrm{H} 2$ and $\mathrm{H} 3$

65. Poisson's ratio for layer between $\mathrm{H} 1$ and $\mathrm{H} 2$

Appendix Figures

\section{A1. Location of 4C3D OBC survey}

B1. Map of the study area showing seafloor bathymetry, large shallow faults, and locations of incised features within the study area

B2. Map showing early-Wisconsinan deltaic depocenters and fluvial systems, as well as significant salt diapirs that affect shallow stratigraphy

B3. Map showing late-Wisconsinan deltaic depocenters and fluvial systems, as well as significant salt diapirs

B4. Portion of high-resolution seismic line illustrating stratigraphic relationships between sand-filled, lowstand incisions and underlying clay-rich, silty, late-highstand, deltaic deposits

B5. Borehole cross section showing major lithologic transitions within the shallow substrate of the study area

C1. Four-component ocean-bottom-sensor (4-C OBS) package

C2. Seismic data-acquisition concept

C3. Swath geometry used to record 4C3D OBC seismic data

C4. Orthogonal geometry used to record 4C3D OBC seismic data

C5. Swath geometry used to record the 4C3D OBC seismic data used in this research

C6. Cable segment used to build an $\mathrm{OBC}$ receiver line having a length of $20 \mathrm{~km}$ or more 


\section{D1. 4-C OBC field record}

D2. Earth model used to model the P-wave responses of the seafloor

D3. Reflectivity series seen by a vertical geophone positioned on the seafloor

D4. Reflectivity series seen by a seafloor hydrophone

D5. Calculated responses for seafloor hydrophones and vertical geophones when the seafloor reflectivity $\mathrm{R}$ is 0.2

D6. Calculated responses for seafloor hydrophones and vertical geophones when the seafloor reflectivity $\mathrm{R}$ is 0.4

D7. Calculated responses for seafloor hydrophones and vertical geophones when the seafloor reflectivity $\mathrm{R}$ is 0.7

D8. Calculated responses for seafloor hydrophones and vertical geophones when the seafloor reflectivity $\mathrm{R}$ is 0.3

D9. Calculated responses for seafloor hydrophones and vertical geophones when the seafloor reflectivity $\mathrm{R}$ is 0.5

D10. Calculated responses for seafloor hydrophones and vertical geophones when the seafloor reflectivity $\mathrm{R}$ is 0.7

E1. Comparison between CMP imaging raypaths and CCP image points

E2. Comparison between $\mathrm{CCP}$ imaging raypaths and CMP image points

E3. Traveltimes for positive offsets are the same as traveltimes for negative offsets in common-midpoint-point imaging

E4. Traveltimes for positive offsets are not the same as traveltimes for negative offsets in common-conversion-point imaging

E5. Comparison of CMP trace (vertical) and CCP trace (curved) positions in seismic image space

E6. Construction of a vertical binned trace in seismic image space from a suite of CCP traces

E7. Simple, straight-raypath model showing that the velocity ratio $V_{p} / V_{s v}$ controls the position of a CCP image point 
E8. Receiver static correction factors involved in seafloor data acquisition

E9. An OBC profile with no receiver statics applied to the data

E10. The same OBC profile (Fig. E9) after one iteration of receiver static corrections

E11. A map of receiver static corrections applied to 4C3D OBC data across the study area

F1. A P-wave profile traversing a gas chimney (crossline coordinates 10,050 through $10,150)$

F2. A converted-SV profile, along with same inline coordinate as that shown in Figure F1

\section{DEFINITION OF TERMS}

The following acronyms will be used throughout this report:

C wave: $\quad$ Converted wave. A reflected SV shear wavefield produced by Pto-SV mode conversions when a downgoing $\mathrm{P}$ wave propagates through a series of reflecting interfaces.

GOM: $\quad$ Gulf of Mexico

NMO: Normal moveout. An NMO velocity is the same as a seismic stacking velocity.

OBC: $\quad$ Ocean bottom cable

P wave: $\quad$ Compressional mode of a seismic wavefield

S wave: $\quad$ Any shear mode (C, SH, or SV) of a seismic wavefield

$\mathrm{V}_{\mathrm{p}}$ : $\quad$ P-wave velocity

$\mathrm{V}_{\mathrm{s}}$ : $\quad$ S-wave velocity

4-C: $\quad$ Four-component marine seismic data acquired with a 3-C geophone and a hydrophone 


\section{EXPERIMENTAL RESULTS AND DISCUSSION \\ GAS-HYDRATE MODEL: NORTHERN GULF OF MEXICO}

Geologic models of gas-hydrate accumulations in the Gulf of Mexico (GOM)

were described during the March 2002 workshop of the Gas Hydrate Joint Industry

Partnership in Houston. The conclusion was that the majority (some participants claimed over 90 percent) of known gas-hydrate deposits in the northern GOM could be represented by the model illustrated in Figure 1. The key features of this model are

- a deep source of thermally generated gas,

- a vertical interface (usually a fault as shown in Figure 1, but sometimes a salt wall) that provides a conduit for upward movement of gas,

- a seafloor mound where the vertical gas migration path intersects the seafloor,

- a wipeout zone of P-wave seismic reflections across the gas chimney associated with the gas-migration path, and

- the absence of any classic bottom simulating reflection (BSR).

This model appears to be limited to the northern part of the GOM. The model does not apply to the Mexican portion of the GOM or to gas-hydrate areas in Alaska or along the Atlantic and Pacific coasts of the United States. It should also be emphasized that this model applies to "known" gas-hydrate deposits. There may be unknown gas-hydrate reservoirs in the northern GOM that are associated with a different geologic environment.

Numerous gas chimneys and P-wave wipeout zones existed inside the image space covered by the 4-C OBC seismic data utilized in this research study. Examples of such phenomena are illustrated in Figures 2 and 3. In each example, the signal-to-noise ratio $(\mathrm{S} / \mathrm{N})$ of the $\mathrm{P}$-wave images inside the gas chimney is too low to allow the internal 
structural and stratigraphic architecture to be determined. C-wave images along the same profiles are shown in Figures 4 and 5, respectively. In each instance, C-wave images show fault geometry and numerous stratal surfaces inside the P-wave wipeout area.

The difference between $\mathrm{P}$ and $\mathrm{C}$ image character across gas-invaded zones is the result of petrophysical differences in gas-filled and water-filled sediments. P-wave velocity $\mathrm{V}_{\mathrm{p}}$ in a homogeneous porous medium is determined from three petrophysical parameters: bulk modulus $\mathrm{K}$, shear modulus $\mu$, and bulk density $\rho$ (Equation 1),

$$
V_{p}=\sqrt{\frac{K+\frac{4}{3} \mu}{\rho} .}
$$

In contrast, $\mathrm{S}$-wave velocity $\mathrm{V}_{\mathrm{s}}$ is controlled by only two parameters, $\mu$ and $\rho$ (Equation 2),

$$
\mathrm{V}_{\mathrm{s}}=\sqrt{\frac{\mu}{\rho}} .
$$

Because bulk modulus $\mathrm{K}$ is the reciprocal of compressibility, $\mathrm{V}_{\mathrm{p}}$ can decrease significantly when the pore filler in sediment changes from water to gas because water has a low compressibility (high K), whereas gas has a high compressibility (low K). The large decrease of $\mathrm{V}_{\mathrm{p}}$ in gas-charged sediment results in poor P-wave image quality inside gas chimneys because of the difficulty of determining image-point coordinates when there is a severe, lateral change in propagation velocity.

However, the shear modulus $\mu$ of a porous medium is determined by the shear modulus of the matrix only and is not affected by changes in pore filler. Neither water nor gas has shear strength; thus, neither fluid affects the value of $\mu$ for a porous medium. As a result, $\mathrm{V}_{\mathrm{s}}$ has almost the same value in a water-filled sand as it does in an adjacent 
gas-filled sand, as long as the sand matrix is unchanged. This velocity behavior causes $\mathrm{C}$ waves to have (approximately) the same reflectivity and image quality inside gas chimneys as they do outside the chimneys, where these same strata are water charged.

The seismic profiles illustrated in Figures 2 through 5 show that 4-C OBC seismic data should allow investigators to construct realistic models of the internal architecture of gas-hydrate systems across the northern GOM, where P-wave wipeout zones have frustrated such attempts to date. With the use of 4-C OBC data, it should be possible to do a better characterization of gas-hydrate reservoirs than can be done with conventional P-wave marine seismic data. The ability to look inside P-wave wipeout zones may be the most popular application of 4-C OBC seismic data in future gas-hydrate studies in the northern GOM.

\section{ESTABLISHING DEPTH-EQUIVALENT P AND C STRATAL SURFACES}

The P-wave and C-wave seismic volumes used in this investigation were timemigrated volumes. The vertical axis of the P-wave volume was P-wave image time; the vertical axis of the $\mathrm{C}$-wave volume was converted-SV image time. The problem posed to the interpreter is to define depth-equivalent seismic events between P-wave and C-wave data. In the absence of shallow sonic (dipole) logs and multicomponent VSP data, evaluating both seismic data volumes is the only option for determining P-wave to Cwave event correlations. A common first intuition is to try correlating seismic events between the two data volumes in section view, as required in 2-D data sets. A search of the P-wave and $\mathrm{C}$-wave sections was made to find characteristic features that should be expected to replicate on $\mathrm{P}$-wave and $\mathrm{C}$-wave profiles to provide a correlation basis. No antithetic faults or other desired geometric features could be found. An attempt was made 
to provide P-to-C correlation based on fault surfaces, which should provide a good basis. However, the shallow faults in the study area were sufficiently steep to make the P-to-C event correlation ambiguous on the order of 50+ milliseconds. Four horizons were picked on P-wave and C-wave volumes on the basis of this fault correlation. Estimates obtained from this initial correlation attempt had an unrealistic increase of $\mathrm{V}_{\mathrm{p}} / \mathrm{V}_{\mathrm{s}}$ ratio with depth, so a further search for a viable correlation technique was undertaken. It was then determined that a correlation method based on attribute maps was needed for accurate depth registration of $\mathrm{P}$-wave and $\mathrm{C}$-wave images. Fortunately, the $\mathrm{P}$ and $\mathrm{C}$ data volumes provided the opportunity to use horizontal data slices as a basis for correlation. The complex sinuous geometry of stream channels and incised valleys showed geometric signatures on horizontal time slices that allowed reliable correlation of P-wave and Cwave times.

The technique used to establish depth equivalences between interpreted P-wave and C-wave stratal surfaces is depicted by the time-slice data displays in Figure 6. In this technique, it is assumed that the interpreter has created a C-wave image surface (either time slice or stratal surface) across the C-wave volume and then has to find the depthequivalent surface in the P-wave volume. This process could work just as well in reverse, where the interpreter first creates a P-wave image surface and then searches vertically through the $\mathrm{C}$-wave volume to find the depth-equivalent surface in $\mathrm{C}$-wave image space.

The choice of the optimal image-surface match is done by 2-D areal correlations of the starting image surface in data volume 1 (C-wave time slice at bottom of Figure 6) with each of several possible surfaces in data volume 2 (P-wave time slices across the top of Figure 6). The objective is to find which P-wave surface has an areal distribution of 
structural and stratigraphic features that best correlates with that of their equivalent features on the C-wave surface. The surfaces in these two image-time domains that exhibit the highest degree of correlation define which P-wave and C-wave surfaces are imaging the same depth surface. These correlations can be done over the total $\mathrm{x}, \mathrm{y}$ seismic image space or over a subset of the image space. The correlation process can be done numerically or visually. Any of several seismic attributes can be displayed on the two surfaces and used for the correlation process. We worked first with reflection amplitudes as we developed this P-to-C depth equalization technique. We did not find amplitude maps to be optimal for image correlation in this instance, but we recommend that amplitude attributes continue to be tested in future efforts at creating depth-equivalent $\mathrm{P}$ and $\mathrm{C}$ data. We found the most robust attribute for P-to-C depth equalization to be reflection coherency. Consequently, we did visual correlations of lateral waveshape coherency in this study and utilized both time slices and stratal surfaces to examine coherency character.

The data examples in Figure 6 imply that the optimal match of $\mathrm{P}$ and $\mathrm{C}$ images of this targeted valley-fill system occurs when $\mathrm{C}$ image time is $1,968 \mathrm{~ms}$ and $\mathrm{P}$ image time is $792 \mathrm{~ms}$. This conclusion is based on visual (not numerical) comparisons of the valleyfill feature in the southern third of the image spaces shown in the data displays. In future work, we intend to investigate numerical correlation procedures that could establish P-toC image-time equivalencies that are more accurate than what have been achieved here using visual techniques. The intent of Figure 6 is to illustrate that the quality of the P-toC image match degrades as $\mathrm{P}$ image time moves up or down from the optimal P image time of $792 \mathrm{~ms}$. The vertical movement of $24 \mathrm{~ms}$ in P image time used in the time-slice 
displays is equivalent to a vertical displacement of approximately $20 \mathrm{~m}(\sim 65 \mathrm{ft})$ in stratigraphic depth, according to the estimated $\mathrm{V}_{\mathrm{p}}$ value of $1.8 \mathrm{~km} / \mathrm{s}$ at these particular image times (see entries for layer $\mathrm{H} 2$ to $\mathrm{H} 1$ on Table 1).

\section{TIME WARPING}

The procedure illustrated in Figure 6 was used to establish several P-to-C depthequivalent image times throughout the $\mathrm{P}$ and $\mathrm{C}$ data volumes. Examples of these $\mathrm{P}$ and $\mathrm{C}$ image comparisons will be shown and discussed in a later section. Before considering these examples, it is important to illustrate the concept and importance of time warping that can be done once depth-equivalent $\mathrm{P}$ and $\mathrm{C}$ stratal surfaces are defined. The objective of time warping is to produce $\mathrm{P}$ and $\mathrm{C}$ data that are depth equivalent, data point by data point.

The term time warping means that $\mathrm{C}$ image time is adjusted to $\mathrm{P}$ image time throughout $\mathrm{C}$-wave image space. The process could be reversed, in that $\mathrm{P}$ image time could be warped to $\mathrm{C}$ image time, but this option is not yet attractive to most interpreters who prefer to work in $\mathrm{P}$-wave image space. Once $\mathrm{C}$ data are converted to $\mathrm{P}$ time, it is easier to evaluate the relative spatial resolution of $\mathrm{P}$ and $\mathrm{C}$ data volumes and to compare $\mathrm{P}$ and $\mathrm{C}$ sequences and facies over targeted stratigraphic intervals.

To illustrate the concept, a north-south profile through the $\mathrm{P}$ data volume is shown in Figure 7. Superimposed on these data are five interpreted horizons. WB is the water bottom and $\mathrm{H} 1$ through $\mathrm{H} 4$ are selected stratal surfaces. Horizons H1 through $\mathrm{H} 4$ had to be phantomed through the gas chimney centered on crossline coordinate 10,000 because

of the poor P image quality inside this gas-charged interval. This same profile through the 
$\mathrm{C}$ volume is displayed in Figure 8. The P-to-C depth calibration procedure described in Figure 6 was used to make $\mathrm{C}$-wave horizons $\mathrm{H} 1$ through $\mathrm{H} 4$ be depth equivalent to $\mathrm{P}$ wave horizons $\mathrm{H} 1$ through $\mathrm{H} 4$. Note that the $\mathrm{C}$ horizons do not have to be phantomed through the gas chimney (crossline coordinate 10,000) because $\mathrm{C}$ image quality inside the gas chimney is quite good. In fact, the $\mathrm{C}$ data show several faults inside the gas chimney that are not visible in the $\mathrm{P}$ data. There is no $\mathrm{C}$-wave reflection event at surface $\mathrm{WB}$, the water bottom (Fig. 8) because no upgoing SV mode can be produced at this fluid-solid interface. The earliest $\mathrm{C}$ reflections originate at stratal surfaces occurring short distances below the seafloor. The P-wave surface WB in Figure 7 was transferred to the $\mathrm{C}$ image (Fig. 8) to define the position of the seafloor in C-wave image space. This concept of defining the seafloor reflection in P-wave image space and then transferring that surface to C-wave image space will be used in all of the seismic attribute calculations and map displays that follow.

Visual comparison shows that each horizon is at an image-time coordinate in $\mathrm{P}$ data space that is different from what it is in $\mathrm{C}$ data space. A cubic splice interpolation procedure was used to adjust $\mathrm{C}$ image time so that each $\mathrm{C}$ horizon coincided with its equivalent image-time coordinate in $\mathrm{P}$-wave image space. We call this procedure $C$-wave time warping. The time-warped version of the $\mathrm{C}$ data is shown in Figure 9. Visual comparisons of Figures 7 and 9 confirm that all horizons are now positioned at the same time coordinates in their respective image spaces. Because the $\mathrm{C}$ horizons are warped to the $\mathrm{P}$ horizons, the new $\mathrm{C}$ horizons (Fig. 9) show a sag across the gas chimney just as the $\mathrm{P}$ horizons do. If the warping process were reversed so that $\mathrm{P}$ image time were adjusted to 
$\mathrm{C}$ image time, the warped $\mathrm{P}$ horizons would be identical to the $\mathrm{C}$ horizons across the gas chimney.

Again, according to visual comparison of Figures 7 and 9, C data obviously have a better spatial resolution down to horizon $\mathrm{H} 3$ than do the $\mathrm{P}$ data. This increased resolution of shallow seafloor strata provided by the $\mathrm{C}$ data will be an important application of 4-C OBC data in gas-hydrate studies. The spatial resolutions of the $\mathrm{P}$ and $\mathrm{C}$ data are approximately the same between horizons $\mathrm{H} 3$ and $\mathrm{H} 2$. Below $\mathrm{H} 2$, the $\mathrm{P}$ data have a better resolution than do the $\mathrm{C}$ data.

These observations are supported by the frequency spectra shown in Figure 10. These spectra show that $\mathrm{P}$ data (curve $\mathrm{P}$ ) have approximately twice the signal bandwidth of $\mathrm{C}$ data (curve $\mathrm{C}$ ) when these wavefields are analyzed in their respective image-time domains. Note in this figure that $\mathrm{C}$ data can have a wider signal bandwidth (thus better spatial resolution) than $\mathrm{P}$ data when the $\mathrm{C}$ data are time warped to make $\mathrm{C}$ stratal surfaces depth equivalent to $P$ stratal surfaces. Specifically, time-warped $C$ data have a wider frequency spectrum from the seafloor down to stratal surface H3 (top two plots, Fig. 10) and a frequency spectrum equivalent to $\mathrm{P}$ data in interval $\mathrm{H} 3$ to $\mathrm{H} 2$. The spectra in the lower right show that $\mathrm{P}$ and warped-C data have similar bandwidths in layer $\mathrm{H} 2$ to $\mathrm{H} 1$, but the warped-C spectrum has greater low-frequency content $(5$ to $30 \mathrm{~Hz}$ ), whereas the $\mathrm{P}$ spectrum has greater high-frequency content $(30$ to $70 \mathrm{~Hz})$.

The end results of $\mathrm{C}$-wave time warping are that (1) $\mathrm{P}$ and $\mathrm{C}$ data are made depth equivalent (to first order), data point by data point, so that $\mathrm{P}$ and $\mathrm{C}$ sequences and facies can be directly compared and (2) the improved spatial resolution of $\mathrm{C}$ data over $\mathrm{P}$ data in 
shallow seafloor strata becomes more obvious. Both outcomes make 4-C OBC data valuable for analyzing gas-hydrate systems.

\section{SEISMIC STRATIGRAPHY IMPLICATIONS OF P AND C STRATAL SURFACES}

A fundamental thesis of seismic stratigraphy is that a seismic reflection event images a stratal surface. In this context, a stratal surface is a surface of deposition at a fixed geologic time (that is, a bedding interface). As a stratal surface is followed over an area, geologic time remains constant on the surface, but the type of lithology above and below the surface can vary from point to point, depending on the lithofacies that were being deposited across the area at that instant in geologic time. The intent of this section is to illustrate depth-equivalent $\mathrm{P}$ and $\mathrm{C}$ images and infer how the combination of $\mathrm{P}$ and $\mathrm{C}$ stratal surfaces broadens the discipline of seismic stratigraphy.

\section{Example 1}

The first example of this $\mathrm{P}$-wave to $\mathrm{C}$-wave image-correlation technique is shown in Figures 11 to 14. These data are the same displays used in Figure 6 and are horizontal time slices through coherency cubes calculated from the $\mathrm{P}$ and $\mathrm{C}$ data volumes. A time slice through the $\mathrm{C}$-wave coherency cube at $1,968 \mathrm{~ms}$ is illustrated in Figure 11. This time slice was selected because it displays a prominent incised-valley feature that can serve as a good search target. The time slice is repeated in Figure 12 with this stratigraphic feature highlighted for emphasis.

A series of time slices was then made through the P-wave coherency cube to find the equivalent image surface in $\mathrm{P}$-wave image space. The optimal match was found at Pwave image time $792 \mathrm{~ms}$ (Fig. 13). This P-wave image is repeated in Figure 14 with the 
incised-valley feature highlighted. The area imaged with C waves (Figs. 11 and 12) is slightly larger than the area imaged with $P$ waves (Figs. 13 and 14) because different data mutes were used in processing the two wavefields.

The targeted incised-valley image in the southern part of the P-wave time slice is quite similar to its equivalent in the $\mathrm{C}$-wave time slice. However, there is a fundamental difference in the $\mathrm{P}$ and $\mathrm{C}$ images north of crossline 10,600. The comparison of these images supports a major premise of multicomponent seismic interpretation: compressional and shear wavefields do not always image the same stratal surfaces. In this instance, the P-wave and C-wave data image similar stratal surfaces south of crossline 10,600 (approximately) but different stratal surfaces north of this boundary. The seismic stratigraphy principle just stated will significantly impact reservoir characterization, seismic stratigraphy, and any discipline where it is important to detect and interpret stratal surfaces within depositional sequences.

The concept that $\mathrm{P}$ and $\mathrm{C}$ waves can image different stratal surfaces is based on the fact that $\mathrm{P}$ and $\mathrm{C}$ modes have different reflectivities at impedance boundaries. It is possible for one mode (either $\mathrm{P}$ or $\mathrm{C}$ ) to have a zero, or near-zero, reflectivity at a stratal surface while the other mode has a large, significant reflectivity. Many depositional processes can create a lithofacies distribution along a valley axis that can result in a different spatial variation in bulk modulus $\mathrm{K}$ than in shear modulus $\mu$. In such cases, Equations 1 and 2 imply that the $V_{p}$ contrast (thus the P-wave reflectivity) will have a different spatial pattern than will the $\mathrm{V}_{\mathrm{s}}$ contrast (thus the $\mathrm{C}$-wave reflectivity). The result will be that $\mathrm{P}$ stratal surfaces are not consistently the same as $\mathrm{C}$ stratal surfaces across the 
depositional features. Such processes and effects no doubt made some contribution to the $\mathrm{P}$ and $\mathrm{C}$ image differences seen in Figures 11 through 14.

Another possibility that needs to be considered when comparing these $\mathrm{P}$ and $\mathrm{C}$ images is that the valley fill may consist of a vertical stack of interfingering thin beds. In this type of stratigraphy, a seismic reflection event will follow a path through the stacked thin beds that is controlled locally by the relationship between the dominant wavelength of the illuminating wavefield and the stratigraphic properties, bed thickness, bed impedance, and amount of overlap between adjacent thin beds. If two wavefields have different dominant wavelengths, the reflections produced by those wavefields do not follow the same path through a vertical sequence of interfingering thin beds. The incisedvalley target in Figures 11 through 14 is positioned between horizons H1 and H2 (Figs. 7 and 8). Inspection of the $\mathrm{P}$ and $\mathrm{C}$ seismic reflection character (Figs. 7 and 8 ) and of the $\mathrm{P}$ and $\mathrm{C}$ frequency spectra (Fig. 10) in the $\mathrm{H} 1$ to $\mathrm{H} 2$ interval leads to the conclusion that the $\mathrm{P}$ and $\mathrm{C}$ modes have different dominant wavelengths at this target depth. It is thus not surprising that each mode depicts the stratigraphy in a different way. Unfortunately, no wells penetrate this incised-valley feature to provide information about the lithology and internal architecture of the valley-fill sediments.

Crossline 10,650 and inline 2800 that traverse the valley-fill facies are labeled in Figures 12 and 14. P-wave and C-wave images along these two seismic profiles are displayed in Figures 15 and 16. The yellow line across each seismic section indicates the position of the time slice in each data volume that is used in the image displays; the vertical green bars mark the edge of the incised feature. Comparison of the $\mathrm{P}$ and $\mathrm{C}$ profiles in Figure 15 indicates that both wave modes (P and C) portray a similar (but not 
identical) cross section of the incisement at each time-slice coordinate. However, in Figure 16 the P-wave data no longer have a distinctive channellike or valleylike character, whereas the $\mathrm{C}$-wave data show a large, mounded feature almost $1,000 \mathrm{~m}$ wide immediately above the time-slice surface. The contrast in $\mathrm{P}$ and $\mathrm{C}$ depictions of stratal surfaces in these two portions of seismic image space is offered as prima facie evidence of the principle that $\mathrm{P}$ and $\mathrm{C}$ wavefields may provide different, but equally valuable, stratal surfaces, seismic sequences, and seismic facies across targeted stratigraphic intervals.

\section{Example 2}

A second comparison of $\mathrm{P}$ and $\mathrm{C}$ images is provided to confirm that the situation described in Example 1 is not unique, but that it is common for P-wave stratal surfaces and C-wave stratal surfaces to image different rock interfaces. This second example is based on the P-wave image in Figure 17 and the $\mathrm{C}$-wave image in Figure 18. Again each image is a time slice through a coherency cube. The P-wave image (Fig. 17) shows a complex system of overlapping, meandering channels. In contrast, the C-wave image

(Fig. 18) shows only one of these channels. The channel detected by the C-wave response is highlighted in the P-wave image repeated as Figure 19. In Example 1 (Figs. 12 and 14), $\mathrm{C}$-wave data seem to provide a better image of an incised-valley target than do P-wave data. In this second example (Figs. 17 and 18), the opposite occurs in that P-wave data provide more image information about a multiple-channel system than do C-wave data.

Without well control, it is impossible to know whether the differences in these $\mathrm{P}$ and $\mathrm{C}$ images are caused by different lithologies in the channel fills or by different relationships between dominant wavelength and channel thickness. One possibility is that 
the one channel that is imaged by the $\mathrm{C}$ wavefield has a lithological character (shear modulus) that differs from the lithofacies in the remaining channels. A second possibility is that the channel in the $\mathrm{C}$ image is thick enough to be resolved, but the other channels are thinner and below $\mathrm{C}$-wave resolution because this target is at a depth where $\mathrm{C}$ resolution is less than P resolution (Figs. 7 and 9). A combination of these factors may be involved. Further work is needed to understand how petrophysical properties and stratigraphic relationships contribute to these observed differences in $\mathrm{P}$ and $\mathrm{C}$ images. The implications of distinct $\mathrm{P}$ and $\mathrm{C}$ stratal surfaces and seismic sequences in hydrocarbon exploration and in the characterization of gas-hydrate systems can be significant.

Inline profile 2100 traverses this targeted channel system as shown in the figures. Locations A, B, C, D in Figure 17 mark individual channels that intersect this P-wave seismic profile. Locations $\mathrm{E}$ and $\mathrm{F}$ in Figure 18 show where the profile crosses the $\mathrm{C}$ wave channel image. The $\mathrm{P}$ and $\mathrm{C}$ data along inline 2100 are displayed in Figure 20 with positions A through $\mathrm{F}$ labeled. The yellow horizon traversing each profile identifies the position of the time slice images shown in Figures 17 and 18. These seismic profiles and their associated image surfaces provide a second example of the principle that $\mathrm{P}$ and $\mathrm{C}$ wavefields often image different stratal surfaces.

\section{Example 3}

A third comparison of $\mathrm{P}$ and $\mathrm{C}$ image surfaces is displayed in Figures 21 and 22. The image target is again a channel feature. In this instance, $\mathrm{P}$ and $\mathrm{C}$ data image equivalent stratal surfaces and produce similar pictures of the target, with the C-wave 
data creating a slightly better image than the $\mathrm{P}$ data, even though there is a strong northsouth acquisition footprint imposed on the shallow C-wave data.

Profile $\mathrm{A}-\mathrm{A}^{\prime}$ shown in the images is an arbitrary seismic line across the channel target. The P- and C-wave reflectivities along this profile are shown in Figure 23 with the channel feature outlined. These time slices and vertical sections confirm that in this instance $\mathrm{P}$ and $\mathrm{C}$ wavefields map identical, or at least highly similar, stratal surfaces associated with this depositional feature. Note that this target is shallower, between horizons $\mathrm{H} 2$ and $\mathrm{H} 3$, where time-warped $\mathrm{C}$ data have a higher frequency content and better vertical resolution than do P data (Fig. 10).

\section{Stratigraphic Importance}

These image comparisons imply that 4-C OBC seismic data will be important for studying complex stratigraphy. It is expected that 4-C data will be particularly valuable for evaluating gas-hydrate systems in the northern GOM because the sequence and lithofacies conditions in these systems are similar to those across our study area, where these image comparisons were made. The stratigraphic importance of 4-C data is that the $\mathrm{C}$-wave mode often images a different suite of stratal surfaces than does the P-wave mode. Both images (P and $\mathrm{C}$ ) are correct; each image provides sequence and facies information that complements the other image. The ability to blend $\mathrm{P}$ and $\mathrm{C}$ images together to achieve greater stratigraphic detail will enhance the appeal of 4-C OBC data in all gas-hydrate investigations, not just studies done in the northern GOM.

The important implication of the $\mathrm{P}$ and $\mathrm{C}$ depth calibration technique developed in this study is that the procedure allows depth-equivalent $\mathrm{P}$ and $\mathrm{C}$ stratal surfaces to be defined across 4-C seismic image space. It is essential that depth-equivalent $\mathrm{P}$ and $\mathrm{C}$ 
surfaces be defined before there is any attempt to calculate $\mathrm{V}_{\mathrm{p}} / \mathrm{V}_{\mathrm{s}}$ and elastic constants in stratigraphic layers. Any gas-hydrate application requiring reliable layer values of $\mathrm{V}_{\mathrm{p}}, \mathrm{V}_{\mathrm{s}}$, $\mathrm{V}_{\mathrm{p}} / \mathrm{V}_{\mathrm{s}}, \mathrm{K}, \mu$, or $\sigma$ will be frustrated if $\mathrm{P}$ and $\mathrm{C}$ images have not first been calibrated to equivalent depth coordinates. The validity of all remaining research findings documented in this report depends on the $\mathrm{P}$-wave to $\mathrm{C}$-wave image correlation procedure illustrated here by these examples. In this particular data set, this procedure was robust and produced accurate $\mathrm{P}$-to-C depth registration of stratigraphic targets and stratal surfaces.

\section{SEISMIC-BASED PROCEDURES FOR DETERMINING $\mathrm{V}_{\mathrm{P}}$ AND $\mathrm{V}_{\mathrm{S}}$ IN SHALLOW LAYERS}

Compressional velocity $\mathrm{V}_{\mathrm{p}}$ and shear velocity $\mathrm{V}_{\mathrm{s}}$ must be determined across a targeted stratigraphic interval in order to calculate dynamic elastic constants within that stratigraphic layer. Seismic-based values of $\mathrm{V}_{\mathrm{p}}$ can be estimated across stratigraphic intervals from prestack data. $\mathrm{V}_{\mathrm{s}}$ across an interval can then be estimated by combining these prestack $V_{p}$ estimates with poststack estimates of $V_{p} / V_{s}$ for that study interval. It is also possible to estimate $V_{s}$ by combining prestack $V_{p}$ analysis with prestack analysis of $\mathrm{C}$-wave stacking velocities $\left(\mathrm{V}_{\mathrm{ps}}\right)$. We evaluated $\mathrm{V}_{\mathrm{ps}}$ stacking velocities and found them unsuitable for estimating $\mathrm{V}_{\mathrm{s}}$, as will be explained in a subsequent section.

\section{Prestack Velocity Analysis}

The basic velocity information created in prestack seismic data analysis is stacking velocity. Two distinct stacking velocities, designated as $\mathrm{V}_{\mathrm{pp}}$ and $\mathrm{V}_{\mathrm{ps}}$, can be generated with 4-C OBC data. The velocity used to stack the P-wave component of 4-C data is $\mathrm{V}_{\mathrm{pp}}$. The subscript notation means that this velocity describes the normal-moveout (NMO) behavior of that portion of the 4-C wavefield that involves a P mode on the 
downgoing path and a $\mathrm{P}$ mode on the upgoing path. The stacking velocity for $\mathrm{C}$ waves is $\mathrm{V}_{\mathrm{ps}}$. This stacking velocity applies to that part of the 4-C data involving a downgoing $\mathrm{P}$ mode and an upgoing SV mode.

Examples of $\mathrm{V}_{\mathrm{pp}}$ and $\mathrm{V}_{\mathrm{ps}}$ stacking velocities across a portion of the study area are shown in Figure 24. There is little variation in these functions over this analysis area, so we will use simple averages of these $\mathrm{V}_{\mathrm{pp}}$ and $\mathrm{V}_{\mathrm{ps}}$ functions in the remaining discussions. These averaged velocity functions are displayed in Figure 25.

The high values of $\mathrm{V}_{\mathrm{ps}}$ at image times less than $0.5 \mathrm{~s}$ are caused by a fictitious $\mathrm{V}_{\mathrm{s}}$ water-layer velocity being imposed on the data to cause sea level to be the time datum for $\mathrm{C}$-wave data processing. It is customary to use sea level as a time datum for marine seismic data. Sea level is an excellent datum for P-wave data because $\mathrm{P}$ waves travel through the water layer. However, $\mathrm{S}$ waves do not travel through water. Thus it is necessary to assign a fictitious $V_{s}$ velocity to the upgoing $C$ travel path in the water layer so that both $\mathrm{P}$ and $\mathrm{C}$ images will have the same depth coordinate (sea level) as the datum from which each image time is measured.

A key research finding of this study is stacking velocities are not a good choice for determining $V_{s}$ in shallow layers when 4-C OBC data are acquired in shallow water as were the data used in this investigation. This conclusion needs to be reexamined when 4-C OBC data are acquired in deep water. The reason for this claim is that the P-to-SV conversion point occurs almost directly beneath the receiver station for shallow interfaces at the subseafloor depths of many gas-hydrate deposits. As a result, the downgoing $\mathrm{P}$ wave accounts for most ( $\sim 90$ percent) of the total travel path from source to receiver. Because the upgoing $\mathrm{C}$ wave affects only a small part (10 to 15 percent) of the total travel 
path, the value of $\mathrm{V}_{\mathrm{s}}$ in a shallow layer has a minor effect on $\mathrm{C}$-wave reflection times from that layer. Thus, analysis of stacking velocities is not a dependable methodology for determining shallow-layer values of $\mathrm{V}_{\mathrm{s}}$ when $\mathrm{OBC}$ data are acquired in shallow water (approximately $100 \mathrm{~m}$ of water depth in this study area). We expect that deep-water OBC data will also not allow $\mathrm{V}_{\mathrm{s}}$ to be estimated in shallow layers from stacking velocities, but we will postpone making such a claim until deep-water OBC data are available for analysis.

These C-wave imaging principles are demonstrated by the two NMO velocity functions displayed in Figure 26. These NMO velocities represent stacking velocities for shallow horizon $\mathrm{H} 4$ defined in Figures 7 and 8. There is little variation in these two functions even when $\mathrm{V}_{\mathrm{s}}$ in the layer above $\mathrm{H} 4$ is changed by a factor of almost 2 , from $254 \mathrm{~m} / \mathrm{s}$ to $482 \mathrm{~m} / \mathrm{s}$. These curves are graphic evidence that $\mathrm{V}_{\mathrm{ps}}$ stacking velocities for shallow interfaces are not greatly impacted by variations in $\mathrm{V}_{\mathrm{s}}$ layer velocities, or, conversely, accurate values of $\mathrm{V}_{\mathrm{s}}$ layer velocities cannot be extracted from $\mathrm{V}_{\mathrm{ps}}$ stacking velocities.

The weak influence of $\mathrm{V}_{\mathrm{s}}$ on shallow-interface imaging is further illustrated by the ray-trace analysis summarized in Figure 27. This figure shows that the distances to mode-conversion points along the shallow H4 surface are almost the same as the distances to the receiver stations. This analysis repeats the point made earlier, that most ( $\sim 90$ percent) of the C-wave travel path for shallow subseafloor reflectors involves the downgoing $\mathrm{P}$ wave. Changing $\mathrm{V}_{\mathrm{s}}$ in the layer above the $\mathrm{H} 4$ surface by a factor of almost 2 (from $254 \mathrm{~m} / \mathrm{s}$ to $482 \mathrm{~m} / \mathrm{s}$ ) moves the common-conversion point less than $25 \mathrm{~m}$, even at offsets of $1,000 \mathrm{~m}$. This ray-trace analysis shows again that $\mathrm{V}_{\mathrm{s}}$ affects only a small part of 
the total travel path and that large changes in $\mathrm{V}_{\mathrm{s}}$ cause minor changes in $\mathrm{C}$-wave arrival times at all offsets. We are thus led to the same conclusion stated earlier, that it is difficult to extract accurate values of $\mathrm{V}_{\mathrm{s}}$ for shallow layers from $\mathrm{V}_{\mathrm{ps}}$ stacking velocities.

The point to be emphasized is that prestack velocity analyses of 4-C seismic data are not the optimal data for determining $\mathrm{V}_{\mathrm{s}}$ in shallow layers. In contrast, reliable values of $\mathrm{V}_{\mathrm{p}}$ in shallow layers can be determined from $\mathrm{V}_{\mathrm{pp}}$ stacking velocities. Thus prestack velocity analyses provide half of the $\mathrm{V}_{\mathrm{p}}$ and $\mathrm{V}_{\mathrm{s}}$ layer-velocity information needed for calculating seismic-based elastic constants. Prestack calculations of $\mathrm{V}_{\mathrm{p}}$ in shallow layers can be used for estimating elastic constants, but $\mathrm{V}_{\mathrm{s}}$ values need to be determined by some other means. The preferred approach, determining layer values of $\mathrm{V}_{\mathrm{s}}$ using poststack data, is considered next.

\section{Poststack Velocity Analysis}

Poststack analysis of 4-C seismic data produces layer values of the velocity ratio $\mathrm{V}_{\mathrm{p}} / \mathrm{V}_{\mathrm{s}}$, not layer values of $\mathrm{V}_{\mathrm{p}}$ and $\mathrm{V}_{\mathrm{s}}$ as separate quantities. The determination of $\mathrm{V}_{\mathrm{p}} / \mathrm{V}_{\mathrm{s}}$ in the four shallow layers created across the $\mathrm{P}$ and $\mathrm{C}$ data volumes is discussed and illustrated in a later section, Seismic-Derived $V_{p} / V_{s}$ Velocity Ratios. That information will not be repeated here.

A key conclusion reached in this investigation is that layer values of $V_{p}$ and $V_{s}$ should be determined by a combination of prestack and poststack velocity analyses. Prestack analysis of $\mathrm{V}_{\mathrm{p}}$ stacking velocities provides layer values of $\mathrm{V}_{\mathrm{p}}$. Poststack data analysis provides layer values of $\mathrm{V}_{\mathrm{p}} / \mathrm{V}_{\mathrm{s}}$. Layer values of $\mathrm{V}_{\mathrm{s}}$ can then be determined using the relationship 


$$
\text { Vs (layer) }=\frac{\mathrm{Vp}(\text { prestack analysis })}{\mathrm{Vp} / \mathrm{Vs} \text { (poststack analysis) }}
$$

The layer value of $\mathrm{V}_{\mathrm{s}}$ given by this equation can now be combined with the prestack determination of $\mathrm{V}_{\mathrm{p}}$ layer velocity to calculate shear moduli and bulk moduli within targeted layers.

\section{COMPARISON OF PRESTACK AND POSTSTACK DETERMINATIONS OF LAYER PARAMETERS}

Poststack and prestack values of layer thicknesses and velocities across a small portion of the study area are listed in Tables 1 and 2 , respectively. The $T_{p p}$ and $T_{p s}$ entries in Table 1 (columns 2 and 3) were generated by the poststack process of interpreting depth-equivalent surfaces $\mathrm{H} 1, \mathrm{H} 2, \mathrm{H} 3$, and $\mathrm{H} 4$ in the $\mathrm{P}$ and $\mathrm{C}$ data volumes (Figs. 7 and 8) across this study area. Local averages of these interpreted $T_{p p}$ and $T_{p s}$ image times were then transferred to the stacking velocity functions in Figure 25 to define rms velocities $V_{p p}$ and $V_{p s}$ (columns 4 and 5) at the base of each layer. Simple differencing of the interpreted $\mathrm{T}_{\mathrm{pp}}$ and $\mathrm{T}_{\mathrm{ps}}$ horizon times produced time thicknesses $\Delta \mathrm{T}_{\mathrm{pp}}, \Delta \mathrm{T}_{\mathrm{ps}}$, and $\Delta \mathrm{T}_{\mathrm{ss}}$ for each layer (columns 6, 7, and 8). The equation defined later in Figure 30 was used to determine $\Delta \mathrm{T}_{\mathrm{ss}}$. The last column in Table 1 lists the $\mathrm{V}_{\mathrm{p}} / \mathrm{V}_{\mathrm{s}}$ ratio (or $\Delta \mathrm{T}_{\mathrm{ss}} / \Delta \mathrm{T}_{\mathrm{pp}}$ ratio) in each layer resulting from this poststack data analysis, which is the $V_{p} / V_{s}$ quantity needed in Equation 3.

Prestack data analyses are summarized in Table 2. Columns 2, 3, and 4 are, respectively, the layer values for $\mathrm{V}_{\mathrm{p}}, \mathrm{V}_{\mathrm{s}}$, and $\mathrm{V}_{\mathrm{p}} / \mathrm{V}_{\mathrm{s}}$ determined from stacking velocities. Note the differences between these prestack determinations of $\mathrm{V}_{\mathrm{p}} / \mathrm{V}_{\mathrm{s}}$ and the poststack values of $\mathrm{V}_{\mathrm{p}} / \mathrm{V}_{\mathrm{s}}$ listed in Table 1. Columns 5 and 6 of Table 2 list two calculations of 
Table 1. Time thicknesses and $\mathrm{V}_{\mathrm{p}} / \mathrm{V}_{\mathrm{s}}$ ratios resulting from poststack interpretation of depth-equivalent surfaces across $\mathrm{P}$ and $\mathrm{C}$ data volumes.

\begin{tabular}{lcccccccc}
\hline Layer & $\mathrm{T}_{\mathrm{pp}}$ & $\mathrm{T}_{\mathrm{ps}}$ & $\mathrm{V}_{\mathrm{pp}}$ & $\mathrm{V}_{\mathrm{ps}}$ & $\Delta \mathrm{T}_{\mathrm{pp}}$ & $\Delta \mathrm{T}_{\mathrm{ps}}$ & $\Delta \mathrm{T}_{\mathrm{ss}}$ & $\mathrm{V}_{\mathrm{p}} / \mathrm{V}_{\mathrm{s}}$ \\
\hline Seafloor to H4 & 0.2627 & 0.7819 & 1.6394 & 0.8650 & 0.1827 & 0.7019 & 1.2211 & 6.68 \\
H4 to H3 & 0.3427 & 0.9951 & 1.6760 & 0.8861 & 0.0800 & 0.2132 & 0.3464 & 4.33 \\
H3 to H2 & 0.4917 & 1.3763 & 1.7341 & 0.9300 & 0.1490 & 0.3812 & 0.6134 & 4.12 \\
H2 to H1 & 0.7455 & 1.8625 & 1.8186 & 0.9918 & 0.2538 & 0.4862 & 0.7186 & 2.83 \\
\hline
\end{tabular}

Assumptions: $\mathrm{T}_{\mathrm{pp}}=\mathrm{T}_{\mathrm{ps}}=0.080 \mathrm{~s}$ at seafloor

$\mathrm{V}_{\mathrm{pp}}=\mathrm{V}_{\mathrm{ps}}=1.5 \mathrm{~km} / \mathrm{s}$ in water column

$\mathrm{H} 1, \mathrm{H} 2, \mathrm{H} 3, \mathrm{H} 4=$ Depth-equivalent $\mathrm{P}$ and $\mathrm{C}$ stratal surfaces defined in Figures 7 and 8

$\mathrm{T}_{\mathrm{pp}}=$ Local average of interpreted P-wave image times (in seconds) at base of layer

$\mathrm{T}_{\mathrm{ps}}=$ Local average of interpreted C-wave image times (in seconds) at base of layer

$\mathrm{V}_{\mathrm{pp}}=\mathrm{P}$-wave rms velocity (in $\mathrm{km} / \mathrm{s}$ ) at time $\mathrm{T}_{\mathrm{pp}}$ (from Figure 25 )

$\mathrm{V}_{\mathrm{ps}}=\mathrm{C}$-wave rms velocity (in $\mathrm{km} / \mathrm{s}$ ) at time $\mathrm{T}_{\mathrm{ps}}$ (from Figure 25)

$\Delta \mathrm{T}_{\mathrm{pp}}=$ Two-way P-wave time (in seconds) across layer

$\Delta \mathrm{T}_{\mathrm{ps}}=$ Two-way $\mathrm{C}$-wave time (in seconds) across layer

$\Delta \mathrm{T}_{\mathrm{ss}}=$ Two-way SV time (in seconds) across layer (from Figure 30)

$\mathrm{V}_{\mathrm{p}} / \mathrm{V}_{\mathrm{s}}=\Delta \mathrm{T}_{\mathrm{ss}} / \Delta \mathrm{T}_{\mathrm{pp}}$ (ratio based on interpretation of migrated $\mathrm{P}$ and $\mathrm{C}$ data volumes)

Table 2. Layer thicknesses and velocities obtained via prestack data analyses.

\begin{tabular}{lcccccc}
\hline Layer & $\mathrm{V}_{\mathrm{p}}$ & $\mathrm{V}_{\mathrm{s}}(1)$ & $\mathrm{V}_{\mathrm{p}} / \mathrm{V}_{\mathrm{s}}$ & $\Delta \mathrm{Z}_{\mathrm{pp}}$ & $\Delta \mathrm{Z}_{\mathrm{ps}}$ & $\mathrm{V}_{\mathrm{s}}(2)$ \\
\hline Seafloor to H4 & 1.697 & 0.482 & 3.52 & 155 & 294 & 0.254 \\
H4 to H3 & 1.791 & 0.626 & 2.86 & 71 & 108 & 0.414 \\
H3 to H2 & 1.861 & 0.702 & 2.65 & 138 & 215 & 0.452 \\
H2 to H1 & 1.972 & 0.642 & 3.07 & 250 & 231 & 0.696 \\
\hline
\end{tabular}

Assumptions: $\mathrm{T}_{\mathrm{pp}}=\mathrm{T}_{\mathrm{ps}}=0.080 \mathrm{~s}$ at seafloor

$\mathrm{V}_{\mathrm{pp}}=\mathrm{V}_{\mathrm{ps}}=1.5 \mathrm{~km} / \mathrm{s}$ in water column

$\mathrm{H} 1, \mathrm{H} 2, \mathrm{H} 3, \mathrm{H} 4=$ Depth-equivalent $\mathrm{P}$ and $\mathrm{C}$ stratal surfaces defined in Figures 7 and 8.

$\mathrm{V}_{\mathrm{p}}=$ Interval P-wave velocity (in $\mathrm{km} / \mathrm{s}$ ) via prestack $\mathrm{V}_{\mathrm{pp}}$ rms velocity function (Figure 25)

$\mathrm{V}_{\mathrm{S}}(1)=$ Interval $\mathrm{SV}$ velocity (in $\mathrm{km} / \mathrm{s}$ ) via prestack rms velocity functions (Figure 25 )

$\mathrm{V}_{\mathrm{p}} / \mathrm{V}_{\mathrm{s}}=$ Ratio via prestack rms velocity functions (Figure 25)

$\Delta \mathrm{Z}_{\mathrm{pp}}=$ Layer thickness (in meters) using $\mathrm{V}_{\mathrm{p}}$ from this table and $\Delta \mathrm{T}_{\mathrm{pp}}$ from Table 1

$\Delta \mathrm{Z}_{\mathrm{ps}}=$ Layer thickness (in meters) using $\mathrm{V}_{\mathrm{s}}(1)$ from this table and $\Delta \mathrm{T}_{\mathrm{ss}}$ from Table 1

$\mathrm{V}_{\mathrm{s}}(2)=$ Interval $\mathrm{SV}$ velocity (in $\mathrm{km} / \mathrm{s}$ ) from Equation 3 
each layer thicknesses. $\Delta \mathrm{Z}_{\mathrm{pp}}$ is the layer thickness calculated from the prestack determination of layer velocity $\mathrm{V}_{\mathrm{p}} ; \Delta \mathrm{Z}_{\mathrm{ps}}$ is the thickness indicated by the prestack layer value of $\mathrm{V}_{\mathrm{s}}$. There are considerable differences in these two layer-thickness calculations. Layer thicknesses calculated from $V_{p}$ are considered to be accurate, whereas thickness values calculated from $V_{s}$ are not because of the difficulty of determining accurate values of $\mathrm{V}_{\mathrm{s}}$ from $\mathrm{V}_{\mathrm{ps}}$ stacking velocities, as has been discussed. The prestack values of $\mathrm{V}_{\mathrm{p}}$ listed in Table 2 are the $V_{p}$ layer values used in Equation 3.

The last column in Table 2 lists the layer values of $\mathrm{V}_{\mathrm{s}}$ that result from combining $\mathrm{V}_{\mathrm{p}}$ (Table 2) with $\mathrm{V}_{\mathrm{p}} / \mathrm{V}_{\mathrm{s}}$ (Table 1), as specified by Equation 3. The layer thicknesses obtained by multiplying these $\mathrm{V}_{\mathrm{s}}(2)$ values by the $\Delta \mathrm{T}_{\mathrm{ss}}$ values in Table 1 are identical to the $\Delta \mathrm{Z}_{\mathrm{pp}}$ thickness values calculated from $\mathrm{V}_{\mathrm{p}}$ and $\Delta \mathrm{T}_{\mathrm{pp}}$. This equality between $\mathrm{V}_{\mathrm{p}}$-based and $\mathrm{V}_{\mathrm{s}}$-based estimates of layer thicknesses is an essential constraint that ensures that $\mathrm{V}_{\mathrm{p}}$ and $\mathrm{V}_{\mathrm{s}}$ layer velocities are evaluated over equivalent depth intervals. Until this constraint is satisfied, $V_{p}$ and $V_{s}$ cannot be used to calculate elastic constants in layers or to estimate any type of velocity-dependent attribute.

\section{$\mathrm{V}_{\mathrm{P}}$ AND $\mathrm{V}_{\mathrm{S}}$ IN SEAFLOOR SEDIMENTS: PREVIOUS STUDIES}

Hamilton (1979) assembled shallow measurements of $V_{p}$ data from worldwide seafloor test sites where the dominant sediment facies were silts, clays, mudstones, and shales, which were the major lithofacies in the shallow strata across our study site. The depth behavior of these $V_{p}$ data is summarized by the function in Figure 28, which is described by the regression equation,

$$
V_{p}=1.511+1.304 D-0.741 D^{2}+0.257 D^{3} .
$$


In this expression, $\mathrm{D}$ and $\mathrm{V}_{\mathrm{p}}$ have units of $\mathrm{km}$ and $\mathrm{km} / \mathrm{s}$, respectively. The dashed curves in the figure show the trends of the 95-percent confidence limits of the data measurements. Our values of $V_{p}$ estimated from P-wave stacking velocities at stratal layers $\mathrm{H} 4$ to $\mathrm{H} 1$ are shown in the figure for comparison. Except for the deepest surface (H1), these estimates fall within the 95-percent confidence levels of Hamilton's data. The close agreement between our $V_{p}$ values and Hamilton's generalization of worldwide $V_{p}$ behavior implies that the prestack velocity analysis used in this study is a robust and reliable technique for determining $\mathrm{V}_{\mathrm{p}}$ in shallow seafloor strata.

Hamilton (1976) also compiled worldwide measurements of $V_{s}$ in shallow seafloor sediment. His summary description of these data is presented in Figure 29. In some of these borehole tests, $\mathrm{V}_{\mathrm{s}}$ was measured at only one depth level. These single-level measurements are indicated by the isolated small dots. At other sites, $\mathrm{V}_{\mathrm{s}}$ was measured at a succession of depth stations in the manner of a conventional velocity checkshot survey. Data from these multilevel measurements are indicated as solid line segments.

The seafloor sediments in which these measurements were made were predominantly silts and clays, the same lithofacies that existed in the shallow seafloor strata across our study area. Hamilton (1976) summarized the depth behavior of these worldwide silt and clay $\mathrm{V}_{\mathrm{s}}$ data using three regression equations:

$$
\begin{array}{lc}
\mathrm{V}_{\mathrm{s}}=116+4.65 \mathrm{D} & 0 \leq \mathrm{D} \leq 36 \mathrm{~m} \\
\mathrm{~V}_{\mathrm{s}}=237+1.28 \mathrm{D} & 36 \leq \mathrm{D} \leq 120 \mathrm{~m} \\
\mathrm{~V}_{\mathrm{s}}=322+0.58 \mathrm{D} & 120 \leq \mathrm{D} \leq 650 \mathrm{~m}
\end{array}
$$


In these equations, depth $\mathrm{D}$ is in meters and $\mathrm{V}_{\mathrm{s}}$ is in units of $\mathrm{m} / \mathrm{s}$. Our estimates of $\mathrm{V}_{\mathrm{s}}$ at our study site can be compared to Hamilton's data at only the two shallowest stratal surfaces, $\mathrm{H} 4$ and $\mathrm{H} 3$, because of the limited depth range of Hamilton's curves. Both our prestack and poststack estimates of $\mathrm{V}_{\mathrm{s}}$ are shown in Figure 29. The poststack prediction (circled crosses), which we think is the more reliable way to estimate $\mathrm{V}_{\mathrm{s}}$, better approximates the Hamilton trend at the deeper horizon.

It is interesting that Hamilton provided no 95-percent confidence limits for worldwide $\mathrm{V}_{\mathrm{s}}$ behavior in seafloor strata, as was done for $\mathrm{V}_{\mathrm{p}}$ data. This fact, combined with large scatter of the Hamilton $\mathrm{V}_{\mathrm{s}}$ data at shallow depths and the sparse number of data points at depths greater than $75 \mathrm{~m}$, makes it difficult to conclude whether our $\mathrm{V}_{\mathrm{s}}$ estimates are typical or atypical of worldwide seafloor conditions. Our philosophy is that it is essential to have internal consistency between $V_{\mathrm{p}}$-based and $\mathrm{V}_{\mathrm{s}}$-based estimates of layer thickness and stratigraphic depths. We were able to achieve this consistency only with poststack estimates of $\mathrm{V}_{\mathrm{s}}$ and prestack estimates of $\mathrm{V}_{\mathrm{p}}$.

\section{SEISMIC-DERIVED $\mathrm{V}_{\mathrm{p}} / \mathrm{V}_{\mathrm{s}}$ VELOCITY RATIOS}

Pickett (1963) and Domenico (1984) showed that the velocity ratio $\mathrm{V}_{\mathrm{p}} / \mathrm{V}_{\mathrm{s}}$ is a valuable attribute for distinguishing one lithofacies from another. One appeal of 4-C seismic data is that the data allow $\mathrm{V}_{\mathrm{p}} / \mathrm{V}_{\mathrm{s}}$ to be determined across stratigraphic intervals of interest once depth-equivalent surfaces are defined in $\mathrm{P}$ and $\mathrm{C}$ data volumes. The determination and lithofacies interpretation of $\mathrm{V}_{\mathrm{p}} / \mathrm{V}_{\mathrm{s}}$ behavior in shallow seafloor strata were key objectives of this study.

Our approach to $\mathrm{V}_{\mathrm{p}} / \mathrm{V}_{\mathrm{s}}$ analysis was to interpret several depth-equivalent stratal surfaces across the 3-D P-wave and C-wave data volumes and to use these surfaces to 
create $\mathrm{P}$-wave and C-wave time-thickness maps between selected pairs of these surfaces. A simple, zero-incidence wave-propagation model was then used to estimate $V_{p} / V_{s}$ velocity ratios across the layer bracketed by matched pairs of these $\mathrm{P}$ and $\mathrm{C}$ stratal surfaces. This model is illustrated in Figure 30. The raypaths are shown as if they are traversing the strata at large incidence angles only to separate individual raypath components so that they can be labeled in the figure; in truth the numerical technique assumes that the raypaths are vertical and lie atop one another. This normal-incidence assumption is reasonable for the $\mathrm{P}$ and $\mathrm{C}$ data volumes that were interpreted.

The interpretational objective was to define $\mathrm{V}_{\mathrm{p}} / \mathrm{V}_{\mathrm{s}}$ across a targeted stratigraphic interval of thickness $\mathbf{d}$ that was bounded by stratal surfaces A and B (Fig. 30). The key challenge of the interpretational procedure was to select which P-wave reflection and which C-wave reflection imaged the depth coordinate of stratal surface A and then decide which pair of $\mathrm{P}$ and $\mathrm{C}$ reflections imaged the depth coordinate of stratal surface $\mathrm{B}$. This selection of depth-equivalent $\mathrm{P}$ and $\mathrm{C}$ reflections was based on the procedure described in the section Establishing Depth-Equivalent P and C Stratal Surfaces. There were no local multicomponent VSP data or any dipole sonic log data across these shallow strata that could be used to establish relationships between stratigraphic depth and P-wave and Cwave seismic image times.

Examples of shallow P-wave stratal surfaces interpreted across the 3-D P-wave data volume are shown along one profile through the $\mathrm{P}$ volume in Figure 7. These surfaces had to be "phantomed" through poor signal-to-noise $(\mathrm{S} / \mathrm{N})$ portions of the data volume associated with gas chimneys and with thick, gas-charged strata. These zones of reduced $\mathrm{P}$-wave $\mathrm{S} / \mathrm{N}$ are caused by the physics of $\mathrm{P}$-wave propagation described in the 
section Gas-Hydrate Model: Northern Gulf of Mexico. The interpretive procedure described in Figure 6 was used to define which C-wave reflection was depth equivalent to each P-wave stratal surface that was interpreted. These C-wave surfaces are shown along an example profile in Figure 8. Note that gas chimneys and thick gas-charged intervals do not deteriorate the $\mathrm{C}$-wave image as they did the $\mathrm{P}$-wave image, as explained in the earlier section just referenced.

If we accept the assumption that $\mathrm{C}$-wave stratal surfaces $\mathrm{WB}, \mathrm{H} 1, \mathrm{H} 2, \mathrm{H} 3$, and $\mathrm{H} 4$ in Figure 8 are produced at the same depth interfaces as are P-wave stratal surfaces WB, $\mathrm{H} 1, \mathrm{H} 2, \mathrm{H} 3$, and $\mathrm{H} 4$ of Figure 7 , then the $\mathrm{V}_{\mathrm{p}} / \mathrm{V}_{\mathrm{s}}$ model described in Figure 30 can be applied across the interval spanned by any matched $\mathrm{P}$ and $\mathrm{C}$ pairs of these five depthequivalent stratal surfaces. Examples of $\mathrm{V}_{\mathrm{p}} / \mathrm{V}_{\mathrm{s}}$ ratios calculated between selected pairs of stratal surfaces are shown in Figures 31 through 34.

The $\mathrm{V}_{\mathrm{p}} / \mathrm{V}_{\mathrm{s}}$ data in these figures have a lateral, bin-to-bin (or $\mathrm{x}-\mathrm{y}$ ) variation in each layer but a constant value along the vertical dimension of each stacking bin. In other words, the data are estimates for the layer interval, not dynamic data-point-by-data-point estimates along the vertical extent of a layer. Each $V_{p} / V_{s}$ map is shown draped over the structural configuration of the base of the calculation layer (left) and as a simple flat display (right). A normal growth fault cuts across the image space, starting at crossline coordinate 300 on the west and curving to the southeast. The fault throw increases with depth, making the fault location most visible on the deepest horizon (Fig. 34).

The $V_{p} / V_{s}$ ratios have rather large values within the shallowest, most unconsolidated layer (Fig. 31) and reduce in magnitude with each successively deeper layer (Figs. 32 through 34). This depth-dependent trend is exactly what is expected 
because of the effect of increasing sediment compaction and consolidation with increasing depth of burial. Within each layer, $\mathrm{V}_{\mathrm{p}} / \mathrm{V}_{\mathrm{s}}$ usually changes across the dominant growth fault, implying that different lithofacies occur on the upthrown and downthrown sides. Such lithofacies variations are common across many GOM growth faults.

Shales have a higher $V_{p} / V_{s}$ value than do sandstones (Domenico, 1984). Thus the principal lithofacies interpretation of the shallowest layer (Fig. 31) is that the upthrown side of the fault is dominated by shaly facies (red), whereas a portion of the downthrown side is dominated by sandy facies (blue). In the next layer (H4 to H3, Fig. 32), the reverse is true. Sandier facies (blue) persist over a large area north of the fault (upthrown side), and shalier facies (red) cover the area south of the fault. The $\mathrm{V}_{\mathrm{p}} / \mathrm{V}_{\mathrm{s}}$ data imply that there is not a large contrast in lithofacies across the growth fault in the third layer (Fig. 33), but that there is a definite lithofacies change from the upthrown side (shalier, red) to the downthrown side (sandier, blue) for the deepest layer (Fig. 34). The $\mathrm{V}_{\mathrm{p}} / \mathrm{V}_{\mathrm{s}}$ values in this deepest layer are approaching the values measured for consolidated rocks by Domenico (1984).

Statistical distributions of $\mathrm{V}_{\mathrm{p}} / \mathrm{V}_{\mathrm{s}}$ for each layer are shown in Figure 35. These displays support the lithological interpretations made earlier. For example, the bimodal distributions of $\mathrm{V}_{\mathrm{p}} / \mathrm{V}_{\mathrm{s}}$ in layer $\mathrm{H} 3$ to $\mathrm{H} 4$ and layer $\mathrm{H} 1$ to $\mathrm{H} 2$ are due to two distinct lithologies occupying large areas on the upthrown and downthrown sides, respectively, of the growth fault, as shown in Figures 32 and 34. The uniform distributions of $V_{p} / V_{s}$ in layer $\mathrm{H} 2$ to $\mathrm{H} 3$ and layer $\mathrm{WB}$ to $\mathrm{H} 4$ indicate that there is a rather homogeneous mixture of lithofacies on both sides of the fault, as shown in Figures 31 and 33. 


\section{$\mathrm{V}_{\mathrm{p}} / \mathrm{V}_{\mathrm{s}}$ IN SEAFLOOR SEDIMENT: PREVIOUS STUDIES}

We considered Hamilton's (1979) compilation of $\mathrm{V}_{\mathrm{p}} / \mathrm{V}_{\mathrm{s}}$ data across shallow seafloor strata (Figure 36) to be one piece of ground-truth information against which shallow seismic-based estimates of $\mathrm{V}_{\mathrm{p}} / \mathrm{V}_{\mathrm{s}}$ across our study area could be compared. The $\mathrm{V}_{\mathrm{p}} / \mathrm{V}_{\mathrm{s}}$ function shown in Figure 36 is a generalization of numerous $\mathrm{V}_{\mathrm{p}} / \mathrm{V}_{\mathrm{s}}$ measurements made at several seafloor sites around the world and represents $\mathrm{V}_{\mathrm{p}} / \mathrm{V}_{\mathrm{s}}$ behavior in the same types of sediment facies that existed across our study area. A principle exhibited by these data is that the $\mathrm{V}_{\mathrm{p}} / \mathrm{V}_{\mathrm{s}}$ ratio can assume large values of 10 or 12 in shallow marine sediment that is dominated by shale, mudstone, clay, and silt facies. Comparison of these curves with the values in Figures 31 through 34 shows that the $V_{p} / V_{s}$ values determined across our study area agree, in general, with these $V_{p} / V_{s}$ values reported by Hamilton.

Added to Figure 36 and shown by open circles are the $\mathrm{V}_{\mathrm{p}} / \mathrm{V}_{\mathrm{s}}$ values calculated in

Table 2. Also shown by the solid circles are the $\mathrm{V}_{\mathrm{p}} / \mathrm{V}_{\mathrm{s}}$ values associated with the peaks of the statistical distributions summarized in Figure 35, with the maximum peak being used when the distribution was bimodal. Both estimates (the open circles and the solid circles) are plotted at depth coordinates obtained by adding the successive layer thicknesses $\Delta \mathrm{Z}_{\mathrm{pp}}$ in Table 2. The choice of the depth coordinate to use when plotting these $V_{p} / V_{s}$ estimates is arbitrary because the structural displays in Figures 31 through 34 indicate that the $\mathrm{V}_{\mathrm{p}} / \mathrm{V}_{\mathrm{s}}$ values in each layer are distributed over a significant range of depths. Likewise, the choice of $\mathrm{V}_{\mathrm{p}} / \mathrm{V}_{\mathrm{s}}$ to use for any of the layers is arbitrary because of the wide range of $\mathrm{V}_{\mathrm{p}} / \mathrm{V}_{\mathrm{s}}$ values found in a layer (Fig. 35). This freedom to be able to move our $\mathrm{V}_{\mathrm{p}} / \mathrm{V}_{\mathrm{s}}$ estimates up or down in depth in Figure 36, subject to the structural constraints in Figures 31 through 34, or to move them left or right, subject to the constraints of Figure 35, 
allows us to match Hamilton's global curves exactly were we to use them to achieve such a match.

Our conclusion is that the $\mathrm{V}_{\mathrm{p}} / \mathrm{V}_{\mathrm{s}}$ values obtained from 4-C OBC data across our study area are consistent with published data acquired by other techniques and are thus reliable for mapping lithofacies distributions. The ability to determine lithofacies distributions in gas-hydrate systems should be one of the motivations to use 4-C OBC data for gas-hydrate research and exploitation.

The $\mathrm{V}_{\mathrm{p}} / \mathrm{V}_{\mathrm{s}}$ maps in Figures 31 through 34 cover a smaller area where much of our research was concentrated. We also constructed $\mathrm{V}_{\mathrm{p}} / \mathrm{V}_{\mathrm{s}}$ maps over the entire $400+$-squaremile area covered by the $\mathrm{P}$ and $\mathrm{C}$ data and show one of these maps as Figure 37 . Having now established the reliability of our seismic-derived estimates of $V_{p} / V_{s}$, this map can be used to predict lithofacies over a much larger area.

This large-area map depicts $\mathrm{V}_{\mathrm{p}} / \mathrm{V}_{\mathrm{s}}$ behavior in the shallowest study layer, WB to H4. The previous display of $\mathrm{V}_{\mathrm{p}} / \mathrm{V}_{\mathrm{s}}$ data in this same layer (Fig. 31) covers only the southwest corner of this 4-C OBC survey. The circled areas indicate where dominant gas chimneys affect the P-wave data. The gas chimney in the southwest corner is associated with a prominent $V_{p} / V_{s}$ anomaly; other gas chimneys have more subtle effects on $V_{p} / V_{s}$, according to our interpretations of the $\mathrm{H} 4$ surface across those chimneys in the $\mathrm{P}$ and $\mathrm{C}$ volumes.

Usually there is an abrupt change in $\mathrm{V}_{\mathrm{p}} / \mathrm{V}_{\mathrm{s}}$ across a fault (Fig. 37). It is not surprising that faults can affect $\mathrm{V}_{\mathrm{p}} / \mathrm{V}_{\mathrm{s}}$ because the $\mathrm{V}_{\mathrm{p}} / \mathrm{V}_{\mathrm{s}}$ ratio changes from higher to lower values when lithofacies change from shale to sand, and it is common to find higher sand content on one side of a GOM growth fault than on the other. This large-area $V_{p} / V_{s}$ 
map implies that sand content increases on the downthrown (south) side of the fault in the southwest corner, but greater sand content occurs on the upthrown (north) side of the fault in the northeast corner. A fault-bounded area of extremely high $\mathrm{V}_{\mathrm{p}} / \mathrm{V}_{\mathrm{s}}$ values (shaledominated sediment?) appears in the northwest corner. Most of the fault-related changes in $\mathrm{V}_{\mathrm{p}} / \mathrm{V}_{\mathrm{s}}$ are no doubt caused by such changes in lithofacies across the fault, but some of the variation may also be caused by incorrect interpretations and depth equalization of the $\mathrm{P}$ and $\mathrm{C} \mathrm{H} 4$ surface. The $\mathrm{V}_{\mathrm{p}} / \mathrm{V}_{\mathrm{s}}$ effects associated with faults and with slight changes in interpreted horizons are discussed in the following section.

\section{$\mathrm{V}_{\mathrm{p}} / \mathrm{V}_{\mathrm{s}}$ AS A QUALITY CONTROL ON P AND C INTERPRETATION}

In addition to being a powerful lithofacies predictor, the velocity ratio $\mathrm{V}_{\mathrm{p}} / \mathrm{V}_{\mathrm{s}}$ can also be a valuable parameter that indicates when questionable decisions have been made in defining depth-equivalent $\mathrm{P}$ and $\mathrm{C}$ stratal surfaces. For example, $\mathrm{P}$-wave surfaces WB through $\mathrm{H} 1$ in Figure 7 have been proposed as being depth equivalent to the $\mathrm{C}$ events in Figure 8 having the same labels. The $\mathrm{V}_{\mathrm{p}} / \mathrm{V}_{\mathrm{s}}$ behavior along these example seismic sections will now be examined in detail.

The P-wave time thickness $\Delta \mathrm{T}_{\mathrm{p}}$ and $\mathrm{S}$-wave time thickness $\Delta \mathrm{T}_{\mathrm{sv}}$ across each layer defined by these horizons are shown in Figures 38 and 39, together with the $V_{p} / V_{s}$ ratio calculated from these time thicknesses according to the concept described in Figure 30. Examination of Figures 7 and 8 shows that these are two major influences on the shape of the interpreted stratal surfaces: the gas chimney centered on crossline coordinate 10,100 and its associated fault (the latter is better seen in Figure 8). The effects of these two geologic features on the interpreted time layers are labeled in Figures 38 and 39. Note that significant low or high adjustments in $\mathrm{V}_{\mathrm{p}} / \mathrm{V}_{\mathrm{s}}$ occur across both of these geologic 
anomalies. Such variations in $\mathrm{V}_{\mathrm{p}} / \mathrm{V}_{\mathrm{s}}$ should not immediately be assumed to be caused by a lithofacies change in the subsurface. Instead, when such abrupt changes of $\mathrm{V}_{\mathrm{p}} / \mathrm{V}_{\mathrm{s}}$ are observed, interpreters are alerted to reexamine their interpretation of stratal surfaces across these $V_{p} / V_{s}$ anomalies and to perhaps adjust these interpretations for reasons not related to the lithofacies composition of the subsurface.

The sensitivity of $V_{p} / V_{s}$ to rather small variations in stratal surface interpretations is illustrated by the $\mathrm{V}_{\mathrm{p}} / \mathrm{V}_{\mathrm{s}}$ peaks and troughs labeled $\mathrm{A}, \mathrm{B}, \mathrm{C}$ on the bottom curves of Figures 38 and 39. These local extremes in $\mathrm{V}_{\mathrm{p}} / \mathrm{V}_{\mathrm{s}}$ are caused by the modest (about $10 \mathrm{~ms}$ ) variations in $\Delta \mathrm{T}_{\mathrm{p}}$ time thickness labeled $\mathrm{A}, \mathrm{B}, \mathrm{C}$ in each display. These time-thickness variations are, in turn, caused by the minor ripples of the $\mathrm{H} 4$ and $\mathrm{H} 3$ surfaces identified by these same letter labels in Figure 7 . The fact that $V_{p} / V_{s}$ reacts to such modest variations in interpreted stratal surfaces makes the velocity ratio a sensitive and powerful quality-control parameter that alerts interpreters when they may need to make slight adjustments in the positioning of a stratal surface.

Despiking filters, such as short median filters, could be applied to $V_{p} / V_{s}$ map data to minimize, and eliminate in many cases, local peak and trough anomalies. We elected not to do such filtering. Until the multicomponent-seismic-interpretation community and we develop a better understanding and appreciation of this unique $\mathrm{V}_{\mathrm{p}} / \mathrm{V}_{\mathrm{s}}$ parameter, it seems advisable to focus on raw, unaltered estimates of the velocity ratio.

\section{LAYER VALUES OF $V_{P}$ AND $V_{S}$}

Layer values of $V_{p}$ were determined across the seismic image space using P-wave stacking velocities, as previously discussed. Displays of the areal behavior of these $V_{p}$ values are shown for each layer in Figures 40 through 43. Equation 3 was then used to 
combine these $V_{p}$ values with the $V_{p} / V_{s}$ ratio layer values (Figs. 31 through 34) to determine layer values of $\mathrm{V}_{\mathrm{s}}$ across the image space. The resulting $\mathrm{V}_{\mathrm{s}}$ velocity distributions are shown in Figures 44 through 47 . These interval values of $V_{p}$ and $V_{s}$ are the critical parameters needed to calculate elastic moduli of the sediments in the seafloor strata.

\section{SHEAR MODULI AND BULK MODULI}

The strata above gas-hydrate reservoirs can have a wide range of mechanical strengths. For safety and environmental reasons, it is critical that gas-hydrate exploration and exploitation be done at sites where the shear strength of the seafloor sediment is large enough that there is minimal likelihood of sediment slumping. Mechanical failure of strata above a gas-hydrate reservoir can pose a serious hazard to drilling operations and/or result in catastrophic release of methane into the ocean and atmosphere. Both of these adverse outcomes have to be avoided when drilling is done across gas-hydrate areas.

One appeal of multicomponent $\mathrm{OBC}$ seismic data in gas-hydrate applications is that the data allow dynamic elastic constants of strata to be estimated across targeted stratigraphic intervals. The elastic constants of principal interest are the shear modulus $\mu$ and the bulk modulus $\mathrm{K}$. These elastic constants can be calculated using the equations

$$
\mu=\rho V_{s}^{2},
$$

and

$$
\mathrm{K}=\rho\left(\mathrm{V}_{\mathrm{p}}^{2}-\frac{4}{3} \mathrm{~V}_{\mathrm{s}}^{2}\right)
$$


where $\rho$ is the bulk density of the sediment, $V_{p}$ is the P-wave velocity across the interval of interest, and $\mathrm{V}_{\mathrm{s}}$ is the $\mathrm{S}$-wave velocity across the same interval. Note that these equations are a restatement of Equations 1 and 2 discussed earlier.

No measurements of bulk density across shallow strata were available within our study area. We thus set the bulk-density term in Equations 8 and 9 to a value of 2.0 $\mathrm{gm} / \mathrm{cm}^{3}$ and used spatial variations of seismic-based determinations of $V_{p}$ and $V_{s}$ to estimate relative values of $\mu$ and $\mathrm{K}$, not absolute values of these moduli. The layer values of $\mathrm{V}_{\mathrm{p}}$ and $\mathrm{V}_{\mathrm{s}}$ shown in Figures 40 through 47 were used to calculate shear moduli and bulk moduli in each layer. The variation of the relative magnitudes of these moduli across the study area is illustrated in Figures 48 through 51 (shear moduli) and Figures 52 through 55 (bulk moduli).

One observation about the shear modulus is that maps of this parameter (Figs. 48 through 51) are identical to the $V_{s}$ maps in Figures 44 through 47. This correspondence occurs because $\mu$ is proportional to the square of $\mathrm{V}_{\mathrm{s}}$ (Equation 8 ). Thus shear moduli maps are redundant to $\mathrm{V}_{\mathrm{s}}$ maps when appropriate color bars are used to display both maps. Either suite of maps $\left(\mathrm{V}_{\mathrm{s}}\right.$ or $\left.\mu\right)$ will indicate where strata are mechanically weaker (low $\mathrm{V}_{\mathrm{s}}$ and $\mu$ values) and mechanically stronger (high $\mathrm{V}_{\mathrm{s}}$ and $\mu$ values).

Inspection of the $\mathrm{V}_{\mathrm{s}}$ and $\mu$ displays shows that an area of higher shear strength in layer WB to H4 (Fig. 44 or 48) south of the growth fault (the red area centered on crossline 200 and inline 150). This same area has the lowest $\mathrm{V}_{\mathrm{p}} / \mathrm{V}_{\mathrm{s}}$ ratio in layer $\mathrm{WB}$ to H4 (Fig. 31), which suggests that it is a site having increased sand content. In the next 
layer (H4 to H3, Fig. 45 or 49), the sediment on the downthrown (south) side of the fault has less mechanical (shear) strength than the sediments on the upthrown side. Most sediments in layer $\mathrm{H} 3$ to $\mathrm{H} 2$ (Fig. 46 or 50) have approximately the same shear strength. In the deepest layer (Figs. 47 and 51), sediment south of the fault has greater shear strength than do sediments north of the fault.

Bulk-moduli maps are similar to $\mathrm{V}_{\mathrm{p}}$ maps for the first three analysis layers below the seafloor, as can be seen by comparing Figures 52 through 55 (K maps) with Figures 40 through $43\left(\mathrm{~V}_{\mathrm{p}}\right.$ maps). Maps of $\mathrm{K}$ and $\mathrm{V}_{\mathrm{p}}$ differ in the deepest layer $\mathrm{H} 2$ to $\mathrm{H} 1$ (Figs. 55 and 43). This correlation between $\mathrm{K}$ and $\mathrm{V}_{\mathrm{p}}$ follows from Equation 9 and a consideration of the $V_{p} / V_{s}$ behavior in each layer. In shallow seafloor strata, $V_{p}$ is much larger than $V_{s}$, causing $\mathrm{V}_{\mathrm{p}}$ to control the bulk modulus (Equation 9 ). The $\mathrm{V}_{\mathrm{p}} / \mathrm{V}_{\mathrm{s}}$ ratio decreases with increasing depth below the seafloor; and in layer $\mathrm{H} 2$ to $\mathrm{H} 1, \mathrm{~V}_{\mathrm{s}}$ is large enough to begin to influence $\mathrm{K}$ also. As a result, the $\mathrm{K}$ map in this deepest layer is no longer an exact replica of the $V_{p}$ map.

The bulk modulus is the reciprocal of compressibility. High $\mathrm{K}$ values indicate areas of low compressibility (high mechanical strength); low $\mathrm{K}$ values occur in sediment that has high compressibility (low mechanical strength). Comparing the $\mathrm{K}$ and $\mu$ maps layer by layer shows that areas of low shear strength (easy to shear) often have high $\mathrm{K}$ values (difficult to compress). A good example of this behavior occurs across the area north of the growth fault in layer $\mathrm{H} 2$ to $\mathrm{H} 1$ (Figs. 51 and 55). Numerous materials other than these unconsolidated seafloor sediments exhibit this type of elastic behavior-ice, glass, ceramics, and water, for example. In fact, spatial variations in the water content of 
these seafloor strata are probably major reasons that sediment shear strength and compressibility behave as shown by our seismic estimates.

Of these two elastic moduli, $\mathrm{K}$ and $\mu$, the shear modulus $\mu$ is the measurement that engineers wish to know about seafloor strata before they install seafloor facilities. In a later section, we compare our seismic-based estimates of shear moduli with shear strength measurements made by engineering service companies in seafloor test holes near our study area.

\section{ELASTIC CONSTANTS OF SHALLOW SEAFLOOR SEDIMENT: PREVIOUS STUDIES}

Hamilton, during his Naval research career, compiled and published valuable information describing elastic constants of seafloor sediment (for example, Hamilton, 1971, 1979). Hamilton's shear strength data for a wide range of seafloor sediment types are summarized in Figure 56. These data show that in 100-percent sand sediment, coarse sand has quite low shear strength and the shear strength increases as sand-grain size decreases, with the highest shear strength of all seafloor sediment types occurring for very fine sand. In terms of the grain size scale used in this plot, coarse sand corresponds

to $\phi=1$, which is a grain diameter of $1 / 2 \mathrm{~mm}$, and very fine sand corresponds to $\phi=3$ to 4 , which is a grain diameter of $(1 / 2)^{3}$ to $(1 / 2)^{4} \mathrm{~mm}$.

An opposite trend of shear strength versus grain size occurs for silt and clay facies (Fig. 56). Shear strength continually diminishes as grain size decreases over the phi grade scale from 4 to 10 . As a result, clay and silty clay have the lowest shear strength of any seafloor sediment, their shear strengths being a little less than that of coarse sand. 
These shear strength data were measured in sediments occurring at subseafloor depths equivalent to our WB-to-H4 layer. Examination of the color bar on our shear strength map of that layer (Fig. 48) shows that our seismic-derived estimates of $\mu$ have the same numerical range as Hamilton's data (Fig. 56). The close correspondence between these published data and our seismic-based estimates implies that 4-C OBC seismic data should be reliable for evaluating the shear strength of strata overlying marine gas-hydrate deposits. Such shear strength evaluations could be critical when slump failure risks have to be considered across gas-hydrate areas.

\section{LOCAL MEASUREMENTS OF SHEAR STRENGTH}

Oil and gas companies operating inside, and near, our study area provided two valuable reports that summarized shear strength tests of seafloor sediments at sites where drilling platforms had been positioned. These test locations will be referred to as Well A and Well B.

Tests made at Well A for sediments from the mud line to a depth of $40 \mathrm{ft}$ are presented in Figure 57. Tests for sediments between depths of 40 and $250 \mathrm{ft}$ are shown in Figure 58. The moisture content of seafloor sediment has a strong effect on the loadbearing ability of sediment and is a key measurement made by companies that need to install seafloor facilities. The moisture content of the sediment at Well A is shown by the data on the left of each display, with the measured moisture content shown as solid circles. The horizontal dash lines indicate where this natural moisture content is positioned relative to the liquid limit and plastic limit of the sediment. When the moisture content is greater than the liquid limit, the sediment behaves as a liquid. When the moisture content is less than the plastic limit, the sediment behaves as an elastic solid. 
When the moisture content is between these two limits, the sediment behaves as a plastic material.

In a general sense, these engineering tests imply that sediments below a depth of about $110 \mathrm{ft}$ can be assumed to be elastic strata. Sediments shallower than $110 \mathrm{ft}$ exhibit variable plastic behavior and do not behave as true elastic media. In elastic media, there is a linear relationship between strain and stress. In plastic media, strain is related not only to stress but to stress rate as well.

Shear strength data are shown on the right of Figures 57 and 58. These shear strength measurements were made using a variety of laboratory techniques (as labeled in the figures). We will not describe these measurement procedures in this report. The data points in these displays represent the amount of shear stress required to cause catastrophic failure of the sediment. Shear stress values created in situ by propagating seismic waves are much less than these sediment-failure values.

No measurements of sediment moisture content were available at Well B. The only data provided were the shear strength measurements shown in Figure 59. These data appear to have been averaged and smoothed by the contractor who prepared the report for the field operator; the shear strength values do not show the data scatter exhibited in Figures 58 and 59. Even though the data at Well B appear to have been smoothed and adjusted, we have no reason to doubt the reliability of the shear strength depth profile defined by the best-fit curve. For the depth interval between the mud line and a depth of $40 \mathrm{ft}$, the sediments at Well B have a shear strength approximately twice the shear strength of the sediment at Well A. We conclude that the difference in shear strength measured at these two local drilling sites indicates that we should expect to observe 
lateral variations of 2 and greater in seismic-derived estimates of shear modulus across the study area.

It is not possible to transform the shear strength data in Figures 57 through 59 to values of shear moduli because the magnitude of the shear strains that occurred in the sediment tests are not known. For elastic homogeneous media, shear strength is given by

$$
\text { (shear strength) }=\mu(\text { shear strain })
$$

where shear strain in these tests is the strain that results in shear failure of the test sample. Our seismic-derived estimates of $\mu$ in layer WB to $\mathrm{H} 4$ are on the order of $10^{9}$ dynes $/ \mathrm{cm}^{2}$ (Fig. 48). The shear strength data in Figures 58 and 59 are on the order of $10^{6}$ dynes $/ \mathrm{cm}^{2}$ (using the conversion $1.0 \mathrm{psi}=6.9 \times 10^{4} \mathrm{dynes} / \mathrm{cm}^{2}$ ). From Equation 10, the shear strain involved in these local engineering tests of unconsolidated seafloor sediment were then on the order of $10^{-3}$ (dimensionless units). This magnitude of strain is typical of such tests (verbal communication with soil engineers). We conclude that these local measurements of the shear strength of seafloor strata near our study area are further confirmation that our 4-C seismic-based estimates of the elastic moduli of these sediments are reliable.

\section{POISSON'S RATIO}

Poisson's ratio $\sigma$ is the ratio of transverse strain to longitudinal strain. The static version of $\sigma$ for consolidated and unconsolidated sediment is determined by laboratory stress-strain tests. A dynamic version of $\sigma$ can be determined in situ using the velocity ratio $\mathrm{V}_{\mathrm{p}} / \mathrm{V}_{\mathrm{s}}$ measured across an interval of interest and the equation, 


$$
\sigma=0.5\left[\left(\mathrm{~V}_{\mathrm{p}} / \mathrm{V}_{\mathrm{s}}\right)^{2}-2\right] /\left[\left(\mathrm{V}_{\mathrm{p}} / \mathrm{V}_{\mathrm{s}}\right)^{2}-1\right]
$$

Poisson's ratio has a value of 0.5 in media that have no shear rigidity (that is, in media where $\mu=0$, which causes $\mathrm{V}_{\mathrm{s}}=0$ ). This limiting value of $\sigma=0.5$ when $\mathrm{V}_{\mathrm{s}}=0$ is obvious by rewriting Equation 11 as

$$
\sigma=0.5\left(\mathrm{~V}_{\mathrm{p}}^{2}-2 \mathrm{~V}_{\mathrm{s}}^{2}\right) /\left(\mathrm{V}_{\mathrm{p}}^{2}-\mathrm{V}_{\mathrm{s}}^{2}\right)
$$

We found Hamilton's (1979) compilation of Poisson's ratio values in seafloor sediment to be an excellent reference for this analysis. Poisson's ratio behavior in Figure 60 summarizes Hamilton's findings for fine-grained sediment; the curve in Figure 61 shows the behavior of $\sigma$ in shallow, unconsolidated sand facies.

These published data imply that seismic-derived estimates of $\sigma$ for the shallow strata across our study area should be greater than 0.40 and probably greater than 0.45 for the shallowest intervals that can be analyzed in the seismic data volumes. The data in Figure 61 indicate that some sediment near the seafloor behave as a suspension with almost zero rigidity rather than as an elastic solid, causing $\sigma$ to be greater than 0.49 .

Because Poisson's ratio becomes smaller as rigidity increases (because $V_{s}$ becomes larger in Equations 11 and 12), seismic-derived estimates of $\sigma$ can be used to distinguish weak strata (low shear rigidity and high $\sigma$ value) from mechanically stable strata (high shear rigidity and lower $\sigma$ value). Our seismic-based layer estimates of $\sigma$ are displayed as Figures 62 through 65. As stated, there is a reciprocal relationship between shear strength and Poisson's ratio. Low shear strength implies a high Poisson's ratio; high shear strengths indicate low Poisson's ratios. Thus our estimates of Poisson's ratio in a given layer show a color pattern that mimics the color pattern of the $\mu$ estimates in that 
same layer (Figs. 48 through 51); the color bar for the $\sigma$ map is simply the inverse of the color bar for the $\mu$ map. Consequently, shear strength maps and Poisson ratio maps are redundant. Interpreters can use either parameter $(\sigma$ or $\mu)$ to infer the mechanical stability of seafloor strata.

\section{CONCLUSIONS}

We have demonstrated and established that 4-C OBC seismic data should be used to improve the understanding and characterization of gas-hydrate systems across the northern GOM. The key research findings and seismic principles of our study are

1. C waves overcome the problem of not being able to image the interior of shallow, gas-charged seafloor strata with P waves. Because gas hydrates in the northern GOM are typically associated with gas-chimney features, C waves will be invaluable for imaging the internal architecture of those portions of gas-hydrate areas that reside inside gas-charged sediment.

2. A robust procedure for defining depth-equivalent $\mathrm{P}$ and $\mathrm{C}$ stratal surfaces that is based on the internal reflection character of the $\mathrm{P}$ and $\mathrm{C}$ data has been developed and demonstrated. Establishing depth-equivalent $\mathrm{P}$ and $\mathrm{C}$ seismic reflections is fundamental; no reliable petrophysical properties of seafloor strata can be estimated from 4-C data until such depth equalization has been done.

3. A technique for warping $\mathrm{C}$ image time to $\mathrm{P}$ image time has been implemented. This method requires the input of the depth-equalized $\mathrm{P}$ and $\mathrm{C}$ stratal surfaces mentioned in 2. Once a few depth-equalized $\mathrm{P}$ and $\mathrm{C}$ time coordinates are 
established, $\mathrm{C}$ data can be time warped so that $\mathrm{P}$ data and warped-C data are depth equivalent, data point by data point.

4. Time-warped $\mathrm{C}$ data have better spatial resolution in shallow seafloor strata than do P-wave data. This increased spatial resolution will be important for improved characterization of gas-hydrate systems.

5. Using the foundation of depth-equalized $\mathrm{P}$ and $\mathrm{C}$ images, we have shown that key petrophysical parameters $\left(\mathrm{V}_{\mathrm{p}}, \mathrm{V}_{\mathrm{s}}, \mathrm{V}_{\mathrm{p}} / \mathrm{V}_{\mathrm{s}}\right)$ and elastic moduli $(\mu, \mathrm{K}, \sigma)$ can be estimated for seafloor strata using 4-C seismic data. We confirmed the accuracy of these estimates by comparing our seismic-based results with published data and with local engineering measurements of seafloor shear strength.

6. We have shown how maps of the velocity ratio $\mathrm{V}_{\mathrm{p}} / \mathrm{V}_{\mathrm{s}}$ can be used to indicate spatial distributions of lithofacies in seafloor strata. Such maps should be invaluable for understanding the lithofacies character of gas-hydrate systems.

7. We have described the linkages and consistencies between $\mathrm{V}_{\mathrm{p}}$ and $\mathrm{K}$ (when $\mathrm{V}_{\mathrm{p}} / \mathrm{V}_{\mathrm{s}}$ is a large ratio), between $\mathrm{V}_{\mathrm{s}}$ and $\mu$, and between $\mu$ and $\sigma$. As a result of these linkages, there is some redundancy between $\mathrm{V}_{\mathrm{p}}, \mathrm{K}, \mathrm{V}_{\mathrm{s}}, \mu$, and $\sigma$ maps. However, we recommend that maps of all of these seismic-derived attributes be used by gas-hydrate investigators until the gas-hydrate community becomes comfortable with the uses, applications, and limitations of these unique petrophysical parameters provided by $4-\mathrm{C} \mathrm{OBC}$ seismic data.

8. We have illustrated how maps of $\mu$ or $\mathrm{V}_{\mathrm{s}}$ can be used to locate areas of maximum and minimum shear strength in seafloor strata. The ability to 
predict seafloor stability with 4-C seismic data may be one of the most valuable uses of 4-C seismic data in gas-hydrate areas.

Any one of these research findings attests to the value that 4-C OBC seismic data provide to gas-hydrate studies. In combination, all of these conclusions provide compelling evidence that 4-C data should be incorporated into gas-hydrate studies whenever possible.

\section{ACKNOWLEDGMENT}

Seitel Data and WesternGeco provided the 4-C OBC seismic data used in this research investigation.

\section{REFERENCES}

Bard, E., Hamelin, B., and Fairbanks, R. G., 1990, U-Th ages obtained by massspectrometry in corals from Barbados: sea level during the past 130,000 years: Nature, v. 346, p. 456-458.

Berryhill, H. L., Jr., 1987 Late Quaternary facies and structure, northern Gulf of Mexico: American Association of Petroleum Geologists Studies in Geology 23, Tulsa, OK, $289 \mathrm{p}$.

Coleman, J. M., and Roberts, H. H., 1990, Cyclic sedimentation of the northern Gulf of Mexico Shelf, in Armentrout, J. M., and Perkins, B. F., eds., Sequence stratigraphy as an exploration tool: concepts and practices in the Gulf Coast: Gulf Coast Section of the Society of Economic Paleontologists and Mineralogists Foundation Eleventh Annual Research Conference, p. 113-134.

Domenico, S. N., 1984, Rock lithology and porosity determination from shear and compressional wave velocity: Geophysics, v. 49, p. 1188-1195.

Hamilton, E. L., 1971, Elastic properties of marine sediments: Journal of Geophysics Research, v. 76, no. 2, p. 579-604. 
Hamilton, E. L., 1976, Shear-wave velocity versus depth in marine sediments-a review: Geophysics, v. 41, p. 985-996.

Hamilton, E. L., 1979, $\mathrm{V}_{\mathrm{p}} / \mathrm{V}_{\mathrm{s}}$ and Poisson's ratios in marine sediments and rocks: Journal of the Acoustic Society of America, v. 66, no. 4, p. 1093-1101.

Pickett, G. R., 1963, Acoustic character logs and their application in formation evaluation: Journal of Petroleum Technology, v. 15, p. 650-667.

Thomas, M. A., and Anderson, J. B., 1994, Sea-level controls on the facies architecture of the Trinity/Sabine incised-valley system, Texas continental shelf, in Incisedvalley systems: origin and sedimentary sequences: Society of Economic Paleontologists and Mineralogists Special Publication 51, p. 63-82.

Wellner, J. S., Sarzalejo, S., and Anderson, J. B., in press, Late Quaternary stratigraphic evolution of the west Louisiana/East Texas continental shelf, in Fillon, Richard, ed., Late Quaternary stratigraphic evolution of the northern Gulf of Mexico margin: SEPM (Society for Sedimentary Geology), Special Publication. 


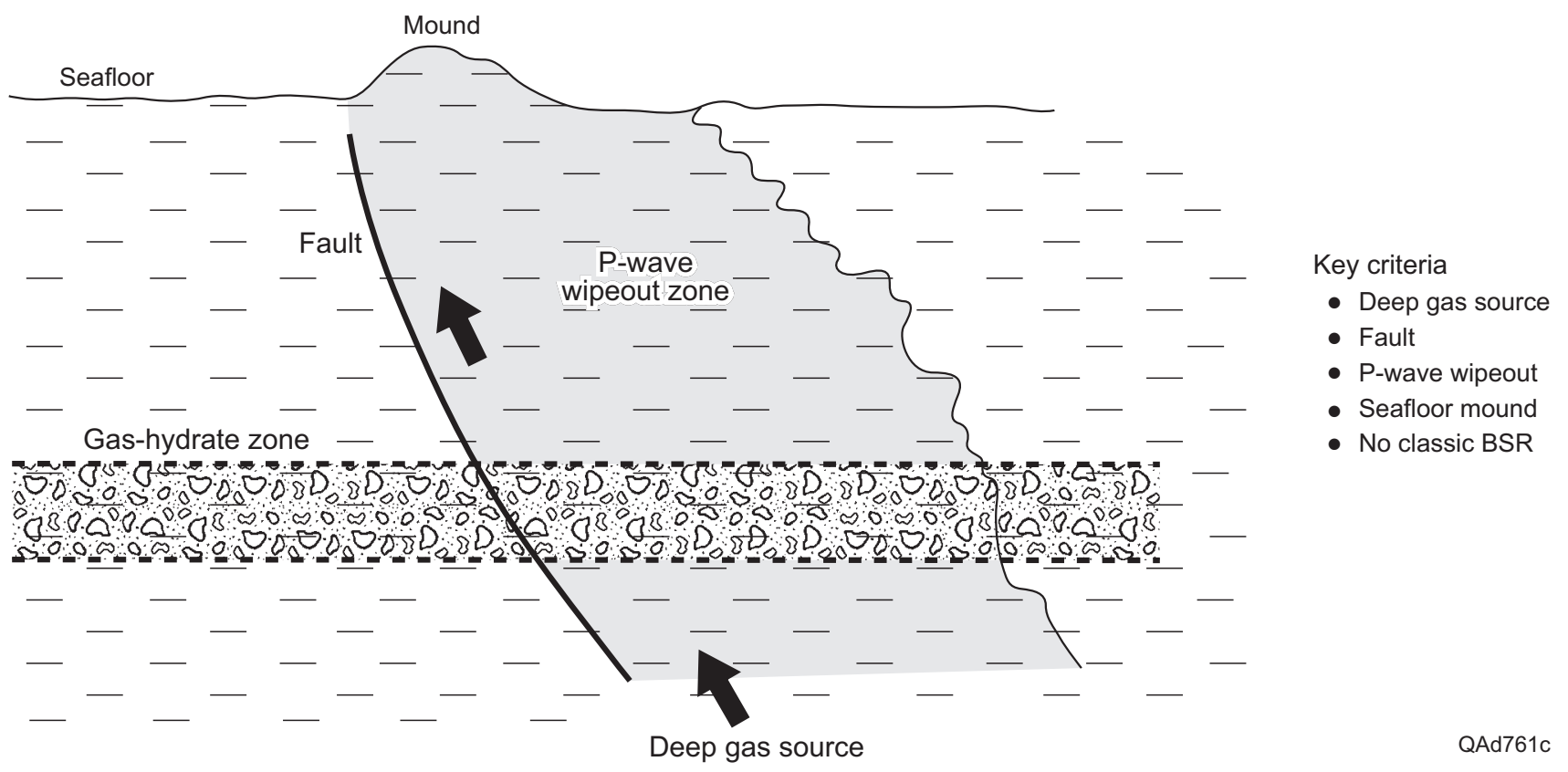

Figure 1. Widely accepted geological model of gas-hydrate systems across the northern Gulf of Mexico. The top of the gas-hydrate stability zone extends upward to the seafloor. The spatial distribution and concentration of gas hydrates within this zone of chemical stability can vary from site to site. 


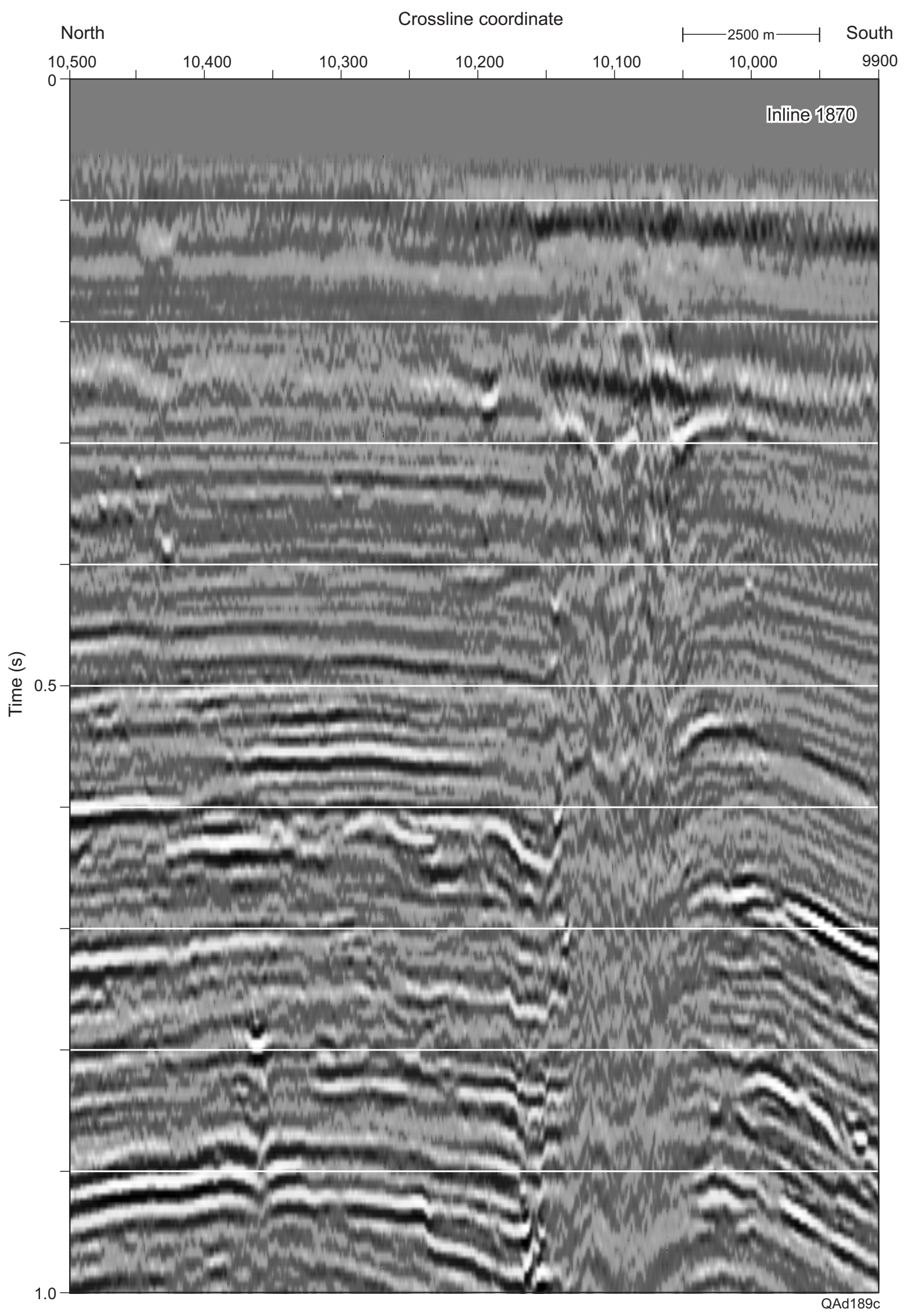

Figure 2. P-wave seismic profile across gas chimney located at crossline coordinate 10,100 (Example 1). Compare with Figure 4. 


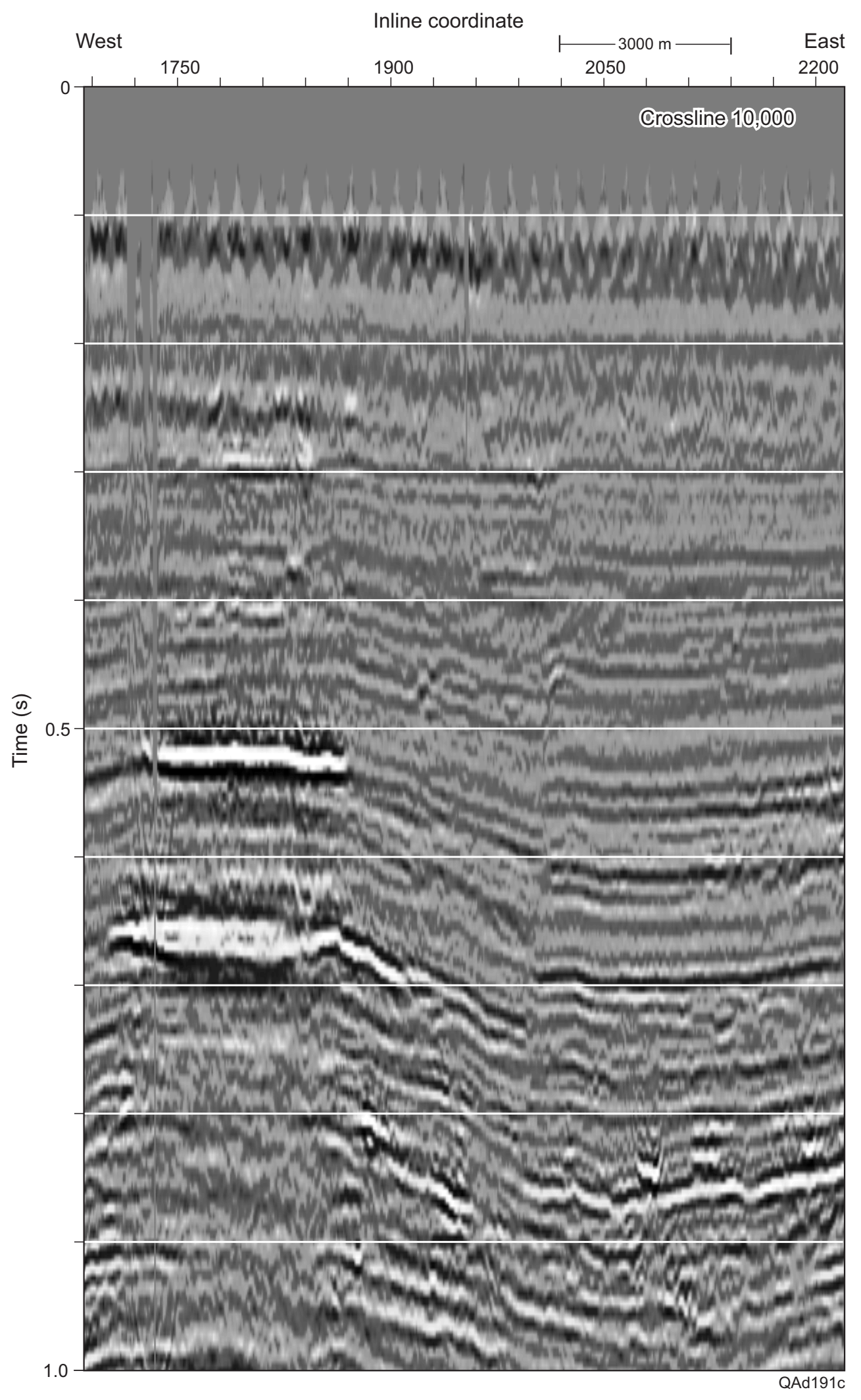

Figure 3. P-wave seismic profile across gas chimney located at inline coordinate 1780 (Example 2). Compare with Figure 5. 


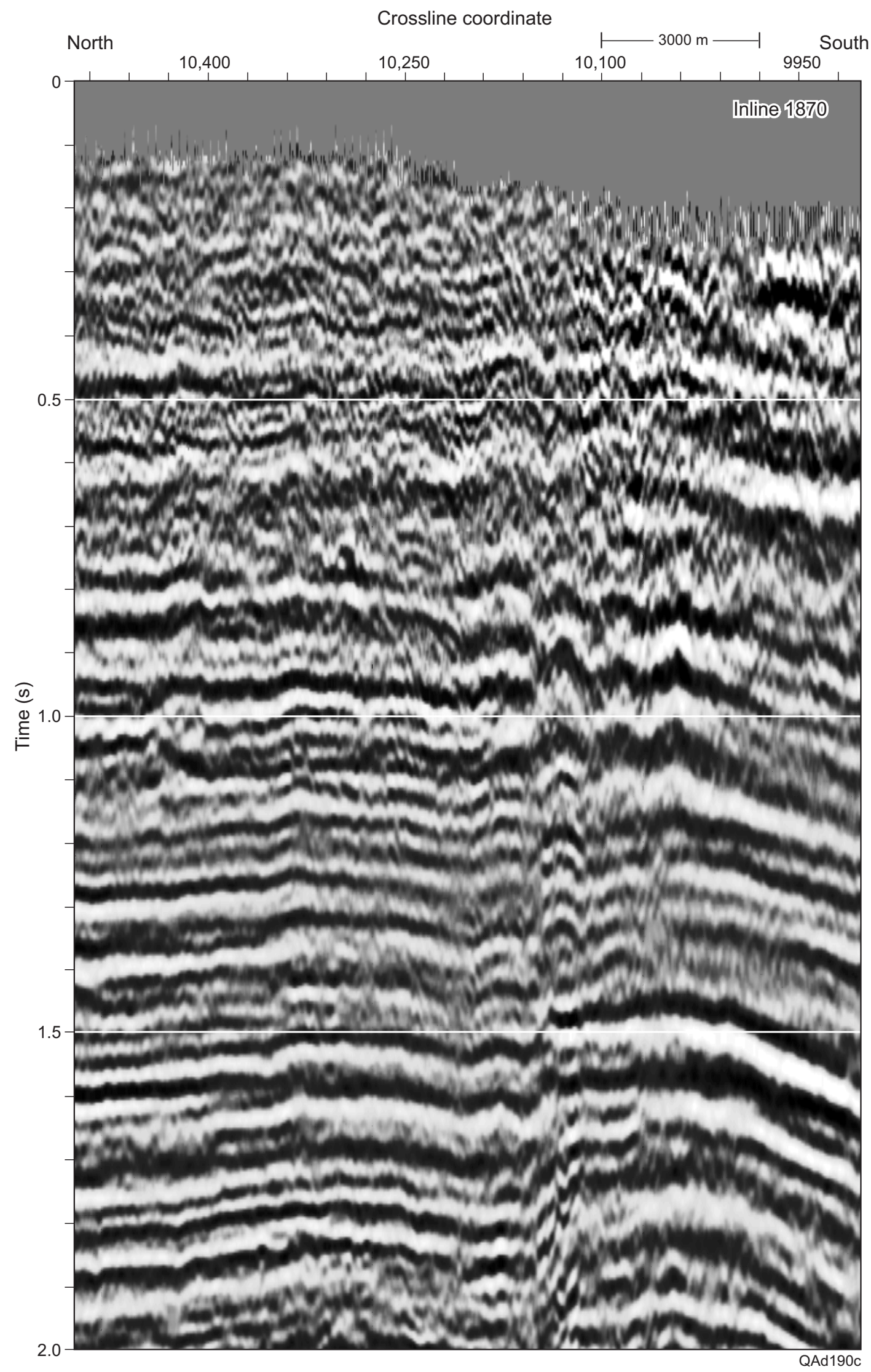

Figure 4. C-wave seismic profile across gas chimney (Example 1). Compare with Figure 2. 


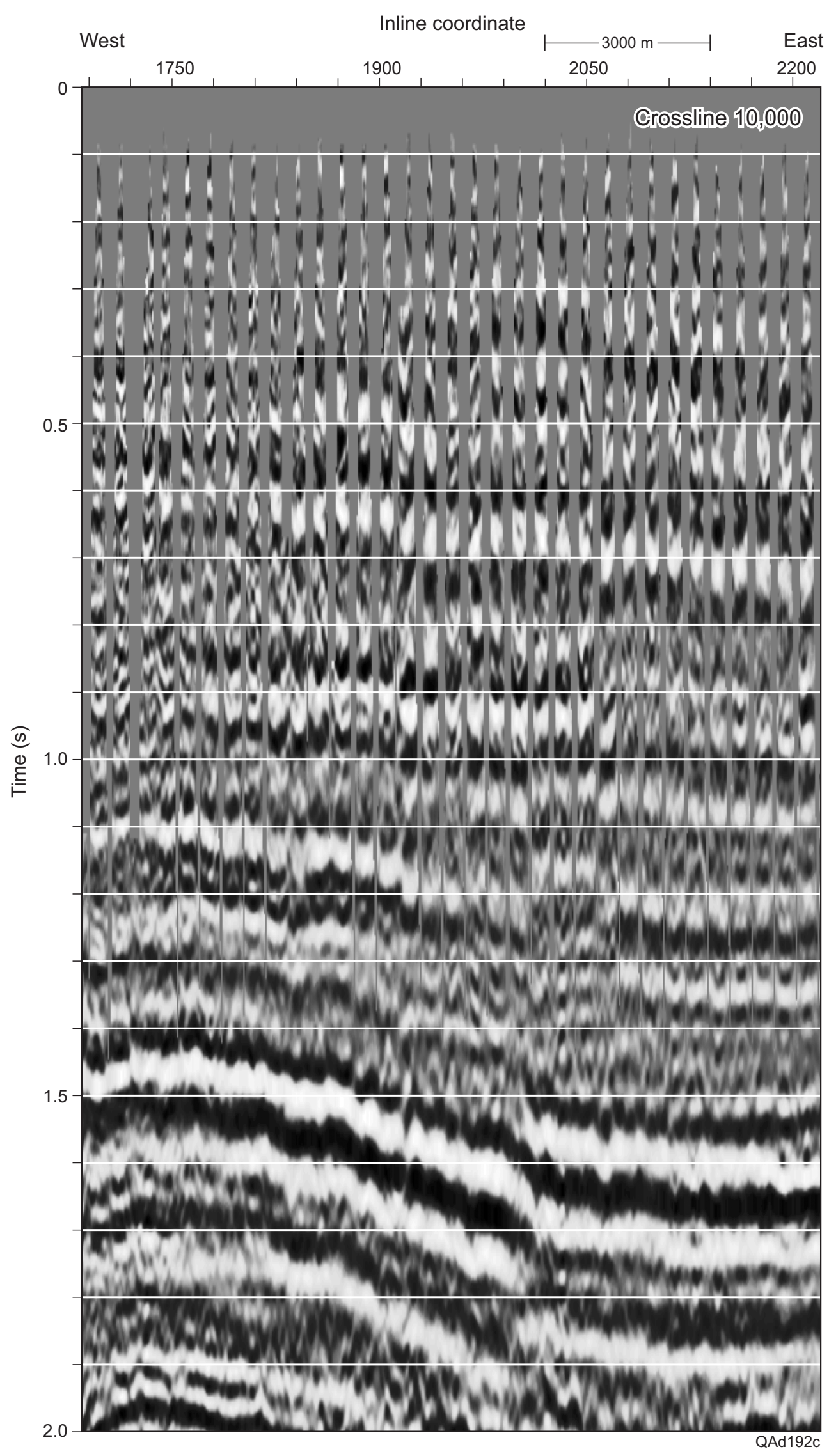

Figure 5. C-wave seismic profile across gas chimney (Example 2). Compare with Figure 3. 


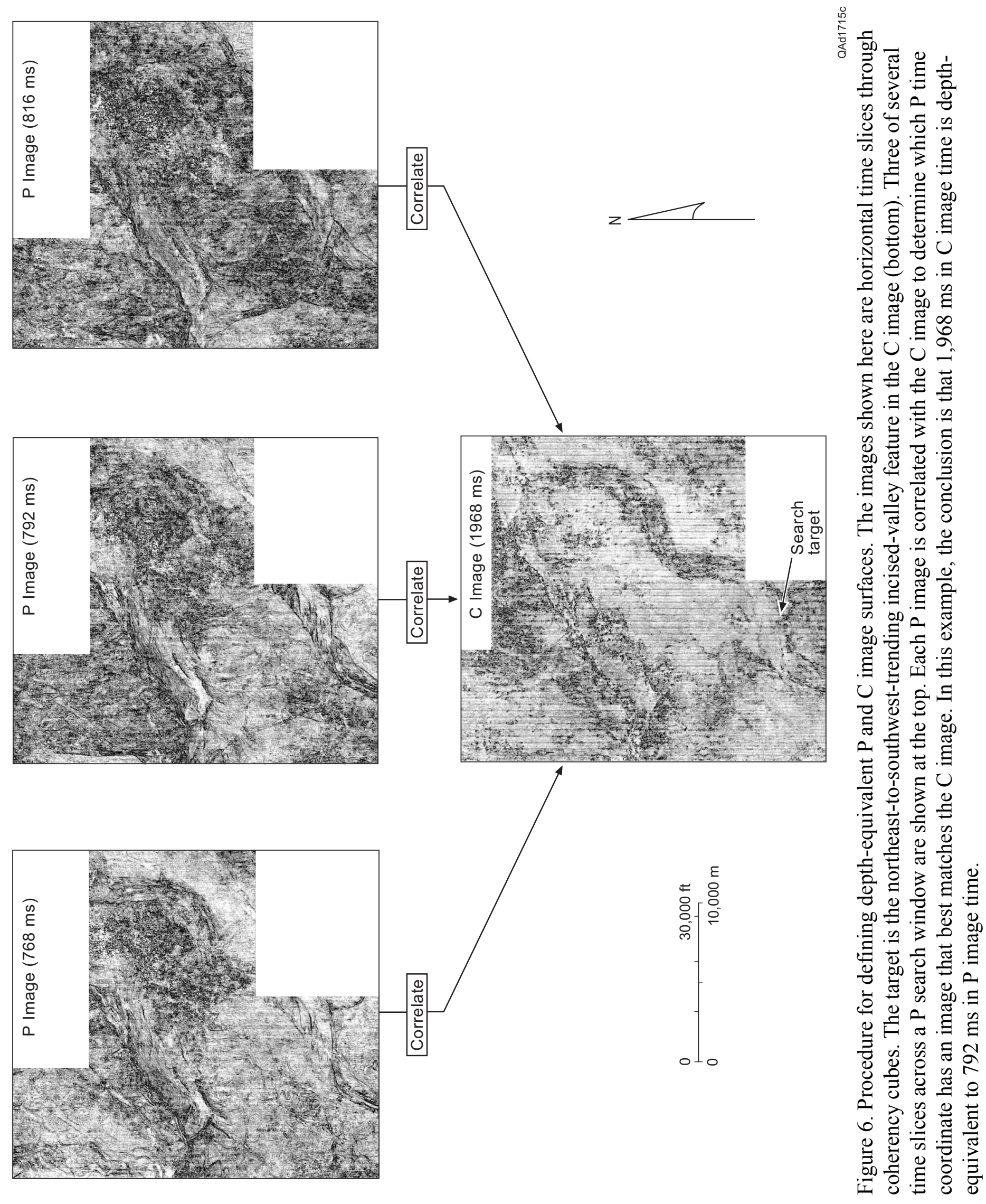




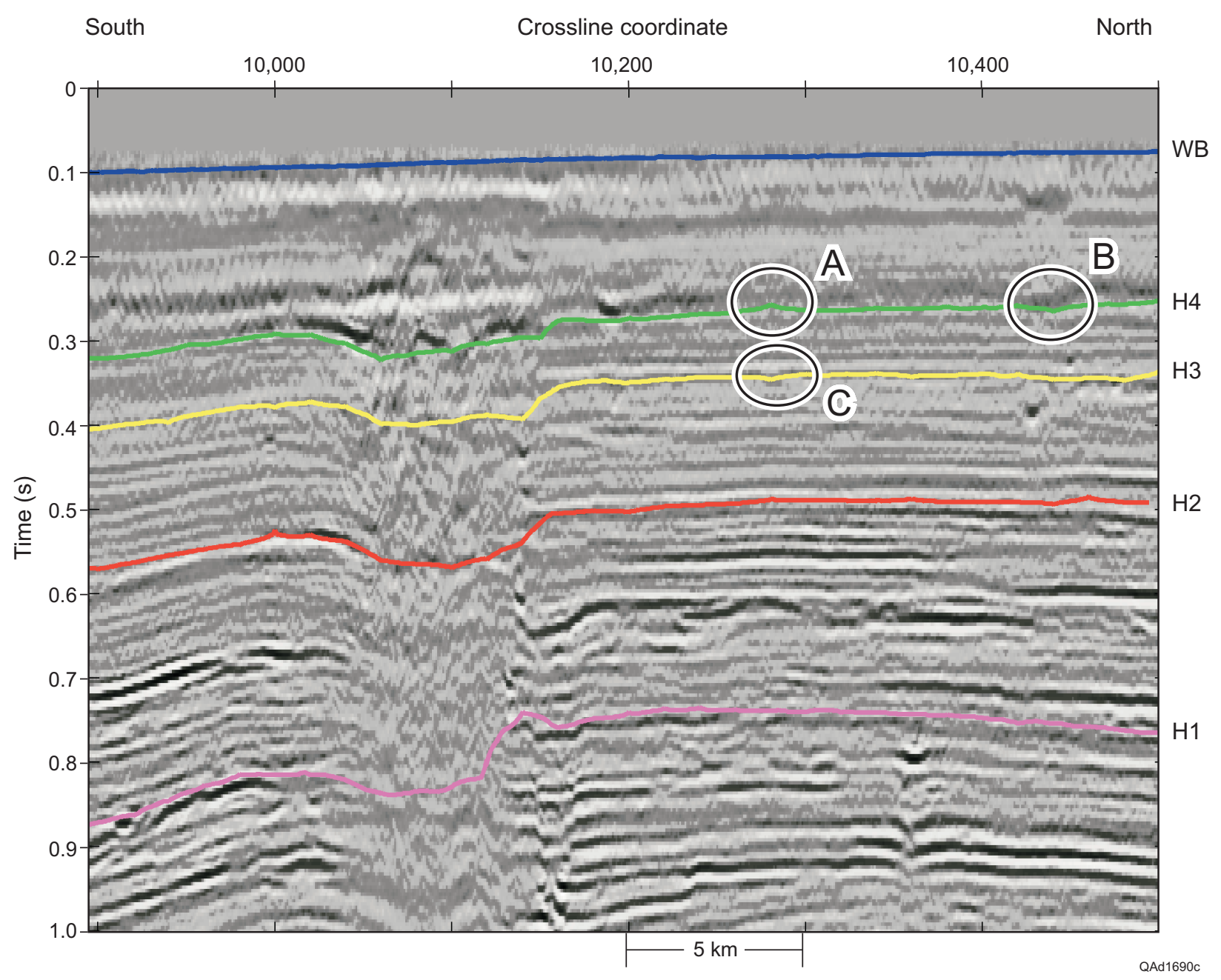

Figure 7. P-wave section showing interpreted horizons that will be used as frequent references. WB is the water bottom. A gas chimney is centered on crossline coordinate 10,100. Features A, B, C will be used in Figures 38 and 39. 


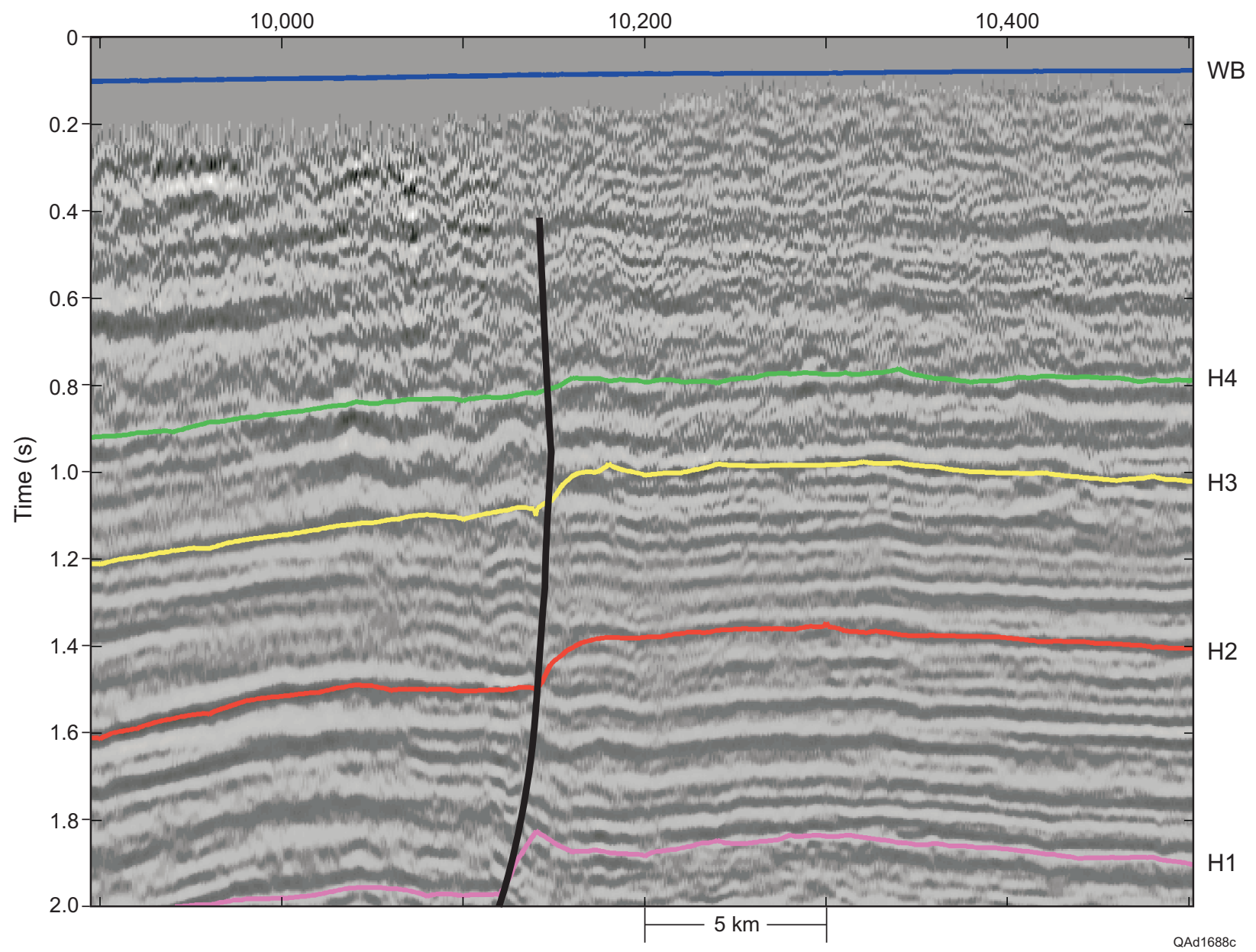

Figure 8. C-wave image along the same profile as the $\mathrm{P}$ data in Figure 7. The horizons shown here are depth-equivalent to the labeled horizons in $\mathrm{P}$ image space. Note the improved image quality inside the gas chimney (crossline 10,100). 


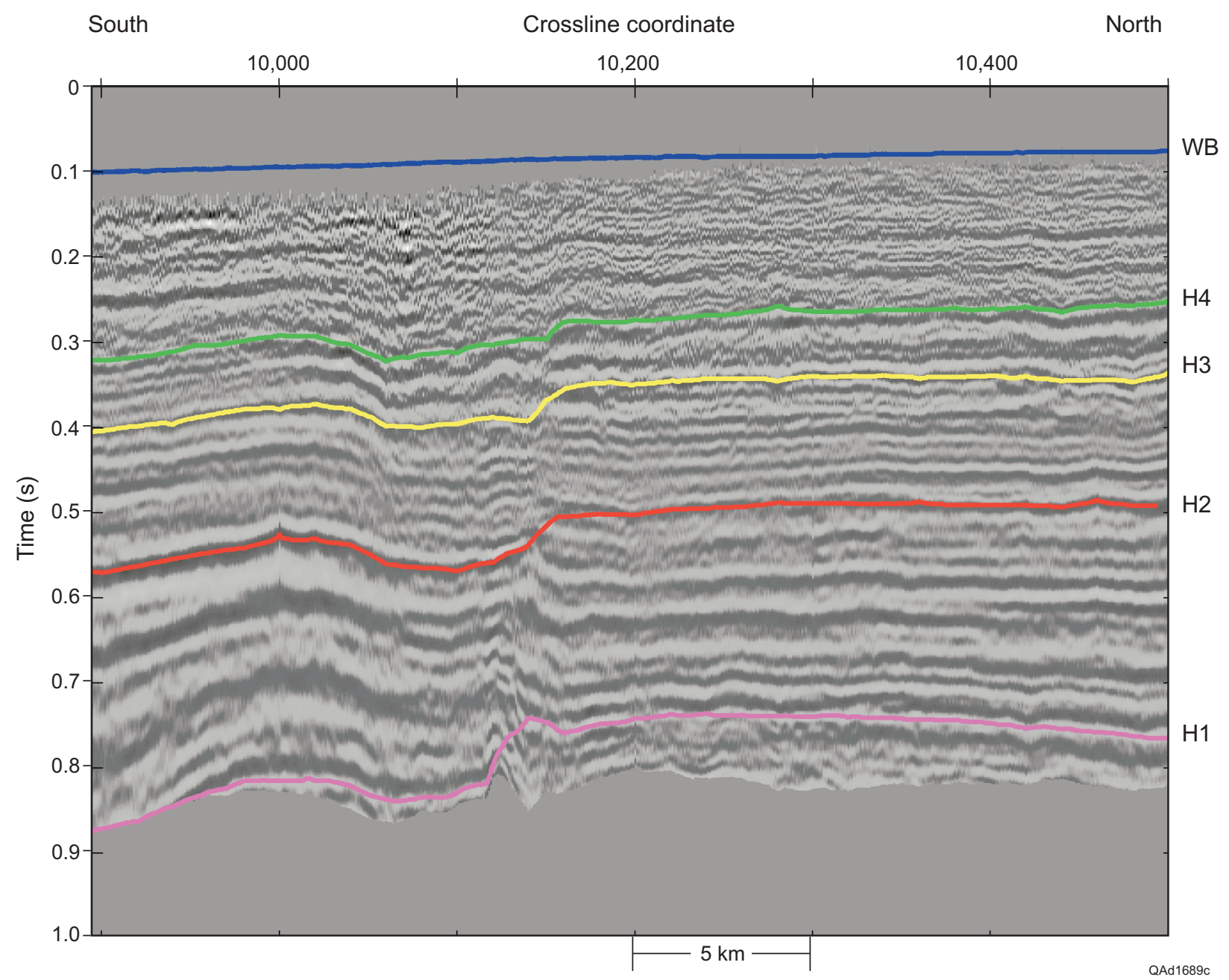

Figure 9. C-wave data of Figure 8 after being warped to $\mathrm{P}$ image time. 

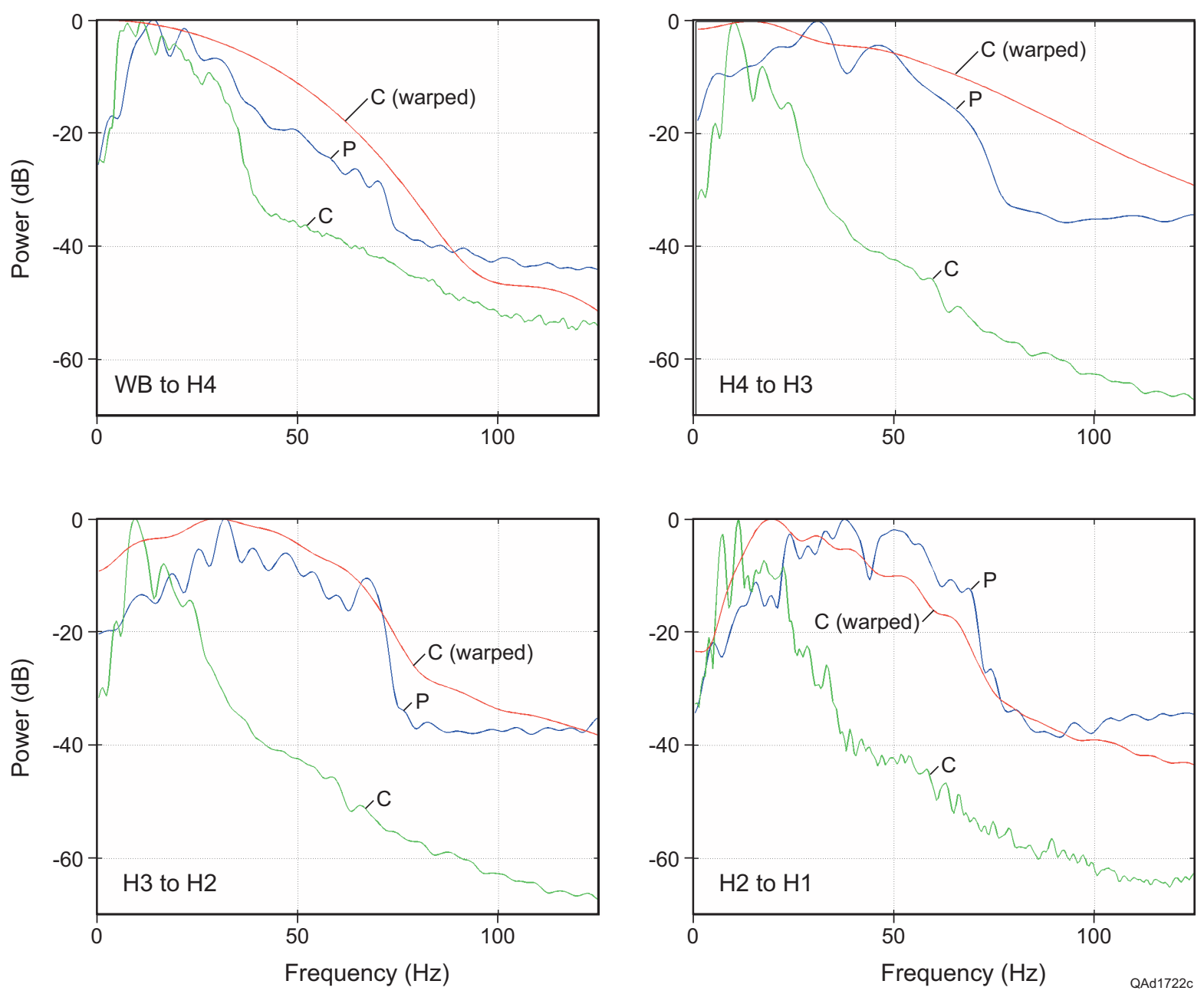

Figure 10. Frequency spectra of $\mathrm{P}, \mathrm{C}$, and warped-C wavefields in the intervals defined by stratal layers $\mathrm{WB}, \mathrm{H} 4, \mathrm{H} 3, \mathrm{H} 2$, and $\mathrm{H} 1$. 


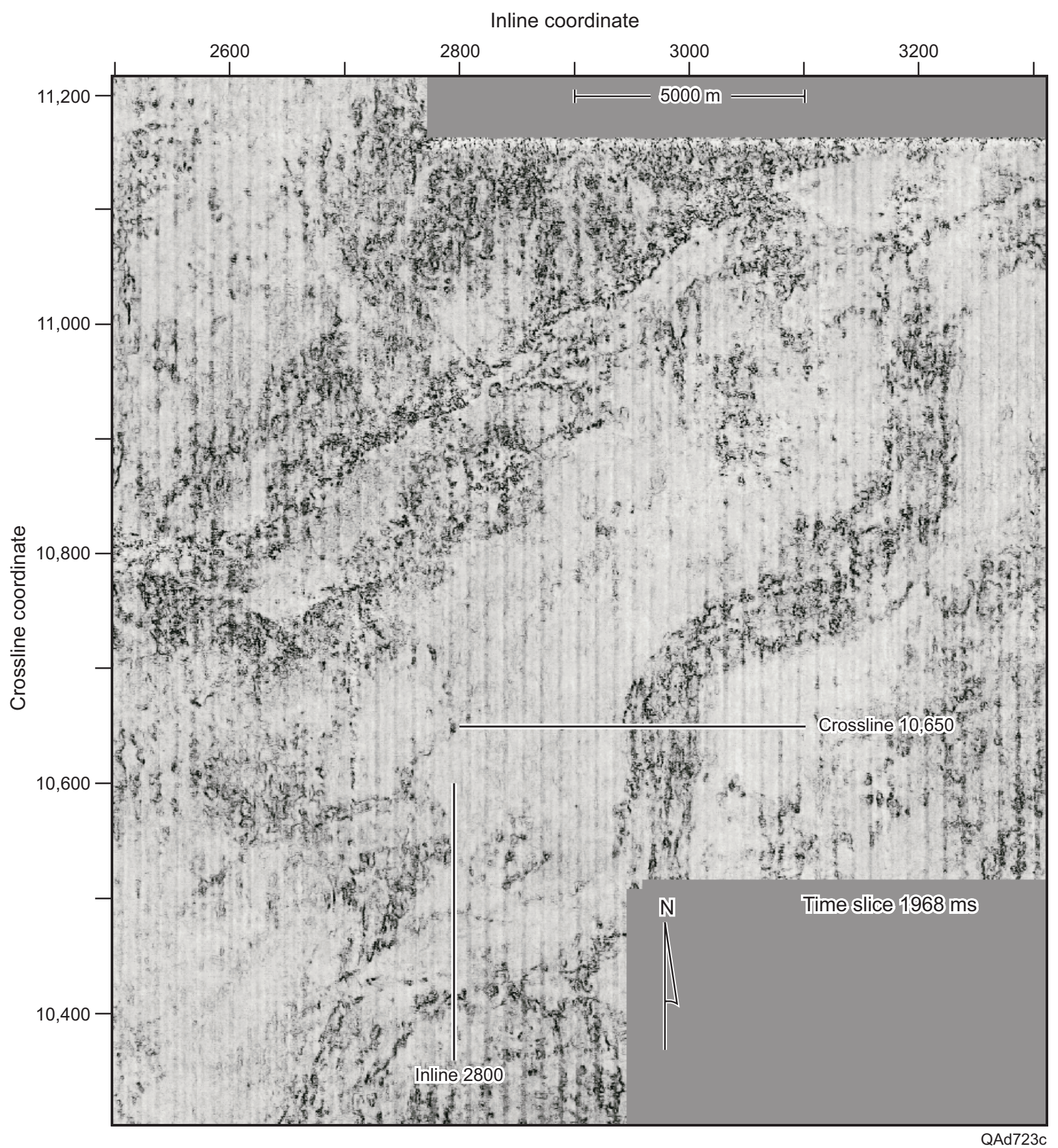

Figure 11. C-wave search target for establishing depth equivalence to $\mathrm{P}$ data (Example 1). This image is a time slice through the $\mathrm{C}$-wave data volume showing an incised valley feature trending northeast from inline, crossline coordinates $(2700,10,400)$. 


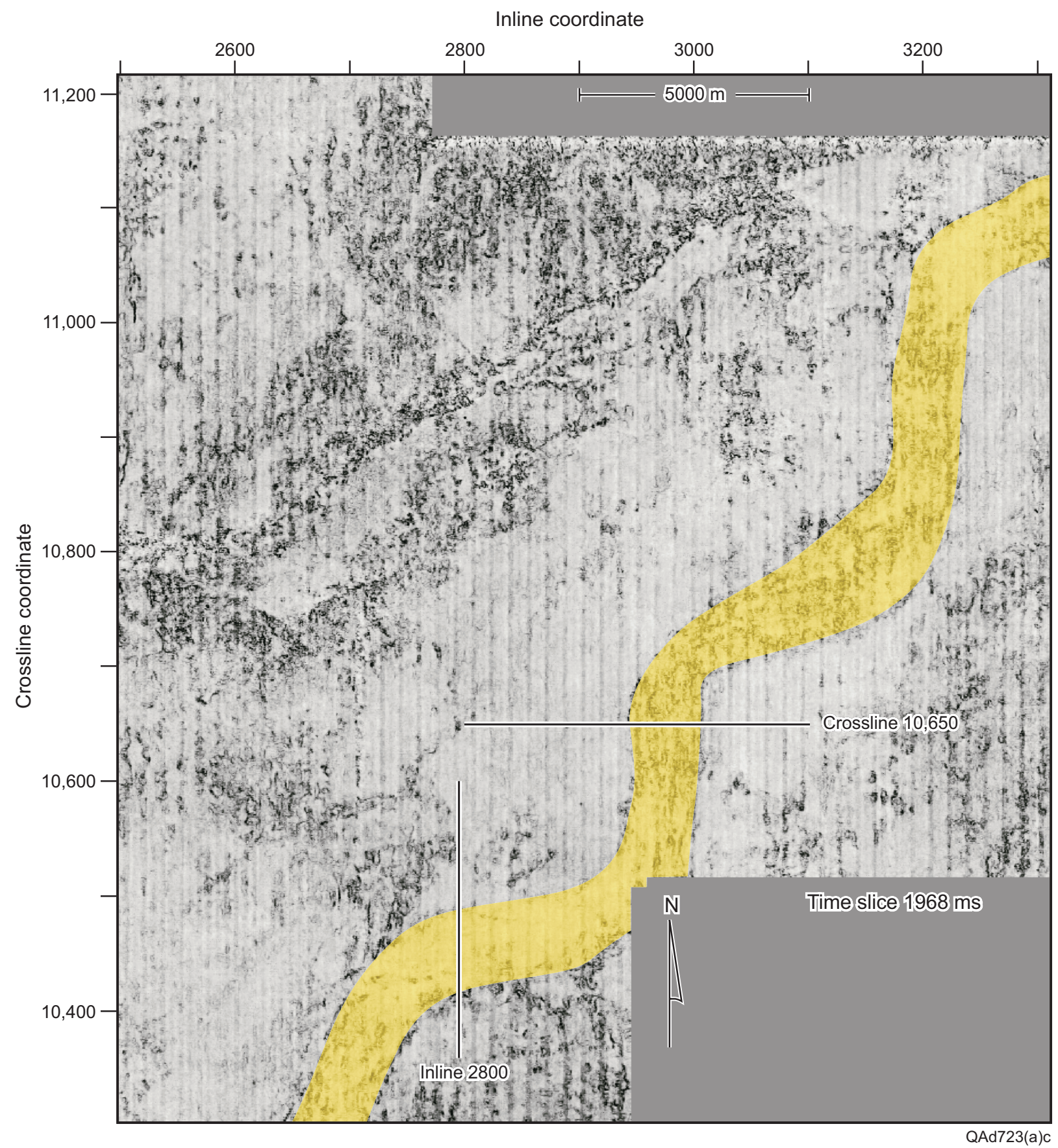

Figure 12. C-wave search target (Example 1) with the incised valley feature emphasized. 


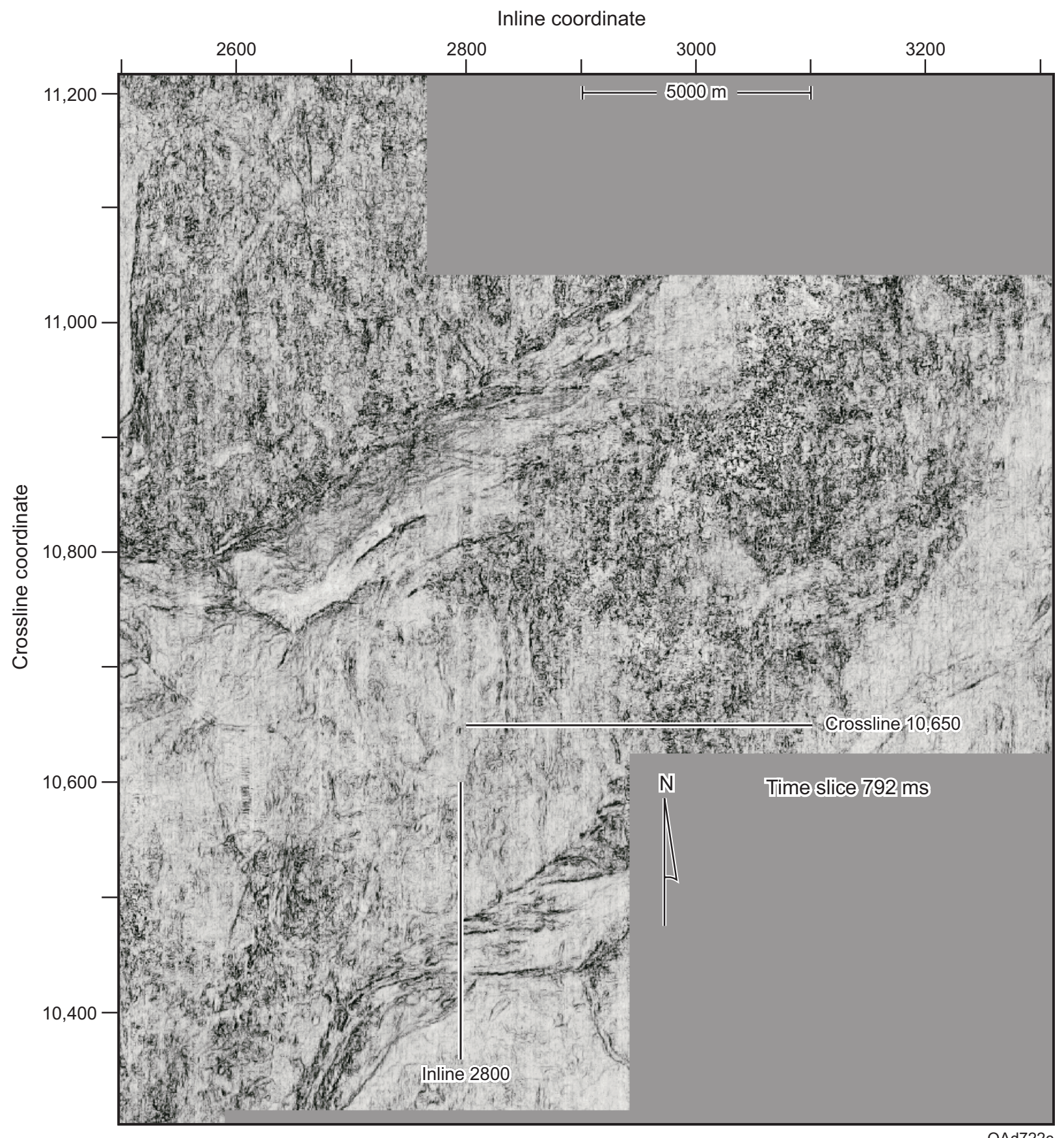

Figure 13. Depth-equivalent P-wave image target (Example 1). This image is a time slice through the P-wave data volume showing an incised valley feature trending northeast from inline, crossline coordinates $(2700,10,400)$. 


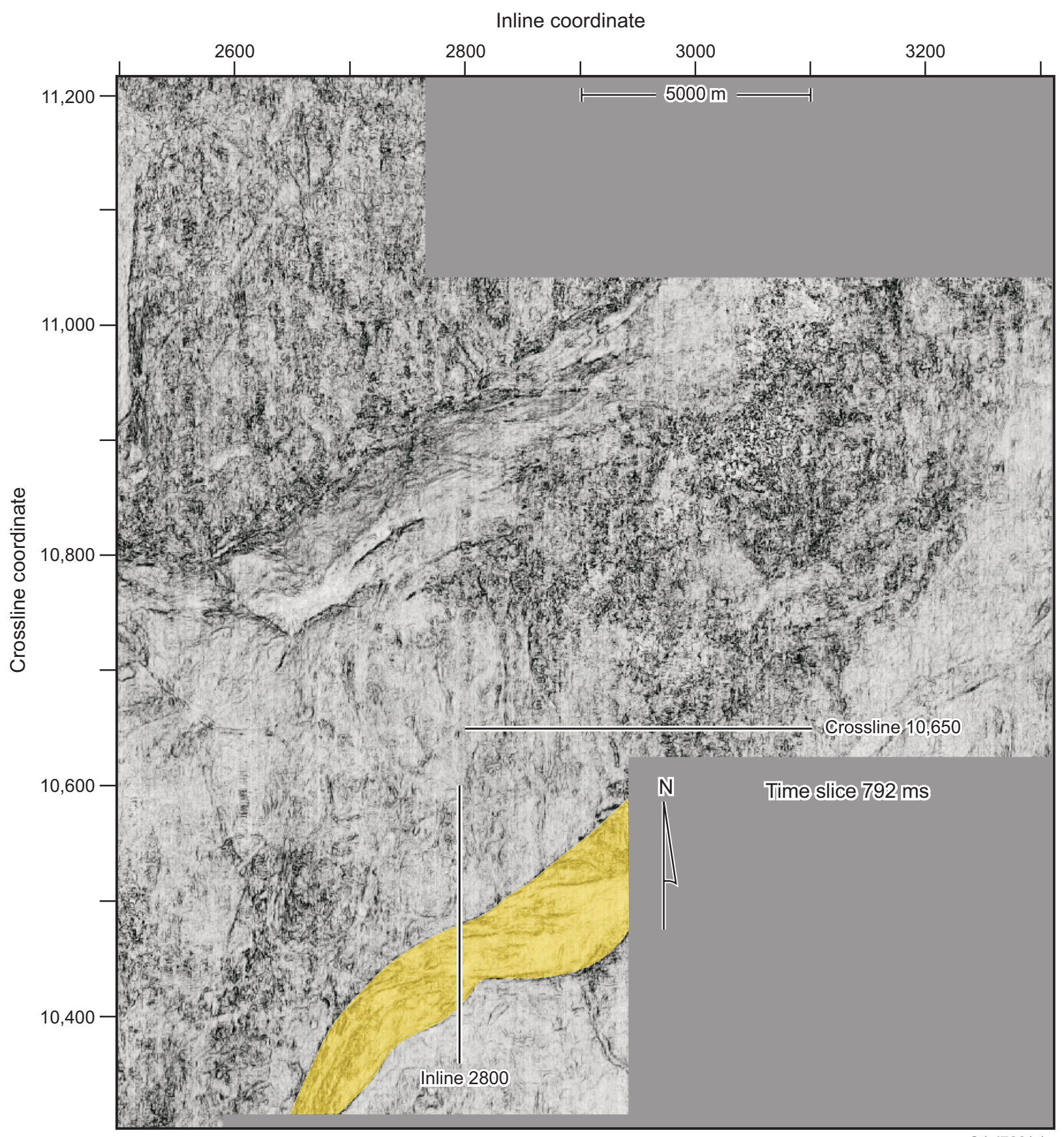

QAd722(a)c

Figure 14. Depth-equivalent P-wave image target (Example 1), with the incised-valley feature emphasized. Compare with Figure 12. 


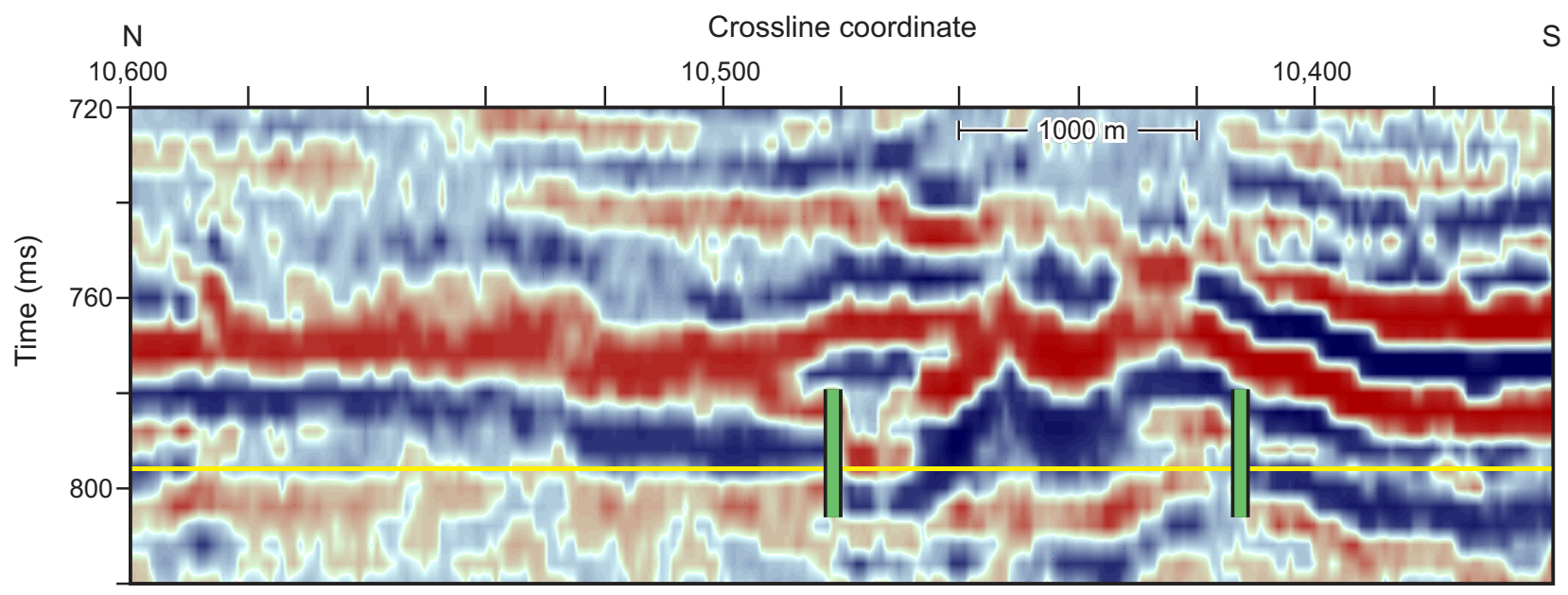

P-wave, Inline 2800

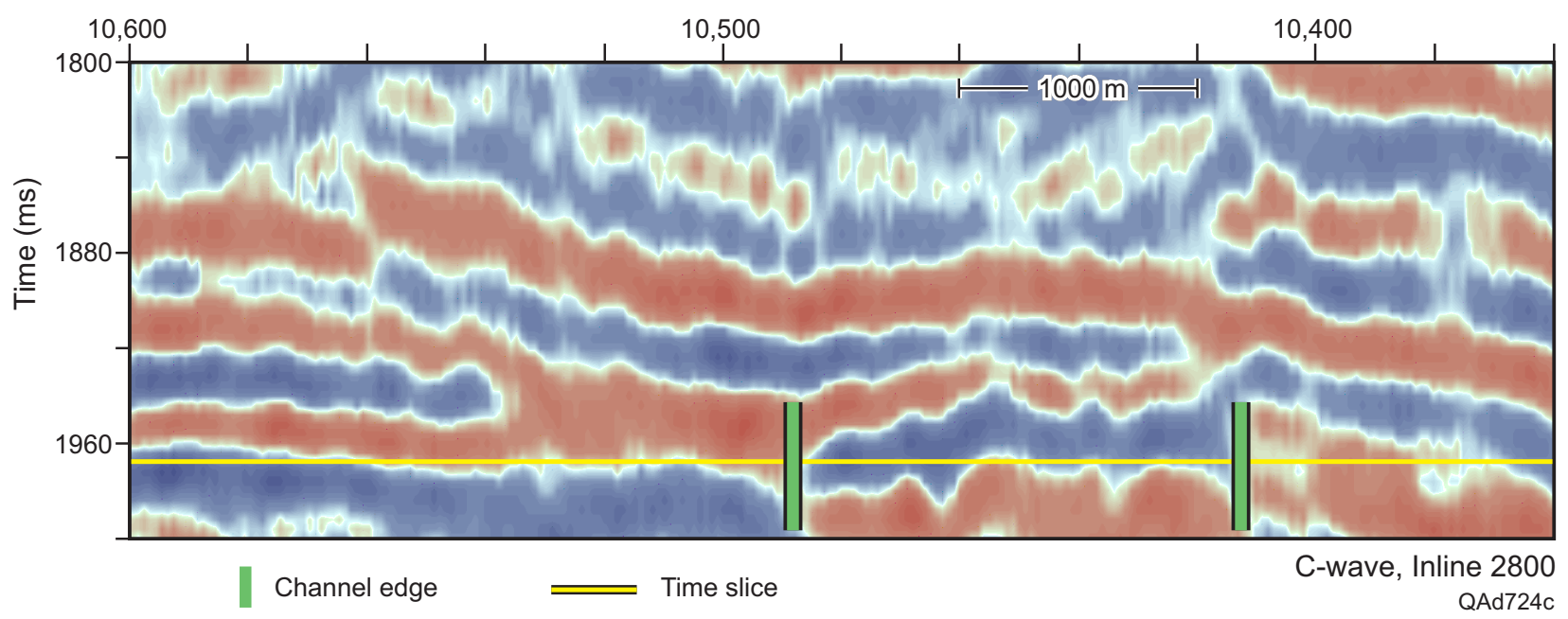

Figure 15. Inline profile 2800 across image target (Example 1). 


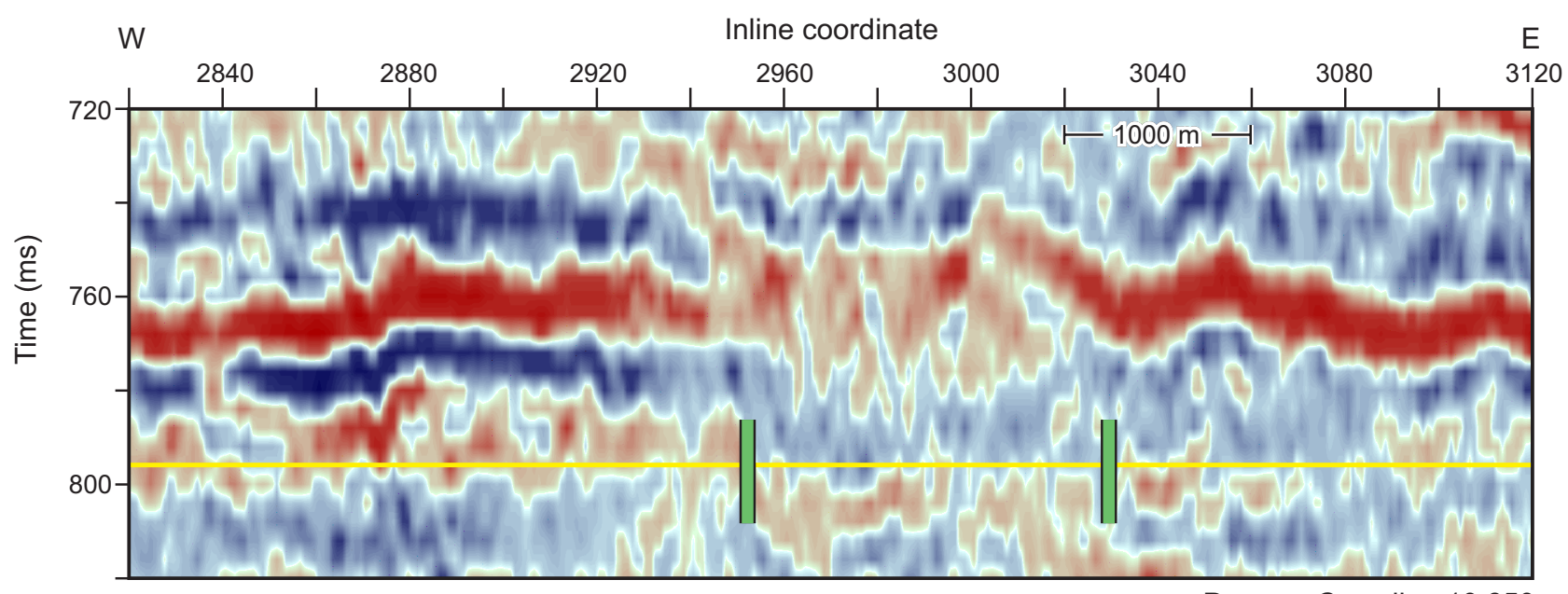

P-wave, Crossline 10,650

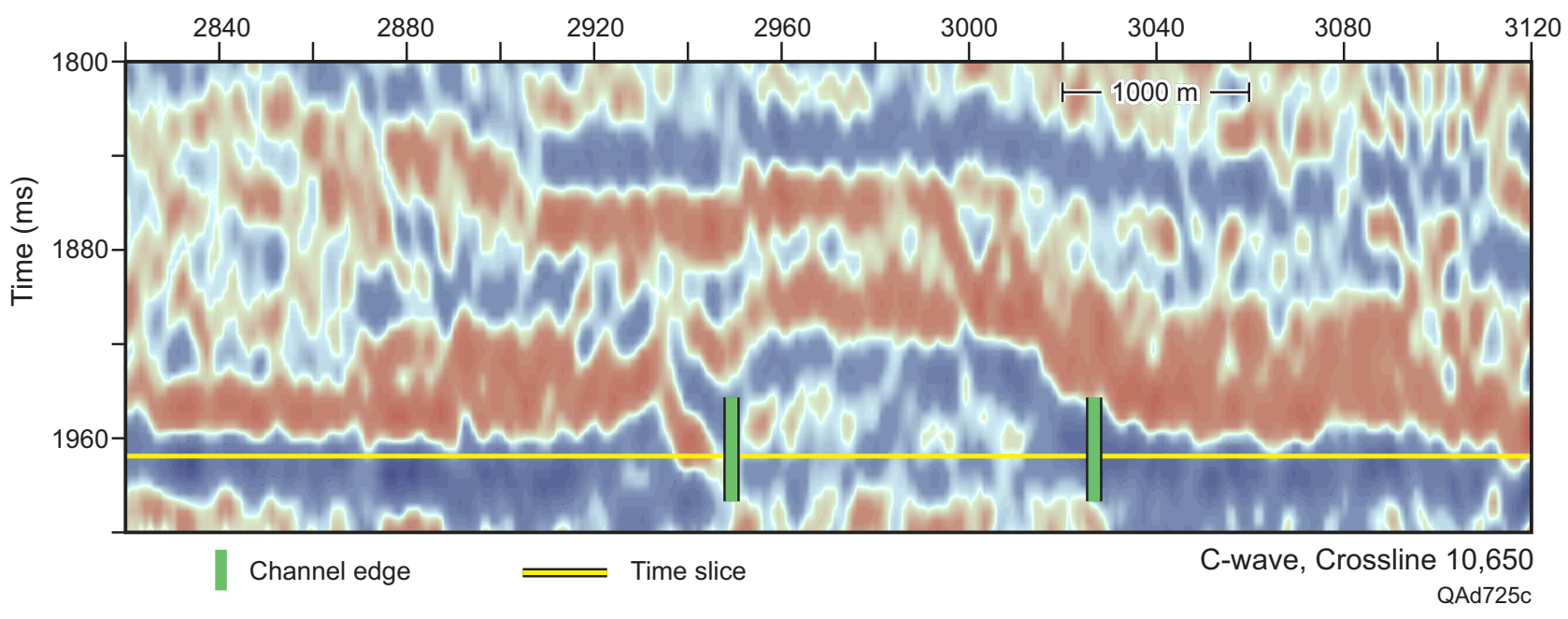

Figure 16. Crossline profile 10,650 across image target (Example 1). 


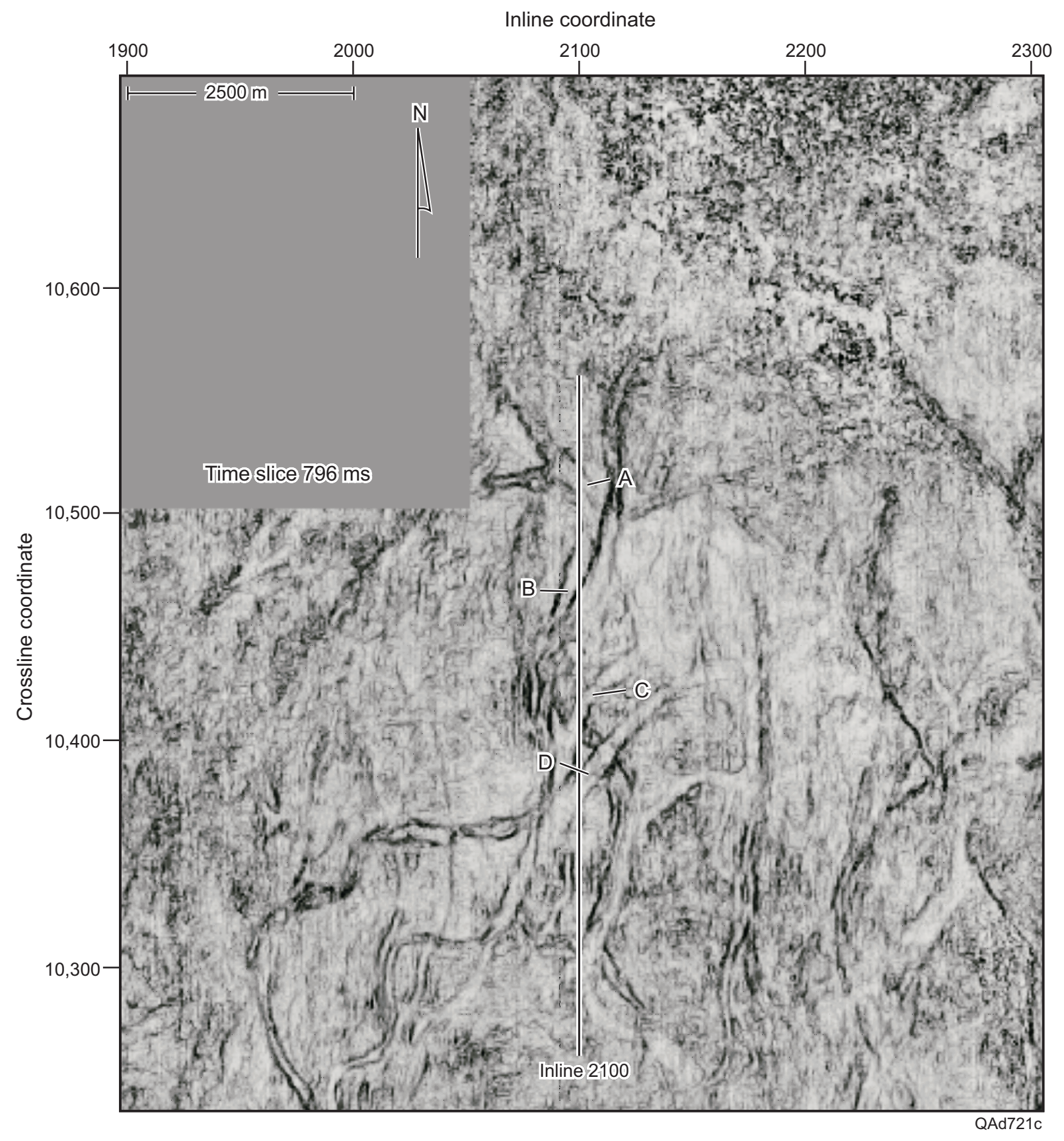

Figure 17. P-wave image search target (Example 2). Compare with Figure 18. 


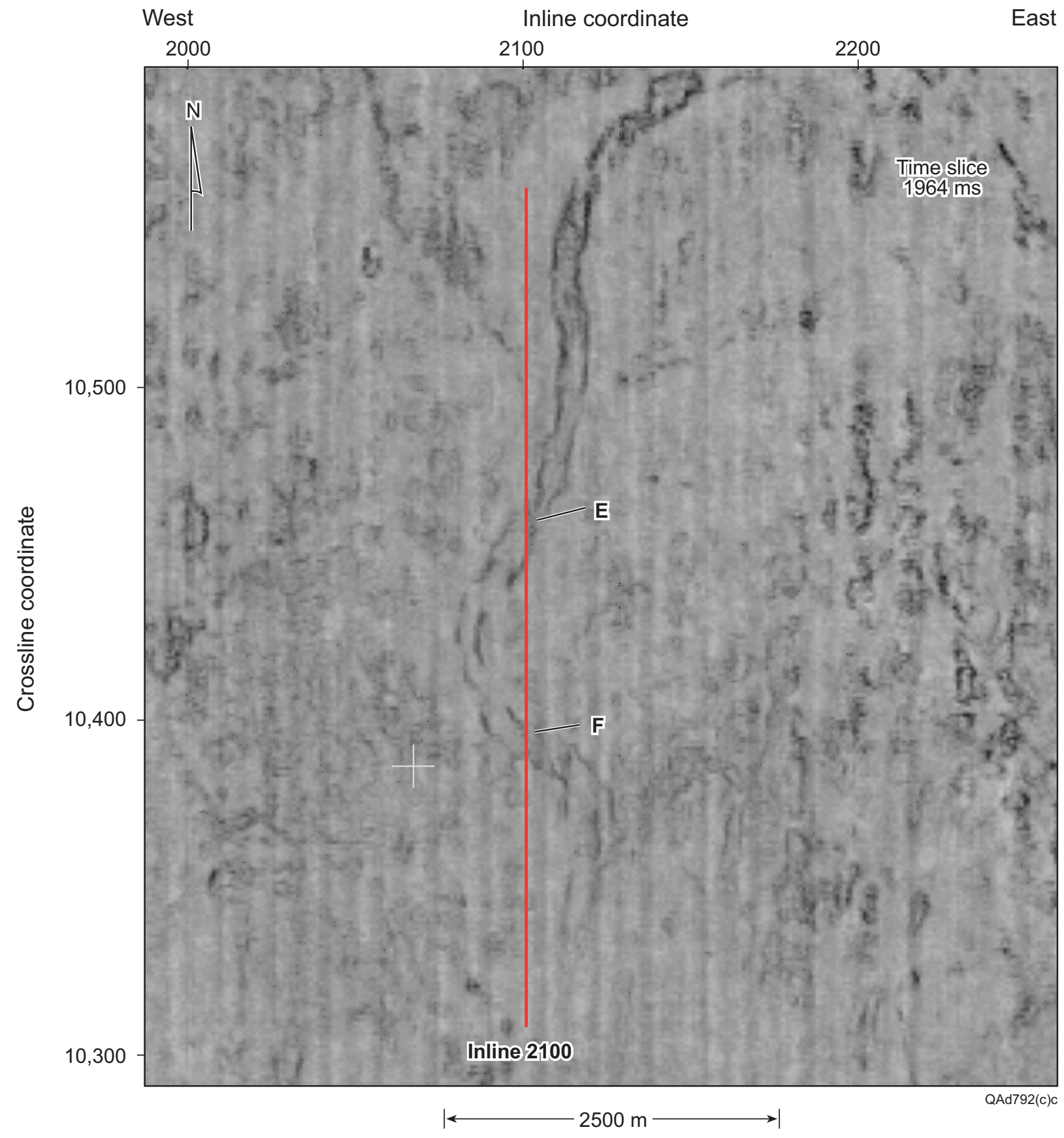

Figure 18. Depth-equivalent C-wave target (Example 2). Compare with Figure 17. 


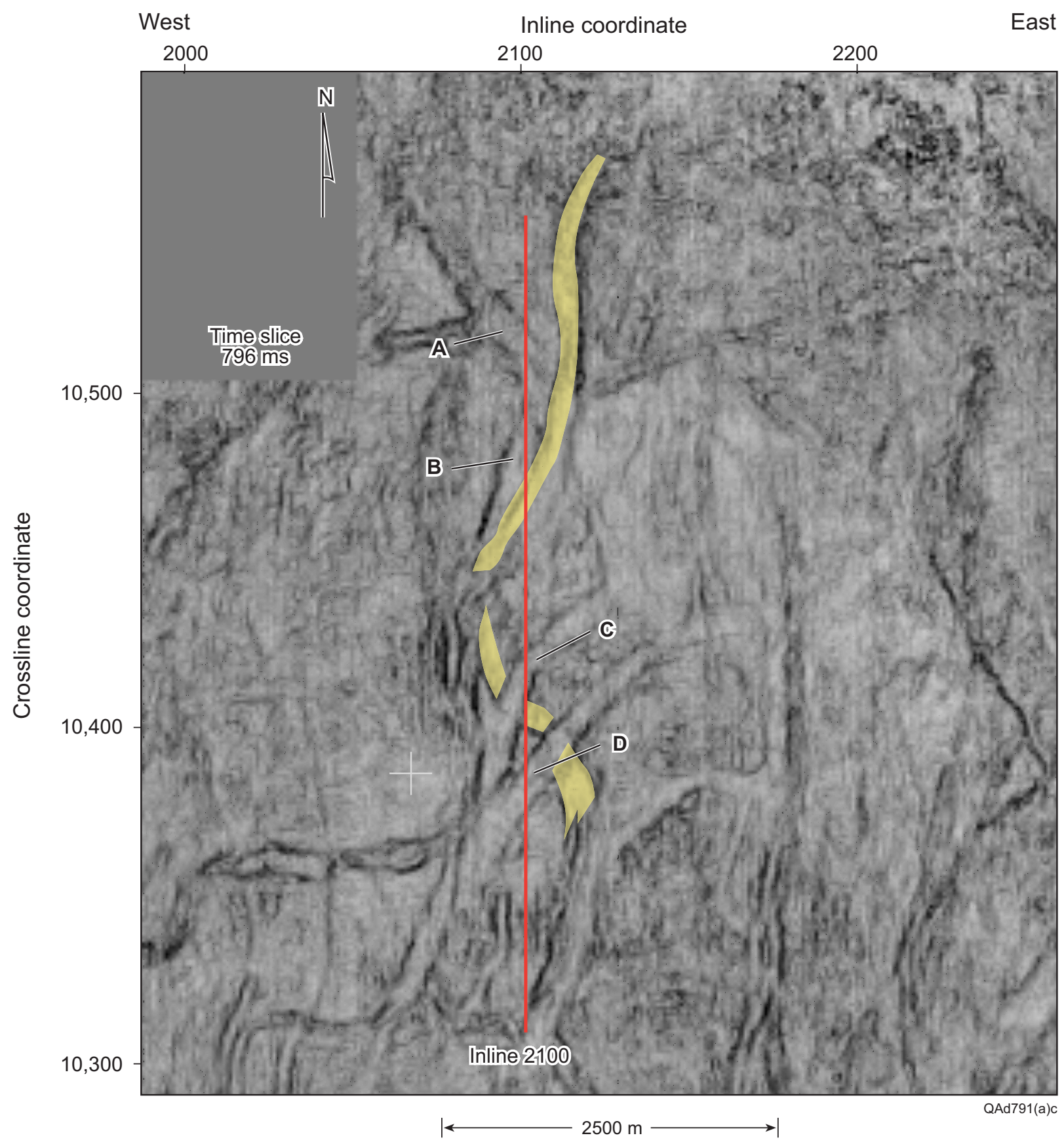

Figure 19. P-wave image with its depth-equivalent $\mathrm{C}$-wave image highlighted (Example 2). Compare with Figures 17 and 18. 

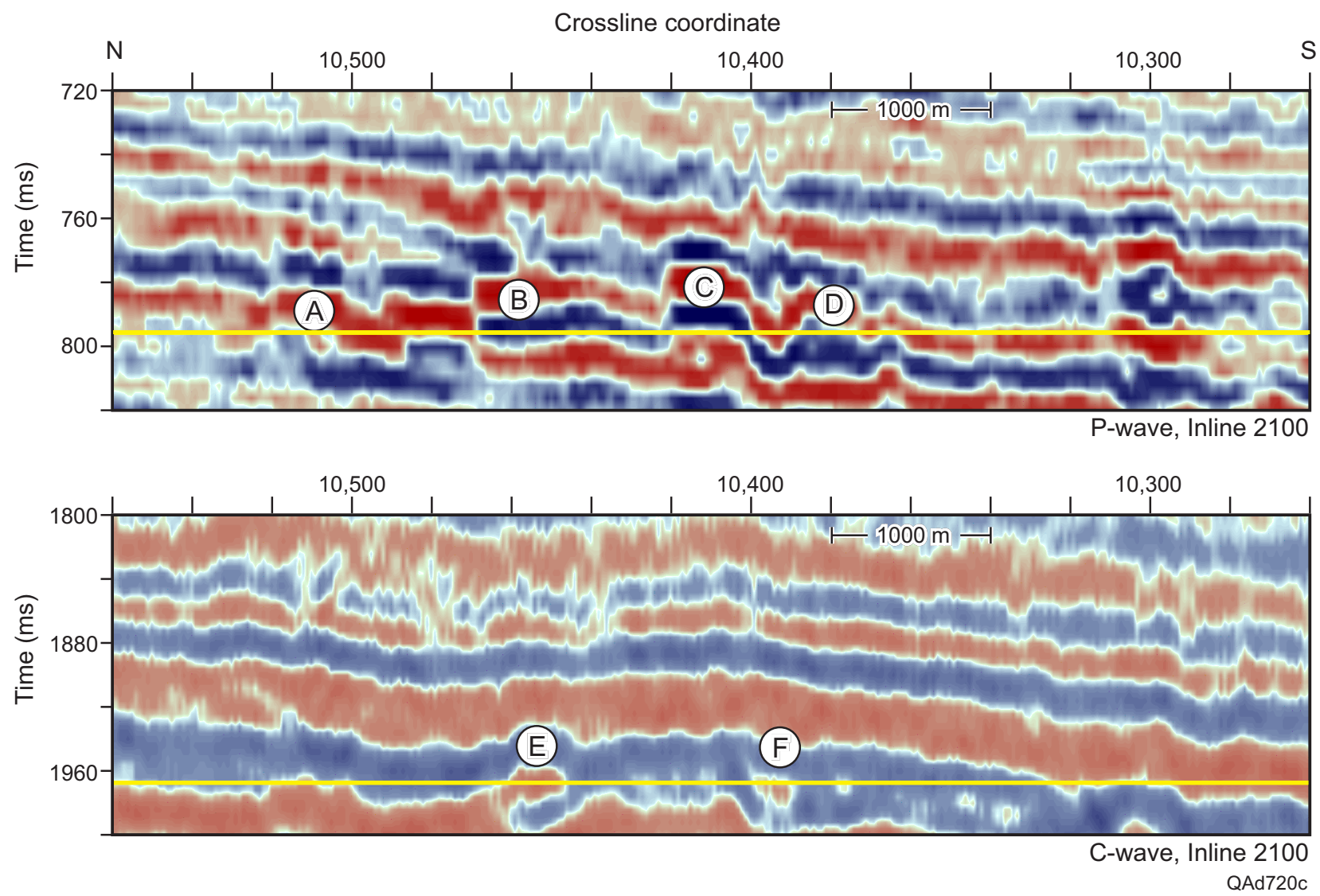

Figure 20. Inline profile 2100 across seismic image space (Example 2). Features A through F are channel intersections defined in Figures 17 and 18. 


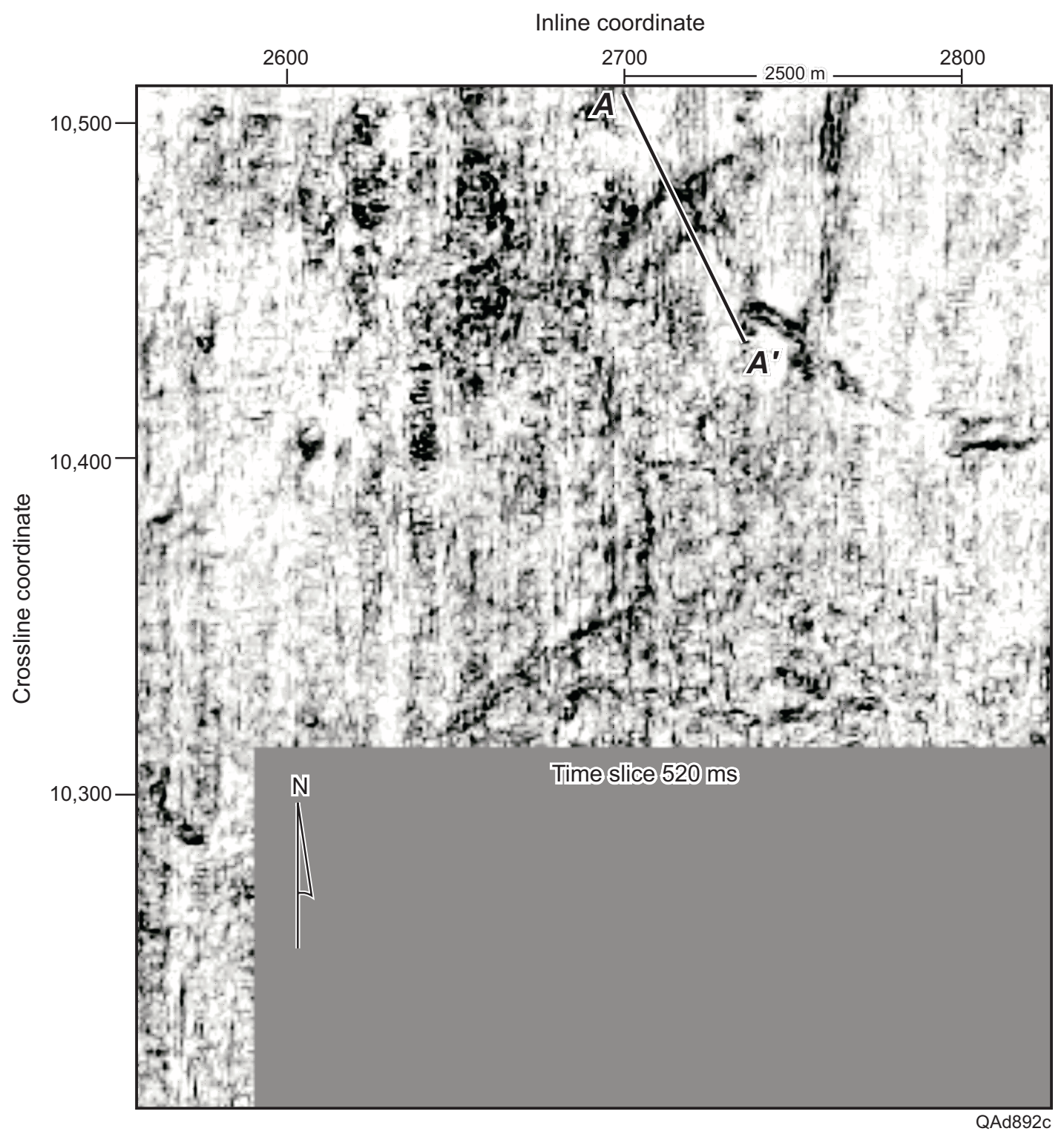

Figure 21. P-wave search target image (Example 3). Compare with Figure 22. Note faint north-south channel feature at inline coordinate 2700. 


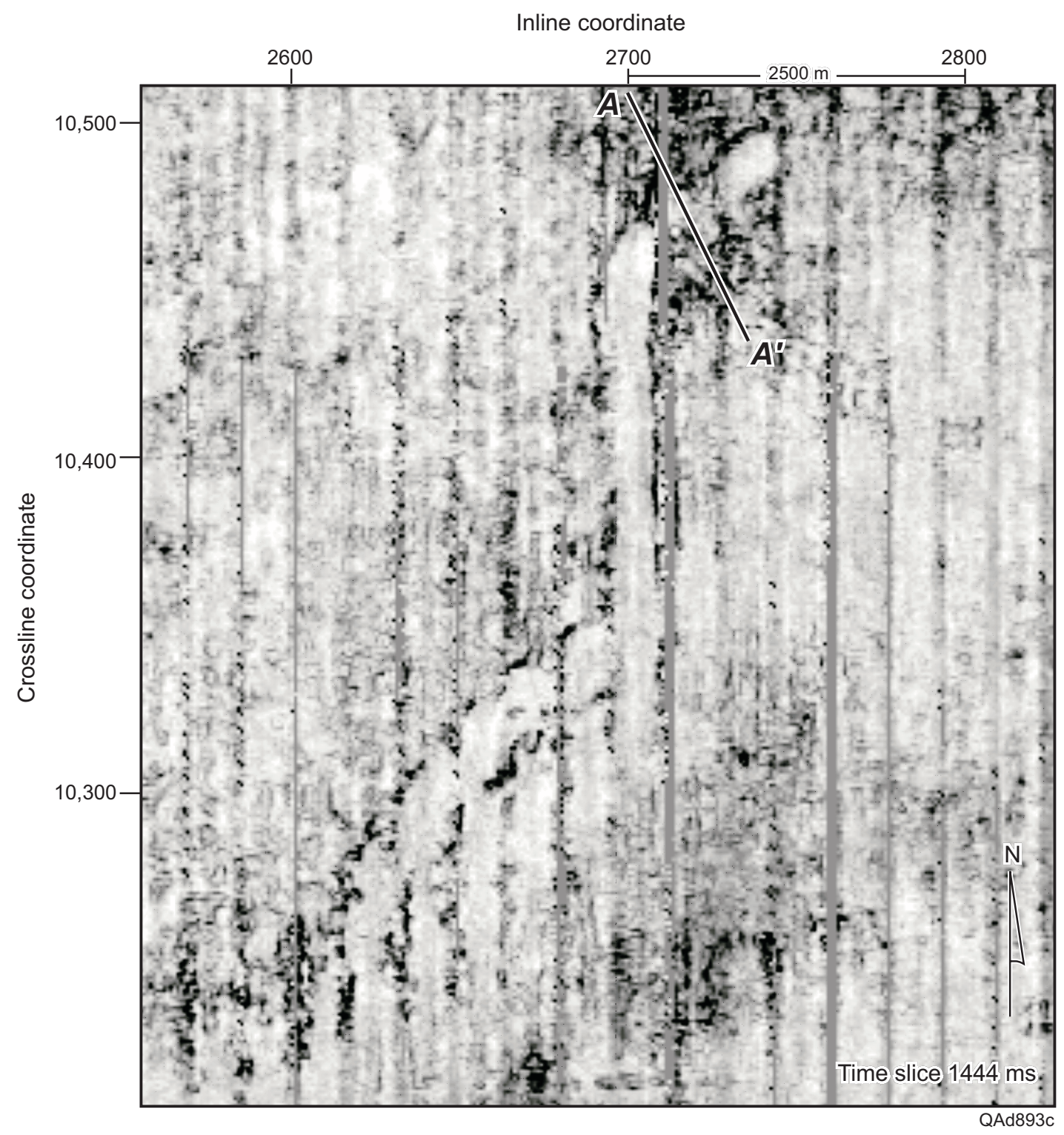

Figure 22. Depth-equivalent C-wave target (Example 3). Compare with Figure 21. Target is north-south channel feature at inline coordinate 2700. Seismic section $\mathrm{A}-\mathrm{A}^{\prime}$ shown in Figure 23. 

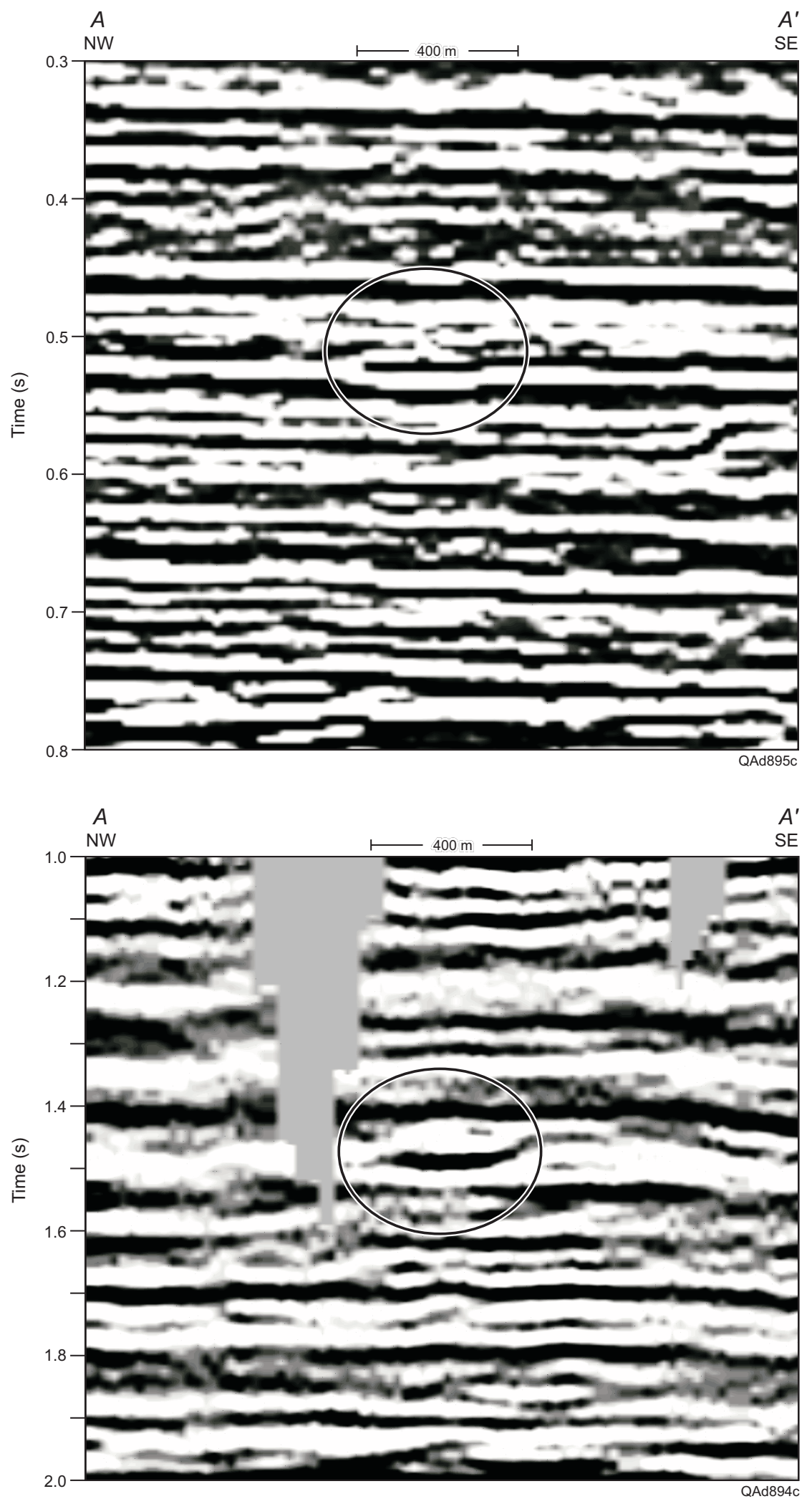

Figure 23. Profile A-A' across seismic image space (Example 3). Channel feature is circled. $\mathrm{P}$ image is the top display; $\mathrm{C}$ image is at the bottom. 


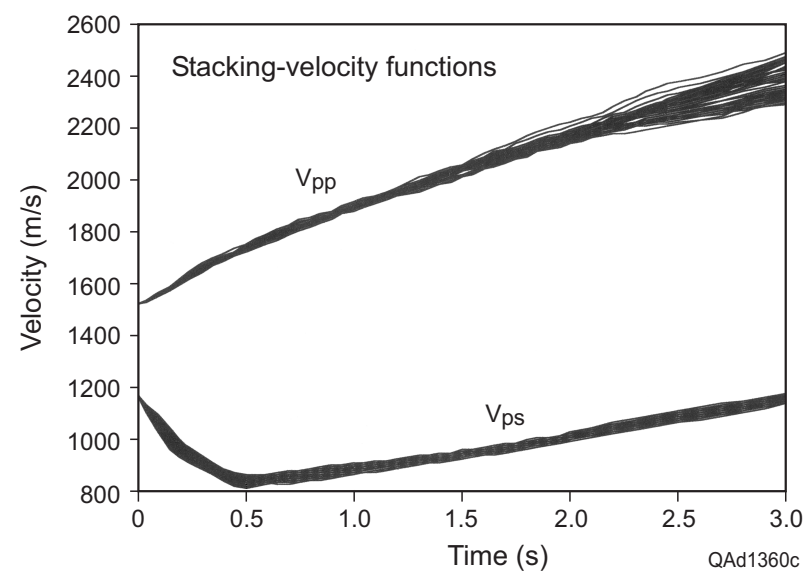

Figure 24. P-wave and C-wave stacking velocities $\mathrm{V}_{\mathrm{pp}}$ and $\mathrm{V}_{\mathrm{ps}}$ across seismic image space.

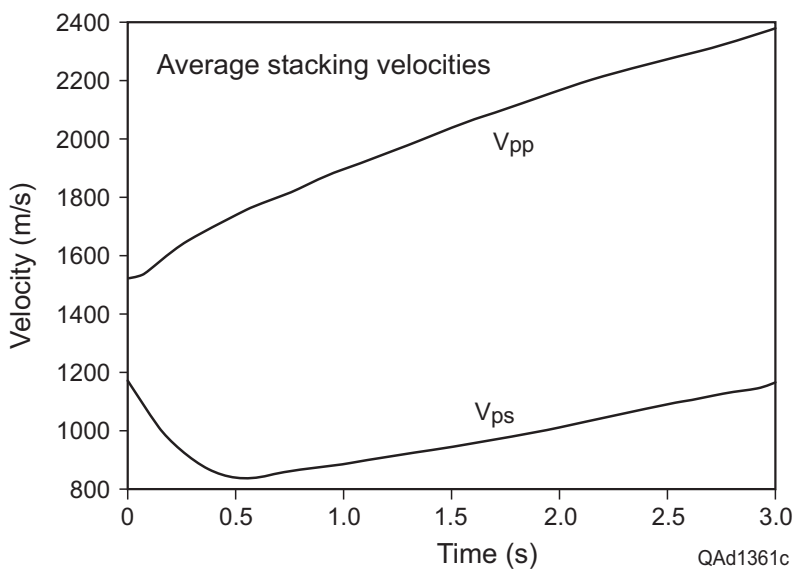

Figure 25. Average P-wave stacking velocity $\left(\mathrm{V}_{\mathrm{pp}}\right)$ and average $\mathrm{C}$-wave stacking velocity $\left(\mathrm{V}_{\mathrm{ps}}\right)$. 


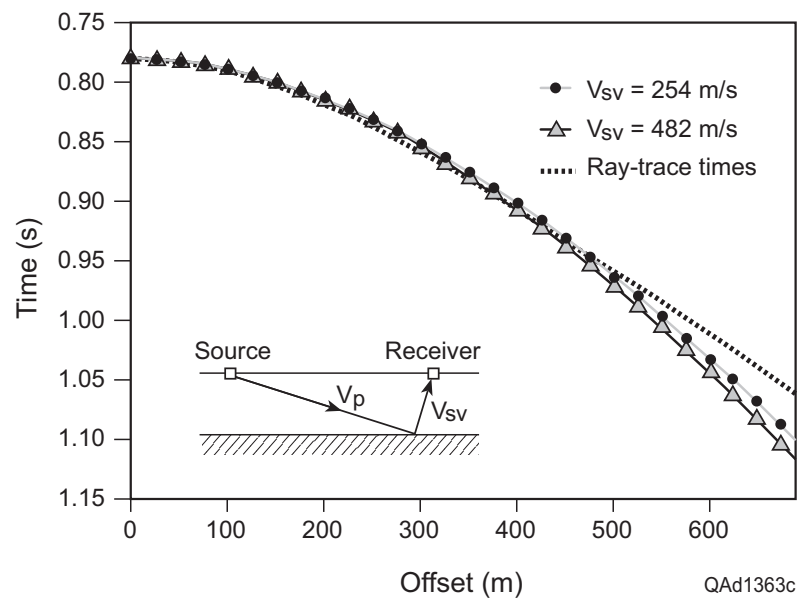

Figure 26. Normal moveout of shallow C-wave reflection event $\mathrm{H} 4$ when $\mathrm{S}$-wave velocity $\mathrm{V}_{\mathrm{SV}}$ in the layer above $\mathrm{H} 4$ is varied from 254 to $482 \mathrm{~m} / \mathrm{s}$. $\mathrm{P}$-wave velocity $\mathrm{V}_{\mathrm{p}}$ in the layer is $1,600 \mathrm{~m} / \mathrm{s}$.

Stratal surface H4 is defined in Figures 7 and 8.

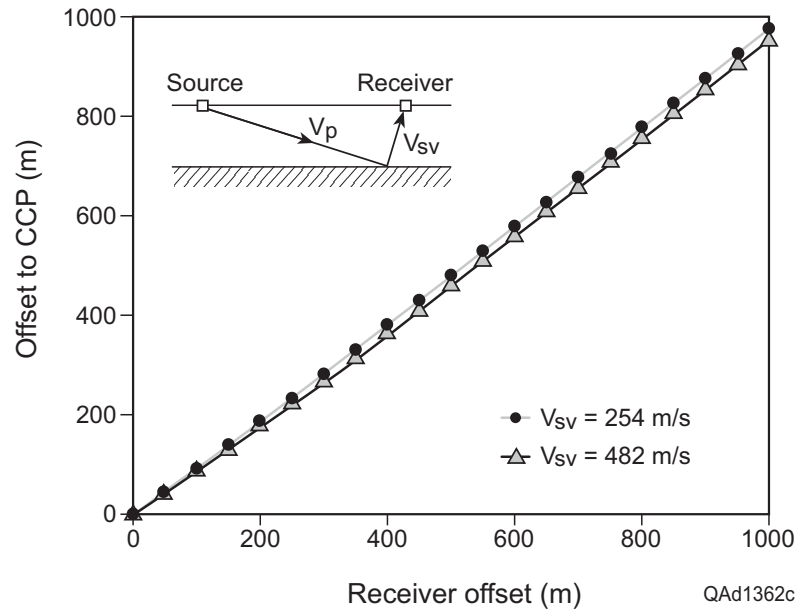

Figure 27. Ray-trace analysis comparing distances to receiver stations and to mode-conversion points at horizon H4. Conversion point moves only a short distance when SV velocity is changed by almost a factor of 2 . 


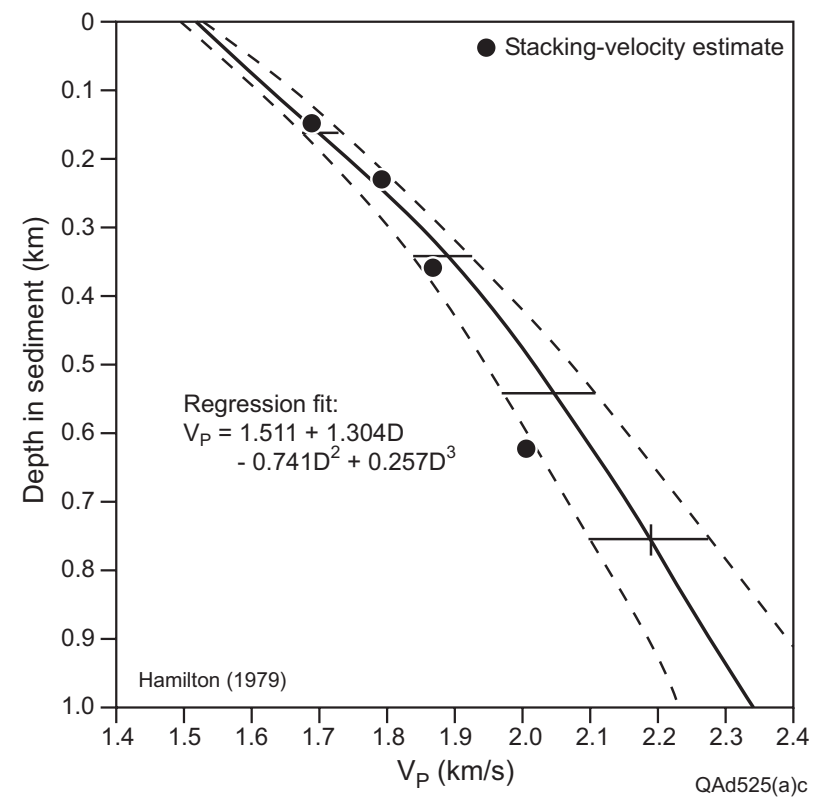

Figure $28 . V_{p}$ behavior in shallow marine silt, clay, mudstone, and shale sediments. The dashed curves show the 95-percent confidence limits (modified from Hamilton, 1979). The solid circles are $V_{p}$ values from Table 2.

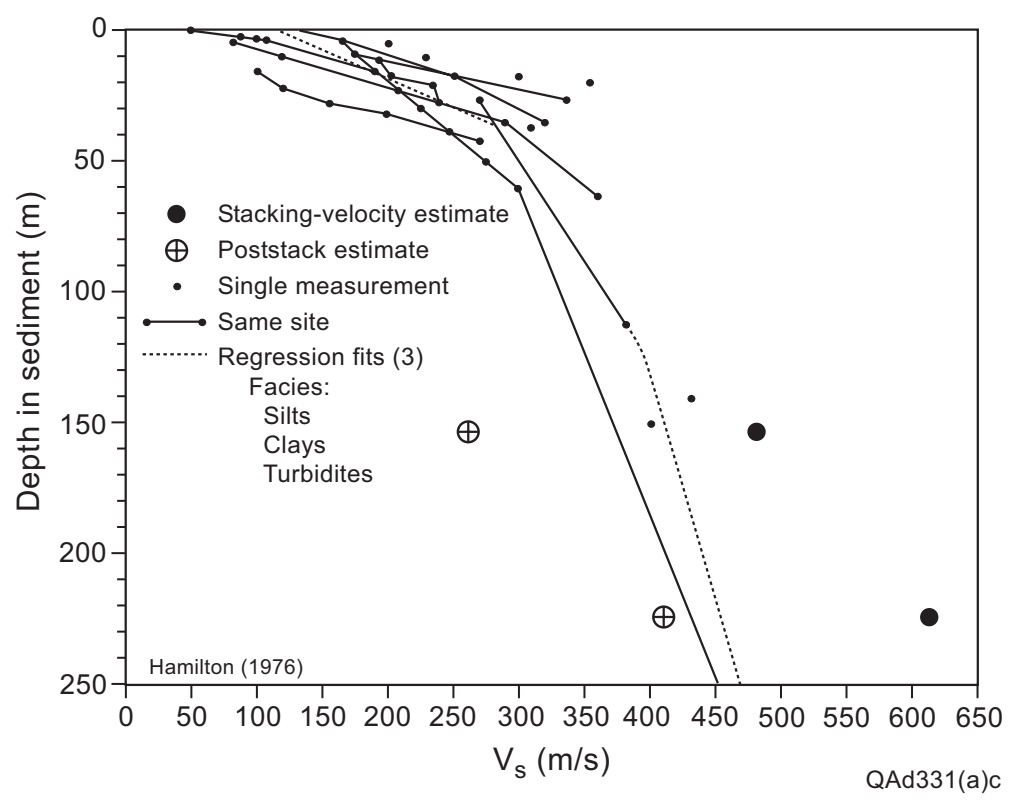

Figure 29. $\mathrm{V}_{\mathrm{s}}$ behavior in shallow fine-grained seafloor sediment (modified from Hamilton, 1976). The circled crosses are the two shallowest $\mathrm{V}_{\mathrm{s}}(1)$ values from Table 2; the solid circles are the equivalent $V_{s}(2)$ values. 


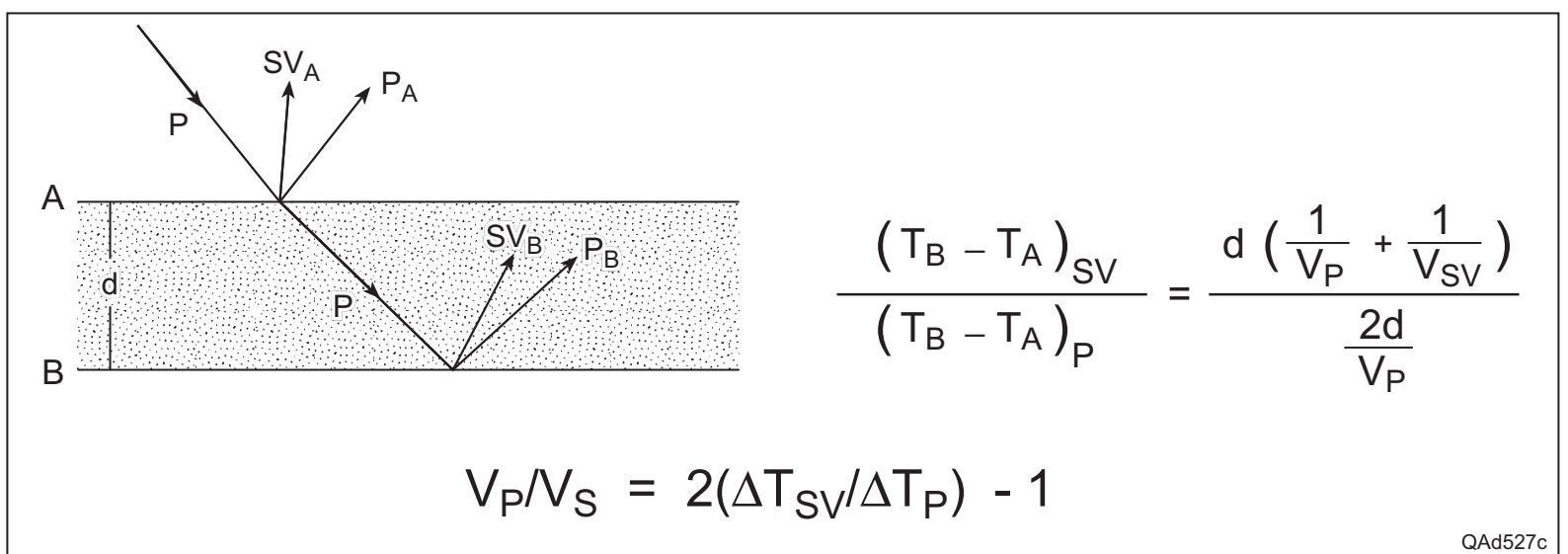

Figure 30. Zero-incidence raypath model used to calculate $\mathrm{V}_{\mathrm{p}} / \mathrm{V}_{\mathrm{s}}$ across targeted intervals of $\mathrm{P}$ and $\mathrm{C}$ images. $\Delta \mathrm{T}_{\mathrm{SV}}$ and $\Delta \mathrm{T}_{\mathrm{P}}$ are, respectively, the differences in $\mathrm{C}$ and $\mathrm{P}$ image times at the bottom (B) and top (A) of the interval. A critical assumption in the model is that the $\mathrm{P}$ and $\mathrm{C}$ reflections used to measure $\Delta \mathrm{T}_{\mathrm{SV}}$ and $\Delta \mathrm{T}_{\mathrm{P}}$ image the same stratal surfaces. 


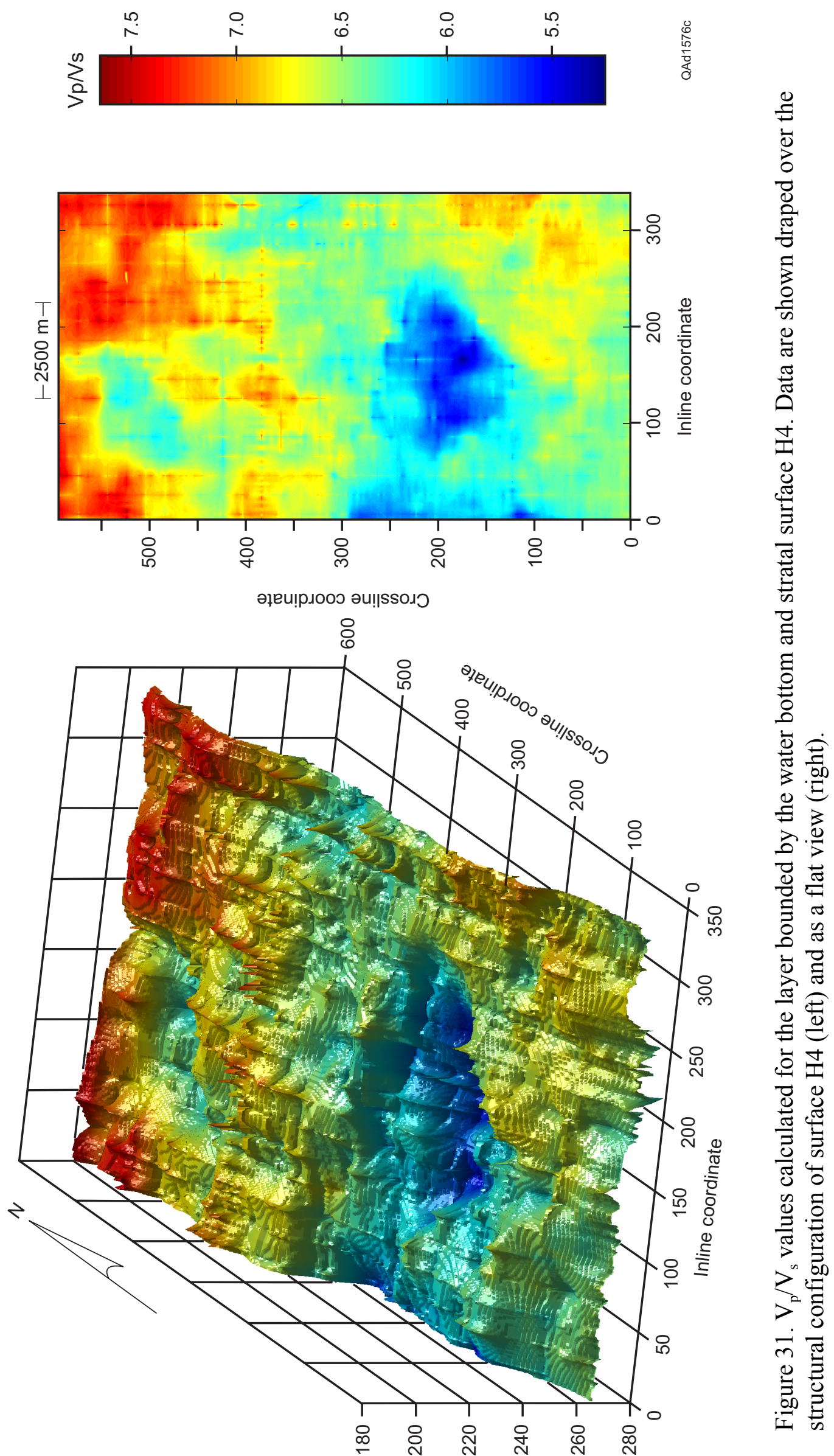

(u) |әлә еәs ueәш мо|әq чұdəح 

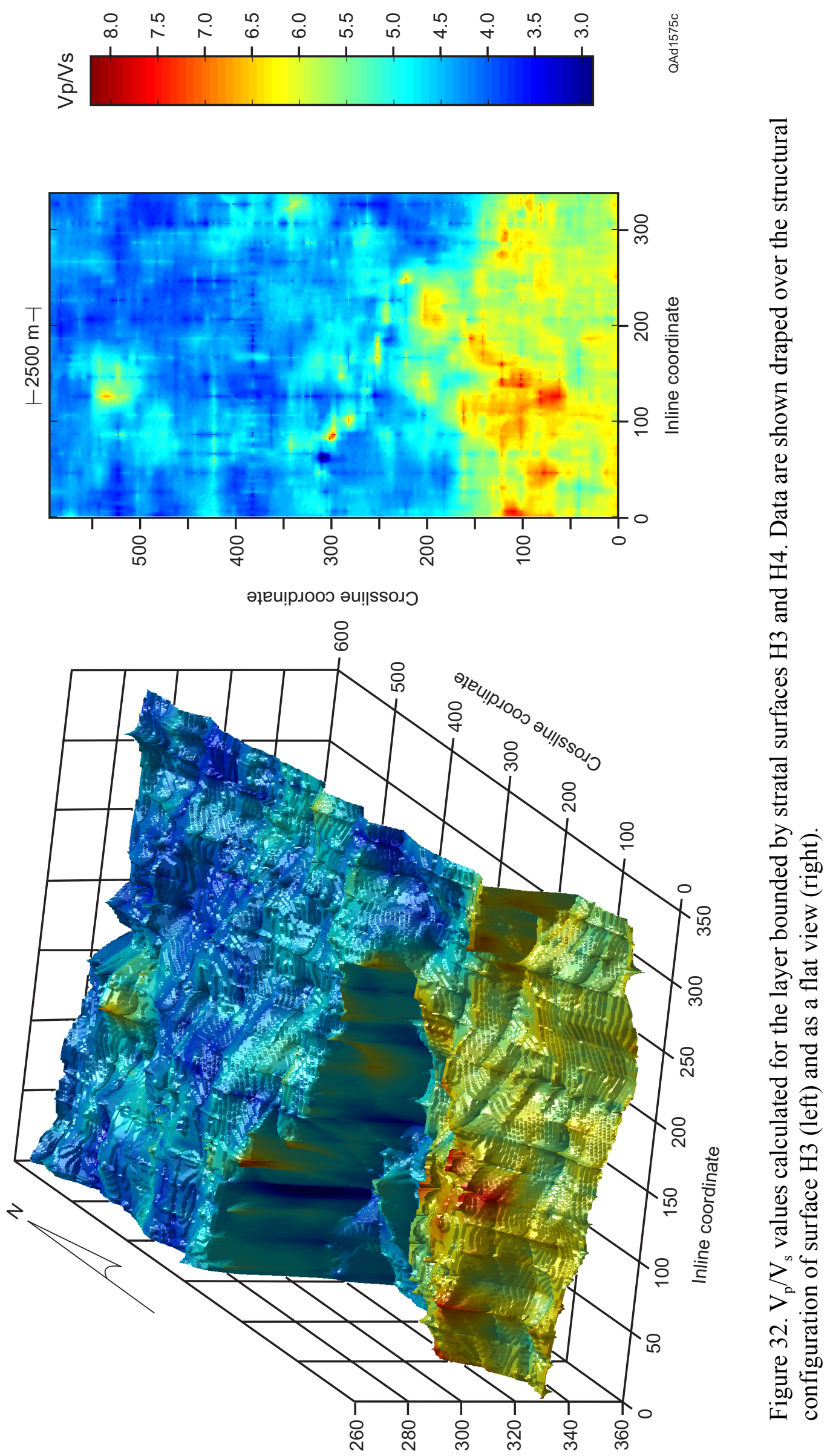

(u) |әлә| еәs ueəш мо|әq чұdə0 


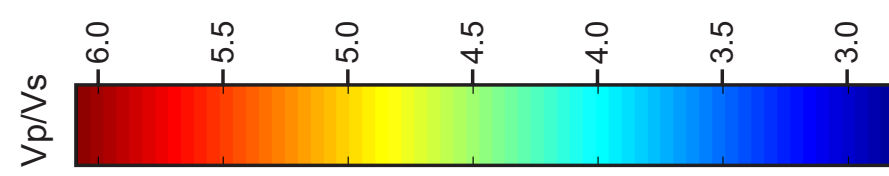

تే
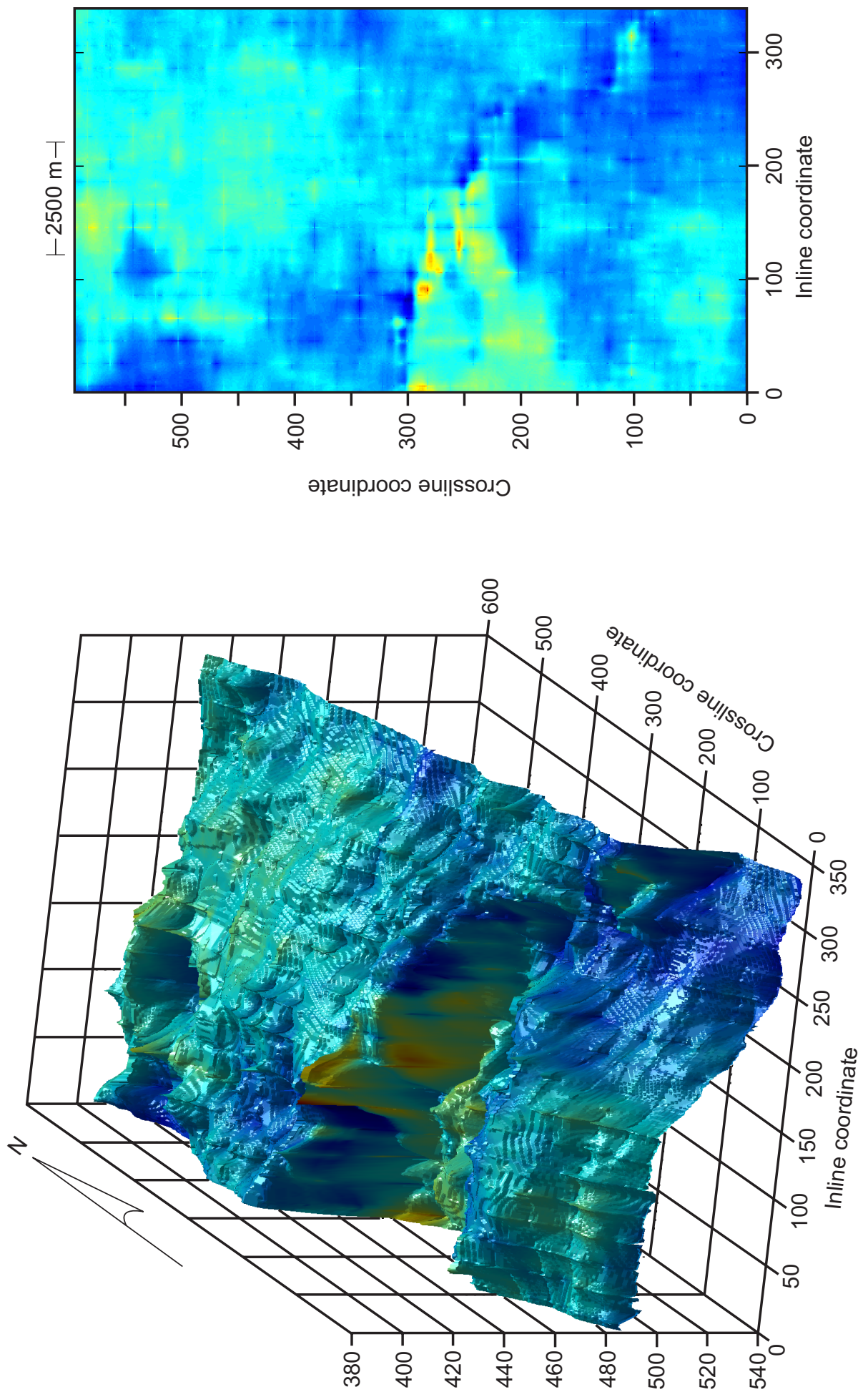

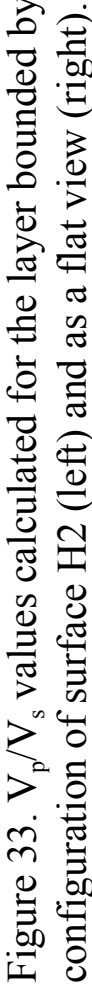

(u) ןәлә еәs ueәш мо|әq पाdә0 


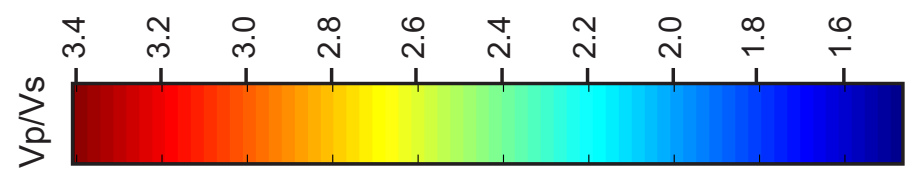

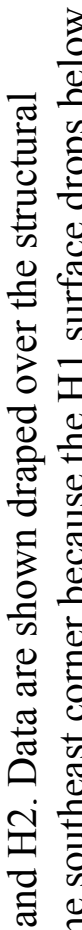
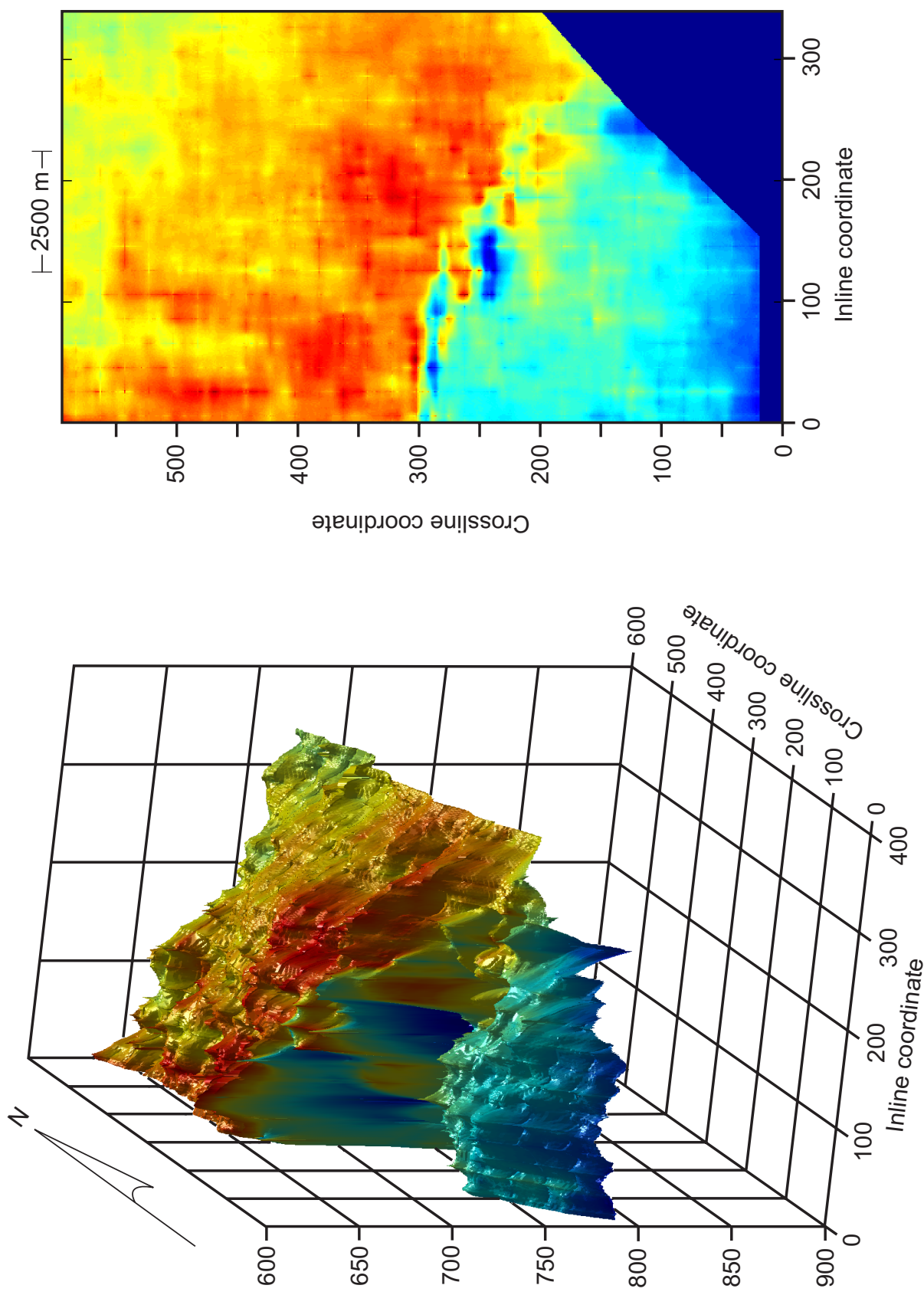

(u) |әлә| eəs ueəu мо|әq чұdə0 

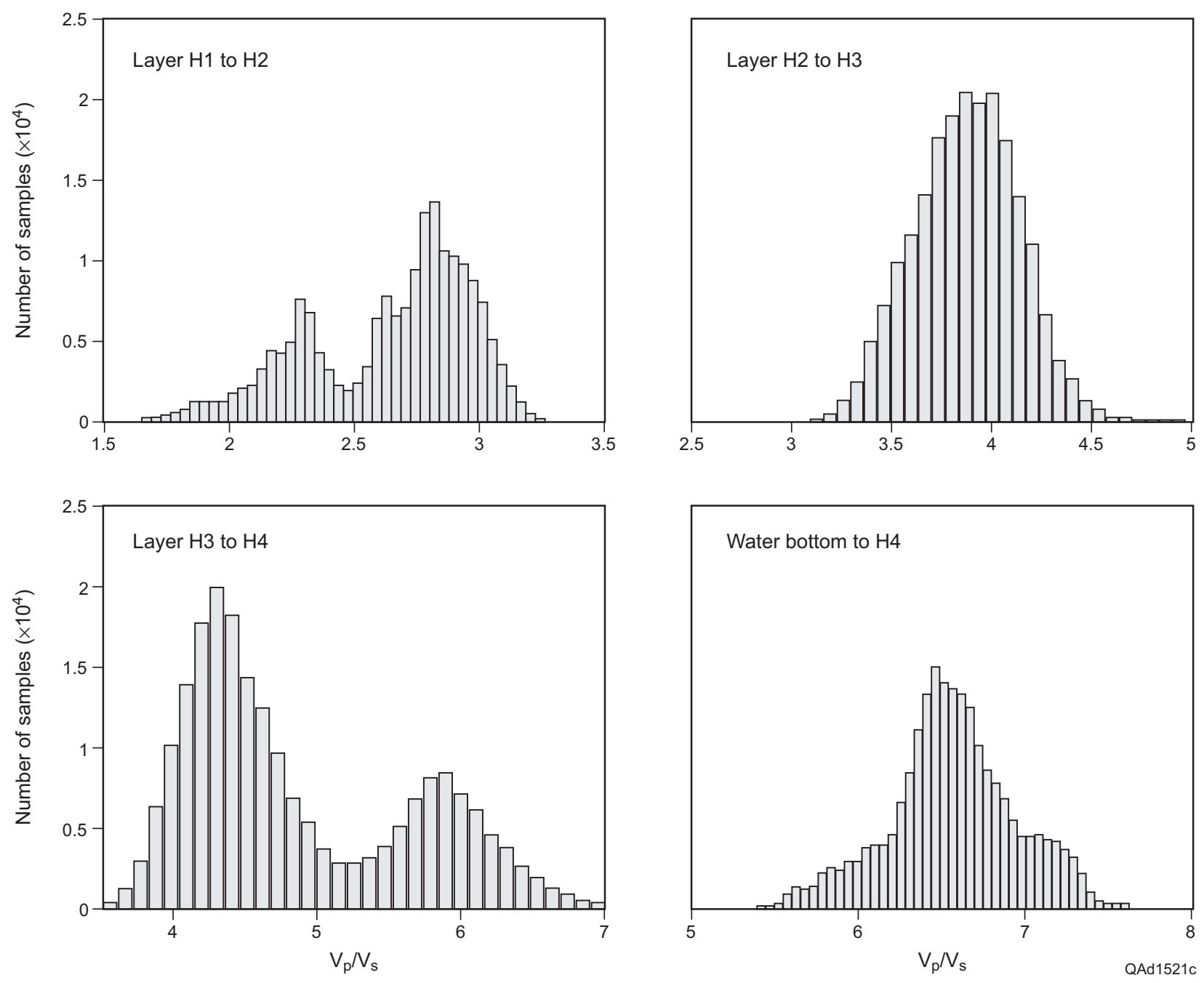

Figure 35. Distributions of $\mathrm{V}_{\mathrm{p}} / \mathrm{V}_{\mathrm{s}}$ in each study layer. Surfaces $\mathrm{H} 1, \mathrm{H} 2, \mathrm{H} 3$, and $\mathrm{H} 4$ are defined in Figures 7 and 8. 


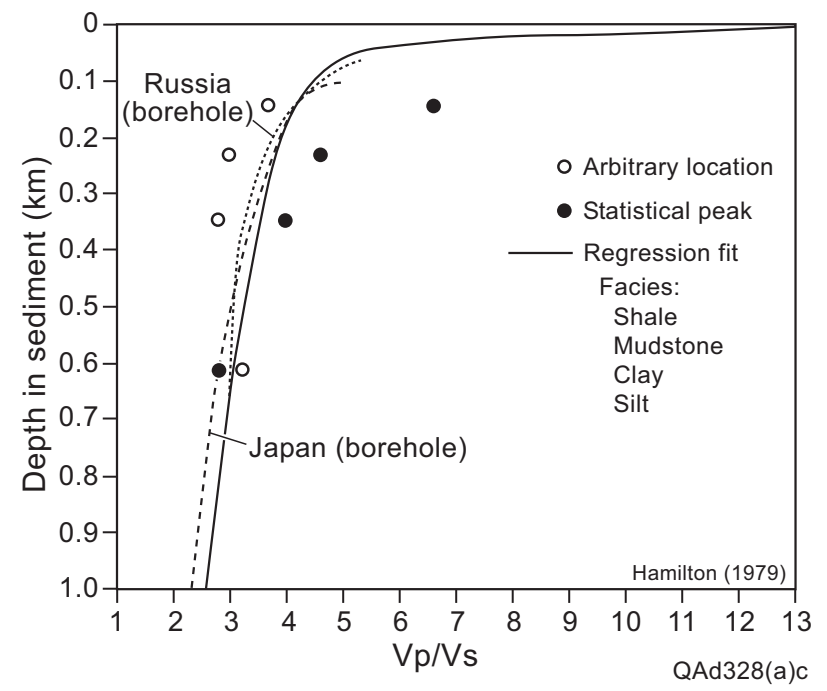

Figure 36. Global $\mathrm{V}_{\mathrm{p}} / \mathrm{V}_{\mathrm{s}}$ behavior in shallow finegrained seafloor sediment (modified from Hamilton, 1979). Estimates of $\mathrm{V}_{\mathrm{p}} / \mathrm{V}_{\mathrm{s}}$ at one location inside our study site (Table 2) are shown by the open circles. The $\mathrm{V}_{\mathrm{p}} / \mathrm{V}_{\mathrm{s}}$ values associated with the peaks of the statistical distributions in Figure 35 are shown by the solid circles 


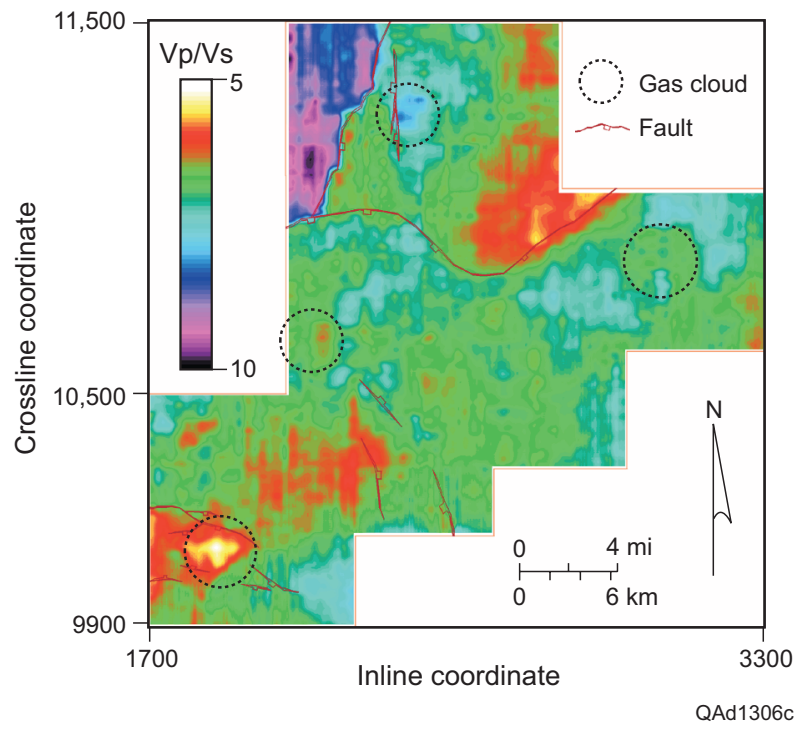

Figure 37. Large-area map of $\mathrm{V}_{\mathrm{p}} / \mathrm{V}_{\mathrm{s}}$ for the shallowest study layer, WB to $H 4$. The $V_{p} / V_{s}$ map in Figure 31 covers only the southwest corner of this large 4-C OBC seismic survey. 

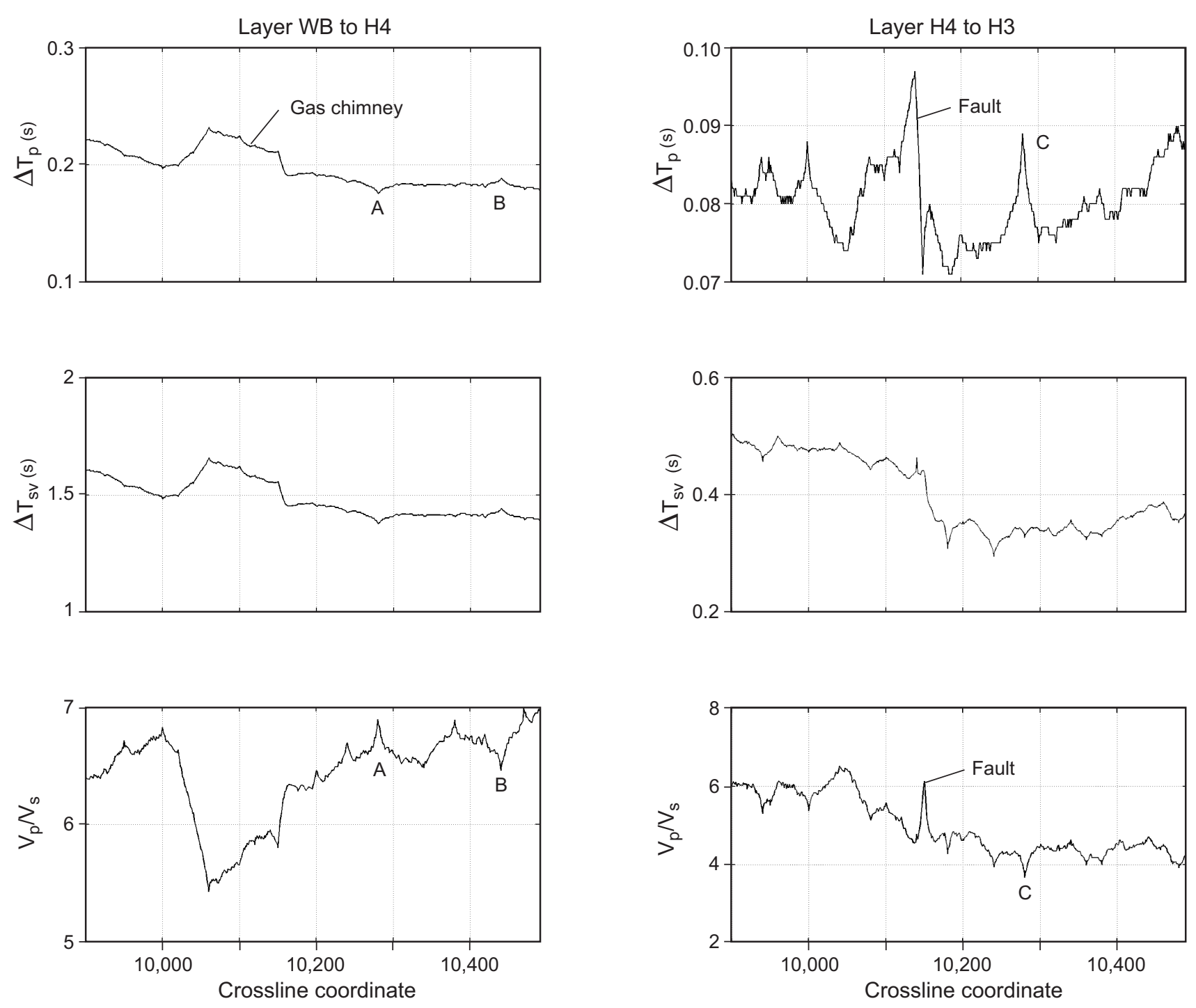

QAd1754c

Figure 38. Time thicknesses and $\mathrm{V}_{\mathrm{p}} / \mathrm{V}_{\mathrm{s}}$ values associated with the layers defined along inline 1870, the seismic profile shown in Figures 7 and 8. 

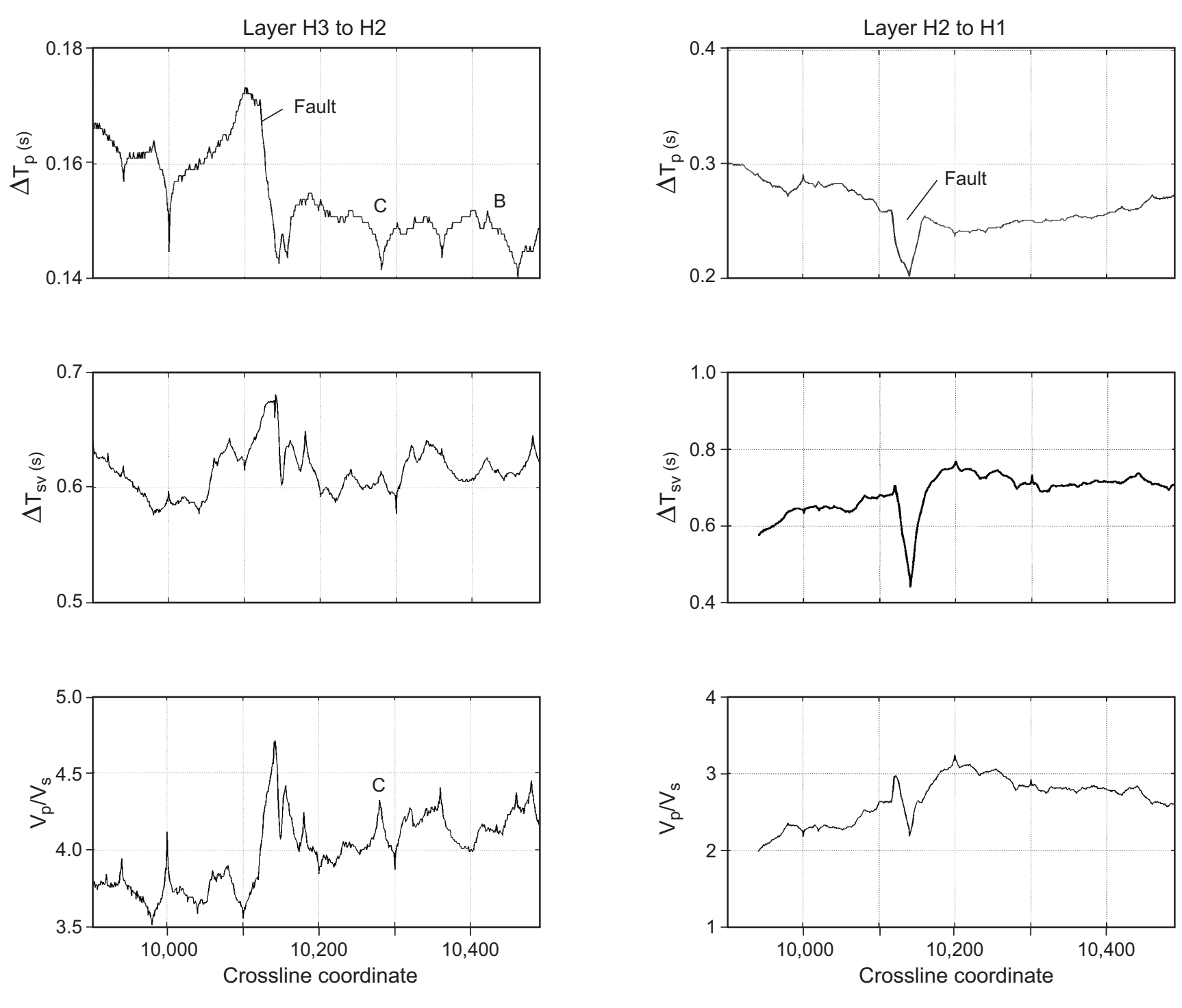

Figure 39. Time thicknesses and $\mathrm{V}_{\mathrm{p}} / \mathrm{V}_{\mathrm{s}}$ values associated with the layers defined along inline 1870, the seismic profile shown in Figures 7 and 8. 

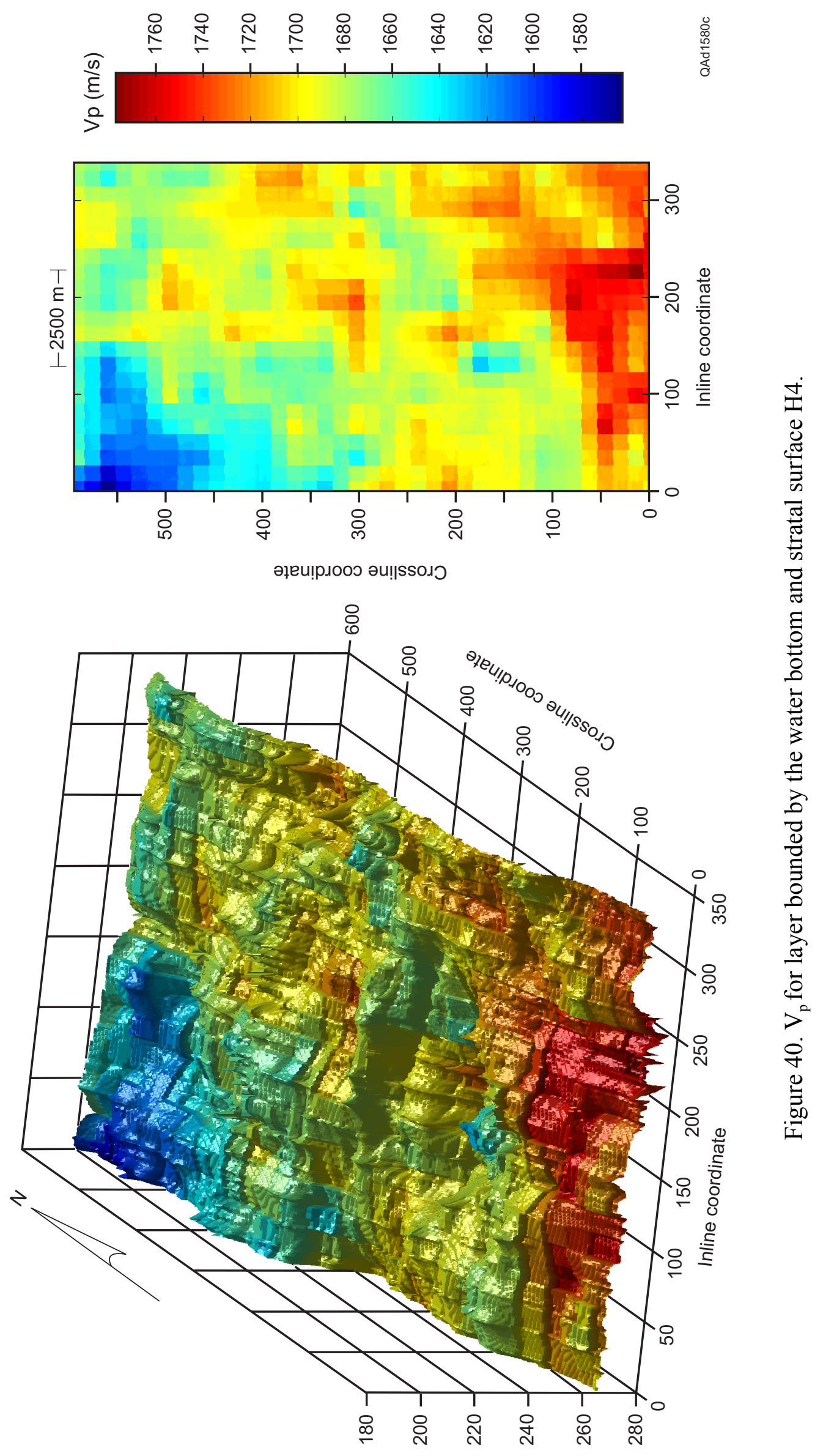

(m) |әлә| еәs ueəu мо|әq पұdə0 

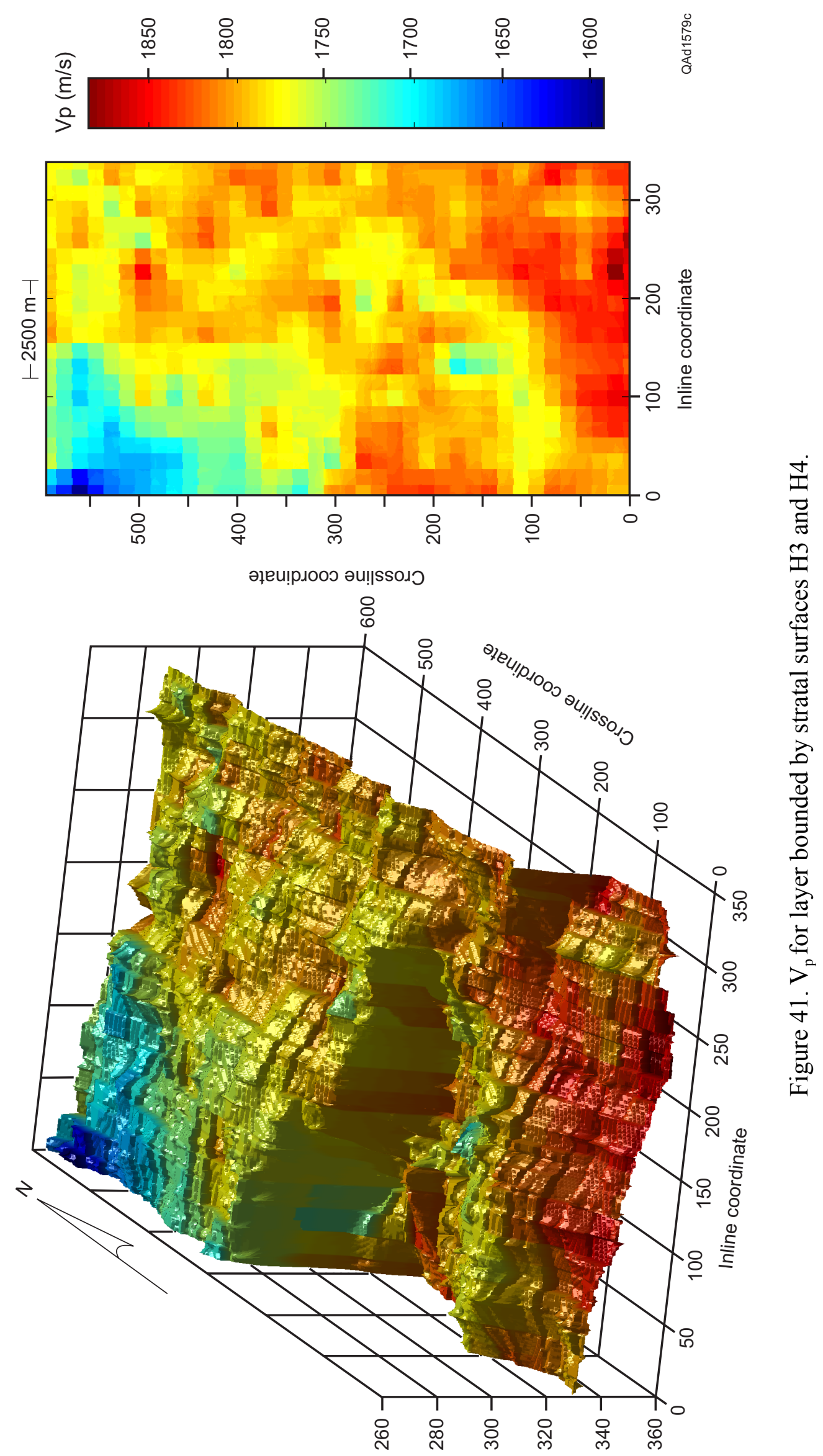

(m) |әлә| еәs ueəu мо|әq чұdə0 

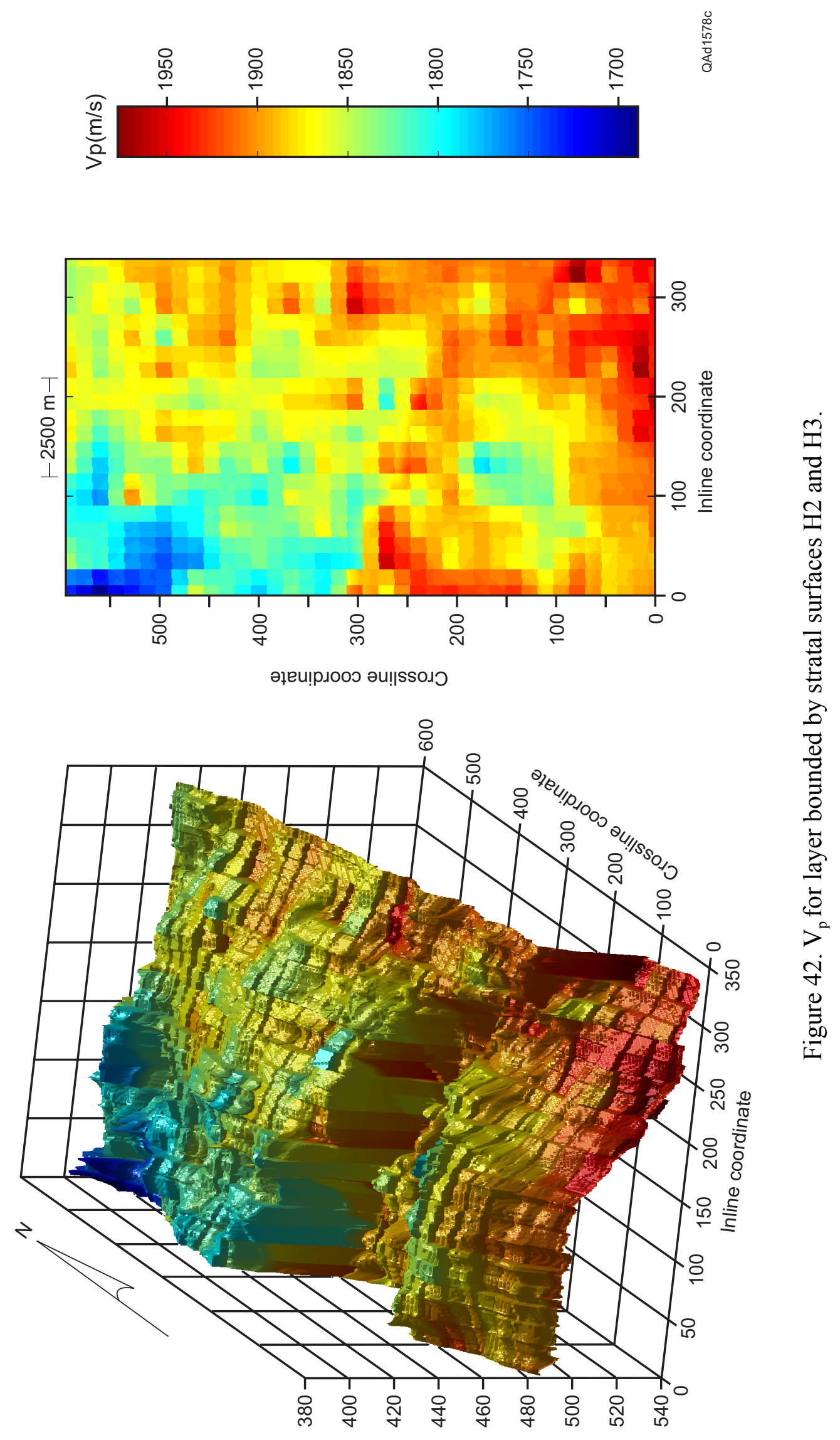

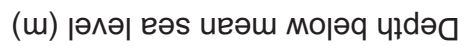



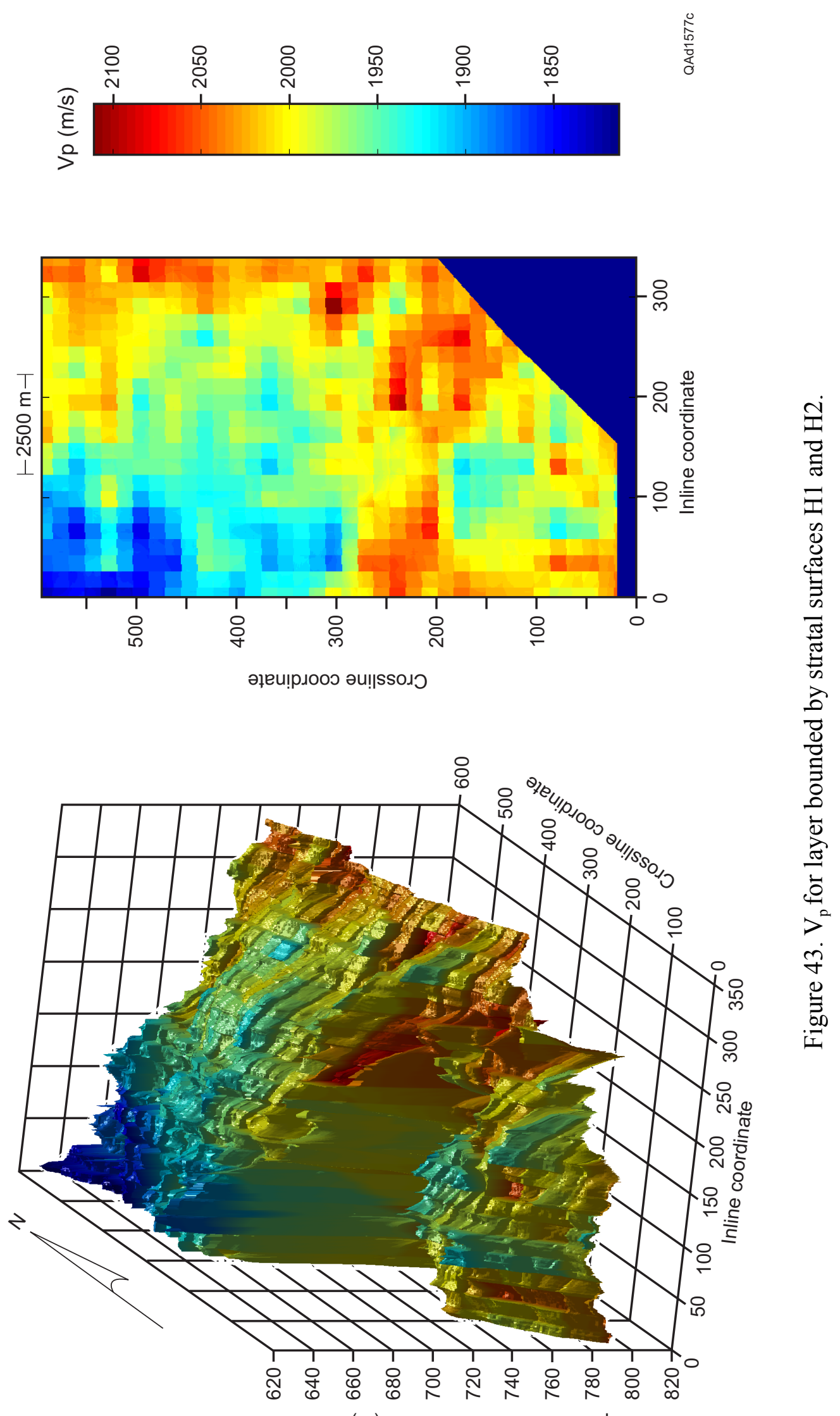

(u) |әлә| еәs ueәш мо|әq чұdә0 


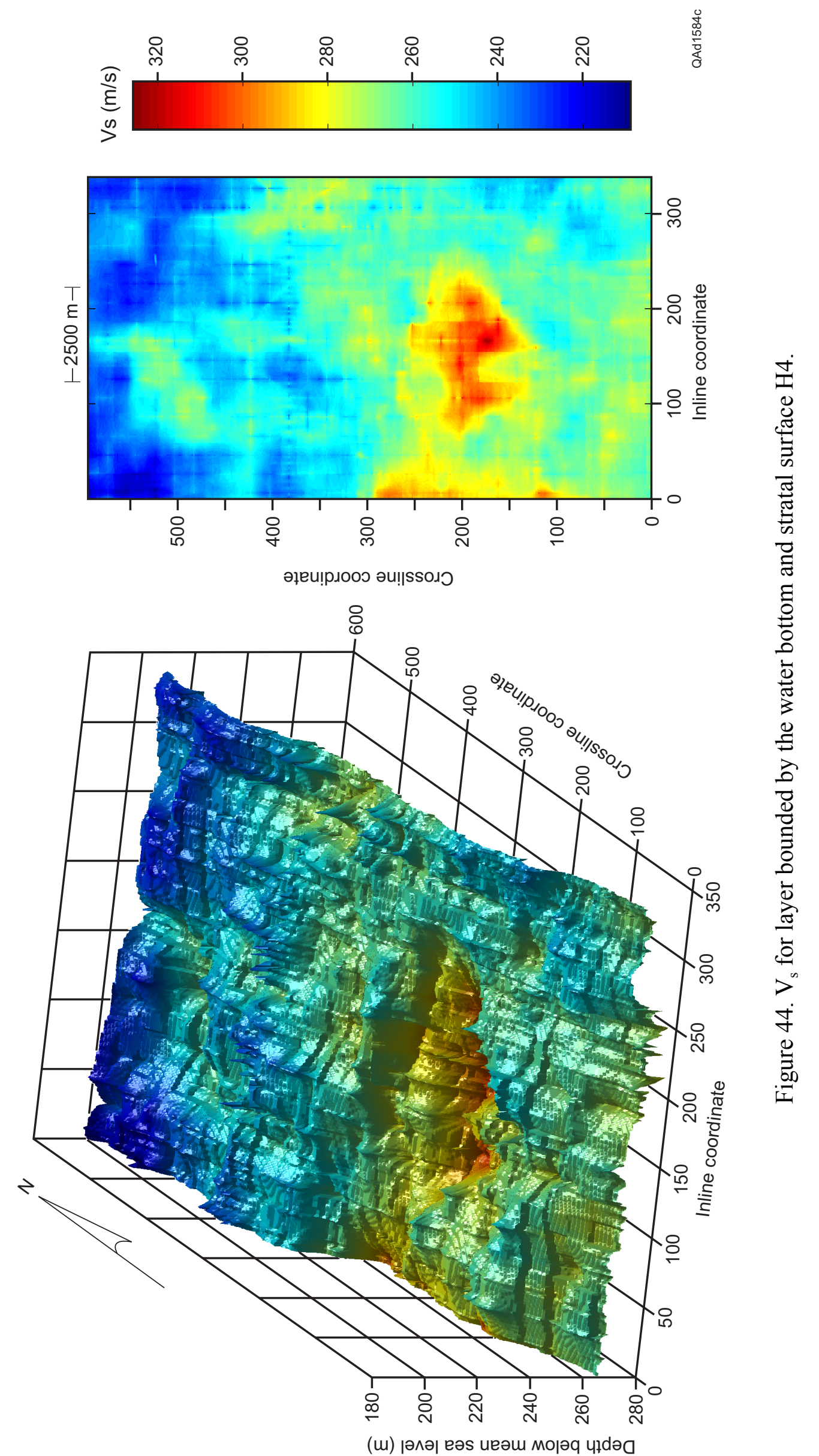



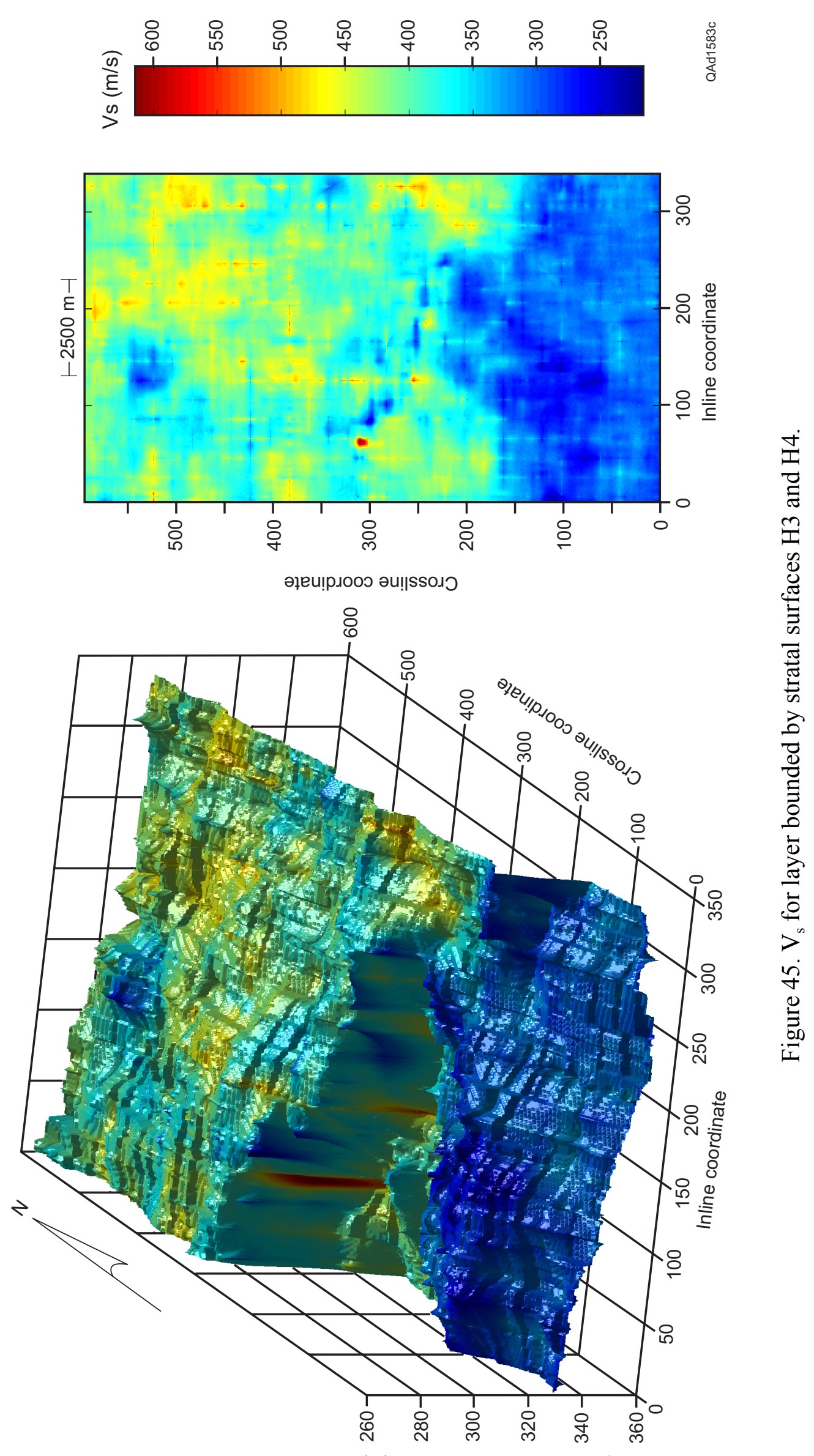

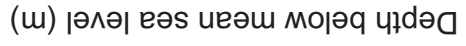



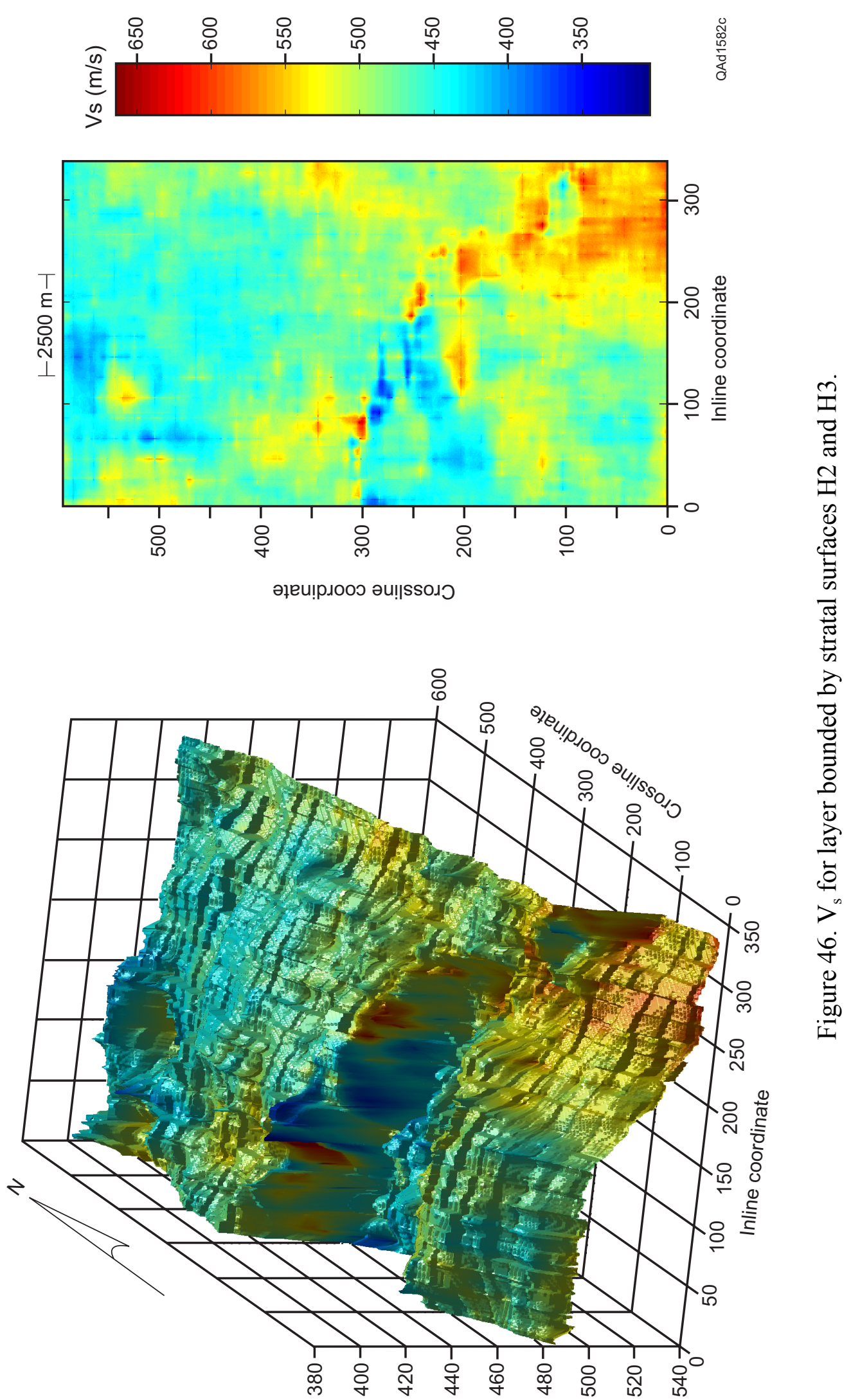

(u) |әлә| еәs ueəu мо|әq чұdə0 

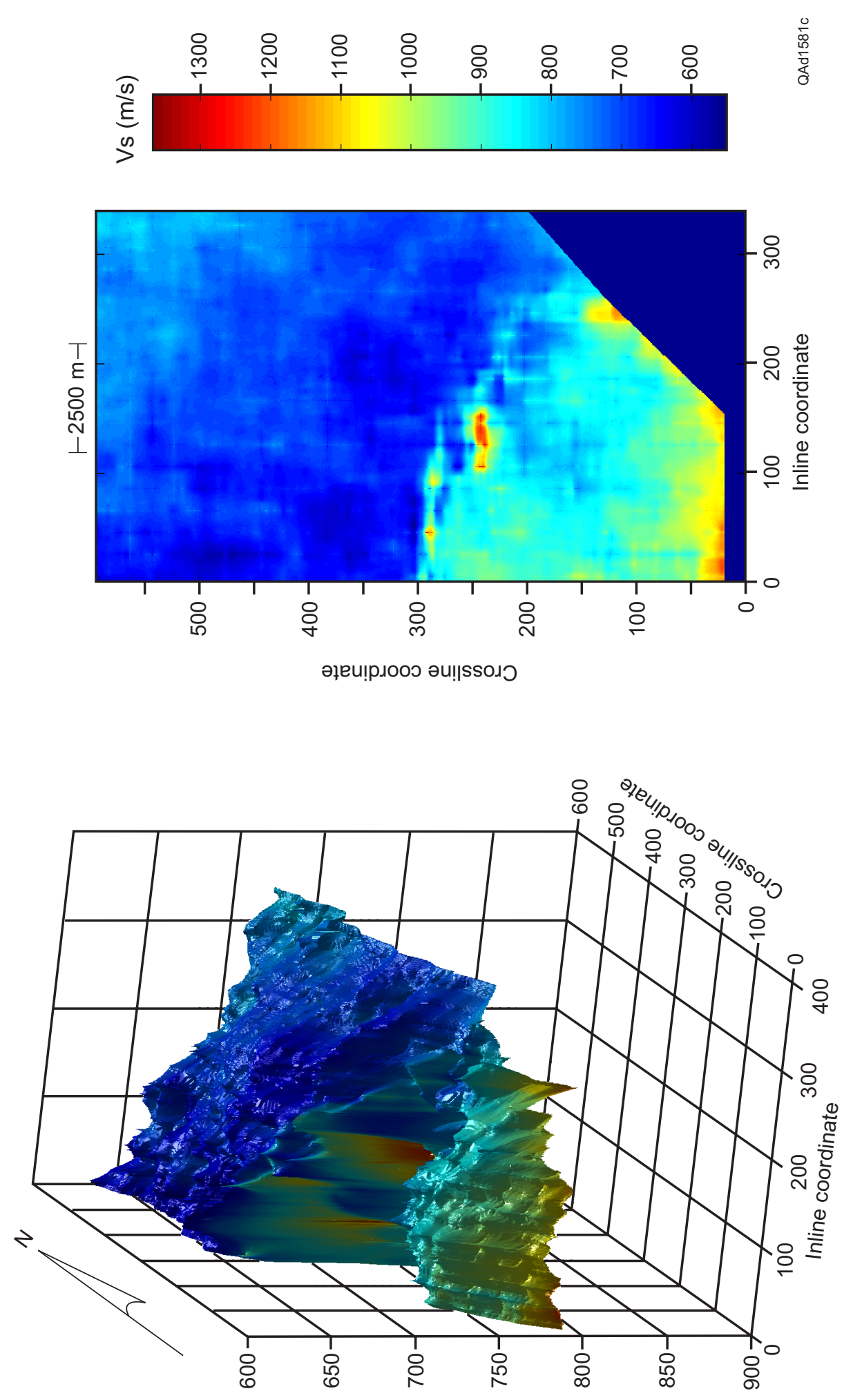

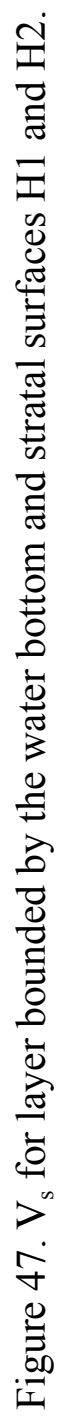

(w) |әлә| еәs ueəu мо|әq чұdə๐ 


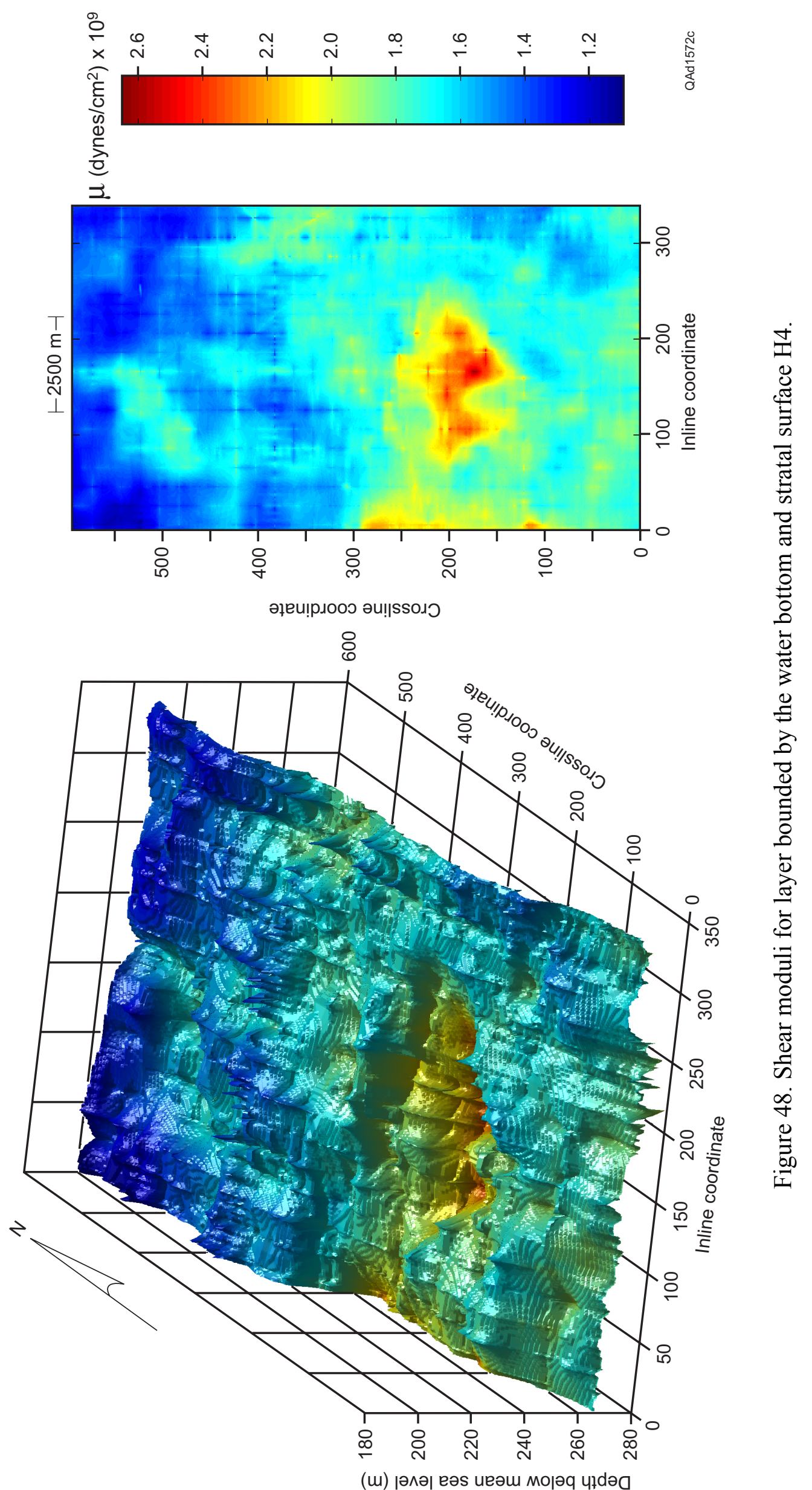




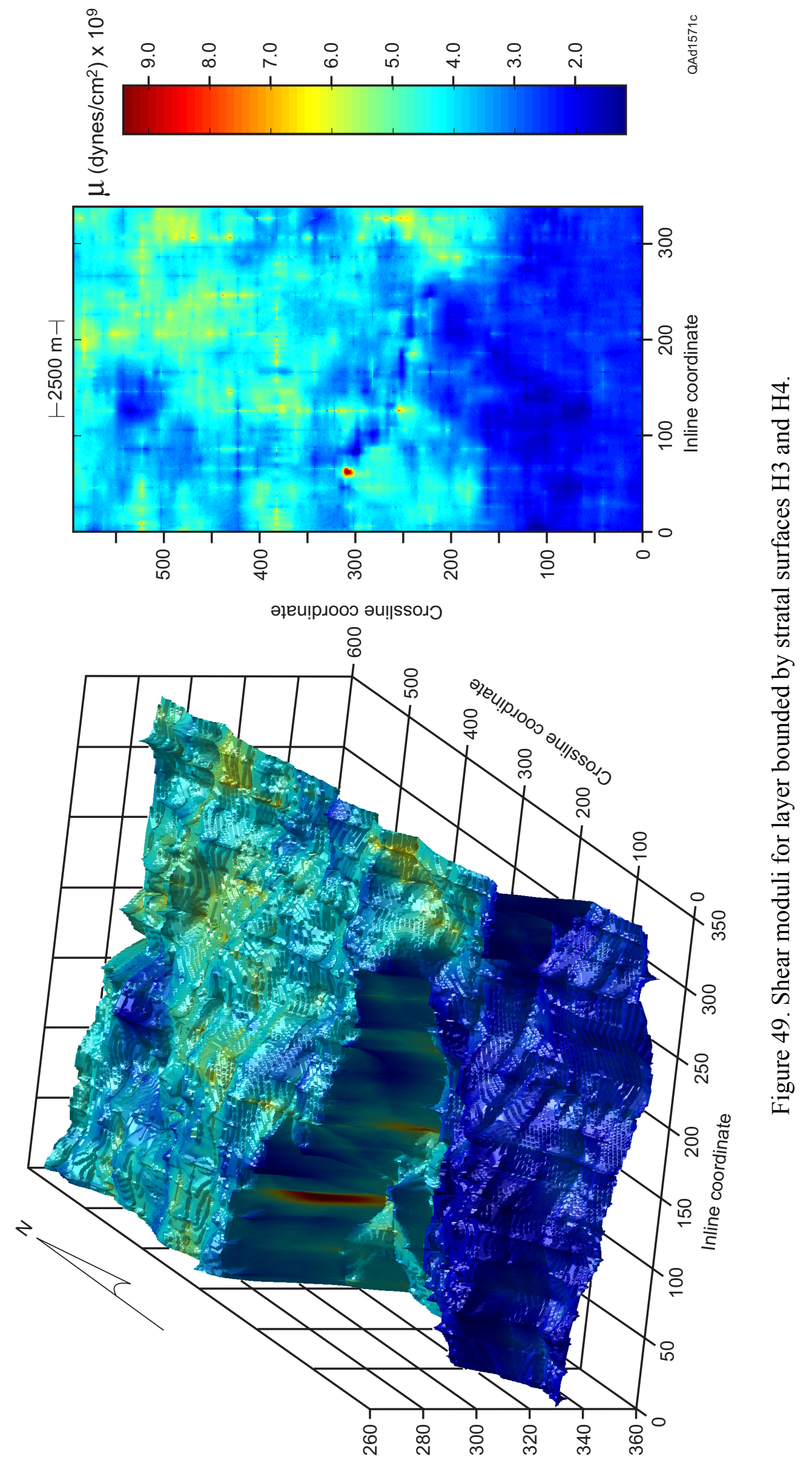

(u) |әлә| еәs ueәш мо|әq чાdә0 


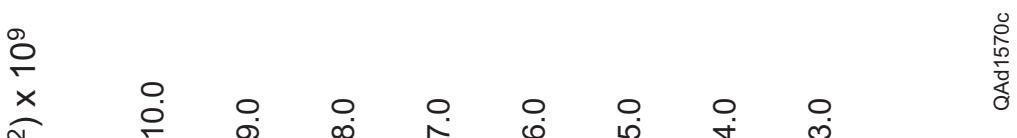
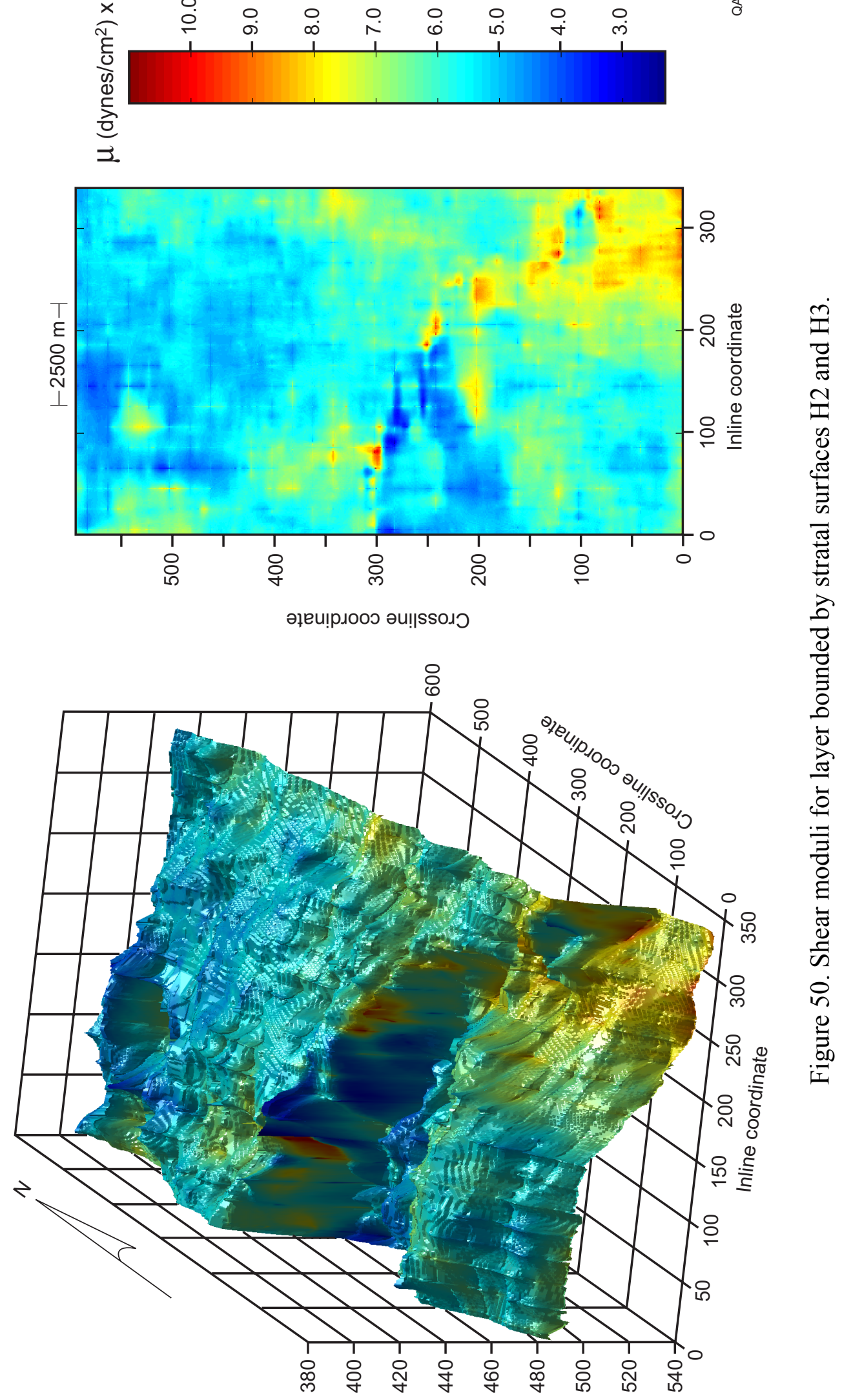

(u) |әлә| еәs иeәш мо|әq чұdә0 

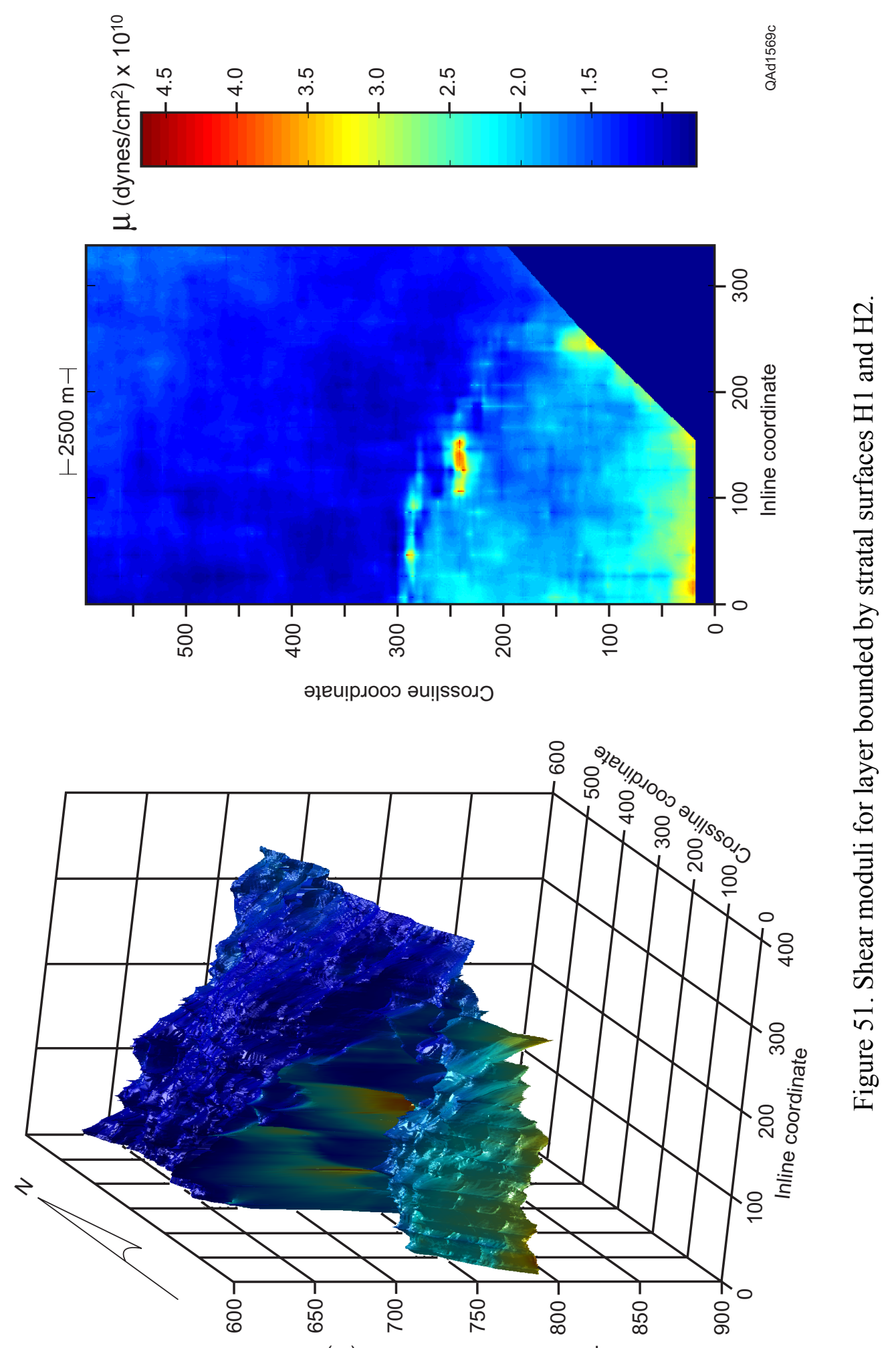

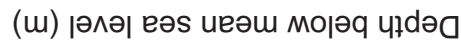

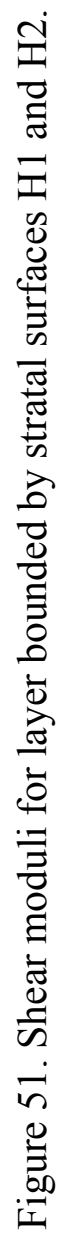



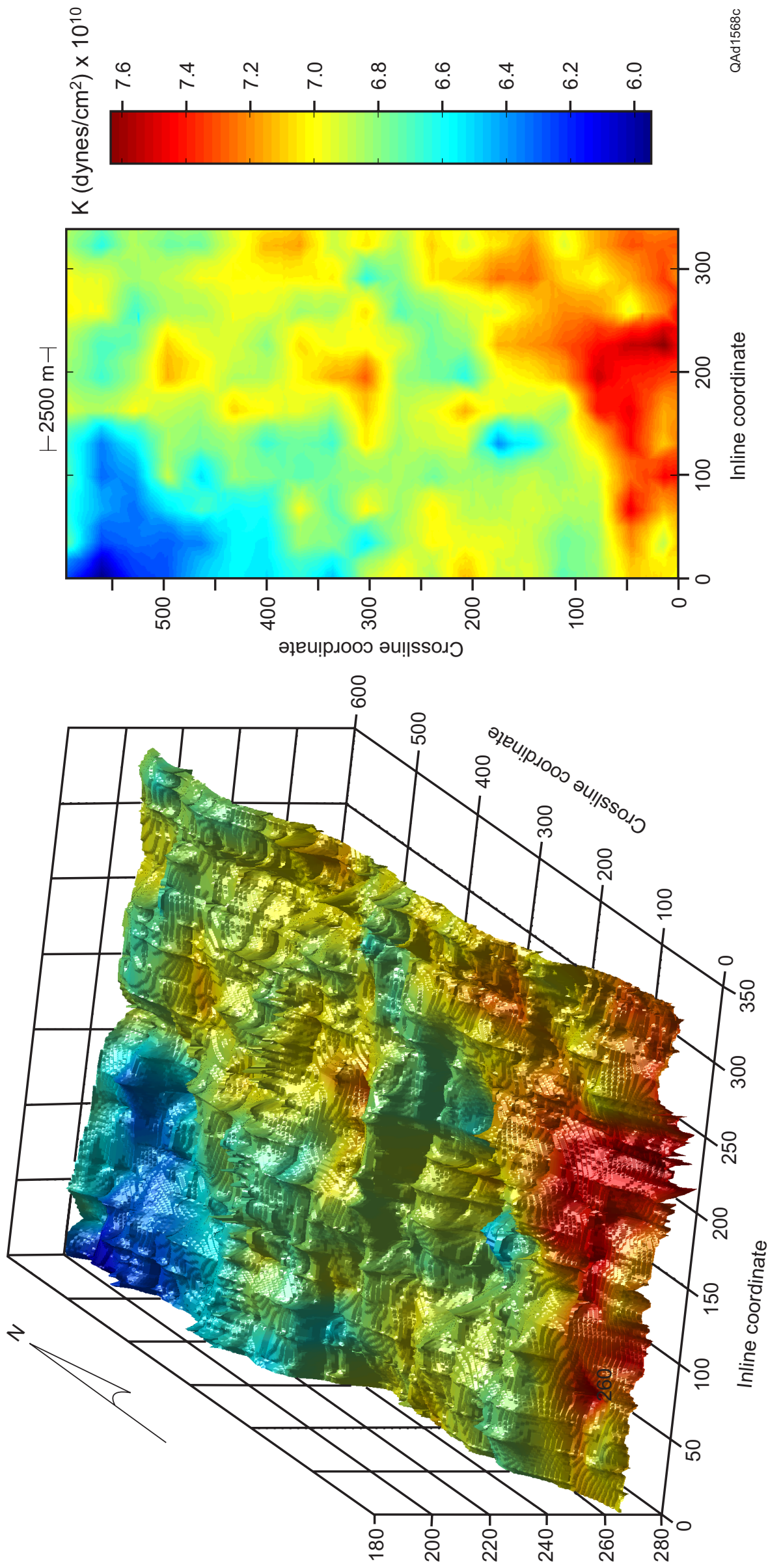

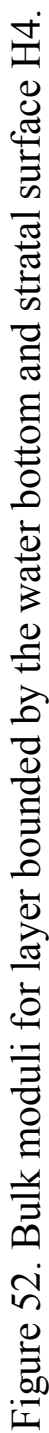

(w) |әлә| еәs иeәш мо|әq чұdə๐ 


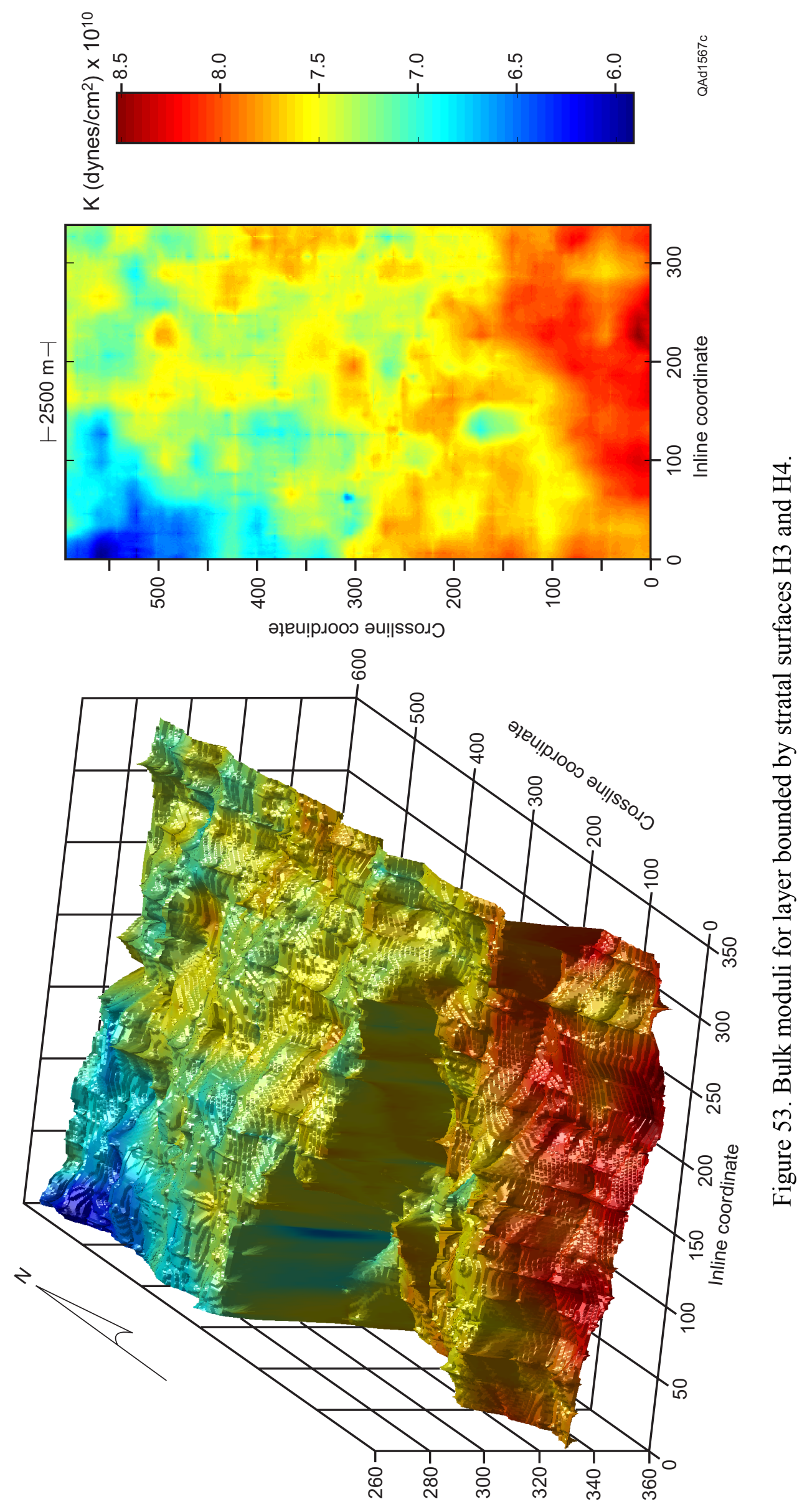

(u) |әлә| еәs иeәш мо|әq чұdә○ 

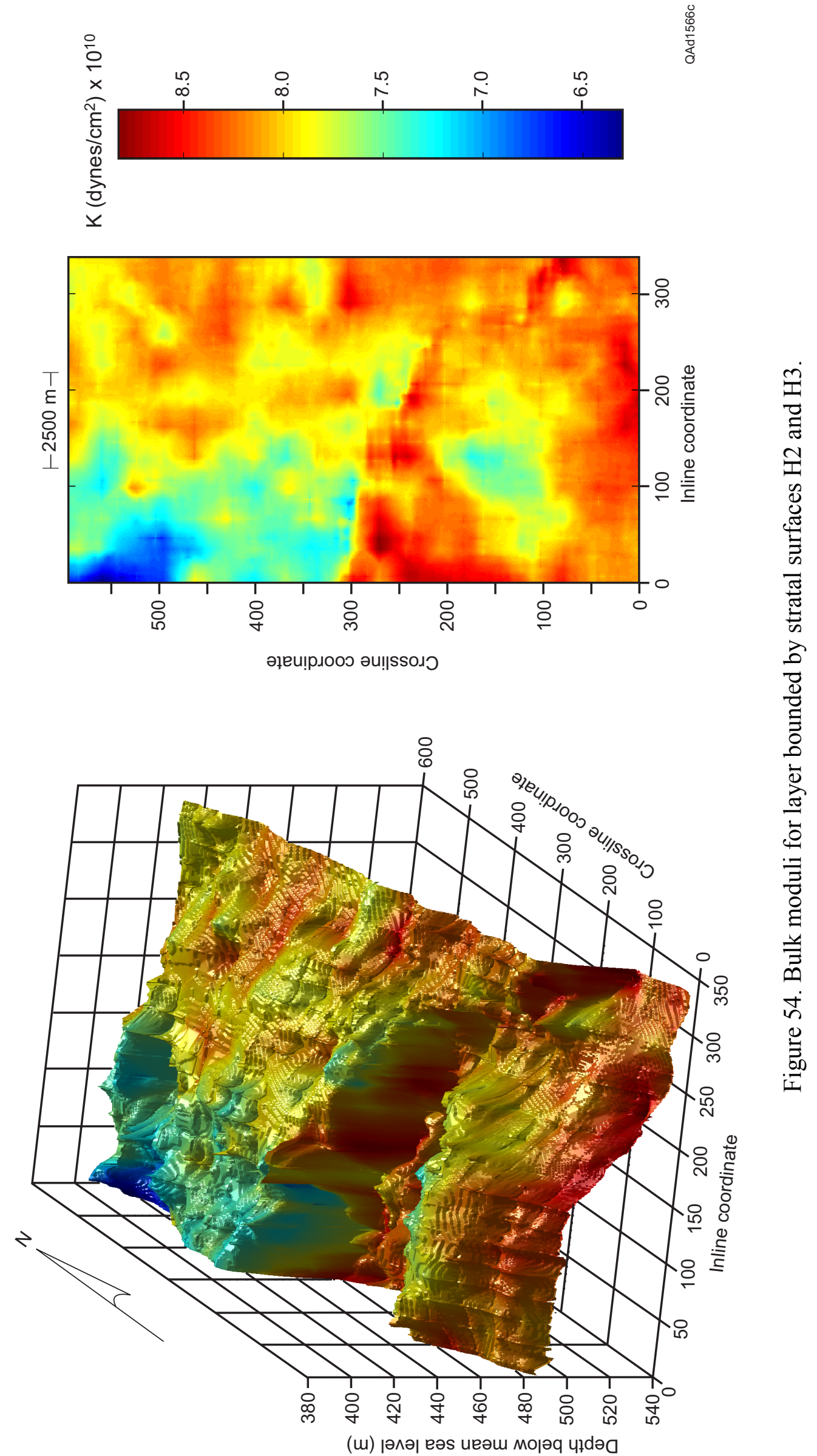

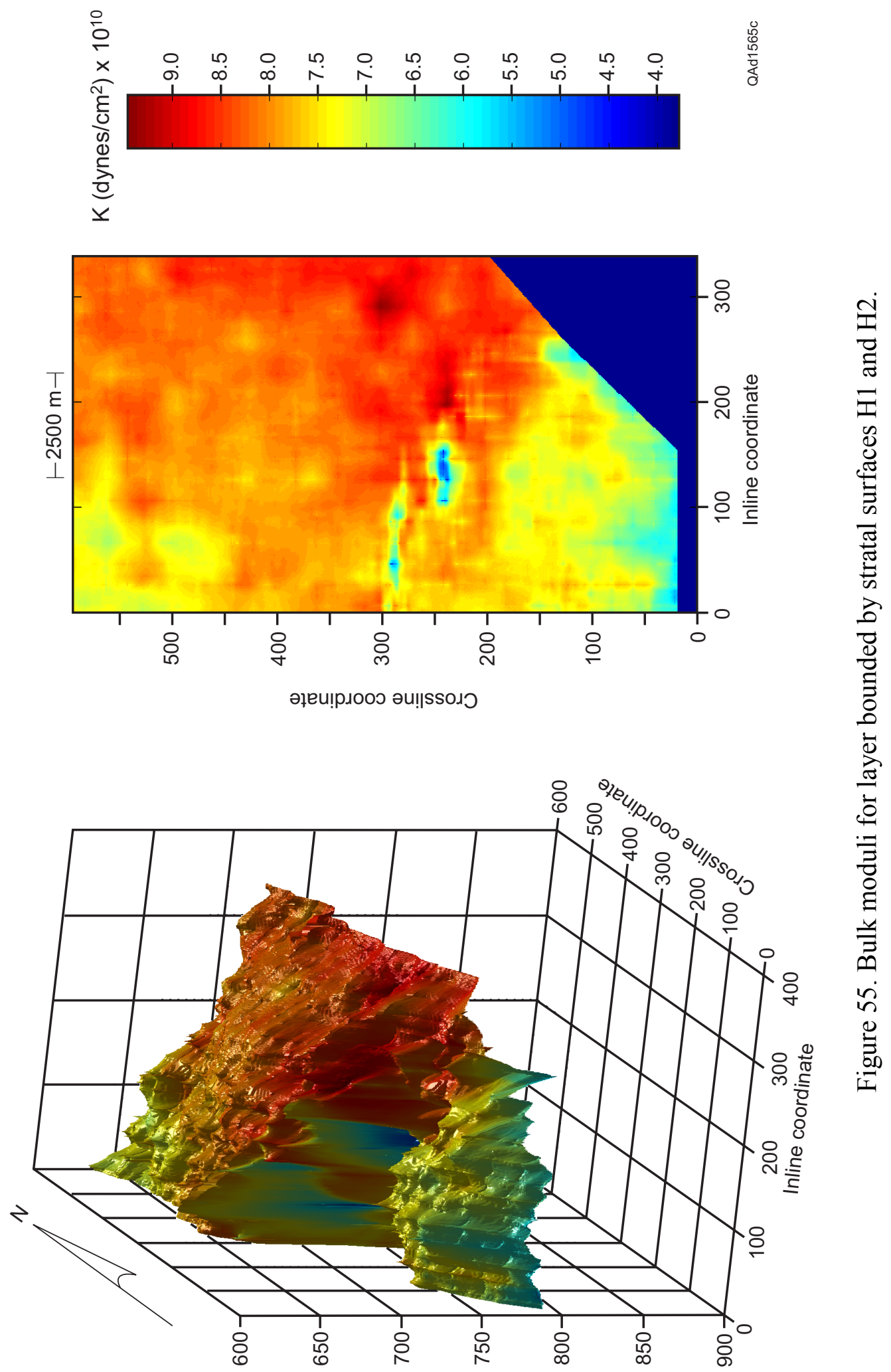

(u) |ә^ә| eəs ueəu мо|әq чұdəવ 


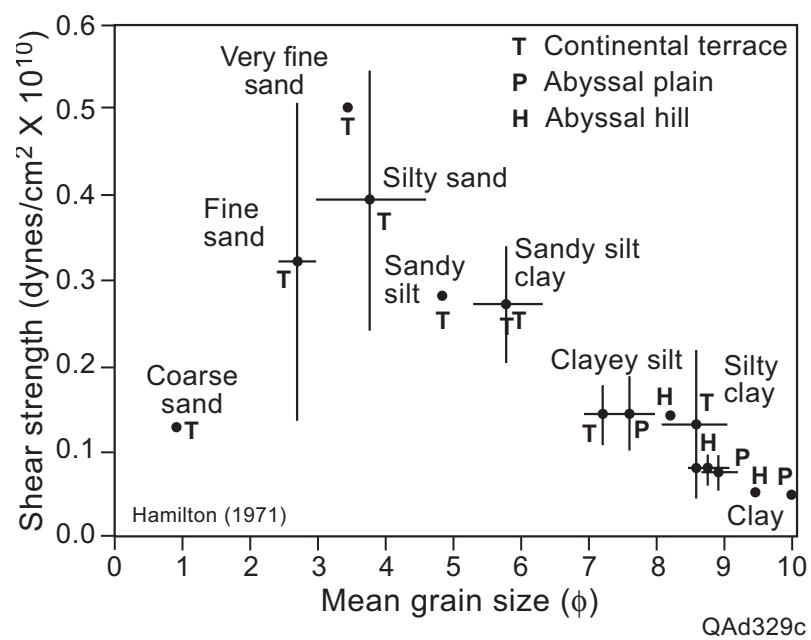

Figure 56. Relationship between shear strength and grain size of seafloor sediment. When $\phi=10$, the grain diameter is $2^{-10} \mathrm{~mm}$ (or $1 / 1024 \mathrm{~mm}$ ). When $\phi=3$, the grain diameter is $2^{-3} \mathrm{~mm}$ (or 1/8 mm) (modified from Hamilton, 1971). 


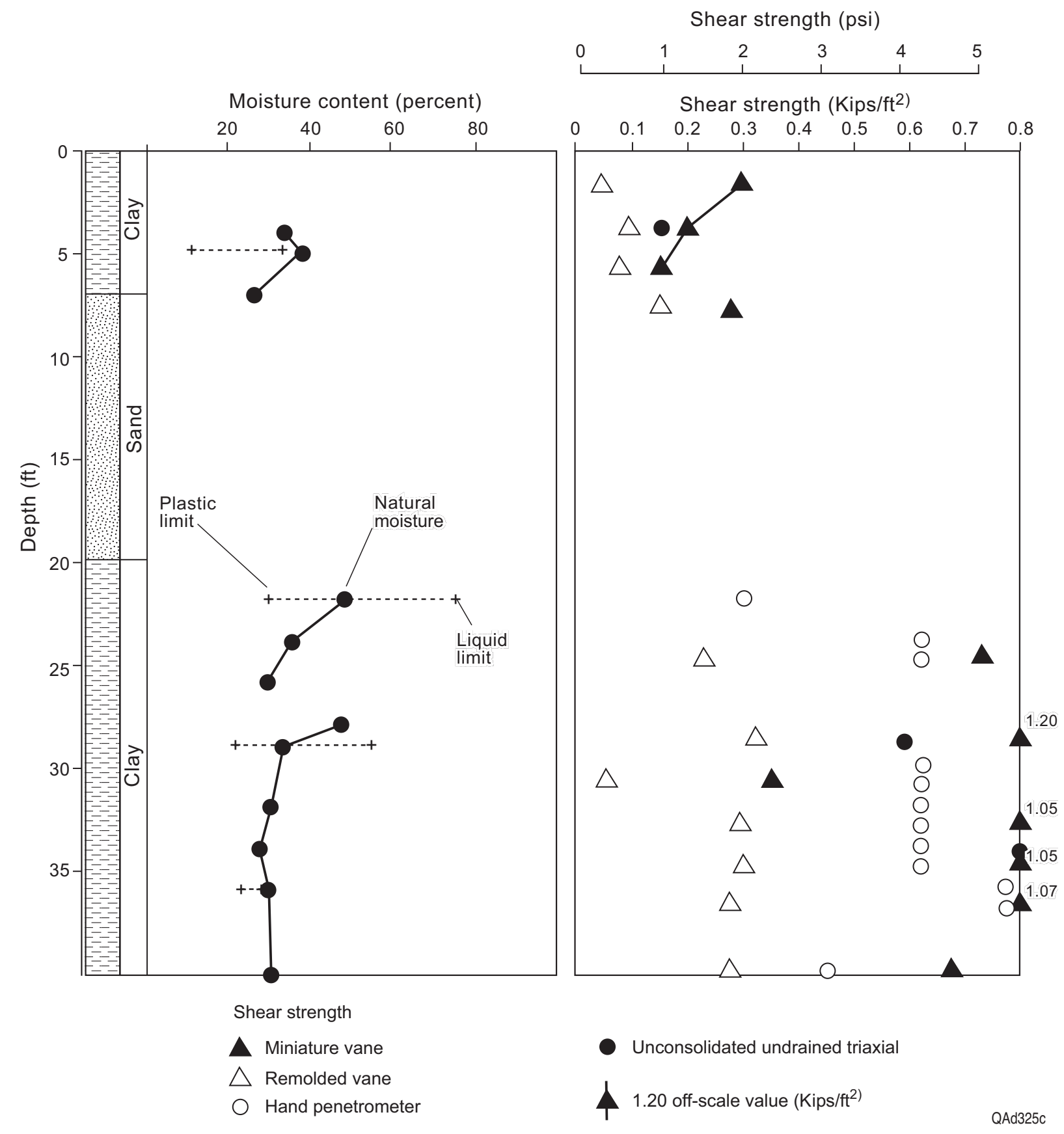

Figure 57. Shear strength and moisture content of first $40 \mathrm{ft}$ of seafloor sediment in Well A near study area. 


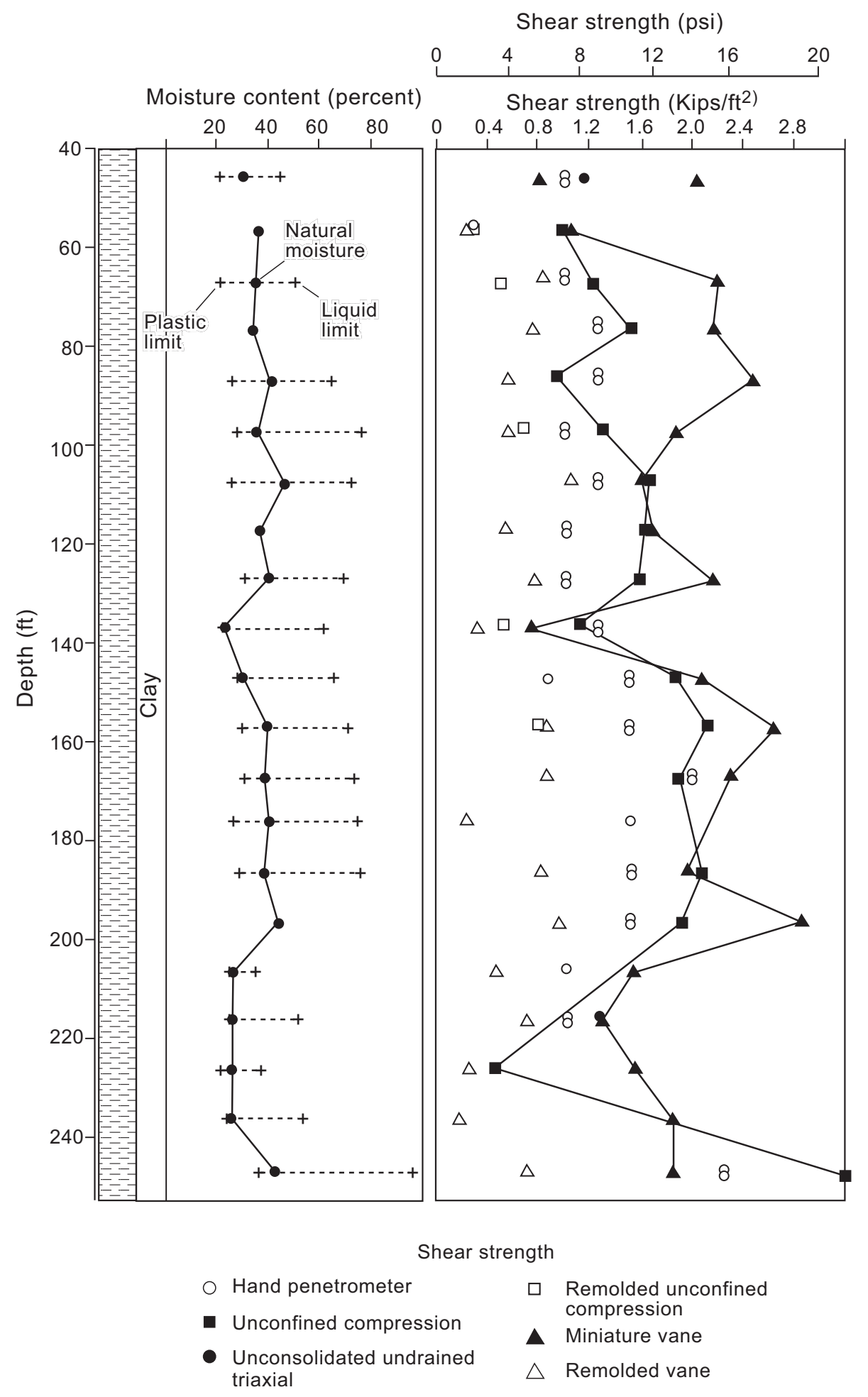

QAd326c

Figure 58. Shear strength and moisture content of first $250 \mathrm{ft}$ of seafloor sediment in Well A near study area. 


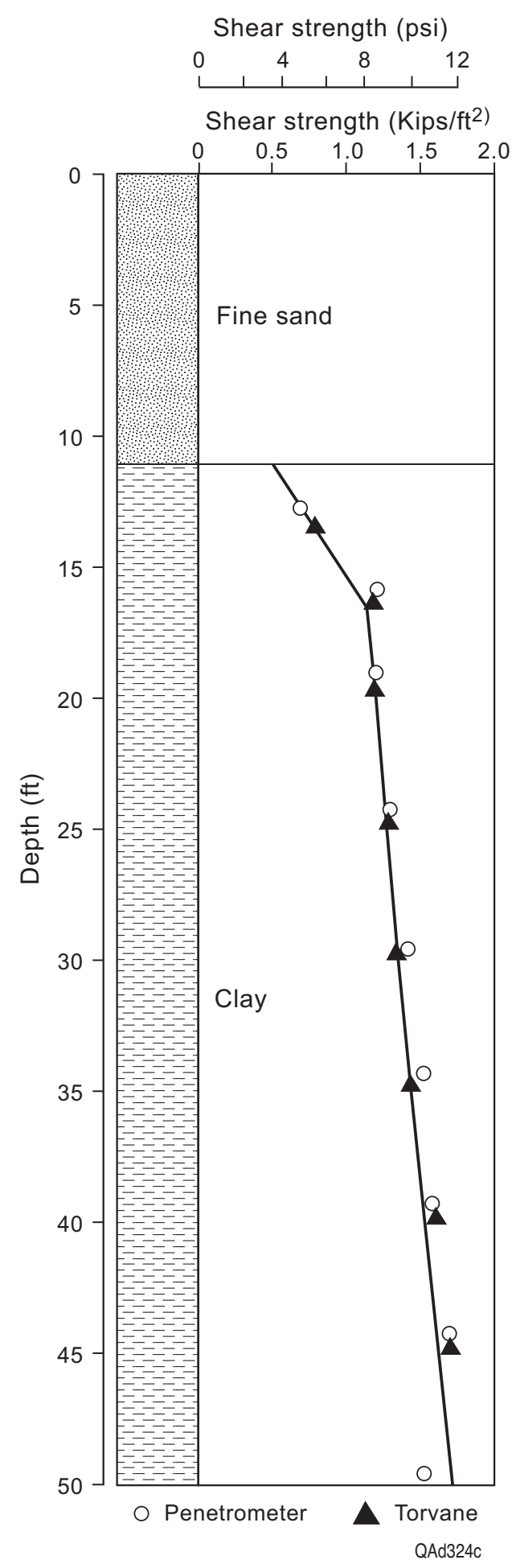

Figure 59. Shear strength of first $50 \mathrm{ft}$ of seafloor sediment in Well B near study area. 


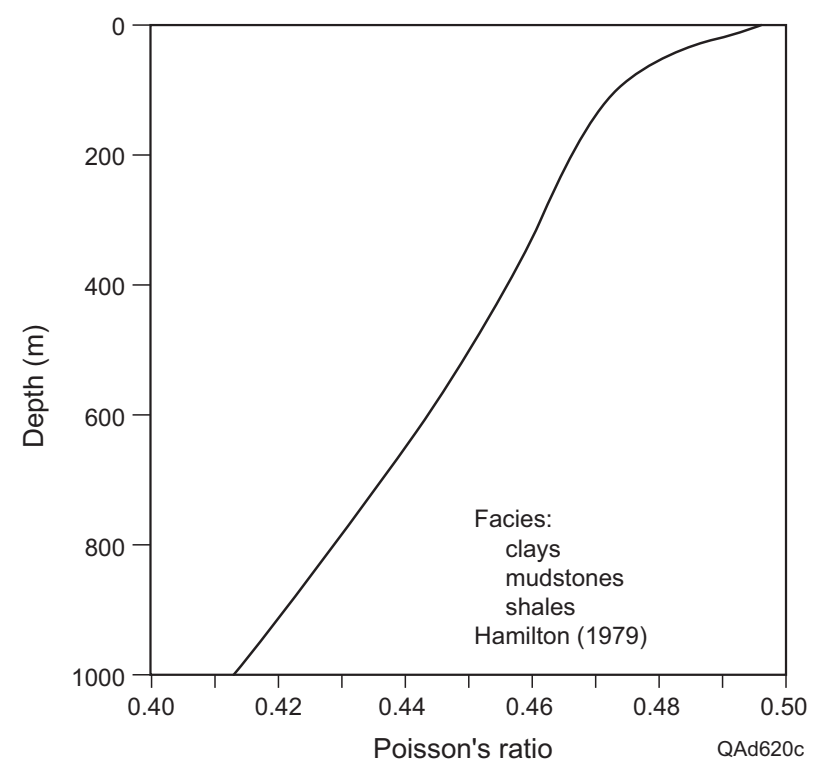

Figure 60. Poisson's ratio in shallow, finegrained, marine silts, clays, mudstones, and shale sediment (modified from Hamilton, 1979). Depth is measured relative to the seafloor. 


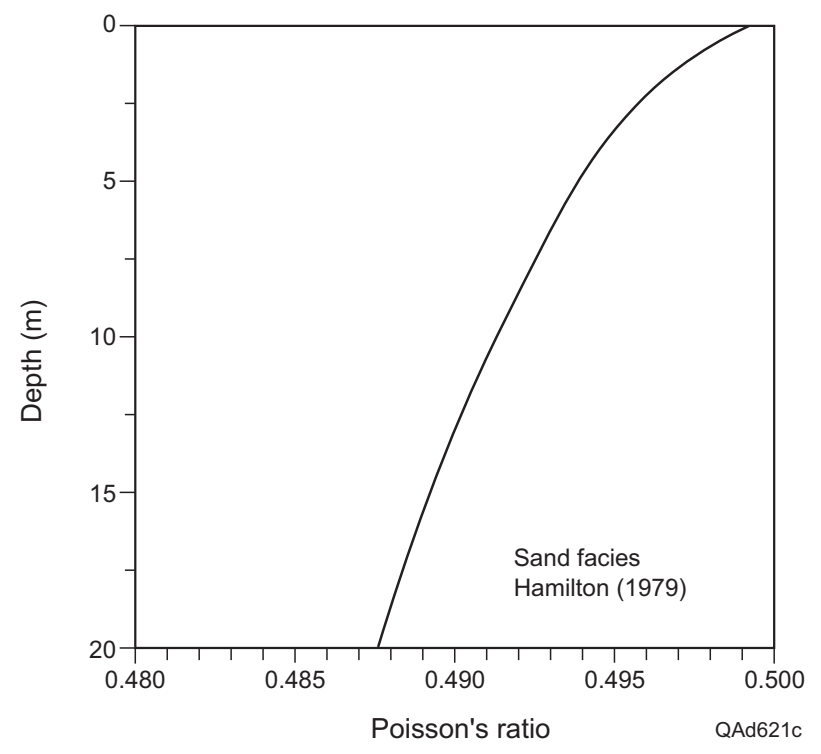

Figure 61. Poisson's ratio in shallow marine sands (modified from Hamilton, 1979). Depth is measured relative to the seafloor. 

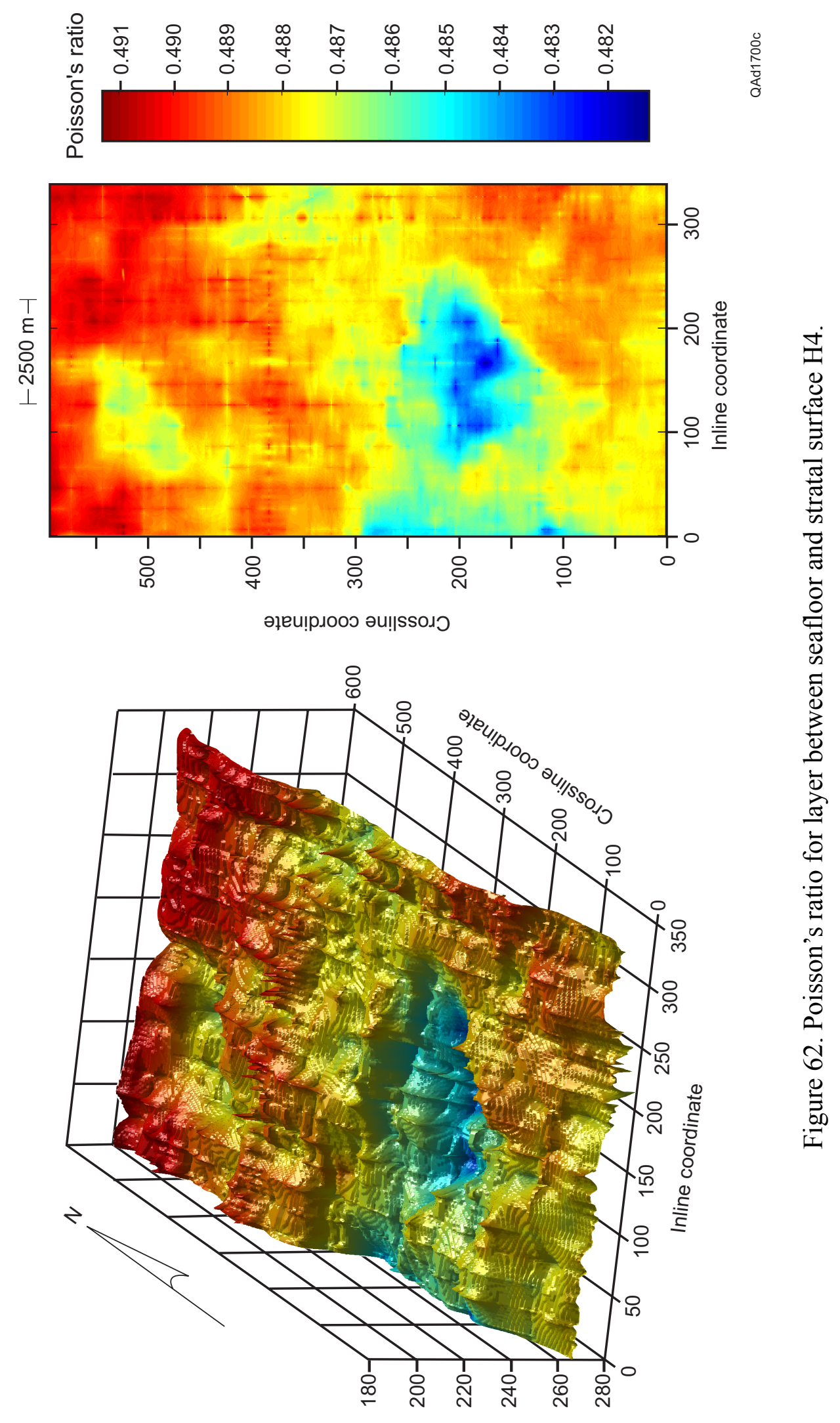

(u) |әлә| еәs иeәш мо|әq чұdə0 

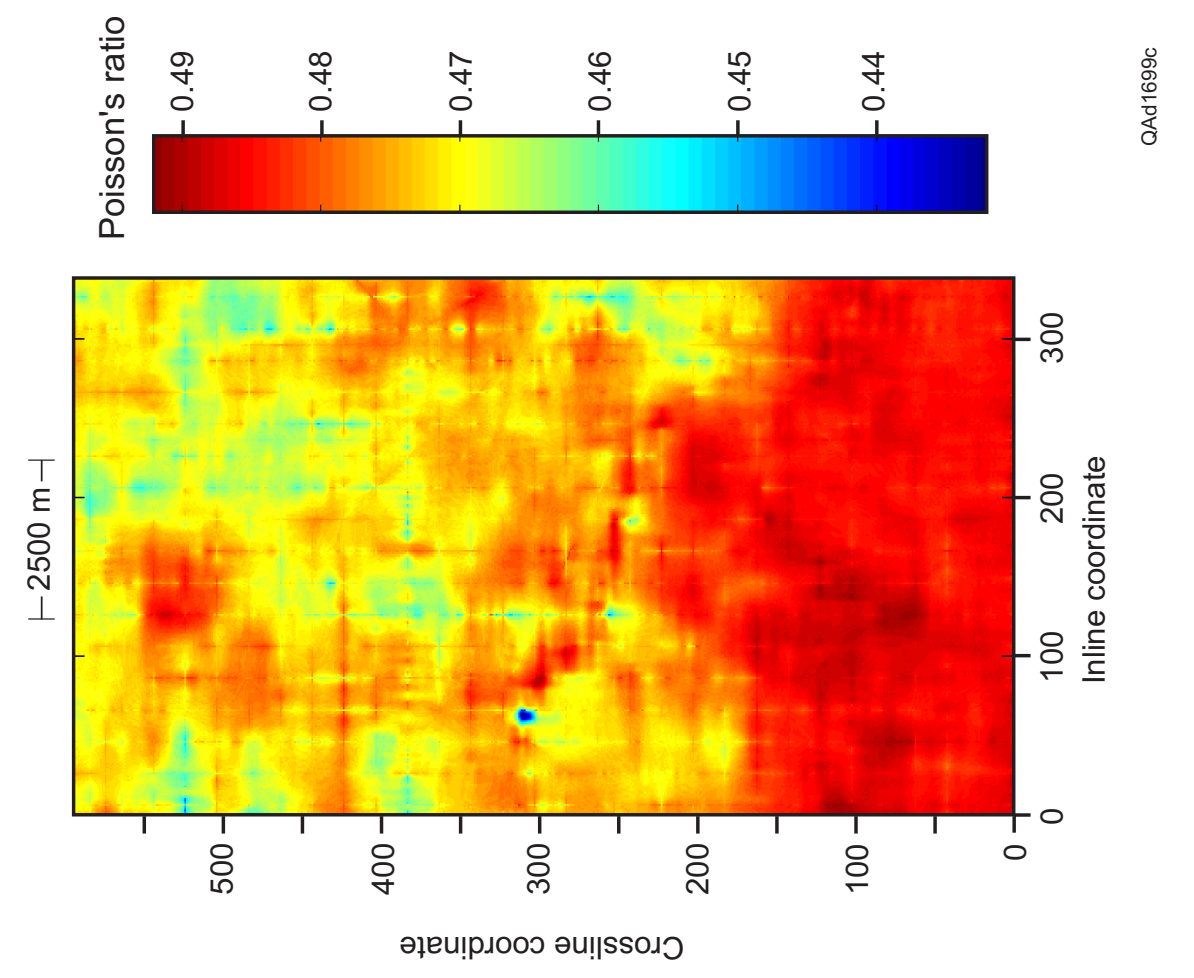

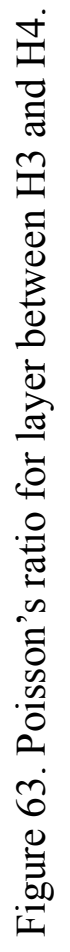

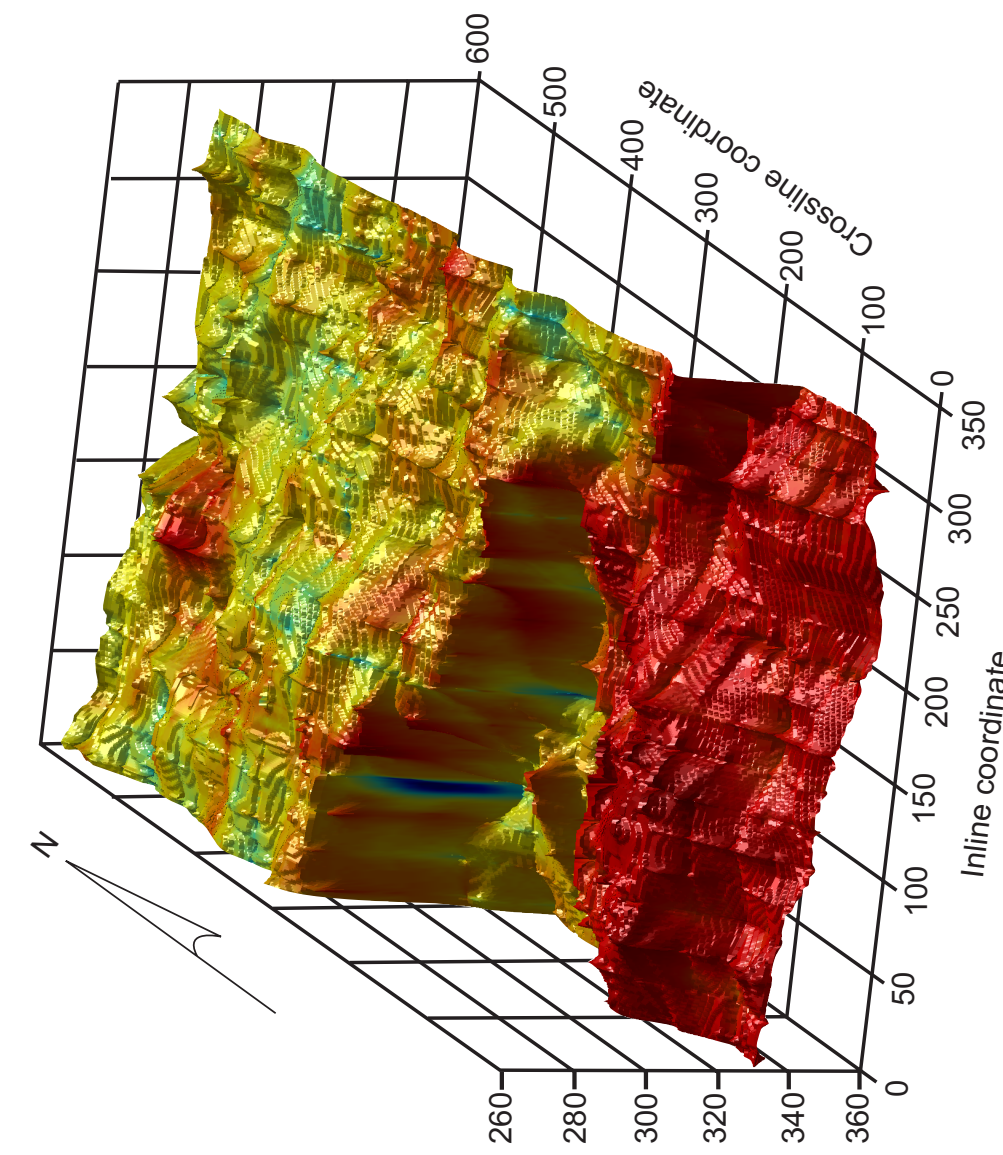

(u) |әлә| еәs иeәш мо|әq чұdə0 

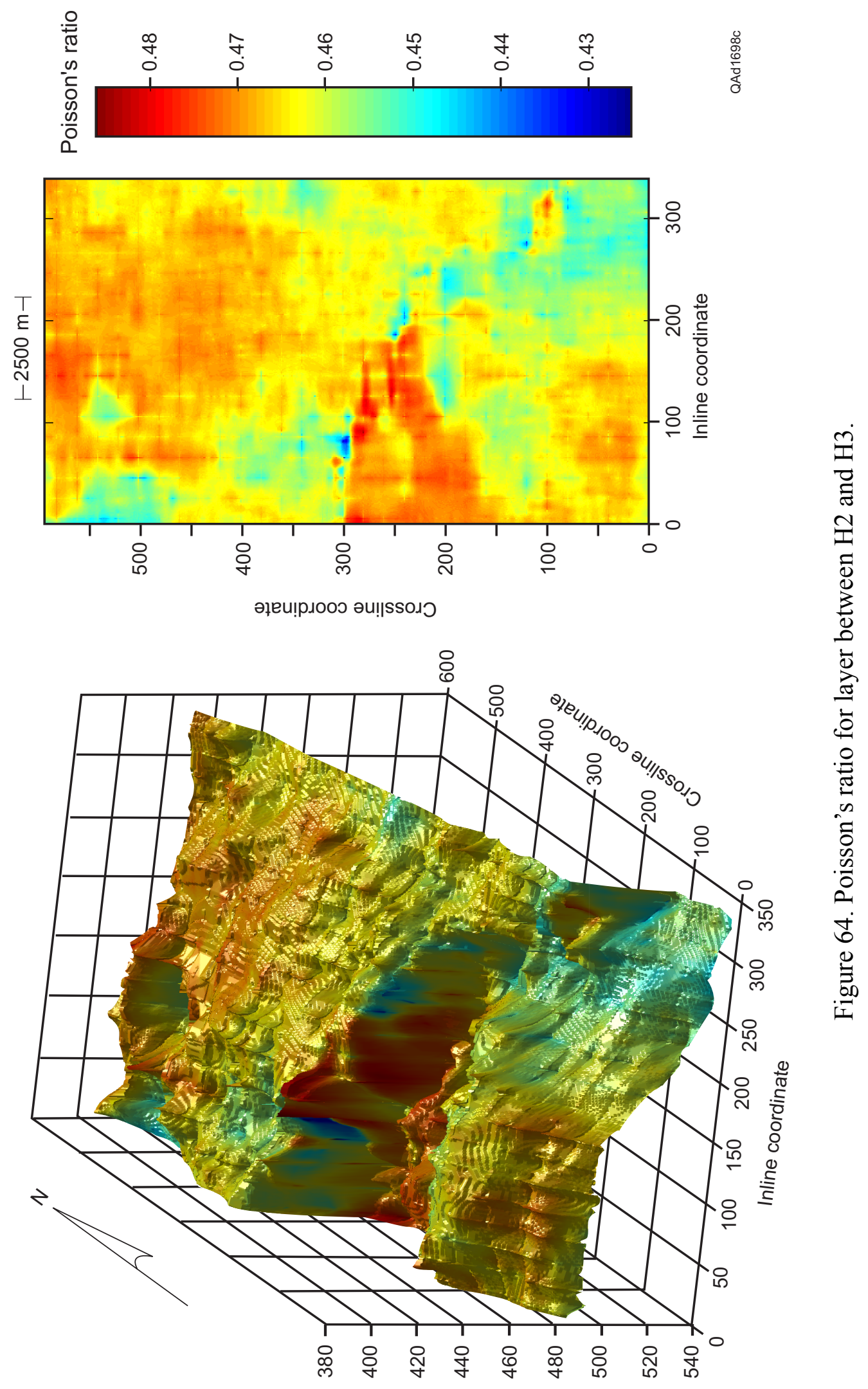

(w) ןәлә| еəs ueəu мо|әq чұdə๐ 

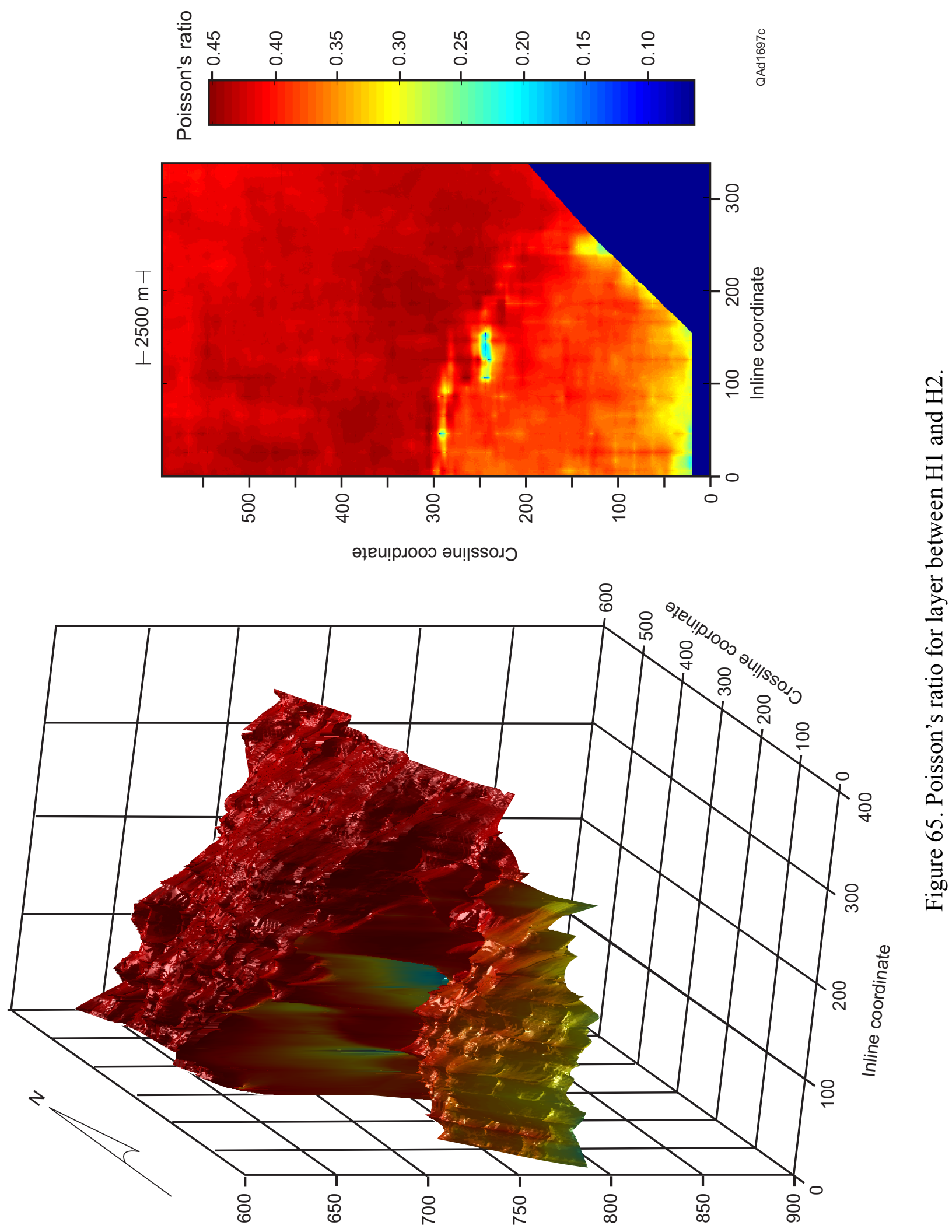

(u) |әлә| еәs ueəu мо|әq чұdə๐ 


\section{APPENDIX A: STUDY AREA}

The four-component, 3-D, ocean-bottom-cable (4C3D OBC) seismic data analyzed in this study cover the 455- $\mathrm{mi}^{2}$ survey in the West Cameron Area of offshore Louisiana defined in Figure A1. The data were acquired by Seitel Data Inc. and WesternGeco as a "spec" survey that can be sold to operators who wish to use converted-SV data in conjunction with P-wave data to better exploit oil and gas prospects across the area.

The research focused on an $80-\mathrm{mi}^{2}$ portion of the survey. This study area was small enough to allow a comprehensive database of shallow subsurface control to be built, yet large enough to span a variety of shallow geologic conditions similar to what is expected to exist across gas-hydrate prospects. Digital copies of 4C3D OBC seismic field records were provided by Seitel Data and WesternGeco over this $80-\mathrm{mi}^{2}$ study area, not over the entire $455-\mathrm{mi}^{2}$ survey. But even this reduced number of $4 \mathrm{C} 3 \mathrm{D}$ seismic data $\left(80-\mathrm{mi}^{2}\right)$ is an overwhelming database in terms of the massive disk storage required to maintain the data and the computational systems required to analyze the data.

Time-migrated $\mathrm{P}$ and $\mathrm{C}$ data volumes were analyzed over the total survey area $\left(455 \mathrm{mi}^{2}\right)$. No P-wave data below 1 second (s) and no C data below $2 \mathrm{~s}$ were utilized in these volume interpretations so that the technical value of the deep data spanning oil and gas targets would not be compromised or jeopardize future sales of the seismic data to oil and gas operators.

The technical approach taken in this gas-hydrate research is unique because it is based on applying large-scale, 3-D, multicomponent seismic surveys to improve the understanding of marine gas-hydrate systems. Other gas-hydrate research uses only single-component seismic technology. In those rare instances when multicomponent seismic data have been acquired for gas-hydrate research, the data acquisition has involved only a few receiver stations and a few 
source stations, sometimes only three or four of each. In contrast, the 4C3D OBC data used in this study were acquired at thousands of receiver stations spaced $50 \mathrm{~m}$ apart over an area of approximately $1,000 \mathrm{~km}^{2}$ using wavefields generated at thousands of source stations spaced $75 \mathrm{~m}$ apart over this same survey area.

The reason for focusing research attention on marine multicomponent seismic data is that 4C3D OBC technology provides a C-wave image of gas-hydrate systems in addition to an improved P-wave image. Because P-P and P-SV reflectivities differ at some stratal surfaces, $\mathrm{P}$ and $\mathrm{C}$ data provide two independent, and different, images of subsurface geology. The existence of these two independent seismic images and the availability of facies-sensitive C-wave seismic attributes, which can be combined with conventional facies-sensitive, P-wave seismic attributes, means that marine gas-hydrate systems should be better evaluated using multicomponent seismic data than using conventional single-component seismic data.

The principal barrier to overcome in imaging marine gas-hydrate systems using both $\mathrm{P}$ and $\mathrm{C}$ wavefields is that $\mathrm{C}$ waves do not propagate in fluids and marine gas hydrates are concentrated in sediment that is overlain by rather deep water. This C-wave illumination problem is now solved by the development of four-component ocean-bottom-cable (4-C OBC) seismic technology that positions three-component geophones on the seafloor. These seafloor sensors record reflected SV shear modes created by P-to-SV mode conversions at reflecting interfaces because the transducers are in physical contact with an elastic layer of the Earth and are not suspended in the water column as towed-cable hydrophones are. The important SH shear mode is not acquired using 4-C OBC technology.

The 4-C OBC seismic data used in this study allowed $\mathrm{P}$ and $\mathrm{C}$ data interpretations to be done over the depth intervals where gas hydrates would be positioned if they were present in the 
area. The $\mathrm{P}$ and $\mathrm{C}$ data-processing and interpretation techniques developed in this study can now be transferred to the analysis of deep-water, multicomponent OBC data that span targeted gashydrate reservoirs. 


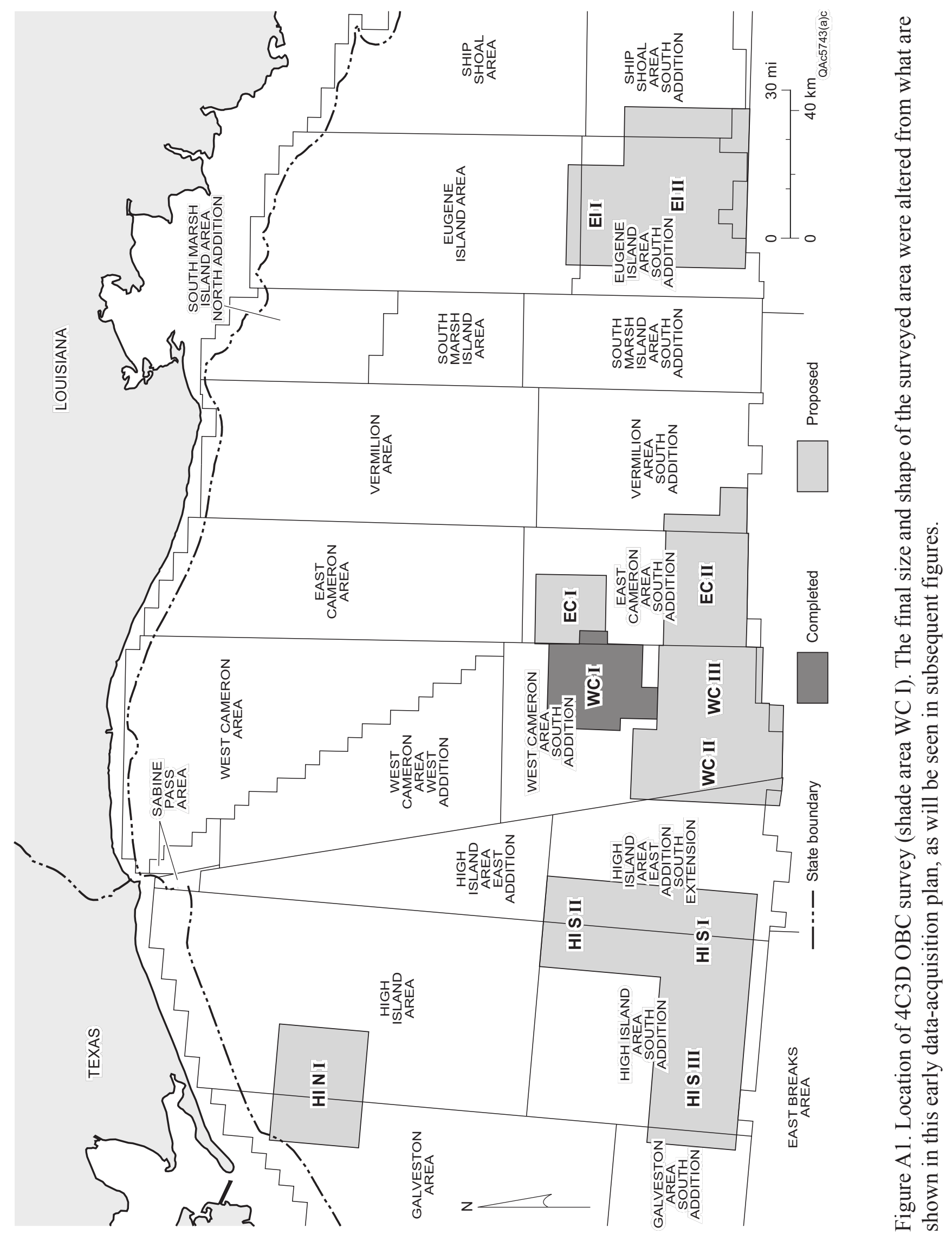




\section{APPENDIX B: GEOLOGIC CHARACTER OF STUDY AREA}

The shallow substrata of the study area (upper $500 \mathrm{~ms}$ of P-wave data) are characterized by lithologic, structural, and general architectural contrast. As will be shown in following sections, it is challenging to resolve the character of these shallow strata in the processed P-wave and SV-wave seismic data volumes donated to this study. It is therefore particularly important to build a reliable depositional model of shallow strata across the study area from nonseismic data. To develop the necessary understanding of the geologic character of the shallow substrate, we collected and analyzed data from industry and academe to map and understand the shallowest portions of the Gulf of Mexico shelf. These data provide an interpretive "baseline" by which the shallow imaging value of conventional 4-C OBC seismic data can be judged.

\section{Geologic Data}

Data available to map and refine the stratigraphic and structural architecture of the shallowest strata across the study area include high-resolution sparker and air-gun seismic data, several lithologic and petrophysical descriptions of shallow boreholes, and one complete shallow core (Fig. B1).

High-resolution seismic data collected by Texaco and made available from Rice University were acquired using a small, 10-inch ${ }^{3}$ air-gun source. These data were filtered to restrict the frequency content to 150 and $1,000 \mathrm{~Hz}$ (almost 3 octaves) and produced Pwave penetration up to $700 \mathrm{~ms}$, with a vertical resolution of 1 to $2 \mathrm{~m}$. Other seismic lines were available from shallow-hazard surveys obtained from the Minerals Management Service for West Cameron Blocks 563, 572, and 595 inside the study area and Blocks 
548 and 571 immediately outside the study area. These surveys included select seismic lines, bathymetric maps, mapped locations of hydrocarbon seeps and incised channels, and shallow structural maps. Data from these small-area maps were supplemented by Texaco high-resolution seismic data to interpolate between survey areas, the result being the composite map shown in Figure B1.

Borehole records from drill holes penetrating up to $377 \mathrm{ft}$ below the mud line show lithology, shear strength of the sediment, and information on predicted rig-leg penetration depths. These borehole data were tied to seismic data using a time-to-depth conversion of $1550 \mathrm{~m} / \mathrm{s}$ (Wellner and others, in press).

\section{Stratigraphy}

Regional structural and seismic unit analysis of the northern Gulf of Mexico shelf by Berryhill and others (1987) was based on a database of several thousands of kilometers of seismic profiles (Figs. B2 and B3). It is difficult with compare their dataset to the one used in this study area because so few of the Berryhill group data have been published. The Berryhill group divided the shallow (500-ms P-wave time) section into four primary units: (1) pre-Wisconsinan, (2) early Wisconsinan, (3) middle Wisconsinan, and (4) late Wisconsinan to Holocene. These units were tied to our study area using a seismic line over the area published by Berryhill and others (1987), published studies by Coleman and Roberts (1990), and conversations with researchers at Rice University (personal communication, Julia Wellner, 2001; Wellner and others, in press).

Wellner and others (in press) used samples from two boreholes collected near our study area to age-date the stratigraphic study section involved in our research. Wellner's Stage 5e flooding surface is shown on the seismic line in Figure B4. This surface was 
projected into our study area via Wellner's borehole cross section (Wellner and others, in press; their Fig. 21) and was found to occur between P-wave images times of approximately 180 and $190 \mathrm{~ms}$. This flooding surface is documented in Borehole 349-B, located immediately to the southwest of the study area at a depth of $90 \mathrm{~m}$ and represents the initial, early-highstand, Stage 5e flooding event dated at 125,000 yr B.P. The only other key surface rigorously documented by Wellner was the Stage 2 lowstand sequence boundary (SB2), considered by Berryhill and others (1987) to be the late-Wisconsinan lowstand. This surface is characterized by significant distributary and fluvial incision across the Gulf of Mexico shelf and represents the maximum lowstand of sea level during the last glacial maxima (Fig. B3).

A series of incised valleys, up to $80 \mathrm{~ms}$ deep (62 m [203 ft]) in P-wave image time and over $4 \mathrm{~km}$ wide, characterize the SB2 lowstand surface (Fig. B4). The study area falls within the axis of a major fluvial incision feeding a large, late-highstand, shelfedge, deltaic complex centered immediately south of the study area defined as Delta $\mathrm{C}$ by Berryhill and others (1987) and shown in Figure B2. This fluvial incision is defined on high-resolution seismic data (Fig. B4) and shows up to $80 \mathrm{~ms}$ of truncation into underlying Stages 3 and 4, subparallel, progradational, deltaic clinoforms of the latehighstand shelf delta. Boreholes collected within the study area by Fugro-McClelland, Inc., and documented in Coleman and Roberts (1990) show the overlying valley fills to be composed of fine- to medium-grained sands incising into underlying gray clay and silty clay containing some shelly material (Fig. B5). Seismic facies within these valleys are a complex-chaotic and prograding fill. Underlying clays are acoustically layered, continuous, wavy reflector packages in the high-resolution seismic profiles. The Stage 2 
lowstand surface is dated across the shelf as occurring between 22,000 and 17,000 yr ago (Bard and others, 1990).

A series of flooding events have been interpreted within the study area and are associated with high-order, Stage 3, late-highstand flooding events. These events are identified in high-resolution seismic data by their continuous "railroad track" signatures across the study area and appear in core as carbonates interbedded with silts and clays (Coleman and Roberts, 1990). These carbonate depositional events show a sharp impedance contrast with overlying and underlying clays and sands (Fig. B4) and allow detailed age-dating to be done across the stratigraphic section.

A deep, regional, downlap surface can be traced into the study area from the highresolution seismic lines of Wellner and others (in press). This surface was tied outside the study area by these authors to its time-equivalent surface on the Texas-Louisiana shelf where it was dated by Thomas and Anderson (1994) as the Stage 5e flooding surface. This correlation makes the surface approximately 125,000 yr B.P. In West Cameron Block 586, this surface can be correlated to the Stage 5 condensed section of Coleman and Roberts (1990). However, the 5e maximum flooding surface (MFS) visible on seismic data in the northeast portion of the study area does not follow the Stage 5 condensed section of Coleman and Roberts (1990), which was determined using only platform borings. Results from Wellner and others (in press) indicate that much of the sand body mapped by Coleman and Roberts (1990), and identified by them as the Stage 6 delta (Fig. 11 of Wellner and others, in press), is actually the updip component of the Stage 5 delta. This makes the section much younger than previously claimed by Coleman and Roberts (1990). The borehole lithologies provided by the Coleman and Roberts 
(1990) publication can nevertheless be correlated to seismic packages across the area. These boreholes thus provide lithologic understanding of the major seismic packages regardless of their questionable ages.

\section{Structure}

Shallow structure across the study area is dominated by the gentle, southward, homoclinal dip of the Gulf of Mexico shelf, punctuated by a few large, down-to-the-south growth faults that rise to the seafloor (Fig. B1). No obvious salt diapirs pierce the mud line in the immediate study area; however, diapirs do outcrop on the seafloor immediately west of the study area (Wellner and others, in press), and several deep diapirs were mapped around the area by Berryhill and others (1987). Deep diapirs beneath the study area uplift overlying strata, resulting in stratal onlap and thinning over the diapir crests. A significant, deep diapir, with its southeast edge located in the northwest corner of the study area, causes slight uplift of strata in that area. This topographic high was likely present during Wisconsinan time and confined the north edge of a large, lateWisconsinan, Stage 2, lowstand incision across the study area (Fig. B3). Similar influence of diapirs on fluvial and distributary-channel development was documented by Wellner and others (in press).

The single largest normal fault across the study area trends west to east across the middle of the project area and appears to parallel the north edge of the large west- to easttrending incised channel (Fig. B1). It is possible that the fault, which penetrates down several $100 \mathrm{~ms}$ into the $\mathrm{P}$ and $\mathrm{C}$ seismic images, also exerted a control on the orientation of this incised feature. Borehole data from within the study area show three to four orders of magnitude variation in shear strength of sediments between the seafloor and about 
$400 \mathrm{ft}$ below the mud line. Muds are firm, gray clay containing some silt stringers. Sands are fine grained, gray, and unconsolidated. Sands are generally confined to incised distributary channels. 


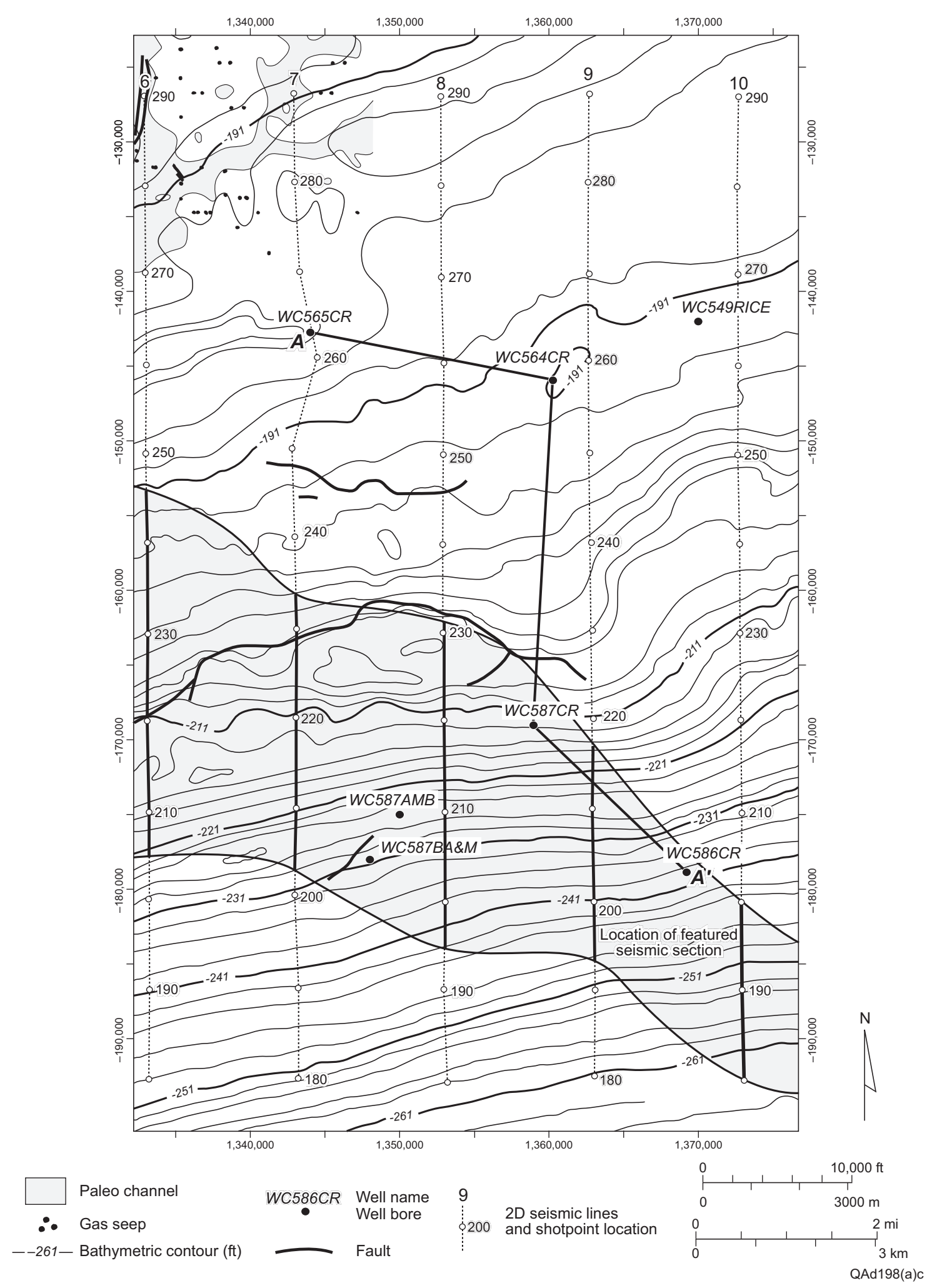

Figure B1. Map of the study area showing seafloor bathymetry, large shallow faults, and locations of incised features within the study area. Texaco high-resolution seismic lines 6 through 10 and borehole locations are also shown. 


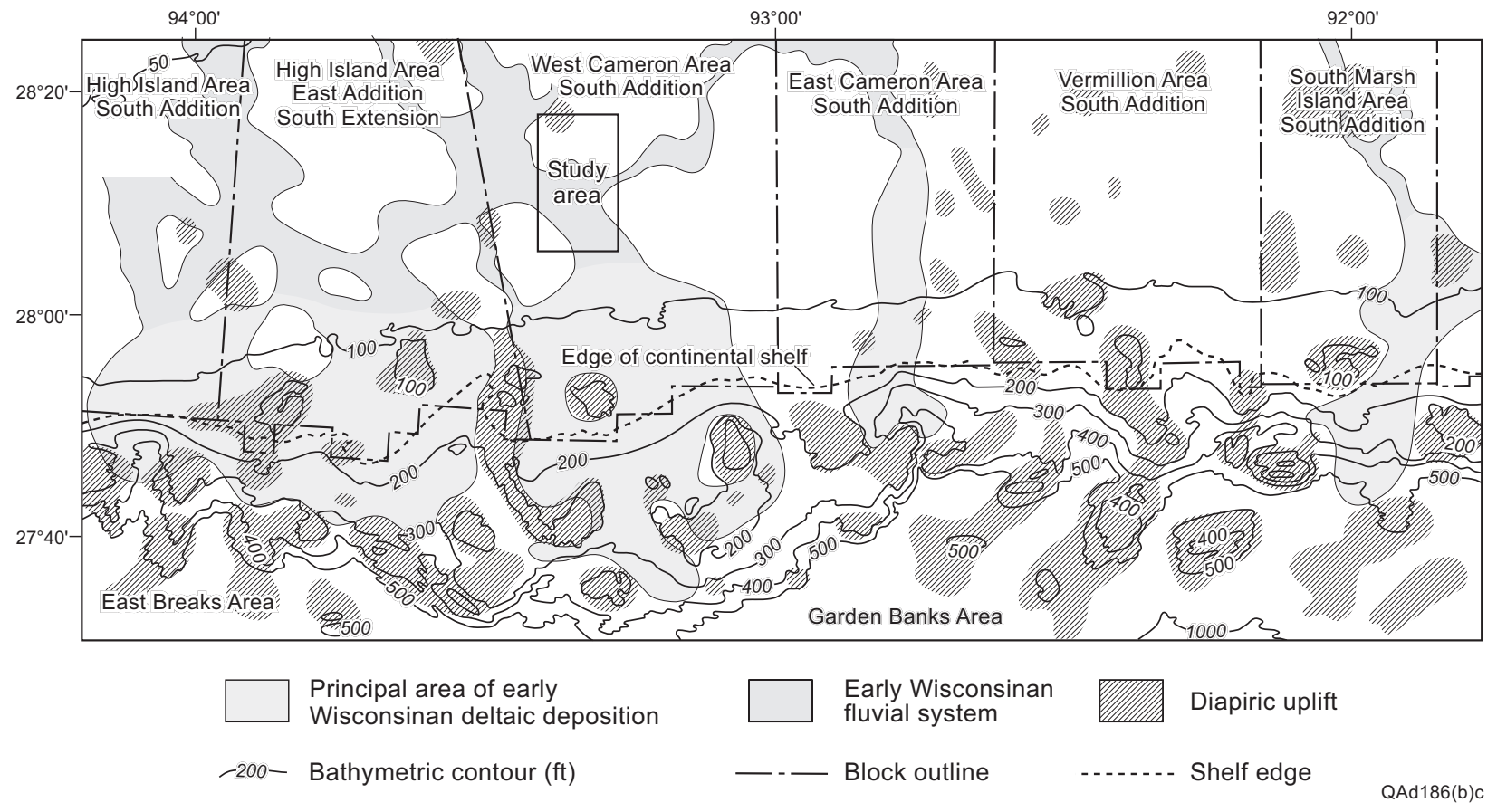

Figure B2. Map showing early-Wisconsinan deltaic depocenters and fluvial systems, as well as significant salt diapirs that affect shallow stratigraphy. Distinct delta systems are labeled A through E. Modified from Berryhill (1987). 


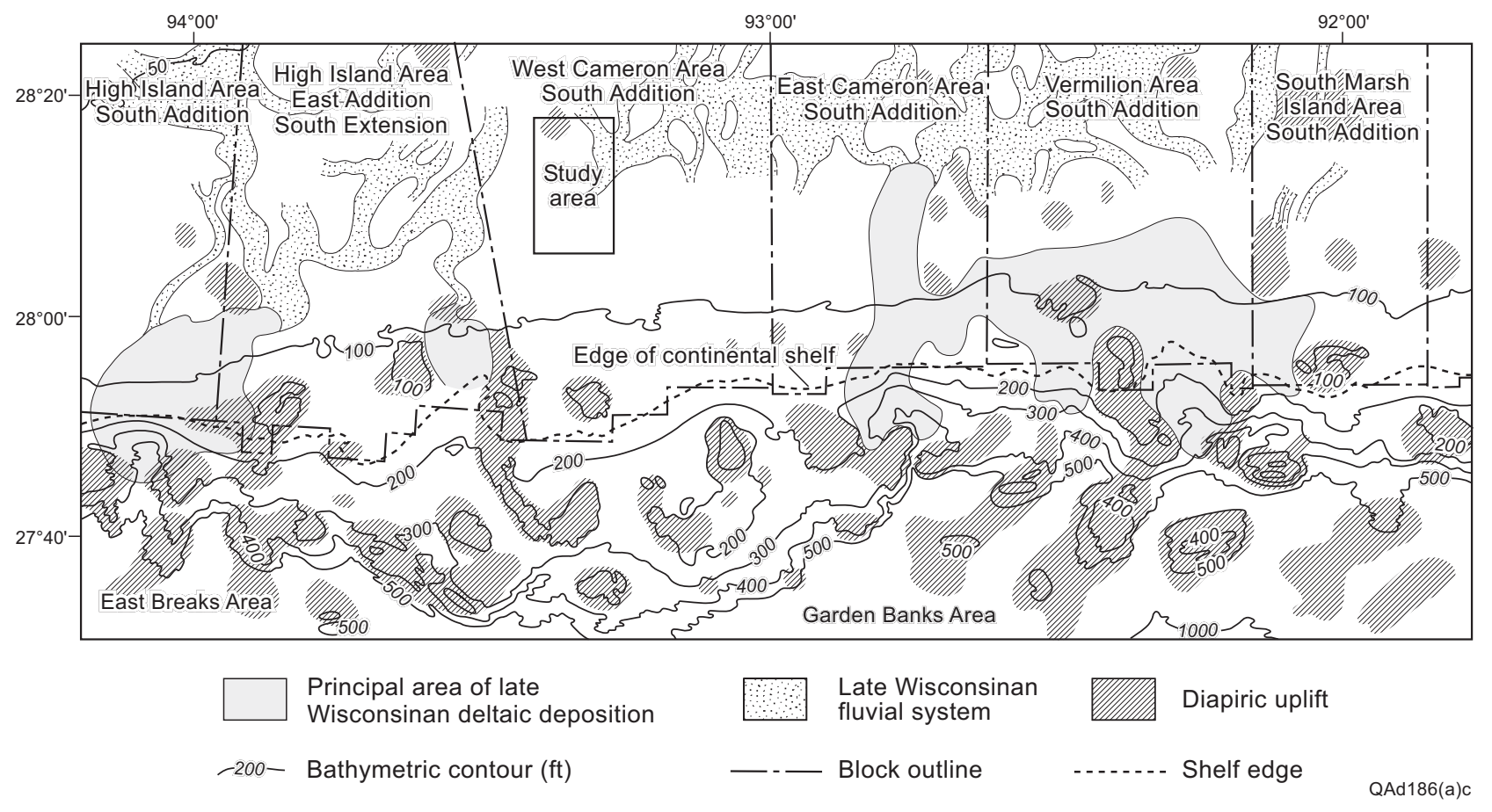

Figure B3. Map showing late-Wisconsinan deltaic depocenters and fluvial systems, as well as significant salt diapirs. By late-Wisconsinan time, the primary feeder system to the Mississippi paleo-delta was located well to the east of the study area. Modified from Berryhill (1987). 

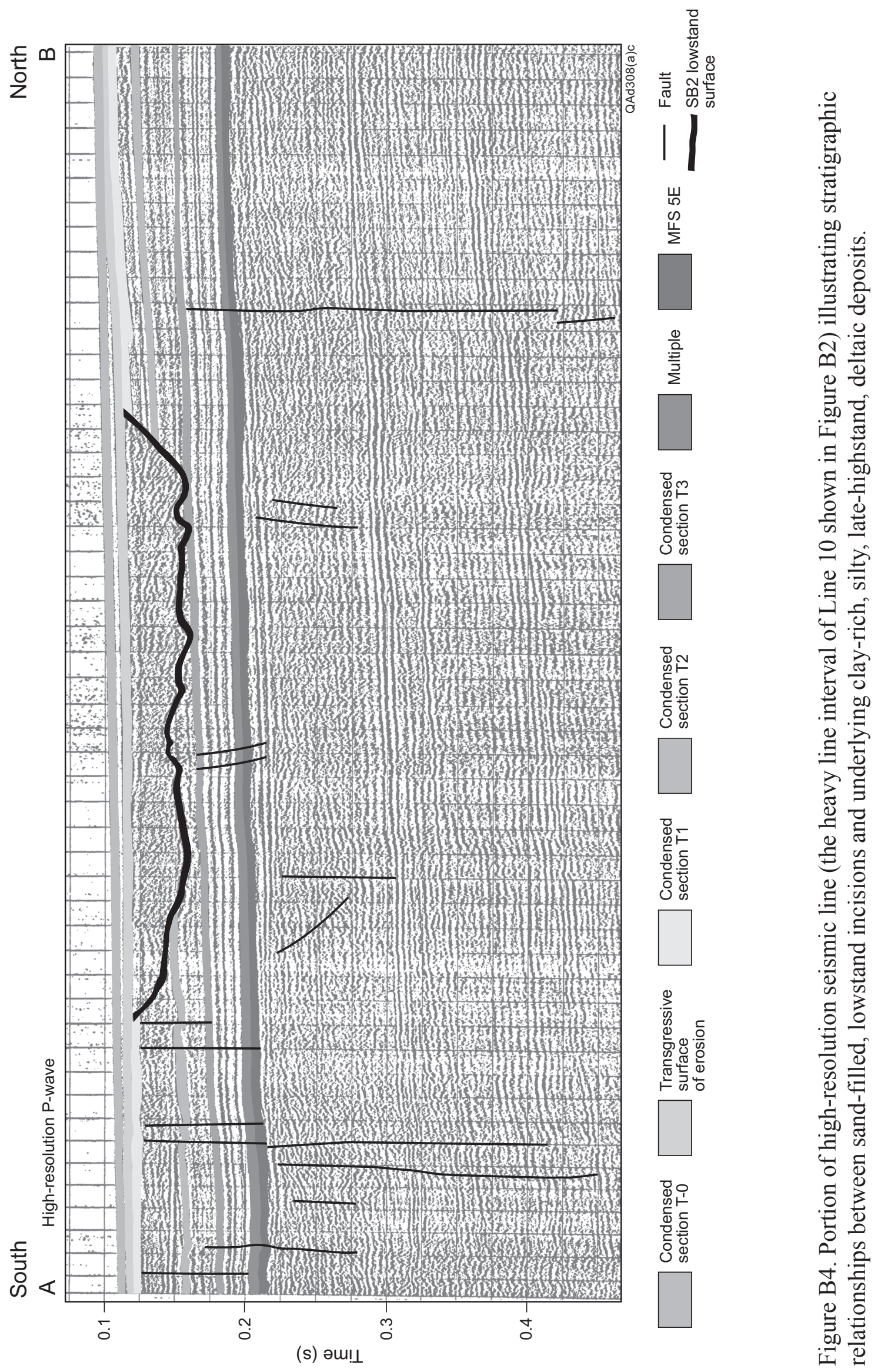


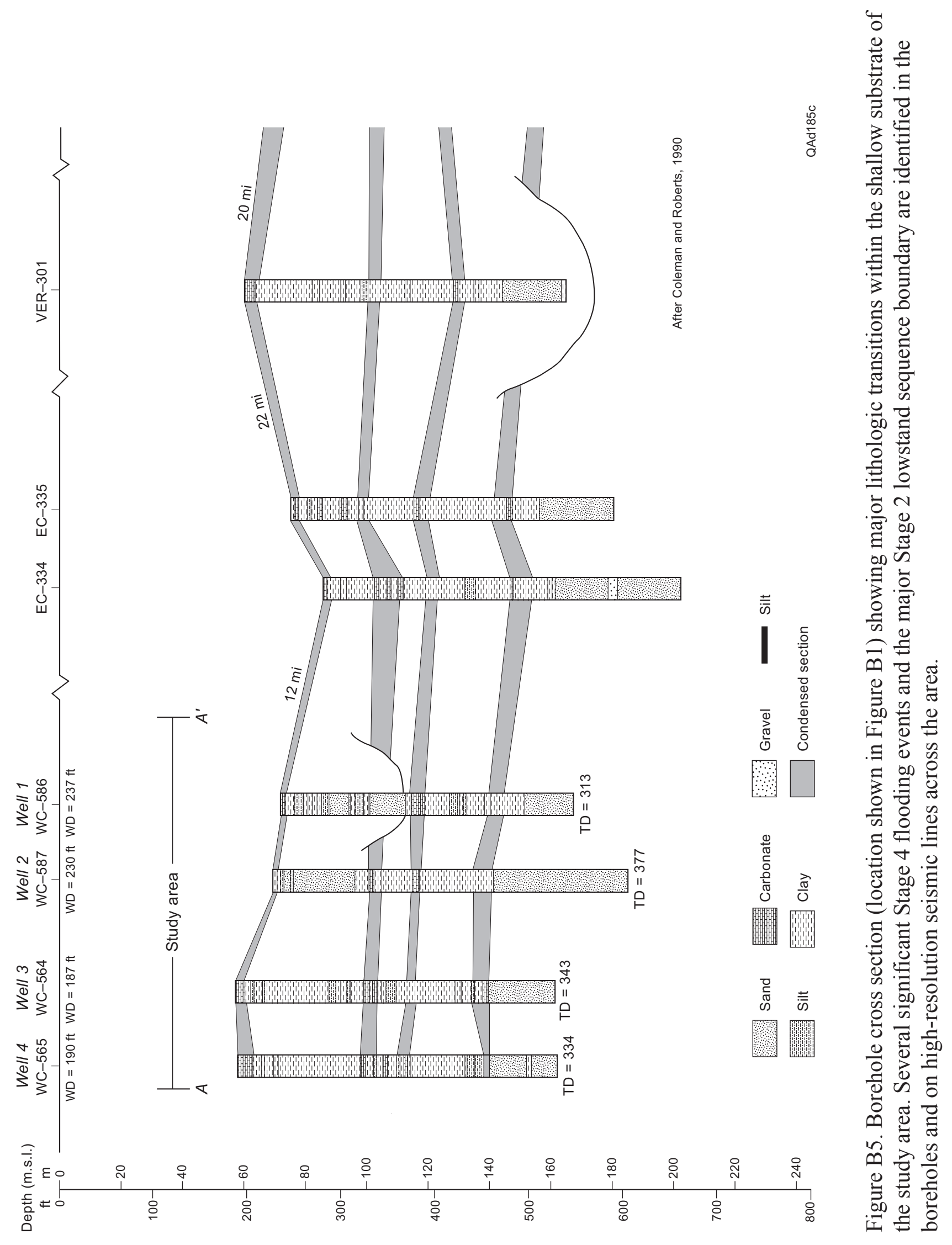




\section{APPENDIX C: MULTICOMPONENT SEISMIC DATA ACQUISITION}

Multicomponent seismic data are acquired in marine environments using

standard, towed air-gun arrays as the energy source and special 4-component (4-C)

sensor packages deployed on the seafloor. The seismic sensors have to be on the seafloor

to record $\mathrm{S}$ waves because $\mathrm{S}$ waves do not propagate in fluids. Marine $\mathrm{S}$-wave data

cannot therefore be acquired by towed hydrophone arrays as is done when conventional

marine P-wave seismic data are recording.

The 4-C sensor that was used to record the seismic data used in this study is shown in Figure C1. This sensor package consists of a gimbaled 3-C geophone that is rotated by gravity always to position its moving-coil elements in the vertical, inline horizontal, and crossline horizontal directions regardless of the angle of repose of the sensor package on the seafloor. The fourth data sensor was the hydrophone labeled in the figure.

The particle-velocity wavefield recorded by the vertical geophone and the pressure wavefield recorded by the hydrophone can be combined to create P-wave data that have optimal attenuation of the water-column reverberations that plague P-wave data acquired by towed hydrophone arrays. The particle-velocity data recorded by the inline and crossline horizontal geophones are used to create the upgoing, reflected SV wavefield arriving at the seafloor.

The source-receiver technology utilized in marine multicomponent seismic data acquisition is illustrated in Figure C2. The energy source is a towed air-gun array, identical to the source used in conventional marine seismic programs. Each seafloor receiver station has a single 4-C sensor package like the one shown in Figure $\mathrm{C} 1$. These 
seafloor sensors are stationary as data are recorded; they are not towed as are conventional hydrophone arrays. A second, anchored boat is connected to the seafloor cable to record the 4-C seismic data as a source boat traverses a grid of source lines.

At nonnormal angles of incidence, the downgoing $\mathrm{P}$ wavefield creates both reflected $\mathrm{P}$ and reflected SV wavefields. The reflected $\mathrm{P}$ wavefield, recorded by the seafloor hydrophone and vertical geophone, can create significant responses on horizontal geophones at large offset distances. The P-wave responses on the horizontal geophones are ignored during data processing, and a $\mathrm{P}$-wave image is built from a weighted combination of hydrophone and vertical-geophone data. Most of the reflected SV wavefield is recorded by the inline and crossline horizontal geophones. That portion of the SV data recorded on the vertical geophone is ignored in data processing. No SH shear data are acquired in 4-C marine seismic data.

\section{Seismic Acquisition Templates}

Two basic data-acquisition templates are used across the seismic industry to record marine multicomponent seismic data. Option 1, shown in Figure C3, is swath shooting. Option 2 (Fig. C4) is orthogonal recording. In both techniques, it is common at this early stage of 4-C OBC technology to have only two or three receiver cables on the seafloor. In option 1 (swath shooting), the shooting boat follows source lines that parallel the $\mathrm{OBC}$ receiver stations. This geometry provides a complete range of source-receiver offsets in only that narrow azimuth corridor that aligns with the long axis (inline direction) of the template. In option 2 (orthogonal shooting), the shooting boat follows source lines that are orthogonal to the seafloor cables. This geometry allows trace offset analyses to be done in all azimuth directions if the length of the source lines is about the 
same as, or greater than, the depth to the target of interest. This type of azimuth-based analysis can be important when anisotropic targets such as fractured reservoirs are interpreted.

A swath geometry was used to record the multicomponent seismic data used in this study. The specific source-receiver geometry is depicted in Figure C5. Two OBC receiver lines (labeled A and B) were deployed at a 400-m spacing. Each OBC line consisted of a series of 150-m segments (Fig. C6) that were connected to make the desired receiver line length of $20 \mathrm{~km}$. Each of these cable segments provided three 4-C sensor stations (labeled 1, 2, 3 in Fig. C6.) The 4-C sensor stations were spaced at intervals of $50 \mathrm{~m}$ along each line. The basic acquisition template consisted of 10 source lines (labeled 1 through 10 in Fig. C5) centered on these two OBC receiver lines. These source lines were spaced $100 \mathrm{~m}$ apart, and the source-station spacing was $75 \mathrm{~m}$ on each source line. Each source line extended $6 \mathrm{~km}$ beyond the ends of the receiver lines. A third parallel OBC receiver line was deployed at a 400-m spacing from line B as data were being recorded by the two-line template created by receiver lines A and B. When data from all of the shotpoints shown in Figure C5 were recorded, the acquisition template was then rolled to include this new OBC line, which will be called line $\mathrm{C}$. The receiver portion of the next data-acquisition template then consisted of line $\mathrm{B}$ and the new $\mathrm{OBC}$ line C. Source lines 5 through 10 were reshot to create the same source-receiver geometry for $\mathrm{OBC}$ lines $\mathrm{B}$ and $\mathrm{C}$ that was used to record data with lines A and B (Fig. C5). As data were recorded by lines B and C, receiver line A was retrieved and deployed at a 400-m parallel offset from line $\mathrm{C}$ to create the next data-acquisition template. 


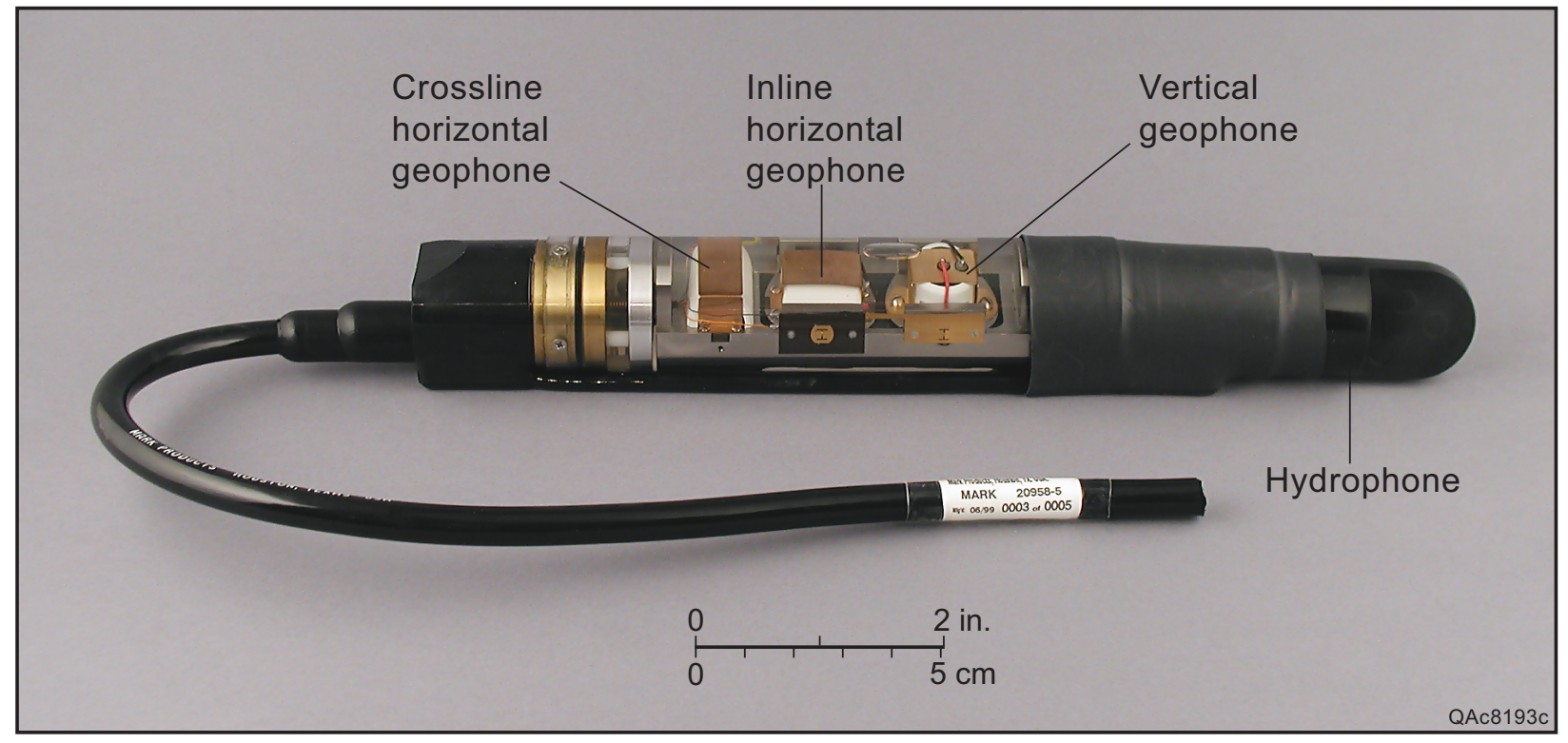

Figure C1. Four-component ocean-bottom-sensor (4-C OBS) package. 


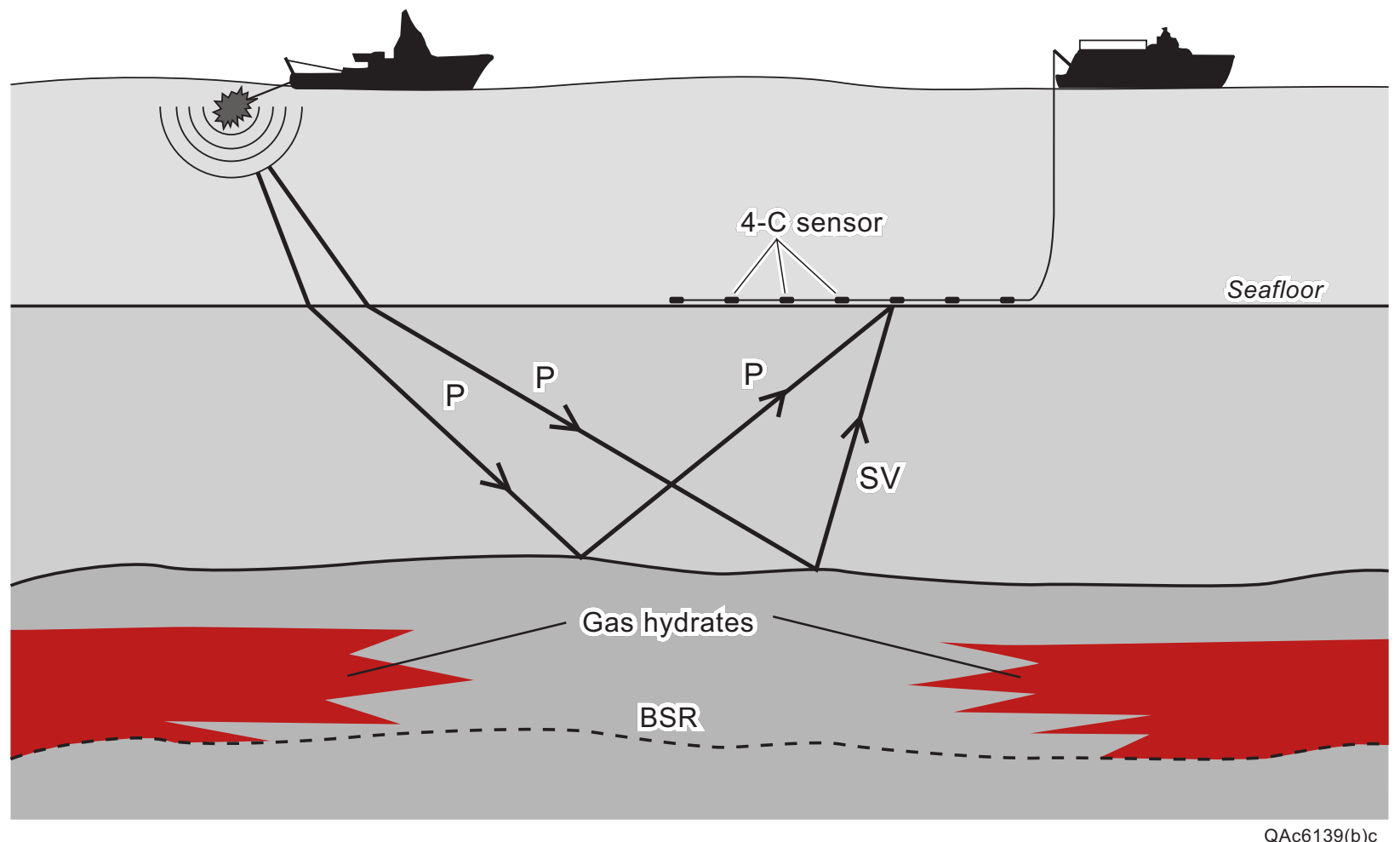

Figure C2. Seismic data-acquisition concept. P denotes a compressional raypath, SV indicates a converted-SV raypath, and BSR is a bottom simulating reflector. 


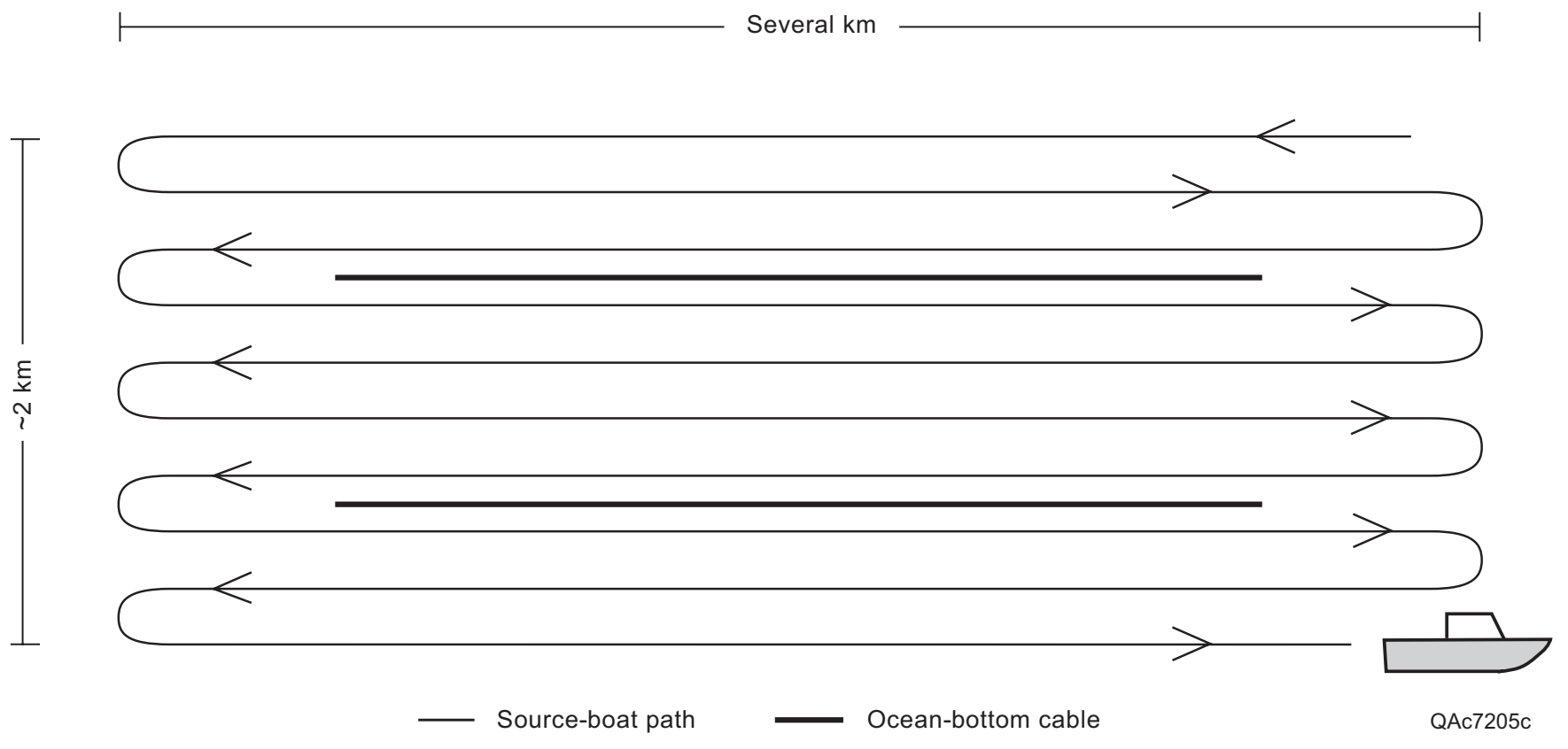

Figure C3. Swath geometry used to record 4C3D OBC seismic data. 


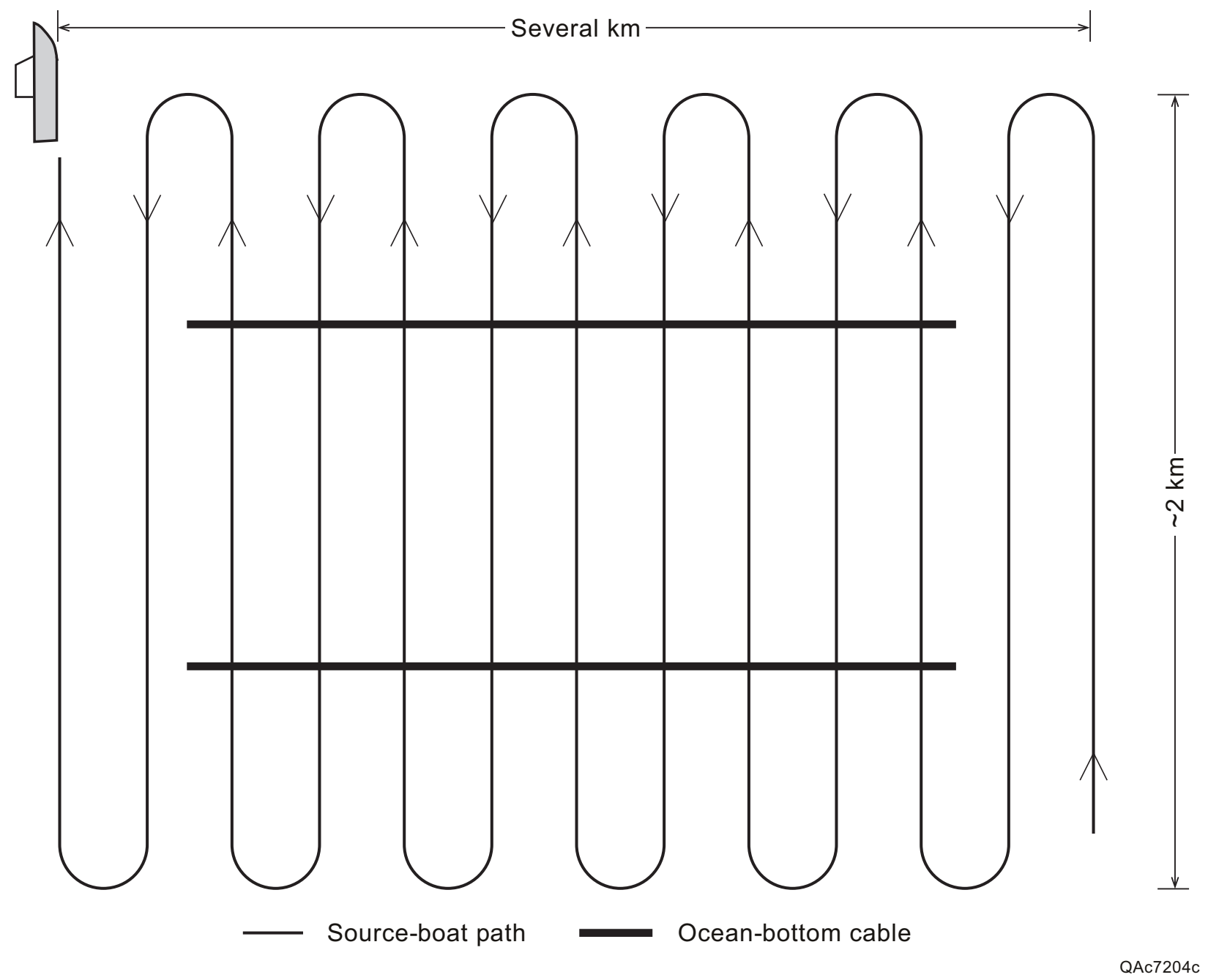

Figure C4. Orthogonal geometry used to record 4C3D OBC seismic data. 


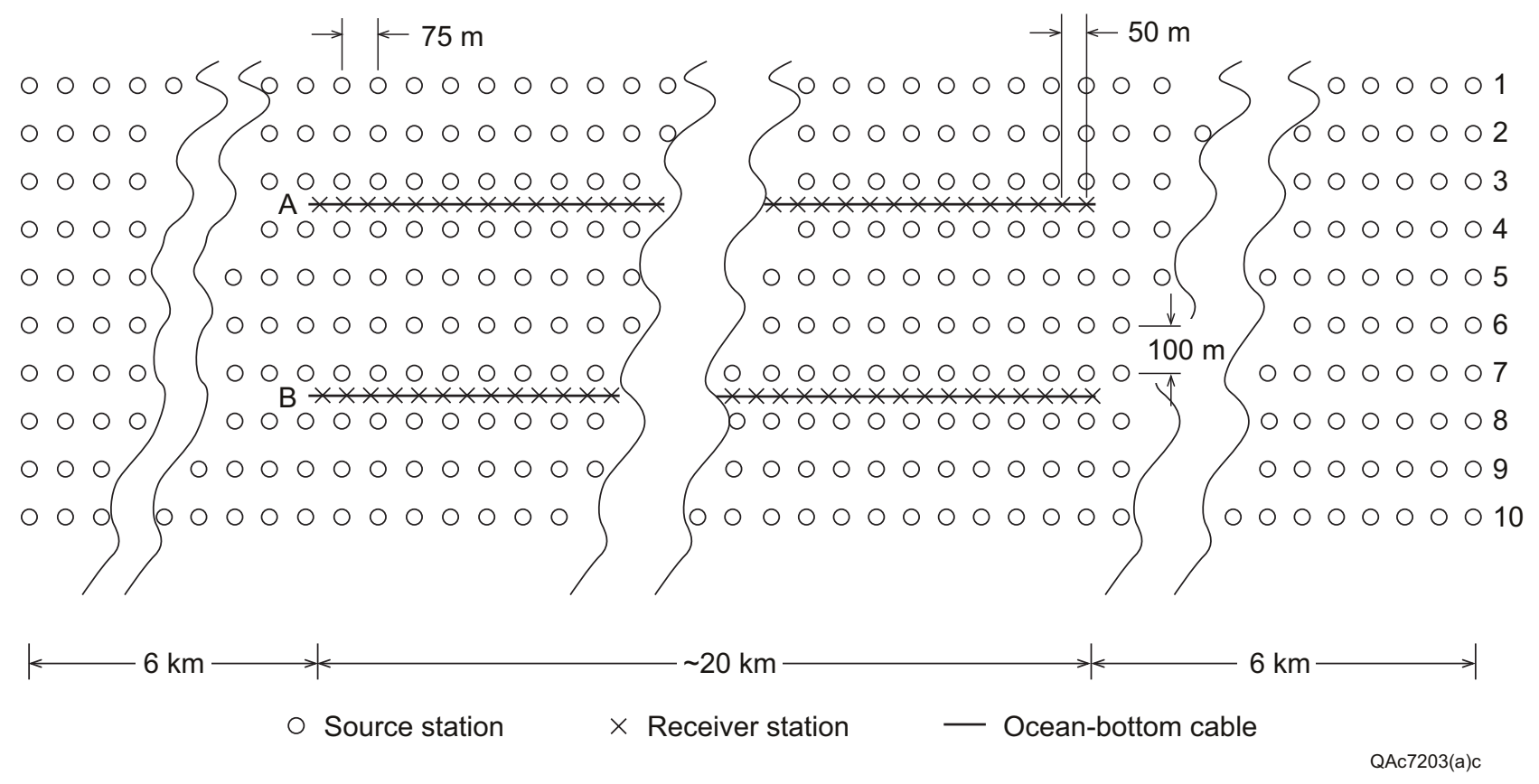

Figure C5. Swath geometry used to record the 4C3D OBC seismic data used in this research. 


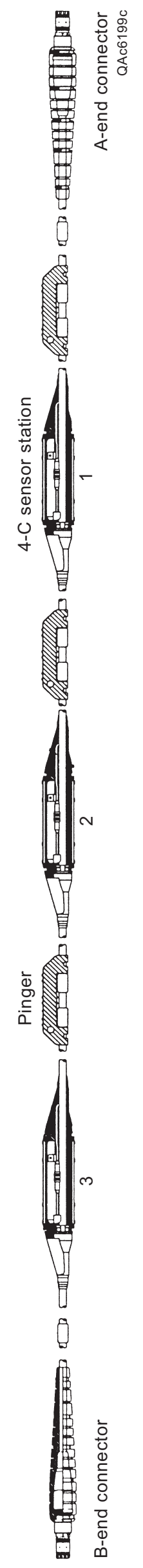

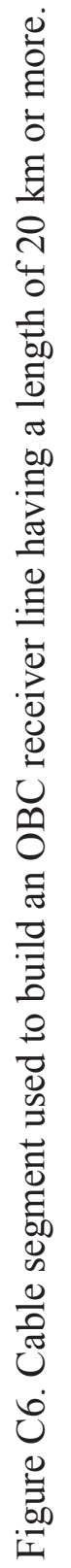




\section{APPENDIX D: NUMERICAL MODELING OF SEAFLOOR SEISMIC SENSOR RESPONSES}

The basic appearance of seismic data differs according to whether they are recorded by seafloor hydrophones or seafloor geophones. Typical data differences are exhibited by the 4-C OBC field record in Figure D1. The horizontal geophones at a 4-C receiver station are affected more by reflected SV modes than by P modes; the vertical geophones and the hydrophone are affected more by reflected $\mathrm{P}$ than by $\mathrm{C}$ waves. To illustrate the differences in $\mathrm{OBC}$ hydrophone and geophone responses, hydrophone data will therefore be compared with only verticalgeophone data, not with horizontal-geophone data, so that data differences expressed by hydrophones and geophones concentrate on only the P-wave mode.

Examination of Figure D1 shows that the response of an OBC hydrophone contains a large number of robust-amplitude events down to an arrival time of $2 \mathrm{~s}$. In contrast, vertical OBC geophones (shown next to the hydrophone data) appear to record fewer events and to produce a lower amplitude wavefield. Numerical modeling demonstrates why these two basic seismic sensors (a hydrophone and a vertical geophone) produce $\mathrm{P}$-wave records that have such fundamental differences.

The Earth model used in the numerical analysis is shown in Figure D2. The top two panels show the raypaths associated with an upgoing reflection event that arrives at the seafloor and then reverberates in the water column. The one-way traveltime across the water column is $\Delta \mathrm{t}$. The algebraic signs of the reflection coefficients for a pressure wavefield at the top and bottom of the water column are shown at the left; algebraic signs of the reflection coefficients associated with a particle-velocity wavefield are shown on the right. The reflection coefficients 
for these two wavefields (pressure and particle velocity) have opposite algebraic signs at each interface.

A wavefield recorded at the seafloor consists of two parts: an upgoing wavefield and a downgoing wavefield. The responses of a seafloor hydrophone and a vertical seafloor geophone were analyzed by our considering each of these component parts: first the upgoing wavefield observed at the seafloor and then the downgoing wavefield.

The sequence of upgoing events observed at the seafloor is labeled $\mathrm{A}, \mathrm{B}, \mathrm{C}, \ldots$ in the raypath diagrams of Figure D2. The reflectivity sequence at the bottom of the figure defines the upgoing wavefield that is created at the seafloor by either a pressure wavefield or a particlevelocity wavefield. The parameter $R$ in this reflectivity sequence is the magnitude of the reflection coefficient at the seafloor; the magnitude of the reflection coefficient at the air-water interface is assumed to be 1.0. The principle demonstrated by this reflectivity series is that the upgoing wavefield recorded at the seafloor by a hydrophone (pressure wavefield) is identical to the upgoing wavefield recorded by a vertical geophone (particle-velocity wavefield).

Any distinctions in seafloor hydrophone and seafloor geophone data therefore have to be caused by differences in the downgoing wavefields that these sensors record. The modeling is expanded to consider these downgoing wavefields in Figures D3 and D4. The sequence of upgoing events in both figures is the reflectivity series determined for upgoing pressure and particle-velocity wavefields in Figure D2. The downgoing wavefield seen by a vertical OBC geophone (Fig. D3) is this upgoing particle-velocity wavefield delayed by $2 \Delta t$ (the two-way time across the water column), and the polarities of the downgoing events are the same as the polarities of the upgoing events because the reflection coefficient at the top of the water column for an upgoing particle-velocity wavefield is positive (Fig. D2). However, the downgoing 
wavefield seen by an OBC hydrophone is different (Fig. D4). A hydrophone sees a downgoing wavefield that is also a time-delayed version of the upgoing pressure wavefield (a time delay of $2 \Delta \mathrm{t}$ ), but the polarity is opposite that seen by a geophone because the reflection coefficient for an upgoing pressure wavefield is negative at the top of the water column (Fig. D2).

The total wavefield measured by an OBC hydrophone and by a vertical OBC geophone is the sum of the upgoing and downgoing wavefields that each sensor "sees" when on the seafloor. These sums are shown as the bottom displays in Figures D3 and D4. The resultant wavefields differ because the downgoing pressure wavefield enforces water-column reverberations, whereas the downgoing particle-velocity wavefield attenuates water-column reverberations.

Several numerical calculations are included in this section to demonstrate how this wave physics causes major differences in the P-wave responses measured by seafloor hydrophones and geophones. The first series of models assumes that the upgoing reflection (event A in Fig. D2) is a simple, compact event. This simple wavelet is labeled source and shown as the top trace in Figures D5, D6, and D7. In these three models, the seafloor reflectivity R increases from 0.2 to 0.4 to 0.7 , showing the effect of a wide range of reverberation amplitudes.

The downgoing wavefield $\mathrm{D}$ in each figure is the downgoing wavefield seen by a vertical OBC geophone (not a hydrophone!). The total geophone response is the sum $U+D$, where $U$ is the upgoing wavefield, but the total hydrophone response is the difference, $\mathrm{U}-\mathrm{D}$. The ghost event and all reverberations are amplified by a factor of $1+\mathrm{R}$ in the hydrophone response but are attenuated by a factor of $1-\mathrm{R}$ in the vertical-geophone response. These ghost and reverberation events are contaminations that make it more difficult to recognize and extract reflection signals. Even though data recorded with a seafloor vertical geophone may look inferior to hydrophone data (Fig. D3), geophone data have less noise contamination. 
A second series of models are included in Figures D8, D9, and D10 to illustrate the effect of a more realistic version of the upgoing reflection wavelet. A towed air-gun array cannot produce the simple source wavelet used in Figures D5, D6, and D7. Instead the source wavelet will contain water-column reverberations because it is positioned near the top of the water column as it is towed. For simplicity, the seafloor reflectivity and the traveltime across the water column at the source station will be assumed to be the same as they are at the $\mathrm{OBC}$ receiver station. The upgoing reflection A at the seafloor (defined in Fig. D2) will then be the reverberating event labeled source in Figures D8, D9, and D10. The seafloor reflectivity R is varied from 0.3 to 0.5 to 0.7 in this sequence of figures. The ghost event and reverberations in the hydrophone response are now amplified by a factor of $1+2 R$, but they are attenuated by a factor of $1-2 R$ in the vertical-geophone response. These factors are twice the magnitudes of those associated with a nonreverberating source wavelet (Figs. D5, D6, and D7). A value $\mathrm{R}=0.3$ (Fig. D8) is typical across much of the seafloor of the Gulf of Mexico. The principle established by this modeling is that ghosts and reverberations are significantly attenuated in an OBC vertical-geophone response for the type of seafloor across our study area, but that these noise events will compose most OBC hydrophone data (Fig. D1). 


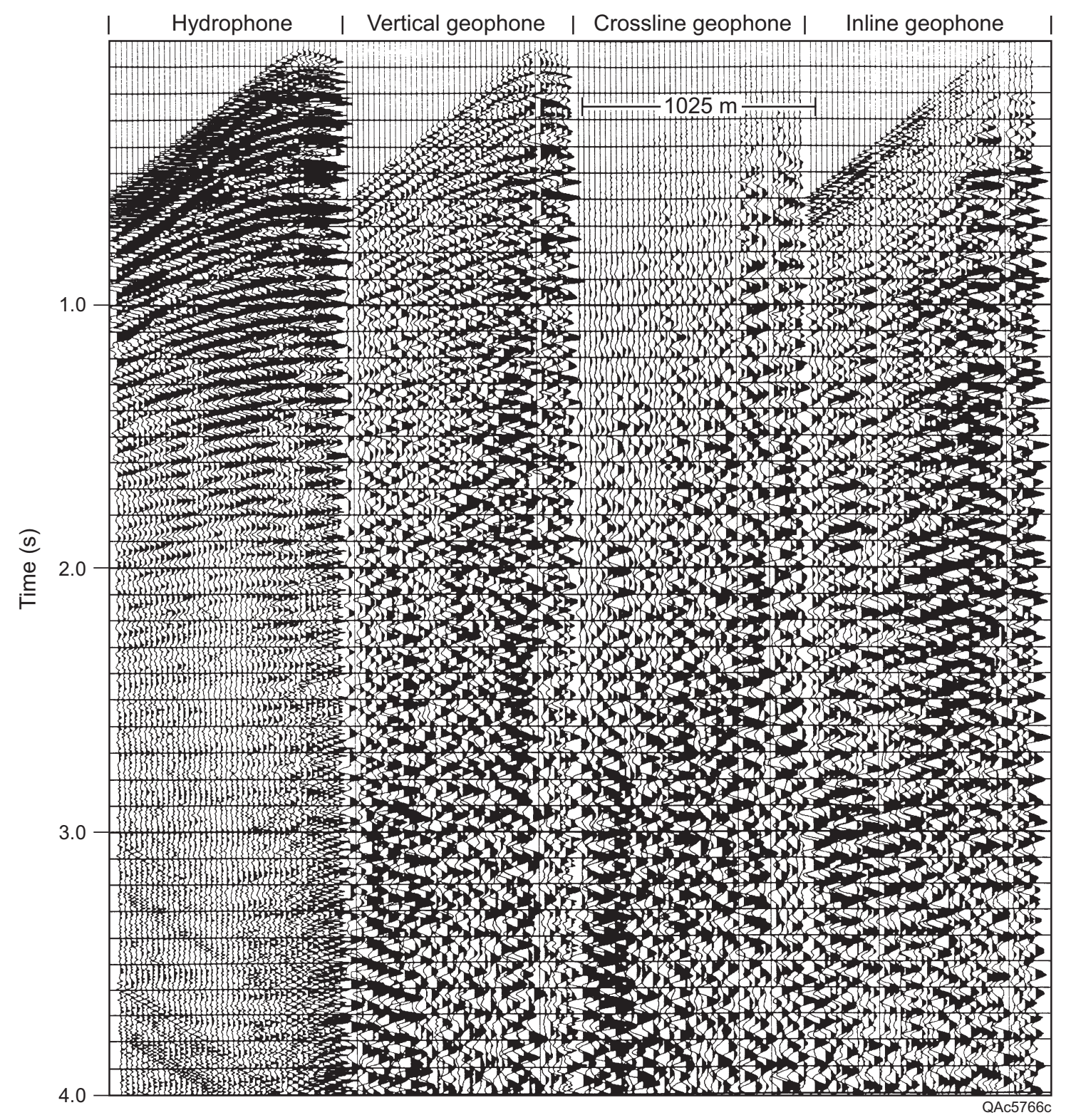

Figure D1. 4-C OBC field record. A time-dependent gain has been applied to increase the amplitudes at late arrival times. 


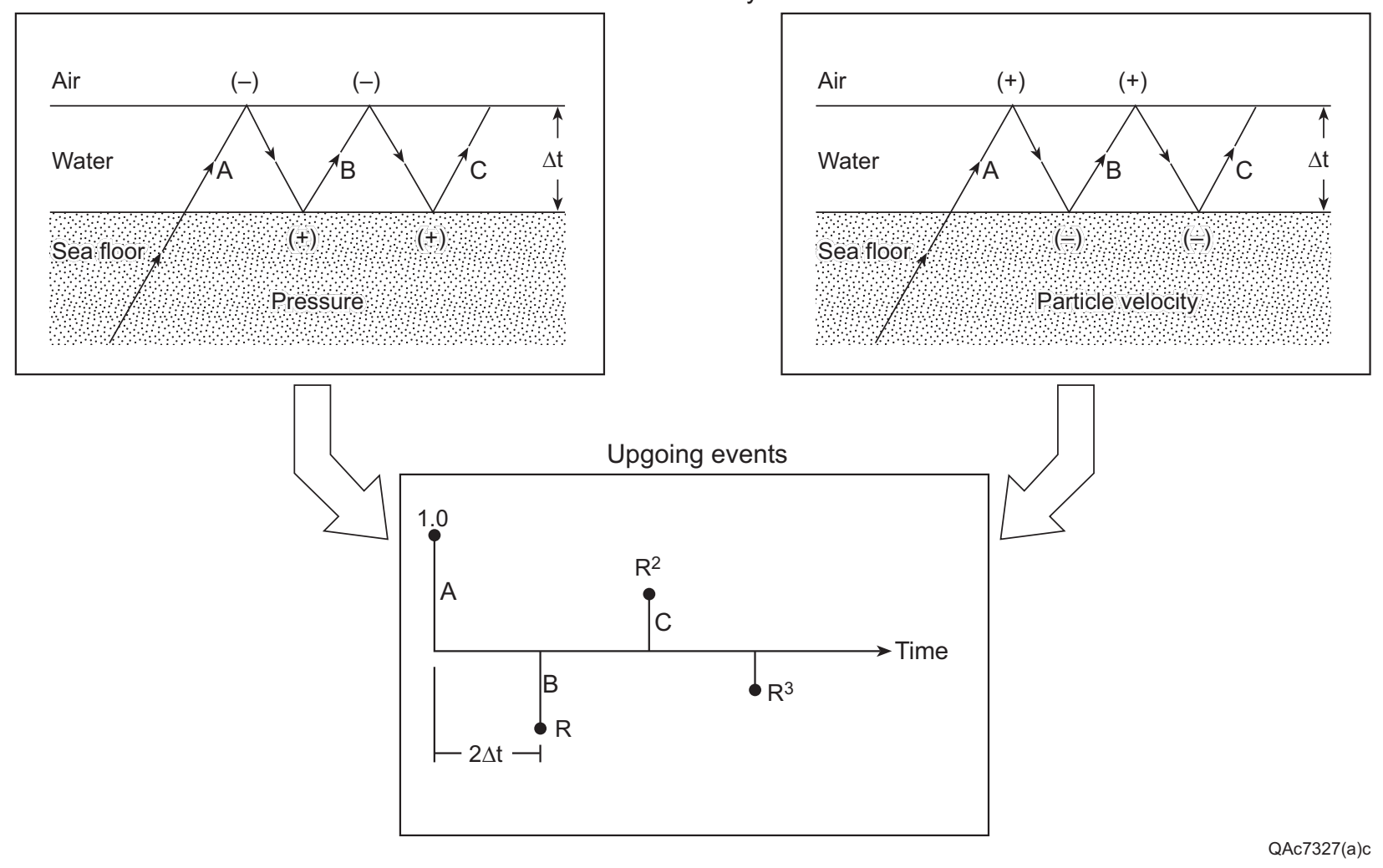

Figure D2. Earth model used to model the P-wave responses of the seafloor. R is the reflectivity coefficient at the seafloor. 


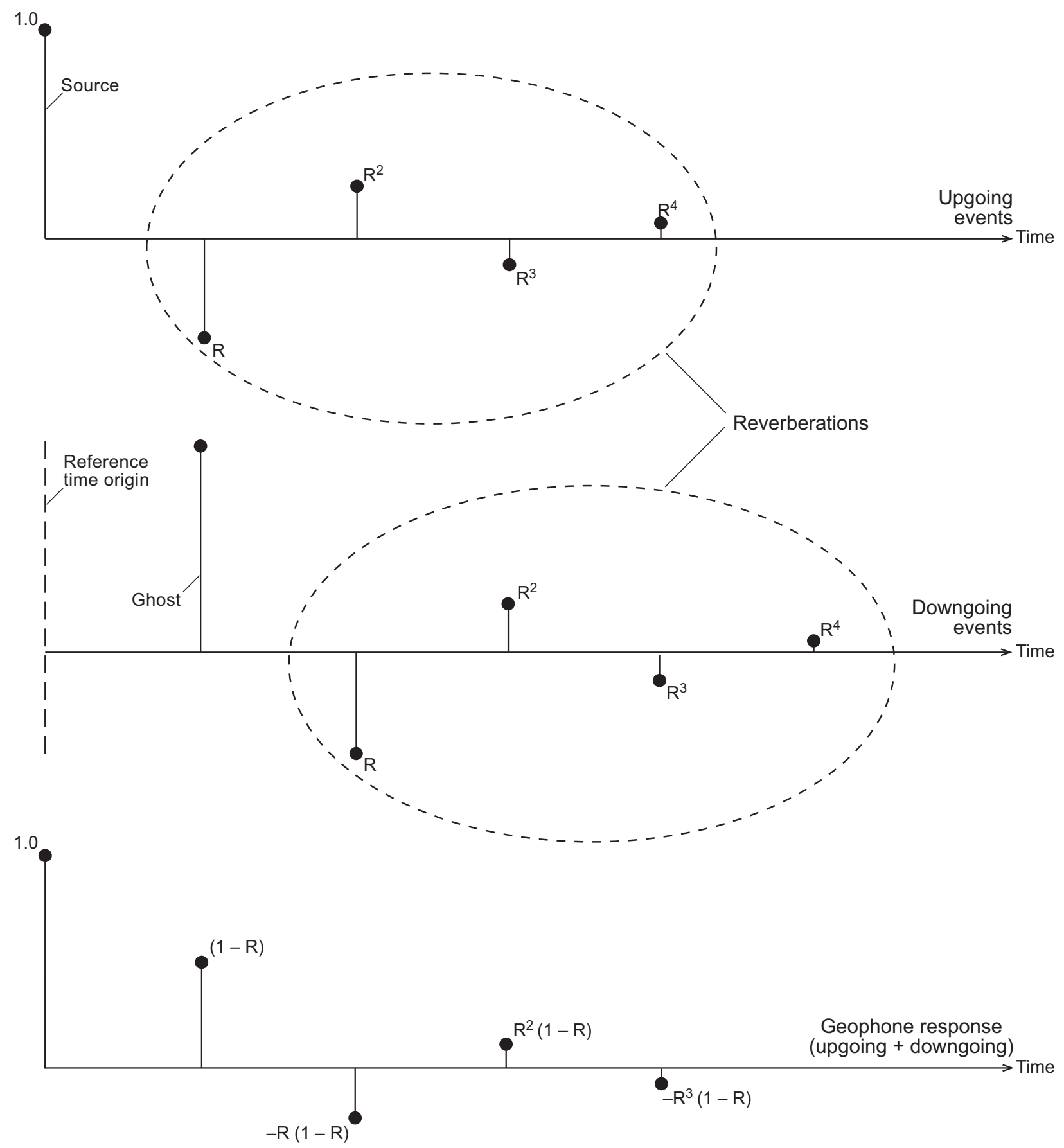

$\longmapsto 2 \Delta t \longrightarrow-$ QAd309c

Figure D3. Reflectivity series seen by a vertical geophone positioned on the seafloor. The upgoing events (top trace) are defined in Figure D2. The downgoing events (center) are a timedelayed copy of the upgoing events. The resultant response (bottom) is the sum of the upgoing and downgoing reflectivity series. 

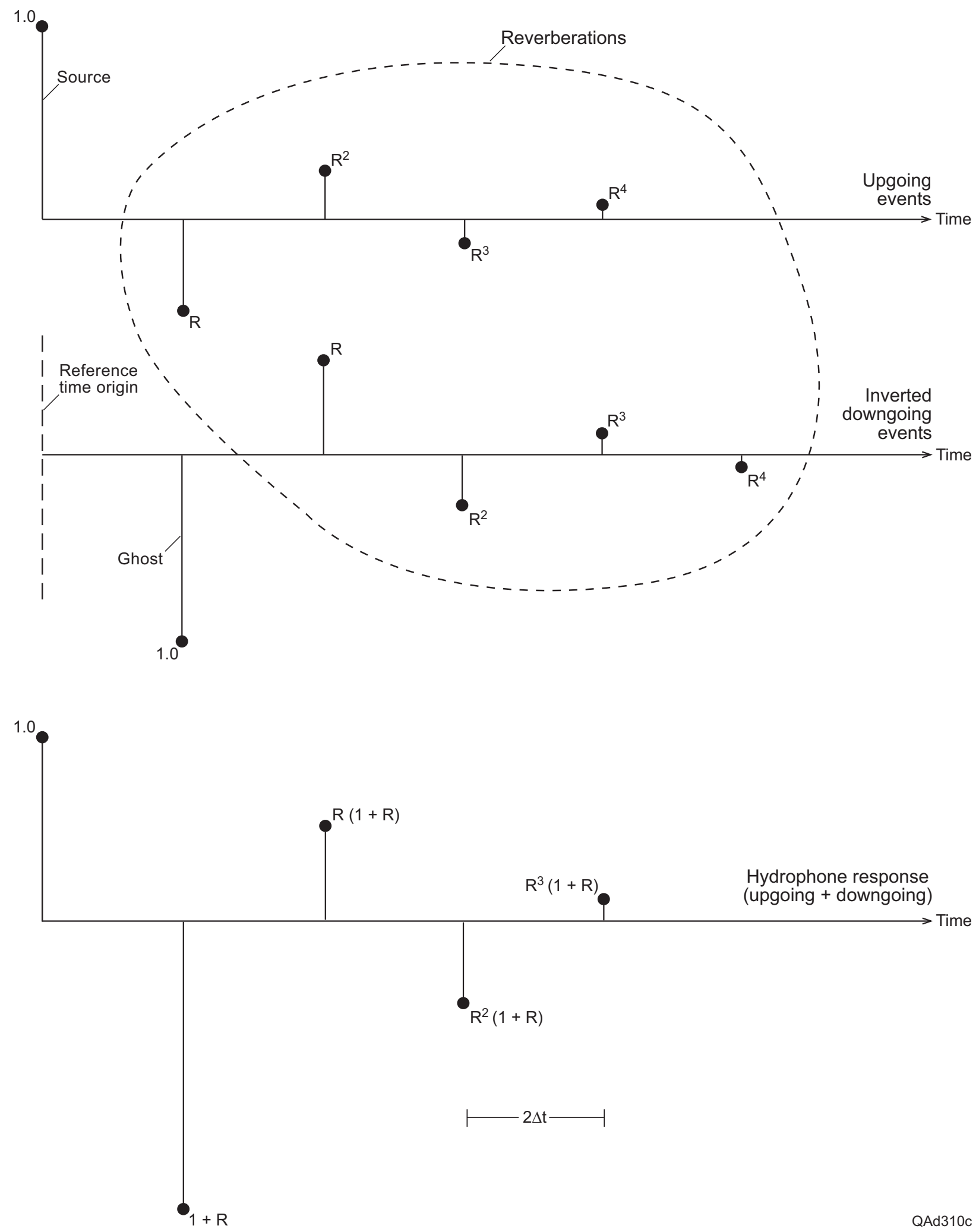

Figure D4. Reflectivity series seen by a seafloor hydrophone. The upgoing events (top trace) are defined in Figure D2. The downgoing events (center) are an inverted and time-delayed copy of the upgoing events. The resultant response (bottom) is the sum of the upgoing and downgoing reflectivity series. 

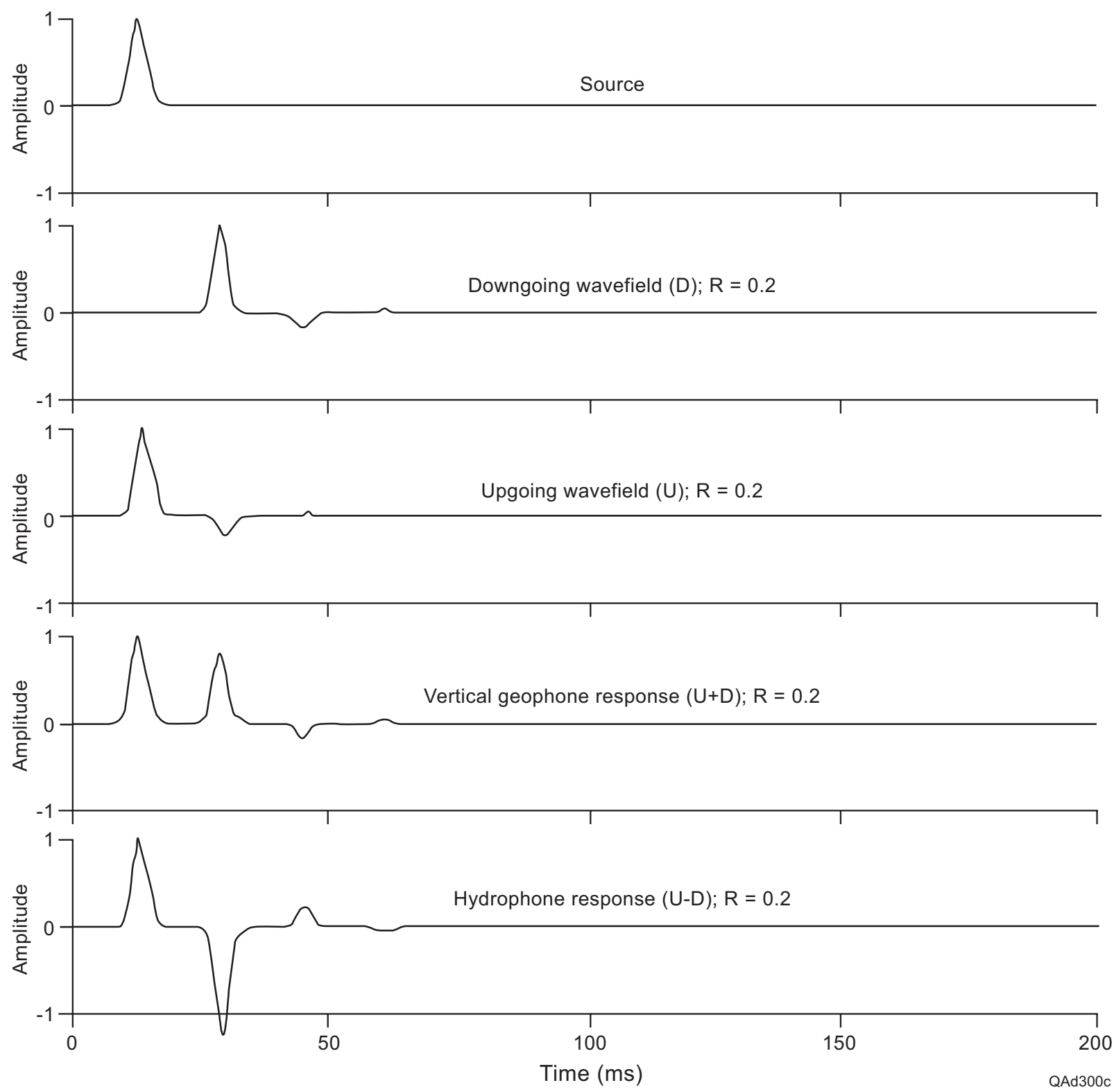

Figure D5. Calculated responses for seafloor hydrophones and vertical geophones when the seafloor reflectivity $\mathrm{R}$ is 0.2 . The source wavelet has no reverberations. 

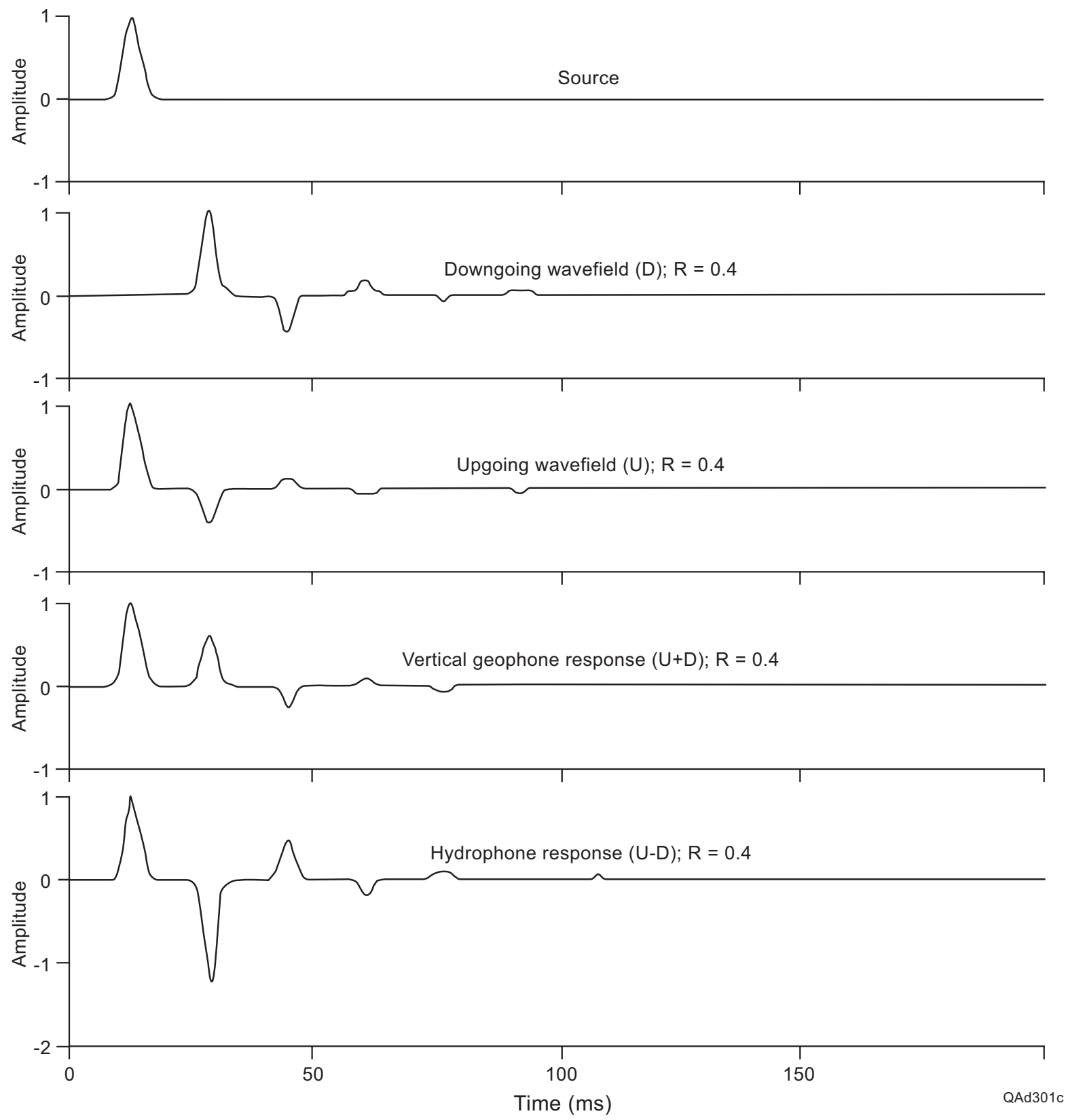

Figure D6. Calculated responses for seafloor hydrophones and vertical geophones when the seafloor reflectivity $\mathrm{R}$ is 0.4 . The source wavelet has no reverberations. 

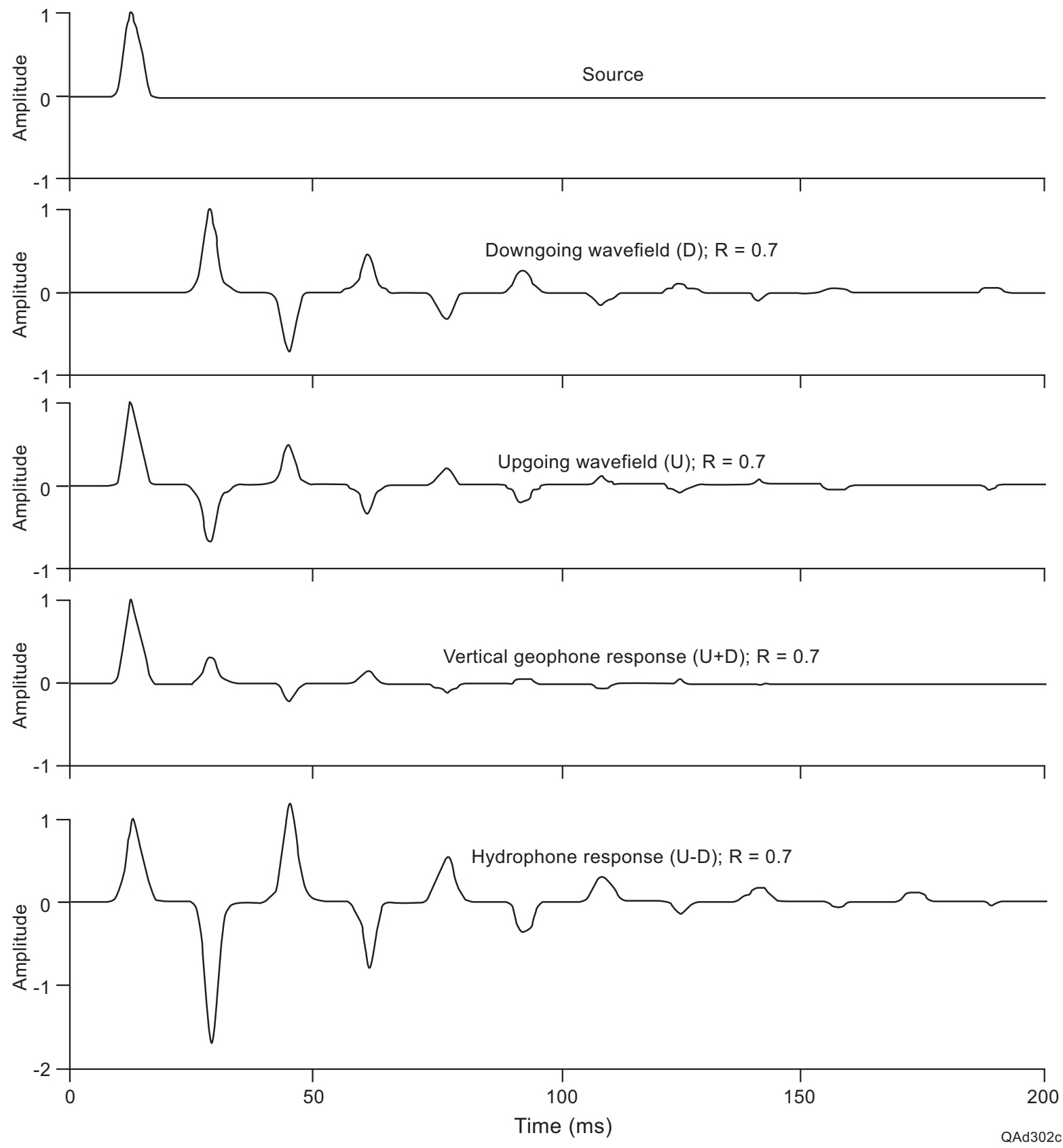

Figure D7. Calculated responses for seafloor hydrophones and vertical geophones when the seafloor reflectivity $\mathrm{R}$ is 0.7 . The source wavelet has no reverberations. 

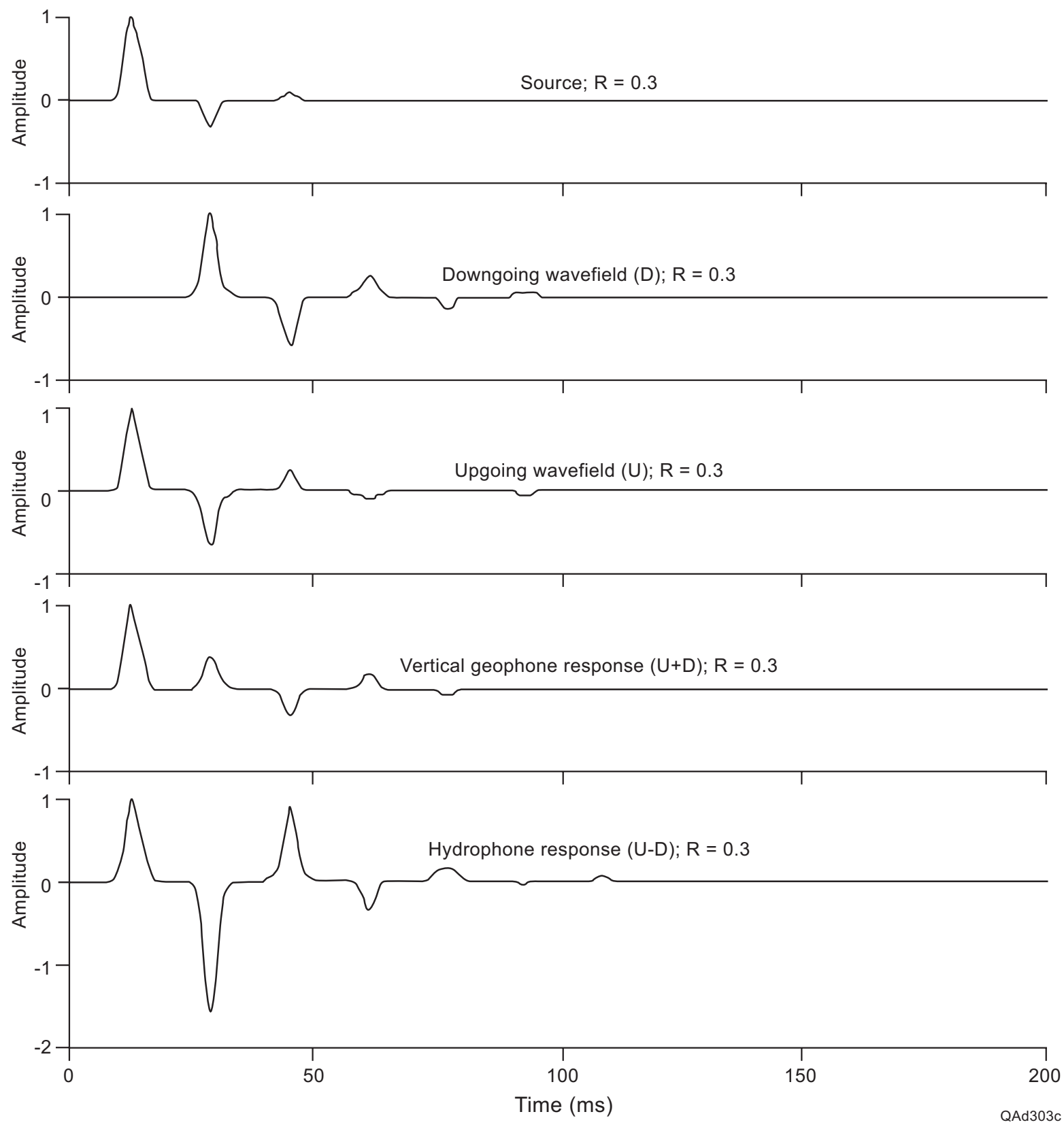

Figure D8. Calculated responses for seafloor hydrophones and vertical geophones when the seafloor reflectivity $\mathrm{R}$ is 0.3 . The source wavelet now has a reverberation period of $2 \Delta \mathrm{t}$ (Figs. D3 and D4) and a reverberation amplitude that is controlled by the seafloor reflectivity R. 

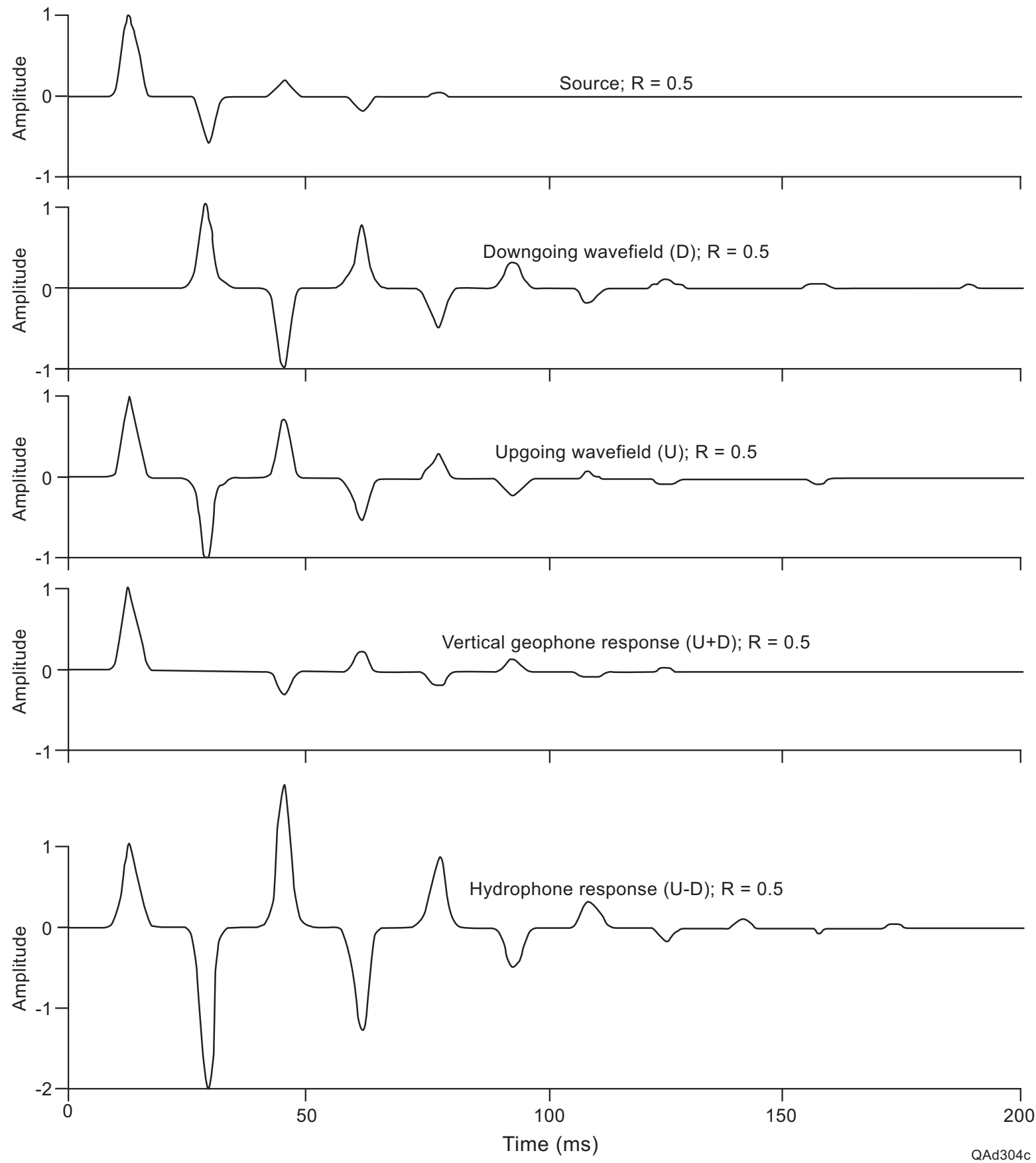

Figure D9. Calculated responses for seafloor hydrophones and vertical geophones when the seafloor reflectivity $\mathrm{R}$ is 0.5 . The source wavelet now has a reverberation period of $2 \Delta \mathrm{t}$ and a reverberation amplitude that is controlled by the seafloor reflectivity $\mathrm{R}$. 

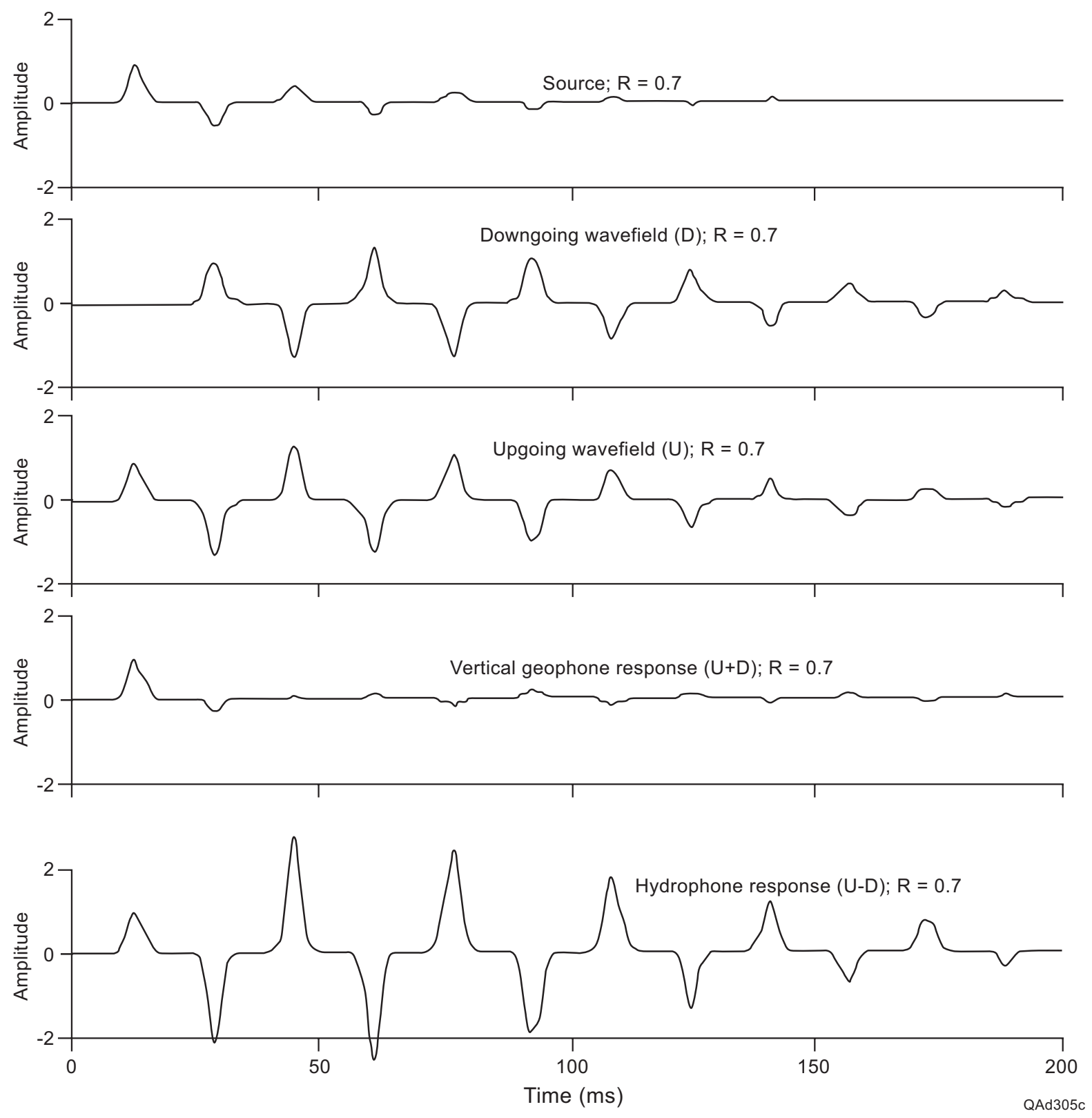

Figure D10. Calculated responses for seafloor hydrophones and vertical geophones when the seafloor reflectivity $\mathrm{R}$ is 0.7 . The source wavelet now has a reverberation period of $2 \Delta \mathrm{t}$ and a reverberation amplitude that is controlled by the seafloor reflectivity $\mathrm{R}$. 


\section{APPENDIX E: SEISMIC DATA PROCESSING ISSUES}

The P-wave and converted-SV wavefields acquired in marine OBC programs are processed by two distinct types of imaging software that differ in fundamental ways. Some of these differences in P and SV data processing, as well as their effects on shallow gas-hydrate studies, are described in the following sections.

\section{Common-Midpoint Imaging}

The P-wave part of OBC data is processed by common-midpoint (CMP) algorithms that have been used for decades in the seismic industry. The basic requirement for CMP imaging is that the velocity of the reflected, upgoing wavefield is the same as the velocity of the downgoing, illuminating wavefield. In P-wave imaging, downgoing and upgoing wavefields both travel at $\mathrm{P}$ velocity. Time-proven CMP software can thus be used to process OBC data to create $\mathrm{P}$-wave images. The raypaths involved in CMP imaging are shown in Figure E1. Note that CMP reflection points from different stratal depths stack vertically above each other at CMP coordinate $\mathrm{X}_{\mathrm{m}}$ in a flat-layered Earth. The reflection point trend labeled CCP is discussed in the next section.

\section{Common-Conversion-Point Imaging}

The reflected SV wavefield contained in 4-C OBC data is a series of upgoing SV reflection events that are created by P-to-SV mode conversions when a downgoing $\mathrm{P}$ wave arrives at reflecting stratal surfaces at nonnormal angles of incidence. In 4-C SV imaging, the downgoing wavefield is thus a P wavefield, and the upgoing wavefield is an SV wavefield. Because the downgoing wavefield has a faster velocity ( $\mathrm{P}$ wave) than does the upgoing wavefield (SV), the reflecting point does not occur at midpoint coordinate $\mathrm{X}_{\mathrm{m}}$ but at a coordinate 
that is closer to the receiver station than to the source station. This reflection coordinate is called the common conversion point $(\mathrm{CCP})$. The raypaths involved in $\mathrm{CCP}$ imaging are depicted in Figure E2. Note that CCP image points from different stratal depths do not stack vertically above each other as do CMP points but move closer to the receiver station as the depth to the reflecting point decreases.

\section{Contrast between CMP and CCP Velocity Analyses}

The stacking and migration velocities needed for CMP and CCP imaging have to be determined by different analytic procedures. These differences can be explained by considering the simple Earth model in Figure E3. In this model, there is a change in rock facies along the imaging raypaths. The $\mathrm{P}$ and $\mathrm{SV}$ velocities in Facies 1 are assumed to be significantly different from the $\mathrm{P}$ and $\mathrm{SV}$ velocities in Facies 2.

The offset between source and receiver has to be defined now in terms of the direction of the offset from the source. Offsets measured to the right of the source will be defined as positive; offsets to the left of the source will be negative. In CMP imaging (Fig. E3), the same raypath velocity occurs for both positive and negative offsets. The lengths of the travelpaths in Facies 1 and Facies 2 are the same when B is the source and A is the receiver (negative offsets) as they are when $\mathrm{A}$ is the source and B is the receiver (positive offsets). The same CMP stacking and migration velocities are therefore calculated in positive and negative offset directions in CMP data processing.

However, a different conclusion is reached in CCP velocity analysis. The raypaths involved in CCP imaging are shown in Figure E4. If A is the source station and B is the receiver station (positive offsets), the velocity of the downgoing $\mathrm{P}$ wave is controlled by Facies 1, the upgoing SV velocity is controlled by Facies 2, and the reflection point is at coordinate $\mathrm{CCP}_{\mathrm{A}}$. For 
negative offsets ( $\mathrm{B}$ is the source and $\mathrm{A}$ is the receiver), most of the $\mathrm{P}$-wave velocity behavior is controlled by Facies 2, all of the upgoing SV travelpath is now in Facies 1, and the reflection point is coordinate $\mathrm{CCP}_{\mathrm{B}}$. Assuming that velocities in Facies 1 differ from the velocities in Facies 2, CCP stacking/migration velocities calculated for positive and negative offsets are not the same. CCP velocity behavior, where different velocities can be observed in opposite offset directions, is thus fundamentally different from CMP velocity behavior.

Increases (decreases) in the difference between CCP stacking (and migration) velocities in positive- and negative-offset directions indicate increases (decreases) in lithofacies contrast across the space spanned by the offsets. This fact can be used to advantage to evaluate lithofacies assemblages associated with gas-hydrate systems. To date, there are no published examples or evidence that interpreters have used differences in positive-offset and negative-offset CCP velocities to map lithofacies distributions spanned by 4-C OBC surveys. This new velocity parameter, the difference in positive-offset and negative-offset velocities, is available in marine surveys only when 4-C seismic data are acquired. This new attribute is only one of several provided by 4-C OBC data that should allow more detailed interpretations of marine gas-hydrate systems than can be done using single-component marine seismic data.

\section{Contrast between CMP and CCP Stacking}

For a seismic image to be created, the image space between a seismic source and a seismic receiver is segregated into small subareas called stacking bins. During data processing, data traces are positioned across this image space by calculating the bin locations where reflection points occur. In CMP imaging in a flat-layer Earth, reflection points occur at the midpoint between source and receiver stations regardless of the depth of the reflection (Fig. E1). A CMP trace is thus shifted in time (source-static correction, receiver-static correction, other 
static corrections, and normal-moveout correction), and then the entire data trace is positioned vertically at the common midpoint for the source-receiver pair that produced that trace. This type of CMP imaging is depicted in Figure E5 by the vertical data trace in stacking-bin column A, which is at the common midpoint for the indicated source and receiver. This type of stacking, or image building, has been practiced for decades in the seismic industry. Robust CMP stacking algorithms are widespread, and all seismic data-processing shops have extensive experience in CMP processing.

The curved wiggle trace in Figure E5 shows where this same data trace would have to be positioned across the image space if the data were acquired and processed according to the $\mathrm{CCP}$ technology. In this case, the downgoing raypath is a $\mathrm{P}$ wave, and the upgoing raypath is $\mathrm{SV}$. The static and normal-movement time adjustments made to a CCP trace now affect several columns of stacking bins. Segments from several CCP traces have to be patched together to create a vertically stacked trace in each column of stacking bins. For example, three adjacent CCPprocessed data traces are shown in Figure E6. That part of trace A between points 1 and 2 has to be combined with data window 2 to 3 of trace $B$ and with data window 3 to 4 of trace $C$ to create a vertical wiggle trace extending from point 1 to point 4 in the shaded column of stacking bins. CCP stacking is thus fundamentally different from CMP stacking. Much CCP stacking and imaging software is still in development across the seismic industry.

The parameter that controls the curvature of a CCP trace in CCP-image space is the $\mathrm{V}_{\mathrm{p}} / \mathrm{V}_{\mathrm{s}}$ velocity ratio of the propagation medium. A model that illustrates this fact for small incidence angles is presented in Figure E7. This simple, straight-raypath model shows that the CCP coordinate is defined by the offsets $\mathrm{X}_{\mathrm{p}}$ and $\mathrm{X}_{\mathrm{sv}}$ from the source and receiver stations and that these offsets are proportional to the $\mathrm{V}_{\mathrm{p}} / \mathrm{V}_{\mathrm{sv}}$ velocity ratio in the raypath medium. The top 
equation listed in this model is Snell's law of reflection; the middle equation is a statement of the raypath geometry shown in the model; and the bottom equation is valid when the incident and reflected angles are small enough that $\sin (\theta)$ is the same as $\tan (\theta)$. For larger angles of incidence and reflection in a layered Earth, the relationship between the $\mathrm{CCP}$ reflection coordinates and $\mathrm{V}_{\mathrm{p}} / \mathrm{V}_{\mathrm{s}}$ is more complicated than the simple equation in Figure E7, but the velocity ratio $\mathrm{V}_{\mathrm{p}} / \mathrm{V}_{\text {sv }}$ in the Earth layers still controls where the image point is located in CCP image space.

The construction of CCP images concentrates on a determination of accurate values of $\mathrm{V}_{\mathrm{p}} / \mathrm{V}_{\mathrm{s}}$ over the total image space. In practice, seismic data processors take shortcuts. One shortcut is to do asymptotic binning. In asymptotic binning, the CCP coordinate for the deep part of an image trace, which is almost vertical, is calculated, and then the entire CCP trace is assumed to be vertically aligned at that coordinate. This approximation would cause all of the curved trace in Figure E5 to be positioned in stacking bin 7, the asymptotic bin for that trace. The result is that the deep part of the CCP image will be correct, but the upper part incorrect. The amount of error in the shallowest part of an image, where gas hydrates would be, can be enormous when asymptotic binning is used.

Most seismic data-processing shops have abandoned asymptotic binning and replaced that technique with procedures that calculate time-dependent and space-dependent estimates of $\mathrm{V}_{\mathrm{p}} / \mathrm{V}_{\mathrm{s}}$ over the total CCP image space. In so doing, however, they still take some shortcuts. The major shortcut is that little attention is given to determining accurate values of $\mathrm{V}_{\mathrm{p}} / \mathrm{V}_{\mathrm{s}}$ in the shallowest seismic data windows if there is no exploration interest in shallow strata. Data processing is focused on determining accurate $\mathrm{V}_{\mathrm{p}} / \mathrm{V}_{\mathrm{s}}$ values only at those depths where accurate images are needed for oil and gas applications. This philosophy is a practical one in the low- 
margin business of seismic data processing. There is no financial reward for work done to make the shallowest parts of a CCP image correct if no one is interested in shallow geology.

The contractor-provided SV data volume interpreted in this gas-hydrate research was created by our calculating $\mathrm{V}_{\mathrm{p}} / \mathrm{V}_{\mathrm{s}}$ velocity ratios over the total time-space coordinate range spanned by the 4C3D OBC survey. This CCP data processing represents state-of-the-art technology by a leading seismic contractor. However, the data-processing team did not devote much time or effort toward improving the accuracy of $\mathrm{V}_{\mathrm{p}} / \mathrm{V}_{\mathrm{s}}$ evaluations for the geology above the shallowest stratum of interest to oil and gas operators. This limited attention to the shallow part of the SV image space was not a technical deficiency by the contractor; it was a shortcut taken as a matter of good business practice. If an operator wants to pay for improved SV image quality over shallow strata, all contractors would not only adjust their acquisition programs to achieve better SV stacking fold across these strata, but they would also concentrate on calculating accurate $\mathrm{V}_{\mathrm{p}} / \mathrm{V}_{\mathrm{s}}$ values in shallow data windows.

The result of current industrywide CCP data-processing philosophy is that converted-SV images available from 4C3D OBC surveys that have been acquired for oil and gas objectives are incorrect, to varying degrees, for shallow strata. The amount of image error over shallow stratigraphy controls what applications can be developed from commercial oil and gas 4C3D OBC surveys for gas-hydrate interpretations.

Using Static Corrections to Map Sedimentary Facies Associated with Gas Hydrates

During seismic data processing, seismic field data are time-shifted to represent data that are recorded with source and receiver stations distributed across a hypothetical, fixed, horizontal datum plane that forms the top boundary of a constant-velocity, near-surface layer. These time shifts are called static corrections. The principal objective of static corrections is to remove 
variations in reflection arrival times that are caused by elevation differences in sources and receivers and by lateral and vertical changes in the thickness and internal velocity of the weathering layer that underlies source and receiver stations.

Geophysicists use the term weathering layer to refer to the heterogeneous, low-velocity layer that begins at the Earth's surface and extends down to variable depths. This geophysical layer is thicker than the geologic weathering layer associated with in situ decomposition of rocks.

Elevation statics account for differences in the topographic elevations of source and receiver stations. Source statics and receiver statics account for lateral variations in seismic propagation velocity in the near-surface layer immediately below source and receiver stations. Trim statics (or residual statics) do final, small-scale time adjustments of data traces before stacking the data. The emphasis here is to determine whether source and receiver statics can be used to infer lateral variations in shallow sedimentary facies that lie above, and perhaps include, gas-hydrate deposits.

\section{Source Statics}

Source statics are rarely applied to marine seismic data, including OBC data, because all source stations of a marine survey are positioned on a fixed datum plane (a fixed towed depth for the air gun) during acquisition, and all source stations are located in a constant-velocity medium (seawater). A source-related time shift (similar to an elevation static) may be applied to marine data if the depth of the air-gun array varies owing to wave action or towing procedures. Source statics have to be considered only when the Earth layer in contact with the source exhibits velocity variations from one source station to another source station. A marine seismic source will encounter changes in water velocity only in instances where a survey spans areas of variable 
salinity (for example, a delta area where there is large fresh-water outflow mixing with seawater) or waters of variable temperature (for example, when a survey spans a large period of calendar time). No source statics were applied to the 4-C OBC data used in this study.

\section{Receiver Statics}

Receiver statics are rarely needed for marine seismic data that are recorded using towed hydrophone cables because, as described in the preceding section, all receiver stations are maintained on a fixed horizontal plane during data acquisition and all receivers record data inside a medium (seawater) in which there is no lateral variation in seismic propagation velocity. Receiver statics are needed for conventional, towed-cable marine data only when a survey involves waters of differing salinity or temperature. However, receiver statics have to be calculated when seismic sensors are placed on the seafloor. A seafloor model that illustrates factors that affect ocean-bottom receiver statics is shown in Figure E8. In this model, oceanbottom sensors (OBS) can be at different elevations, and the P-wave and S-wave velocities in the heterogeneous, low-velocity layer immediately below the seafloor (and the thickness of that layer) can change significantly between receiver stations. All of these conditions adversely influence reflection arrival times at seafloor receiver stations and require that receiver statics be calculated and then applied to OBC field traces.

An example of the effects of ocean-bottom receiver statics on stacked, mode-converted, OBC data is shown in Figures E9 and E10. The image in Figure E9 was made without calculating or applying receiver statics. Receiver statics were used to make the revised image in Figure E10. Even though there is evidence in this latter image that at least one more iteration of receiver statics calculations should be done, the image quality is improved. Specific improvements occur at all receiver stations between 220 and 240, between 280 and 310, and at 
numerous other receiver stations. The result is that the lateral continuity and structural configuration of all reflections are better, as can be observed for the robust event between 0.5 and 0.6 s. Comparison of such "with statics" and "without statics" images demonstrates that it is essential to calculate and apply receiver statics to OBC data.

A map of contractor-generated receiver statics across the project study area is presented in Figure E11. One research objective was to use available subsurface geological control to create maps showing areal distributions of seafloor sedimentary facies and depositional regimes. One such map example is shown in Figure B1. We compared these geological maps with maps of receiver statics to determine whether areal patterns and trends in receiver statics infer geological processes that have occurred in shallow seafloor strata. For example, the area of large positive (red color) receiver statics in the southwest quadrant of the study area lies atop the large incised channel trend shown in Figure B2, showing that receiver statics distinguish between sandy facies (channel fill) and shale facies. This use of receiver statics is unique for marine studies and provides additional information for evaluating gas-hydrate reservoirs and seafloor stability. 


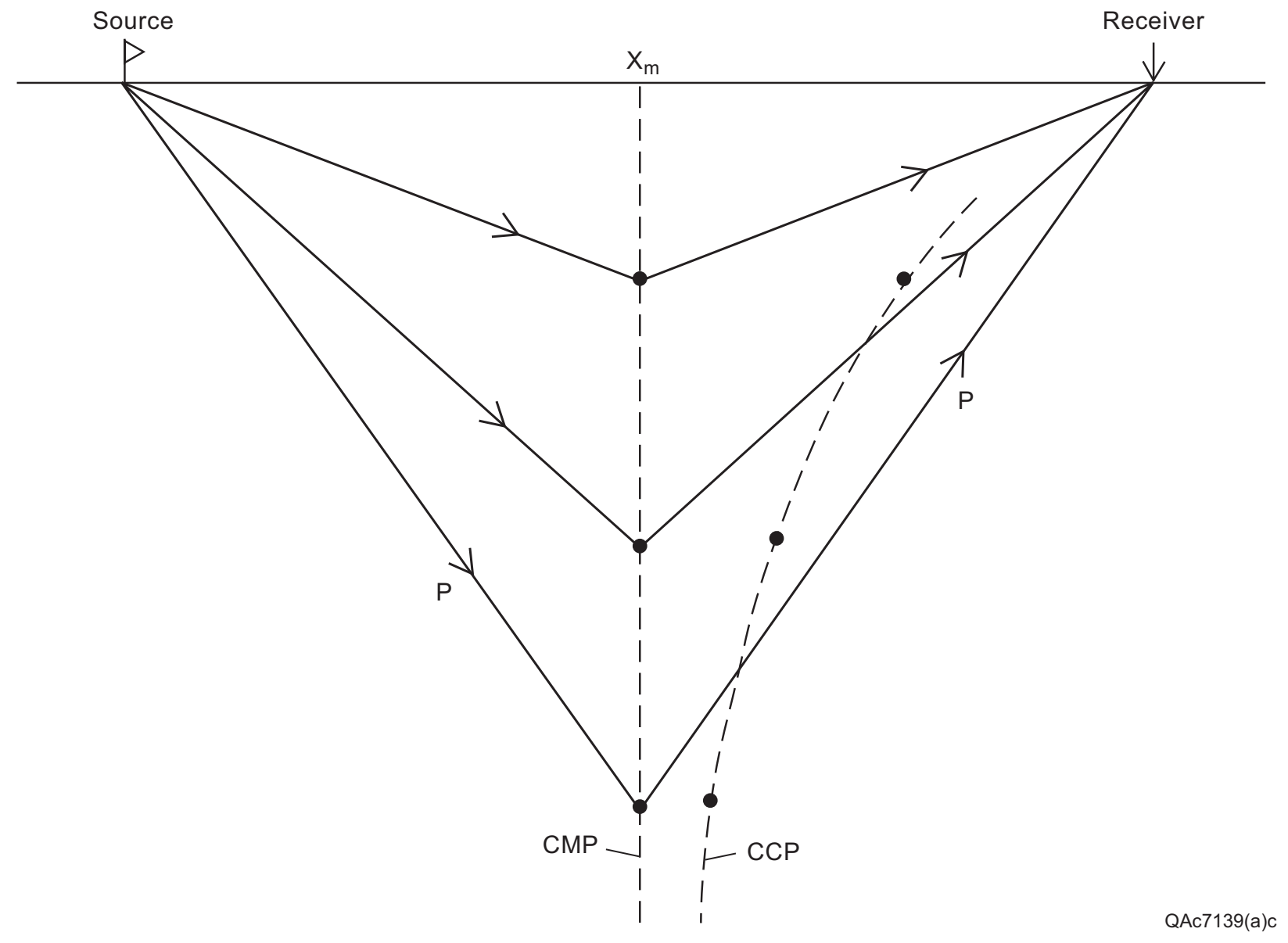

Figure E1. Comparison between CMP imaging raypaths and CCP image points. 


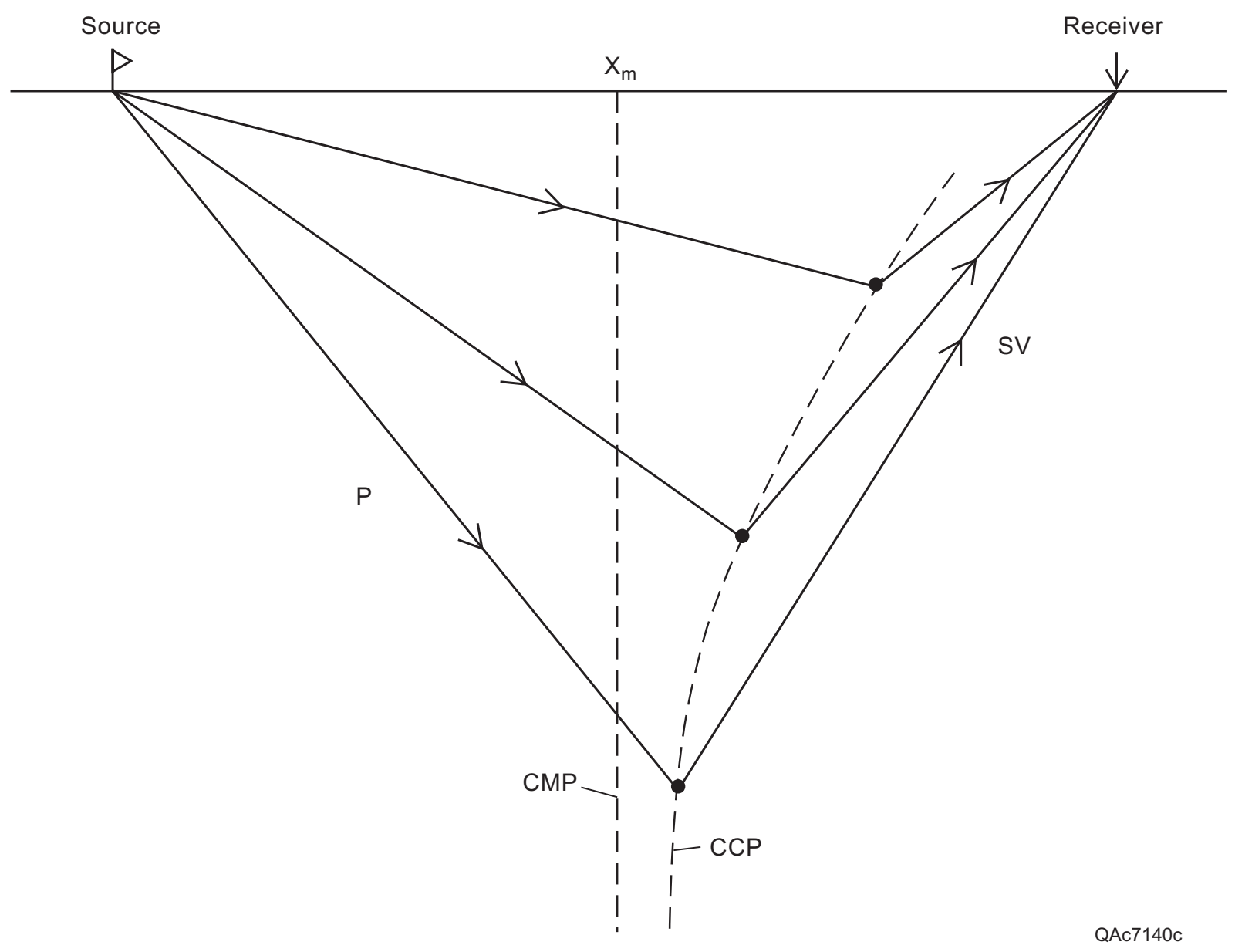

Figure E2. Comparison between CCP imaging raypaths and CMP image points. 


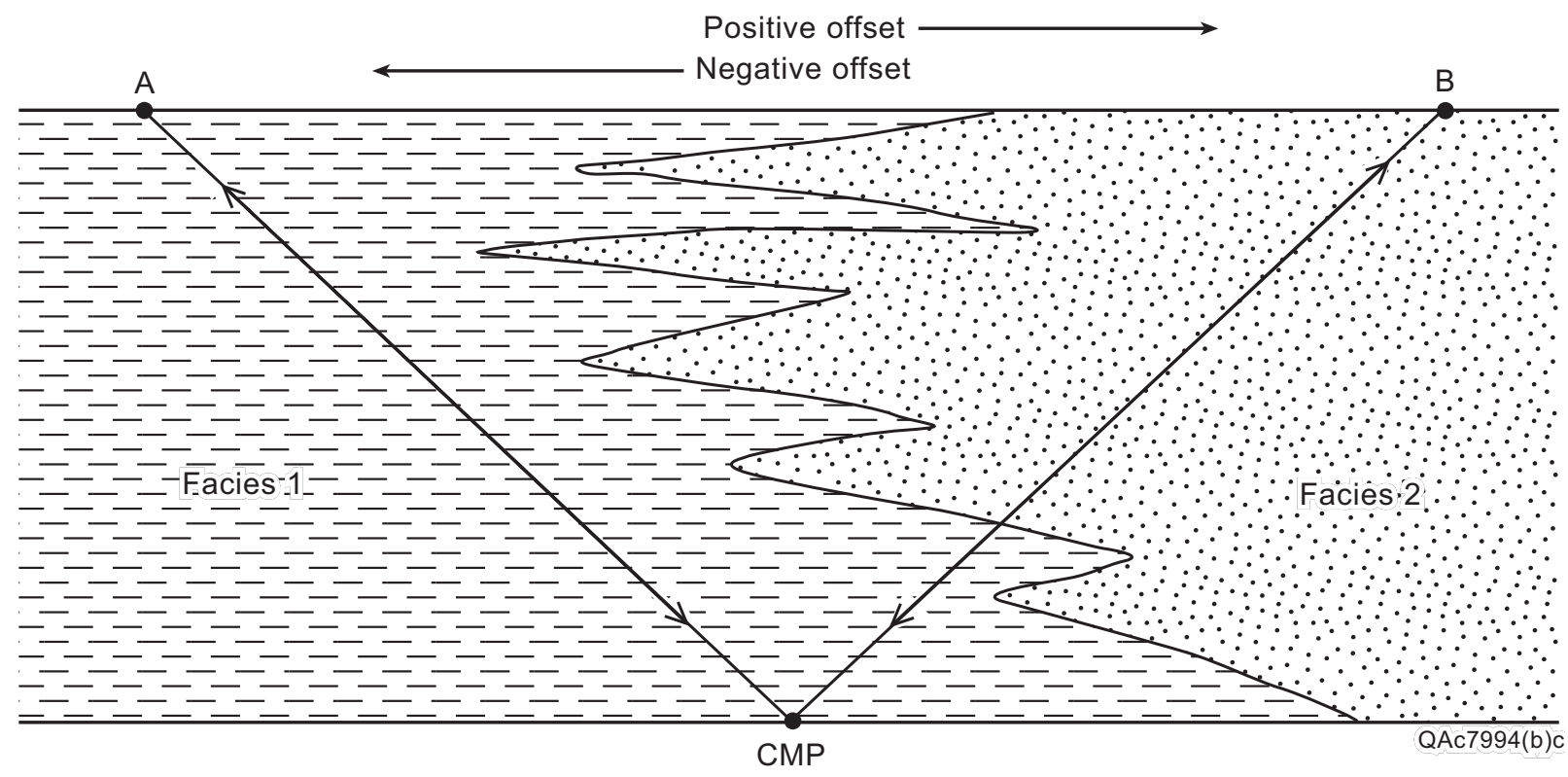

Figure E3. Traveltimes for positive offsets are the same as traveltimes for negative offsets in common-midpoint-point imaging. 


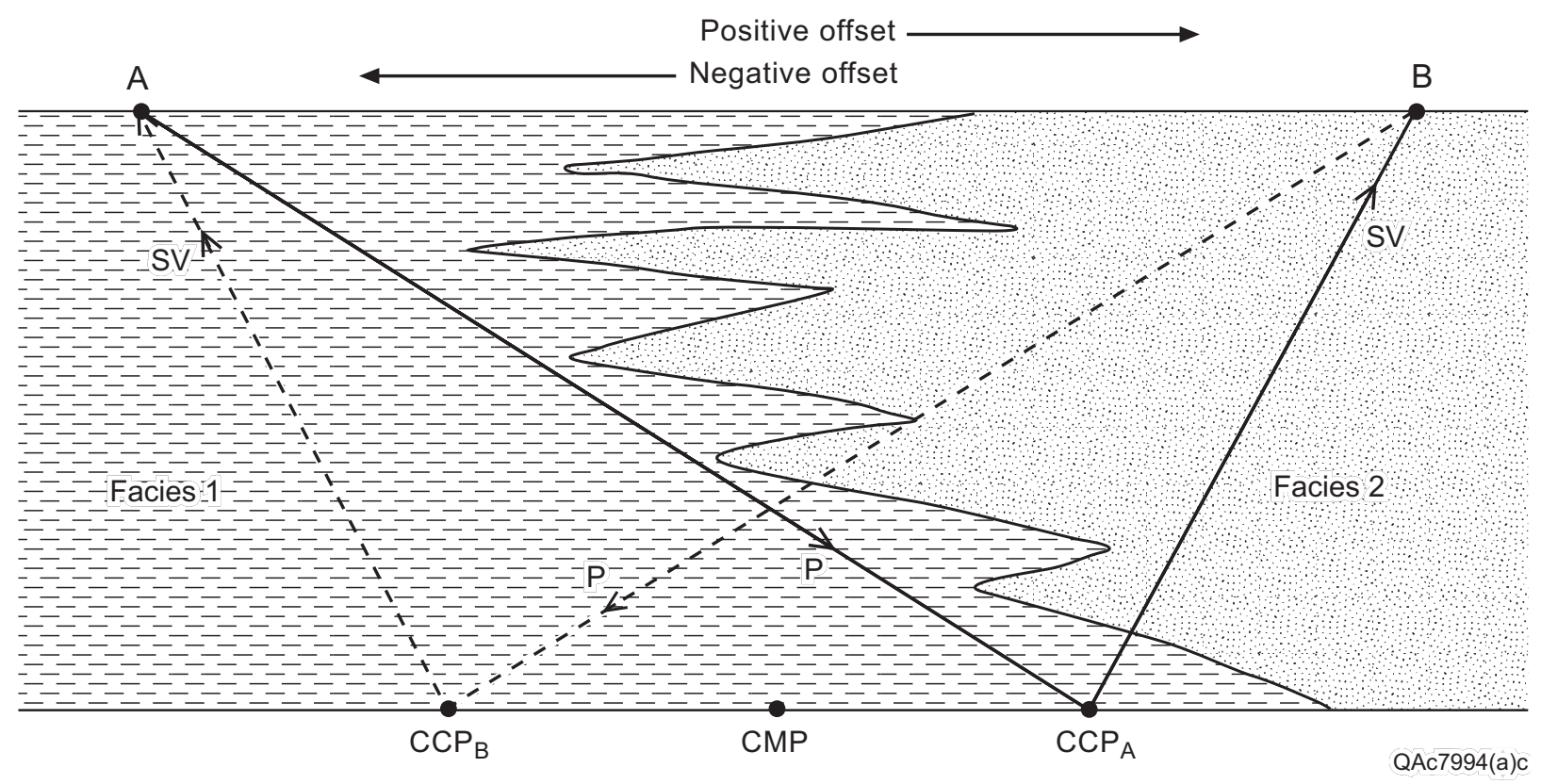

Figure E4. Traveltimes for positive offsets are not the same as traveltimes for negative offsets in common-conversion-point imaging. 


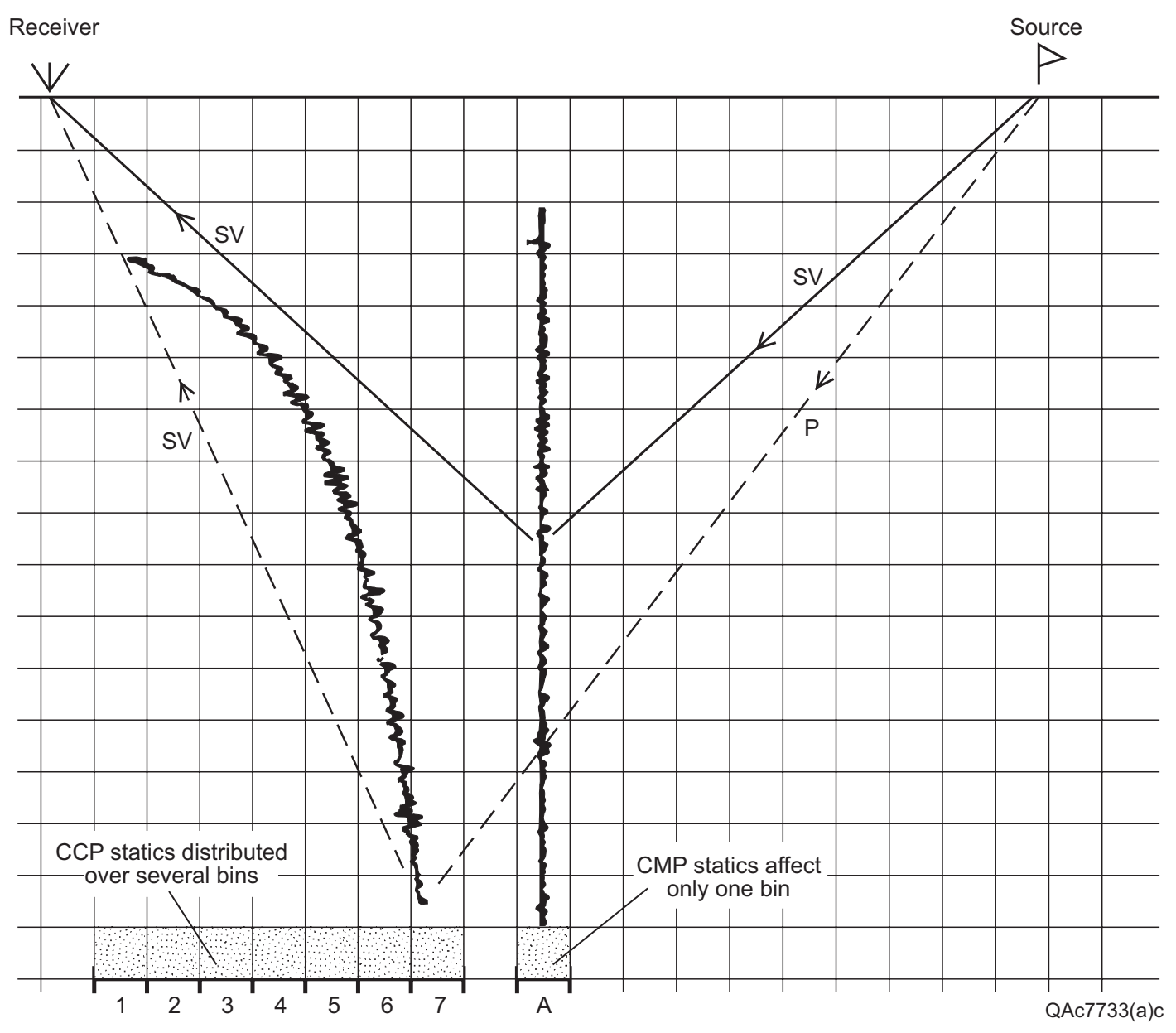

Figure E5. Comparison of CMP trace (vertical) and CCP trace (curved) positions in seismic image space. 


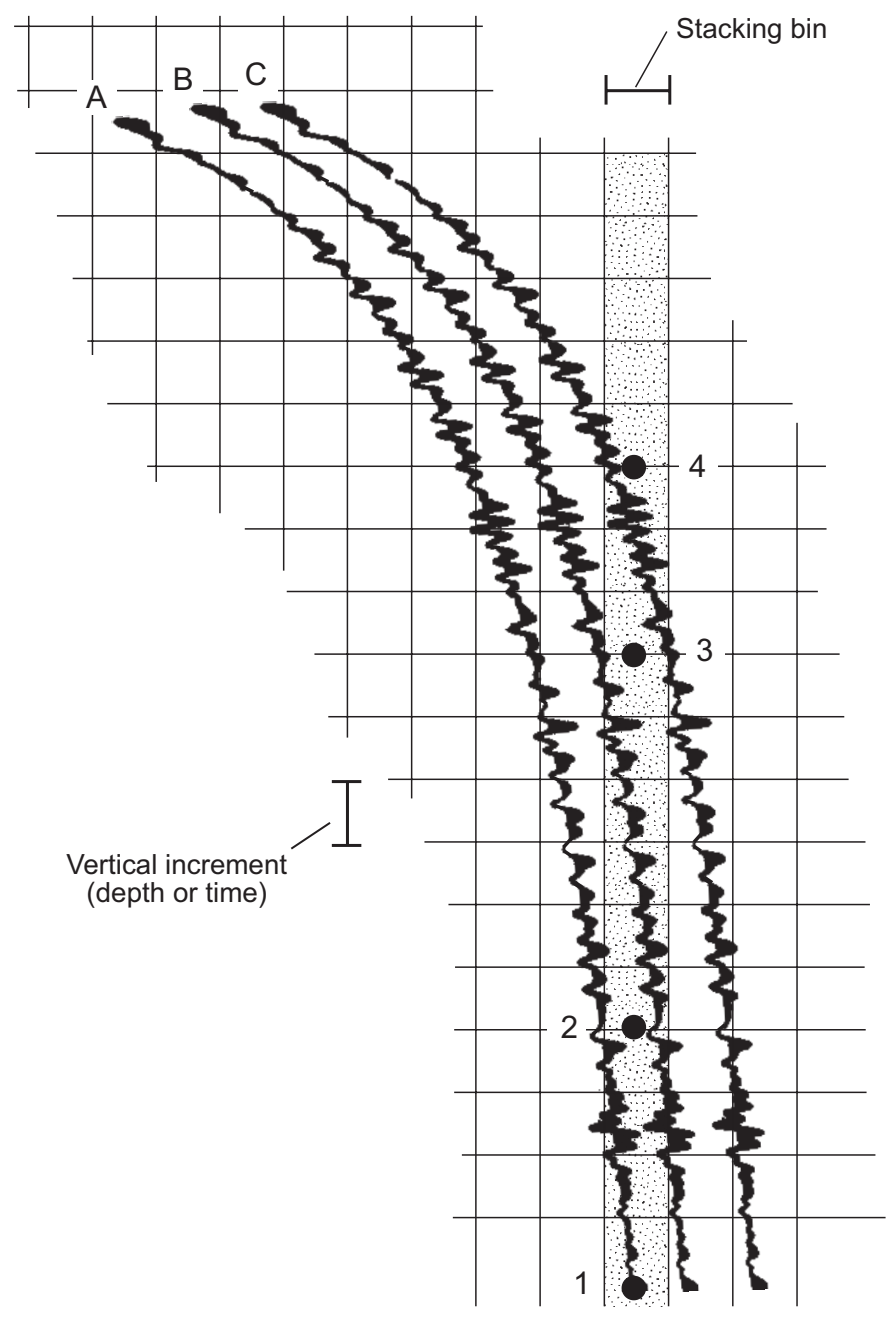

\author{
$A=C C P$ trace; source $A$, \\ receiver $\mathrm{A}$ \\ $B=C C P$ trace; source $B$, \\ receiver $B$ \\ $C=$ CCP trace; source C, \\ receiver $\mathrm{C}$ \\ 1,2 = Static segment from trace $A$ \\ 2,3 = Static segment from trace $B$ \\ $3,4=$ Static segment from trace $C$
}

QAc7734c

Figure E6. Construction of a vertical binned trace (shaded column) in seismic image space from a suite of CCP traces. 


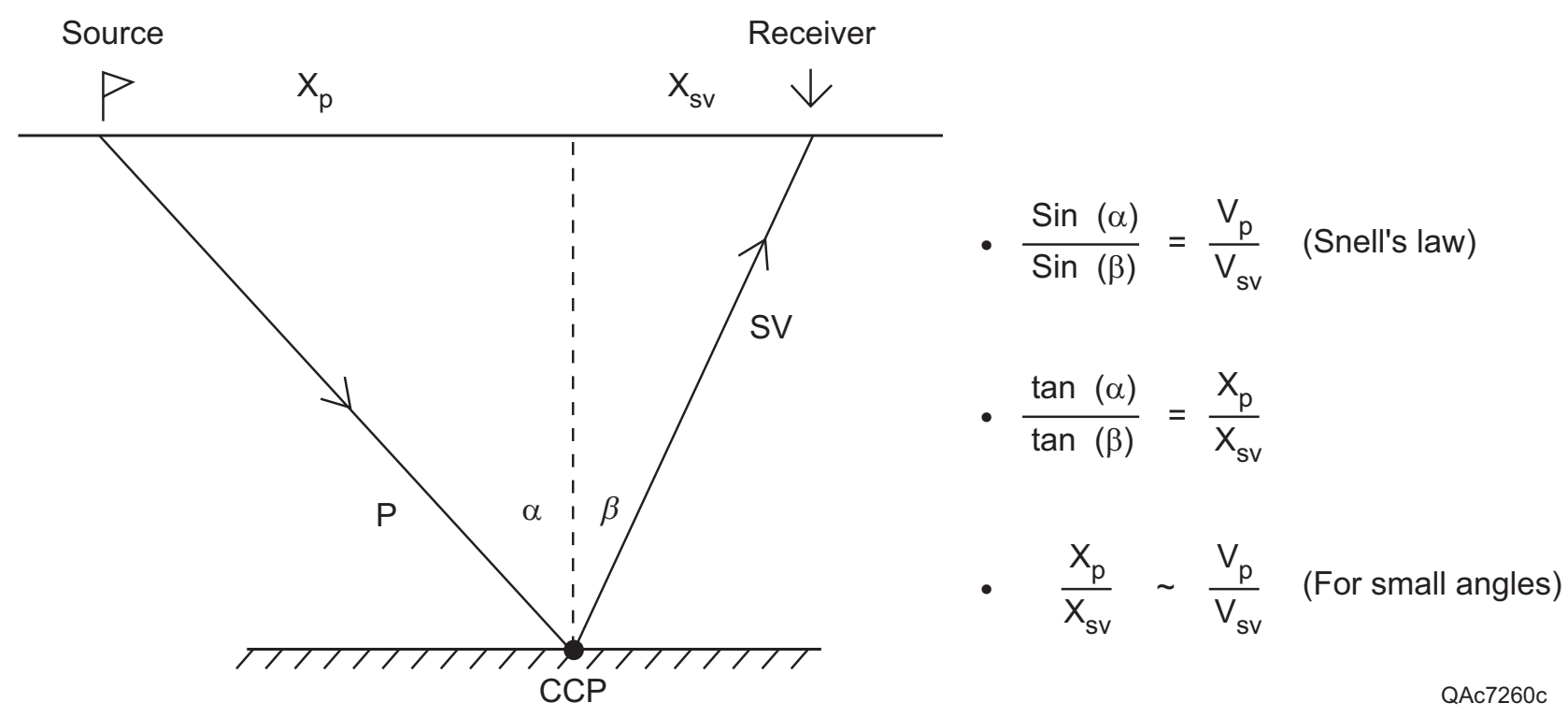

Figure E7. Simple, straight-raypath model showing that the velocity ratio $\mathrm{V} / \mathrm{V}_{\mathrm{sv}}$ controls the position of a CCP image point. 

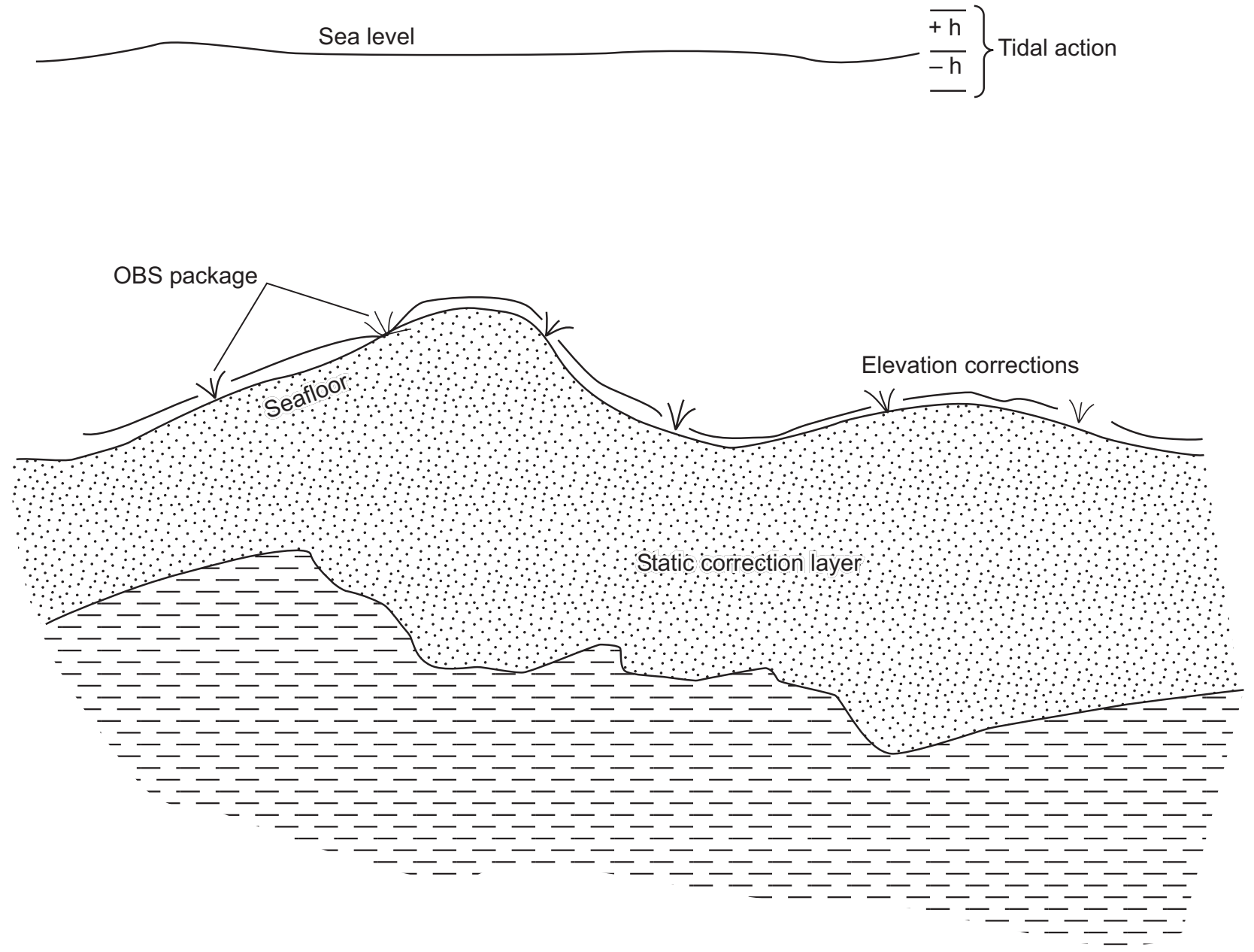

Figure E8. Receiver static correction factors involved in seafloor data acquisition. 


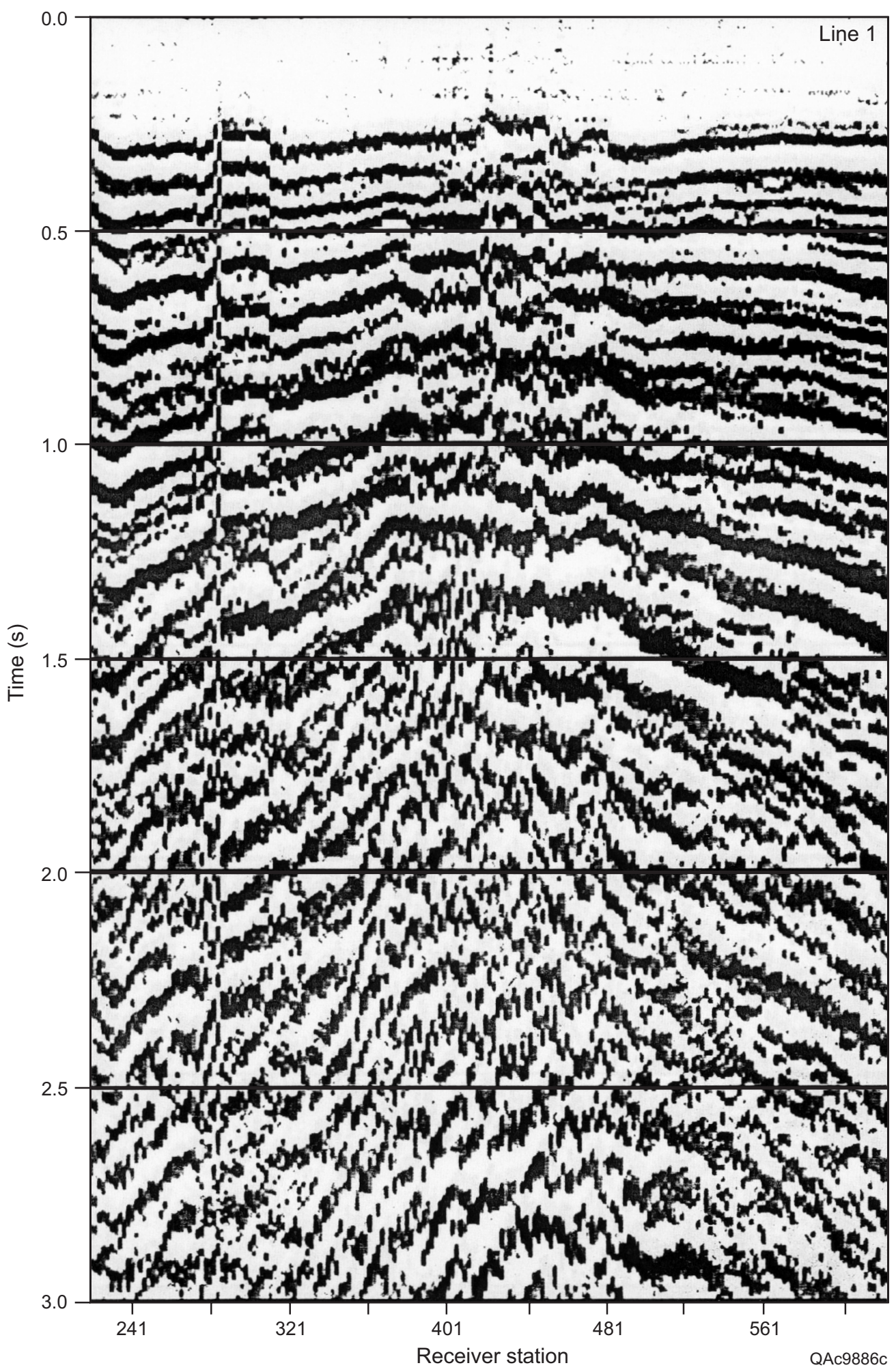

Figure E9. An OBC profile with no receiver statics applied to the data. 


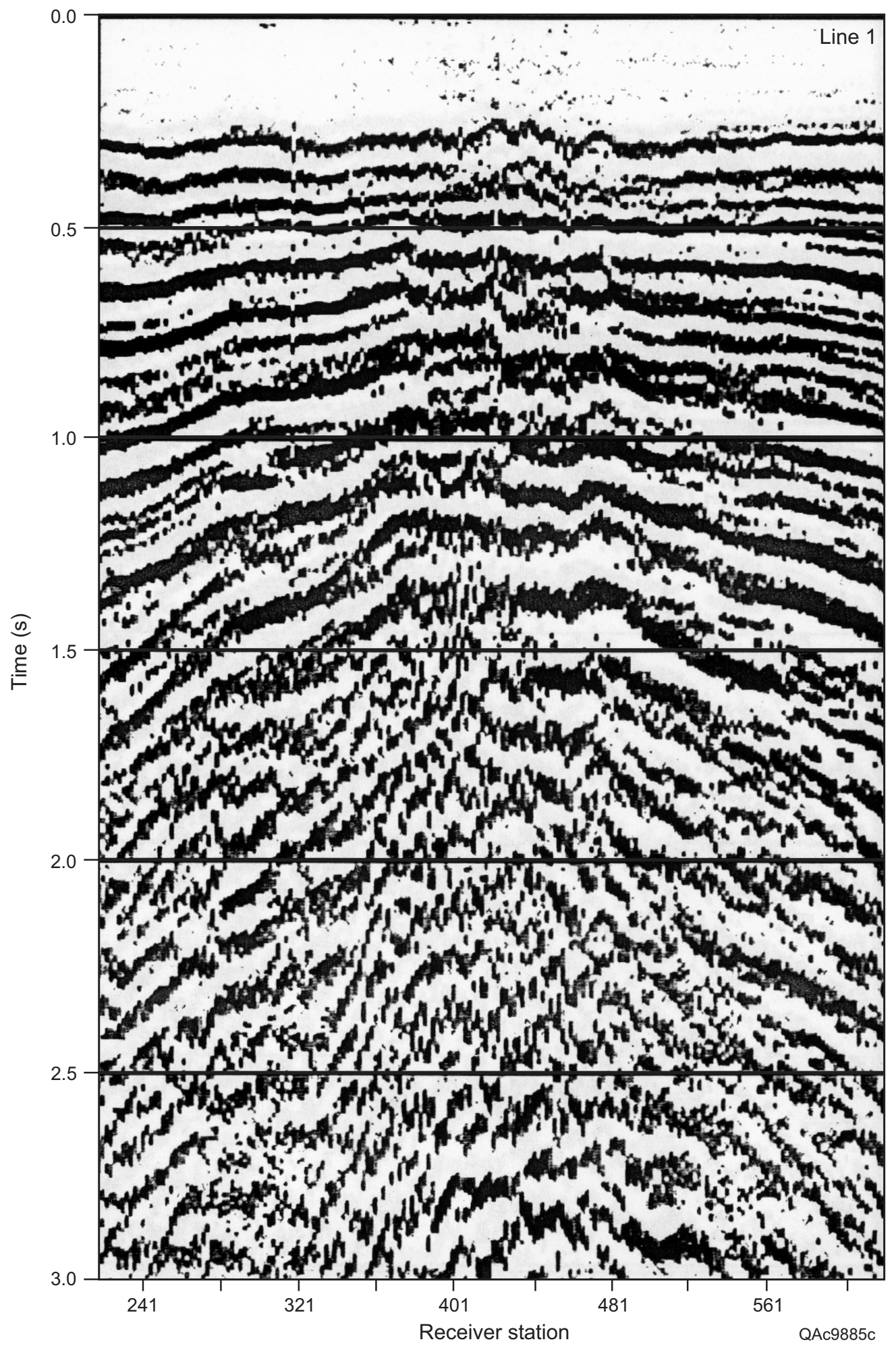

Figure E10. The same OBC profile (Fig. E9) after one iteration of receiver static corrections. 


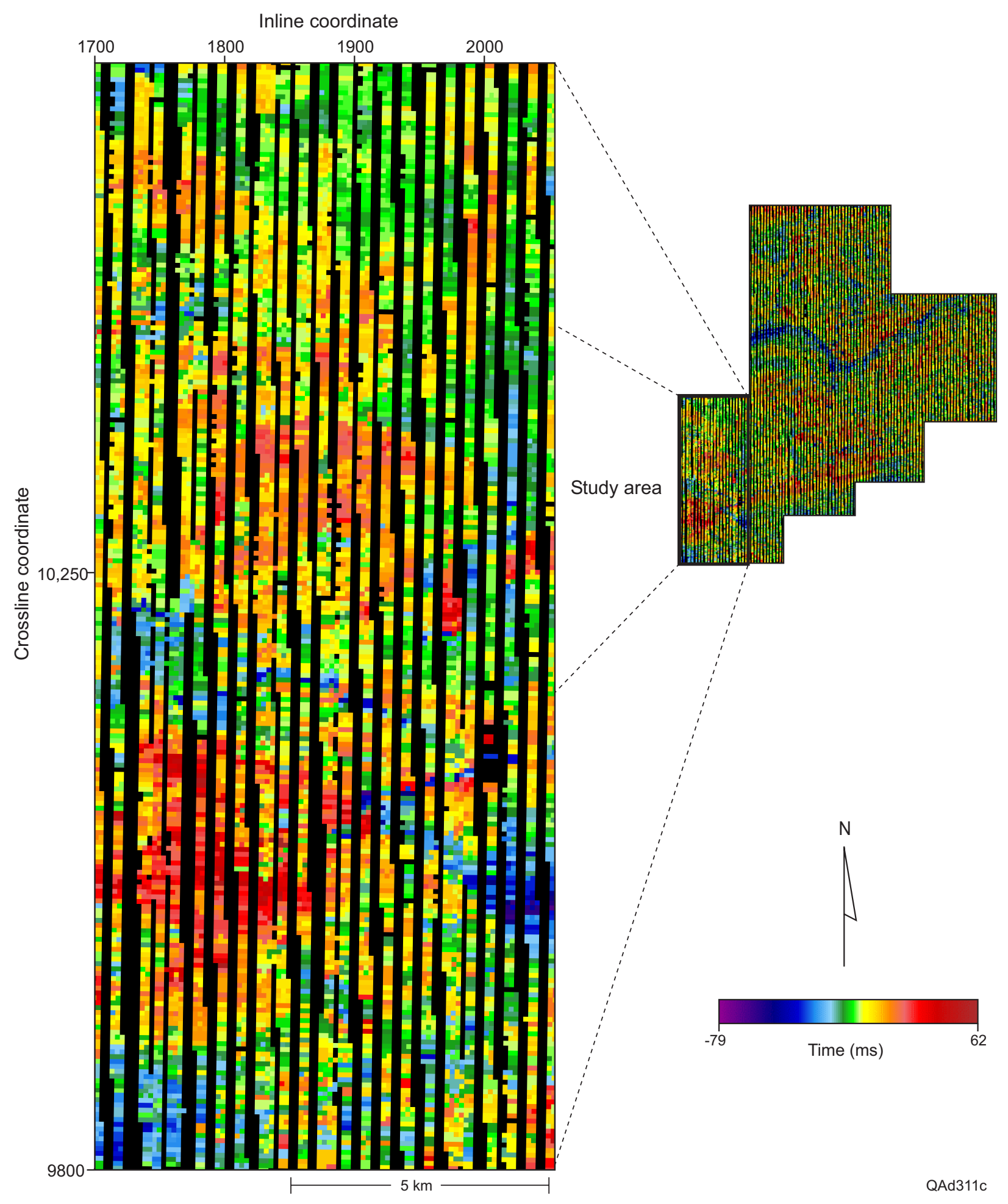

Figure E11. A map of receiver static corrections applied to 4C3D OBC data across the study area. 


\section{APPENDIX F: GEOPHYSICAL DATA QUALITY}

The 3-D, ocean-bottom, multicomponent (4-C) seismic data analyzed in this study were acquired in shallow water ( $<200$ to $275 \mathrm{ft}$ ), offshore Louisiana, West Cameron Area, over an area of approximately $455 \mathrm{mi}^{2}$ (Fig. A1). The primary objectives of this seismic survey were to improve P-wave reflection quality at deep oil/gas reservoirs by combining hydrophone and vertical-geophone data, allow structural interpretations beneath gas clouds by using converted$\mathrm{SV}$ data, and provide new seismic attributes such as $\mathrm{V}_{\mathrm{p}} / \mathrm{V}_{\mathrm{s}}$ velocity ratios for stratigraphic, petrophysical, and reservoir studies of deep exploration targets. WesternGeco acquired the data from April through May 2000 and subsequently processed the data into two separate volumes, $\mathrm{P}$ and converted-SV. The study area of approximately $80 \mathrm{mi}^{2}$, where applications of these data for gas-hydrate applications were done, covered the southwest part of this 4C3D OBC seismic survey. These 4C3D OBC seismic data are a new "spec" survey that is still being marketed to interested oil and gas operators. The oil and gas targets of interest to these operators are deeper than 5,000 ft. The owners of the seismic data, Seitel Data Inc. and WesternGeco, graciously allowed the shallow parts of the P and SV data above these deep oil and gas targets to be used to develop this new gas-hydrates seismic technology. The P-wave data provided for this gashydrate research extend to only $1 \mathrm{~s}$, and the converted SV data extend to only $2 \mathrm{~s}$.

Preliminary analysis of the P and SV data volumes reveals that the frequency content of the P-wave data is reasonably broadband in nature, from 10 to $70 \mathrm{~Hz}$ (almost 3 octaves), but that the signal spectrum is only 10 to $30 \mathrm{~Hz}(1.5$ octaves) for the converted-SV data. Shallow data are dominated by processing artifacts (trace muting and incorrect $\mathrm{V}_{\mathrm{p}} / \mathrm{V}_{\mathrm{s}}$ applications), making interpretation at levels above $0.5 \mathrm{~s}$ of the $\mathrm{P}$ volume and above $1 \mathrm{~s}$ in the converted-SV volume difficult. So many shallow data were muted during data processing that the shallow image has to 
be interpreted as a series of 2-D lines, making any type of areal attribute analysis across shallow intervals a risky proposition. Many shallow imaging problems are caused by the design of the acquisition survey and by subsequent data processing, particularly $\mathrm{V}_{\mathrm{p}} / \mathrm{V}_{\mathrm{s}}$ calculations, because deeper hydrocarbon reservoirs, not shallow strata, were targeted by this Seitel and WesternGeco seismic program. Basically the converted-SV image is reliable for deep targets, but it becomes less accurate as reflector depth decreases. Surveys designed to optimize the imaging of shallower targets would go a long way toward improving the quality of shallow seismic data used in future gas-hydrate studies.

Gas clouds (or gas chimneys) pervade much of the shallow part of the P-wave data volume (Fig. F1), obscuring structural and stratigraphic features beneath the gas-charged intervals. As expected, the $\mathrm{C}$-wave data (Fig. F2) image through these gas-invaded zones and allows interpretation of previously obscured structural and stratigraphic features. The improved image of geologic conditions provided by $\mathrm{C}$ data in gas-charged strata could be critical in some gas-hydrate prospects. Preliminary analysis has determined that it would be prudent to first interpret P-wave data to locate structural components (faults, topographical highs, etc.), next interpret the C-wave data to define those structural features that are hidden by gas effects in the P-wave data, and then interpret the P-wave volume again to fine-tune the structural interpretation. 


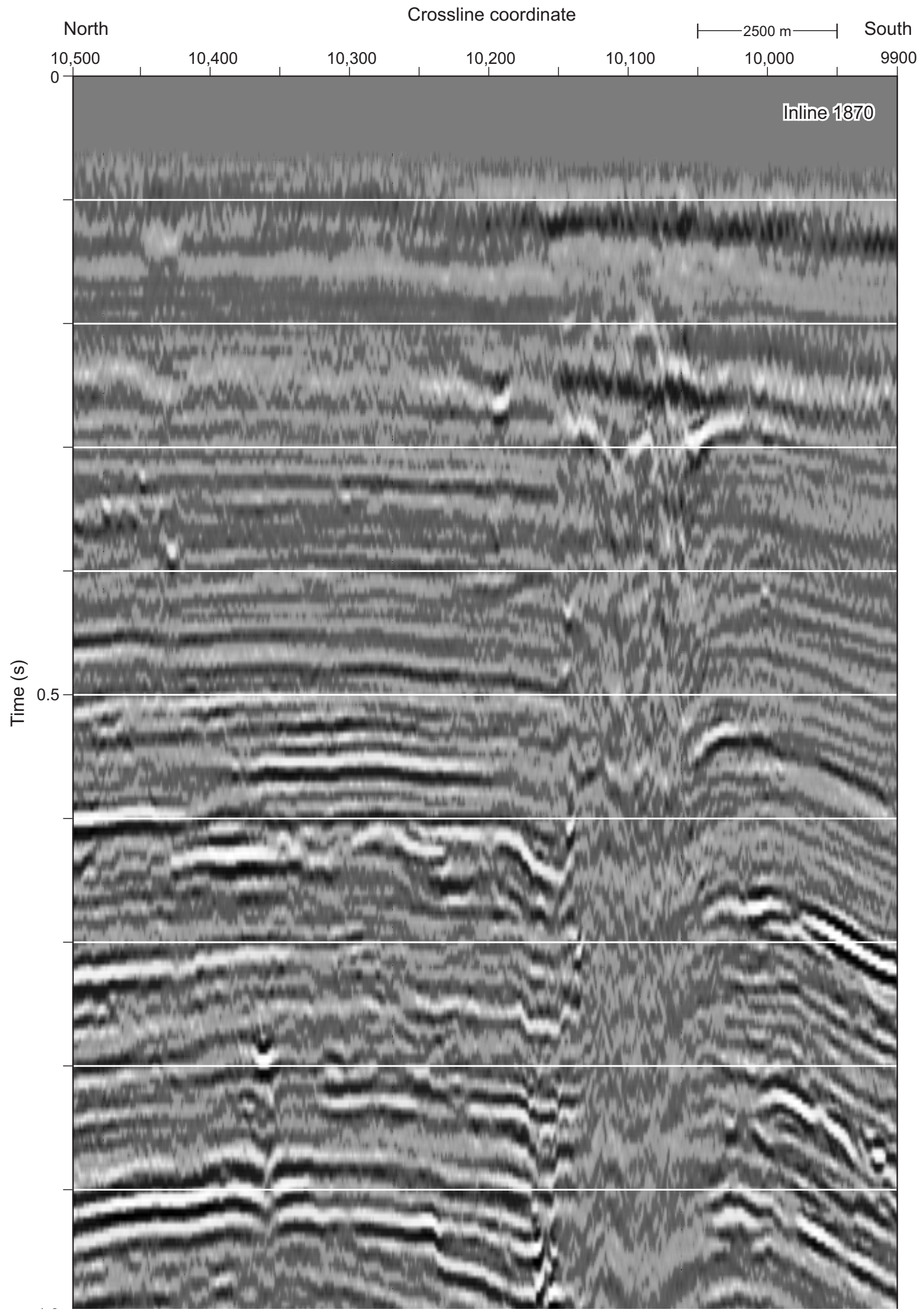

Figure F1. A P-wave profile traversing a gas chimney (crossline coordinates 10,050 through $10,150)$. It is difficult (impossible?) to interpret stratigraphy and structure inside the gas-invaded interval. 


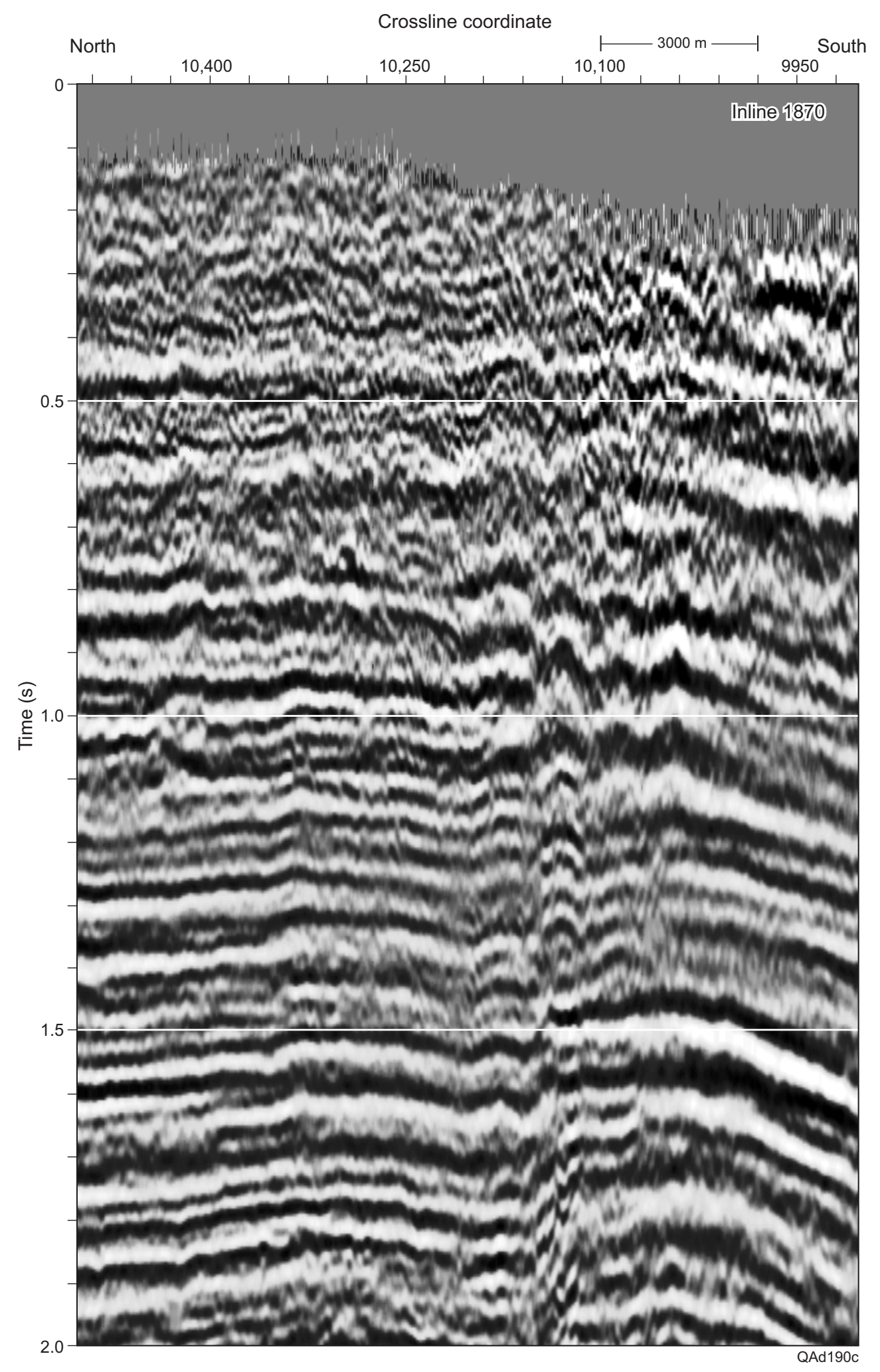

Figure F2. A converted-SV profile, along with same inline coordinate as that shown in Figure F1. The converted-SV data provide an improved image of geologic conditions inside the gas-invaded chimney (crossline coordinates 10,050 through 10,150). 